Universidad de Lima

Facultad de Administración

Carrera de Negocios Internacionales

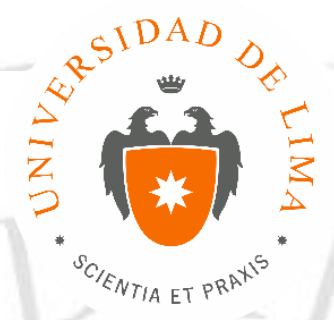

\title{
EXPORTACIÓN DE BANANO ORGÁNICO A CANADÁ
}

Trabajo de investigación para optar el Título Profesional de Licenciado en

Negocios Internacionales

Cynthia La Rosa Duarte

Código 20080530

Gianfranco Camaiora Castañeda

Código 20090165

\author{
Asesor \\ William Arteaga Donayre \\ Lima - Perú
}

Setiembre del 2016 


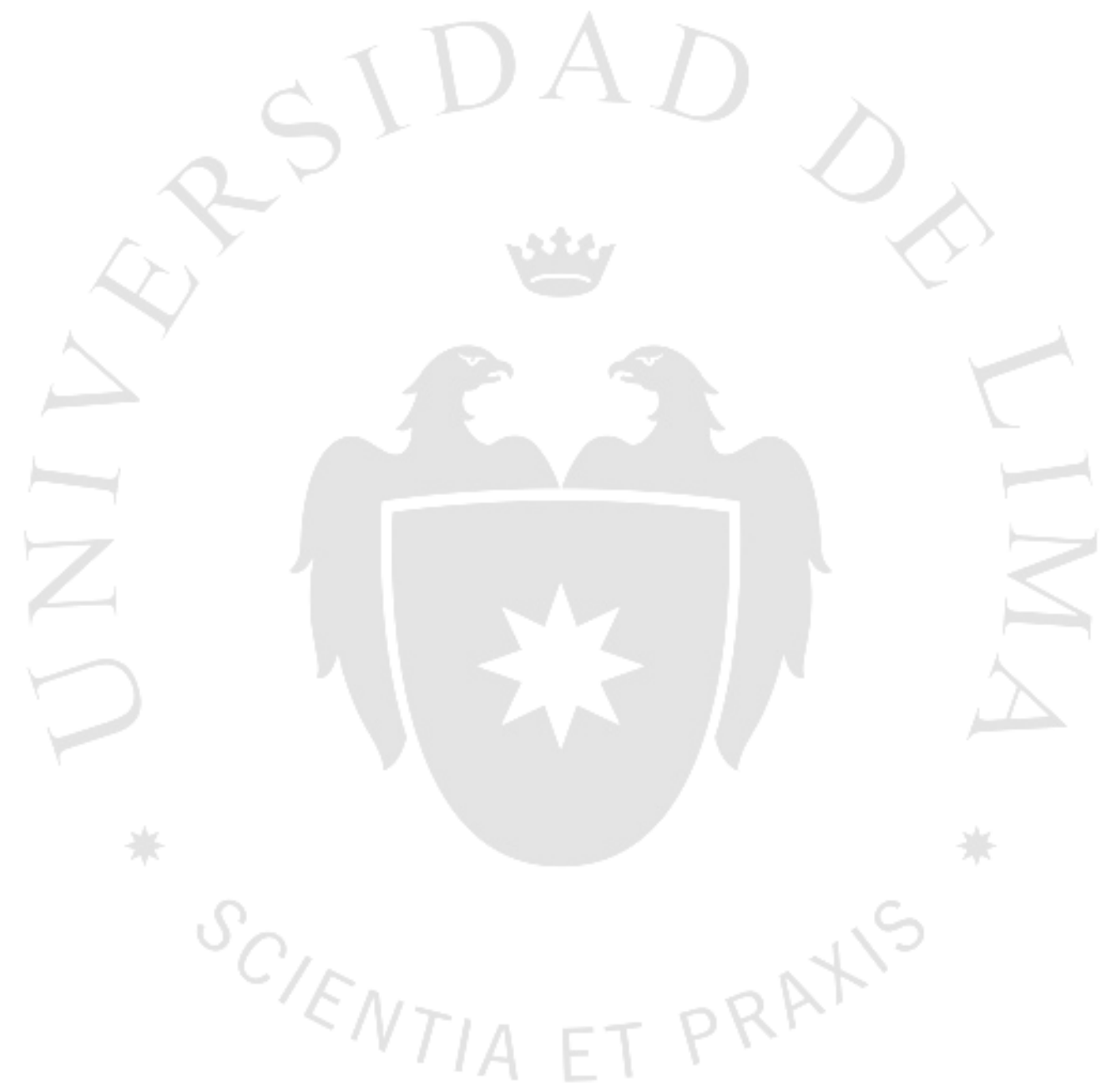


EXPORTACIÓN DE BANANO ORGÁNICO A CANADÁ 


\section{ÍNDICE}

INTRODUCCIÓN

CAPÍTULO I: PLANTEAMIENTO DEL PROBLEMA ......................................15

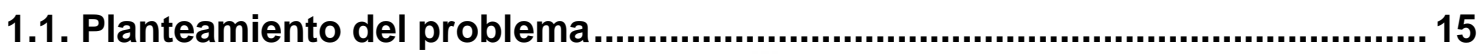

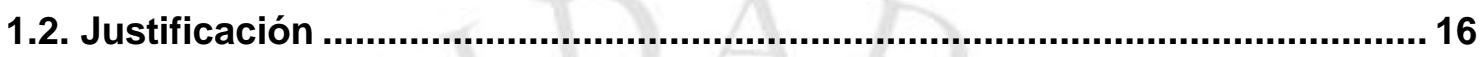

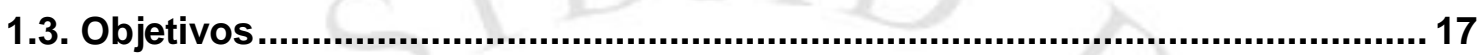

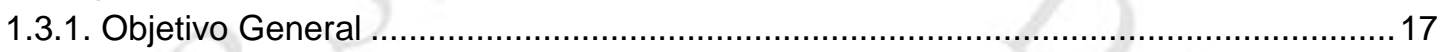

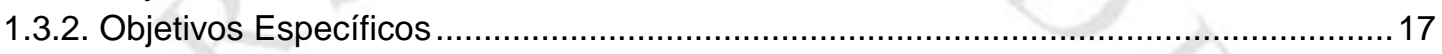

1.4. Delimitación del tema de investigación ...................................................... 18

1.5. Relevancia del tema para el usuario, organización o país ............................. 18

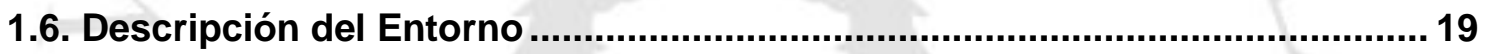

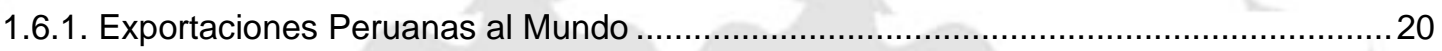

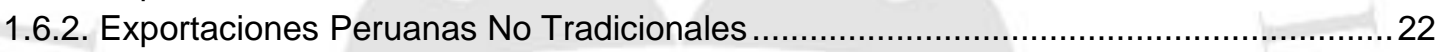

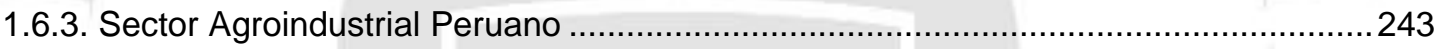

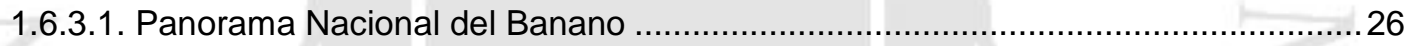

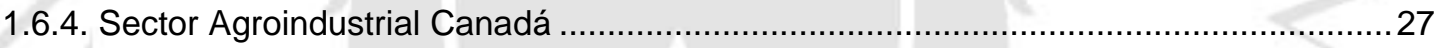

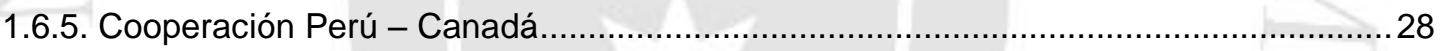

1.7. Análisis de Canadá como potencia mundial ...............................................29

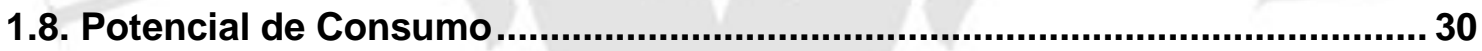

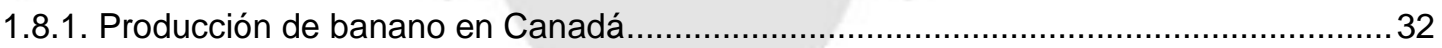

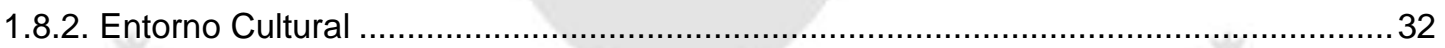

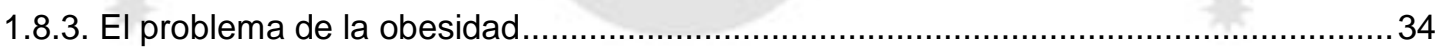

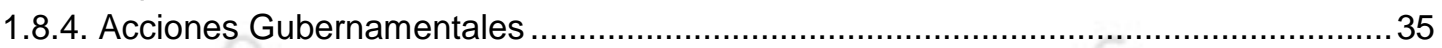

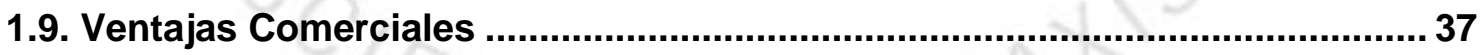

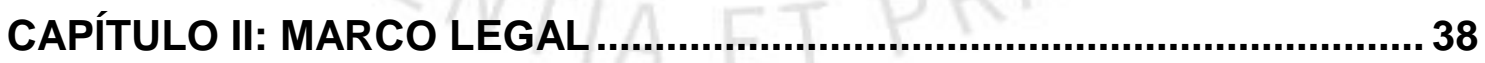

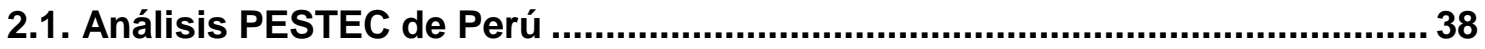

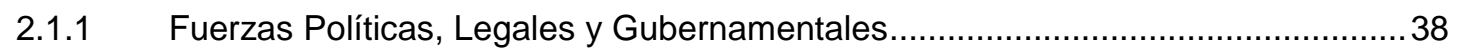

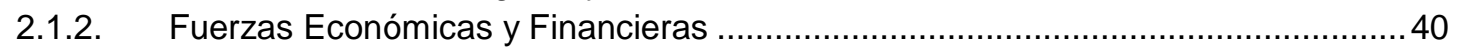

2.1.3. Fuerzas Sociales, Culturales y Demográficas ................................................. 42

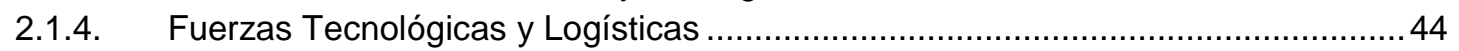

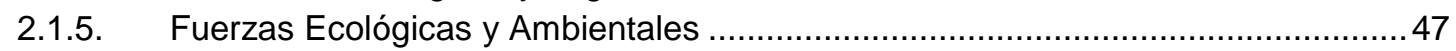

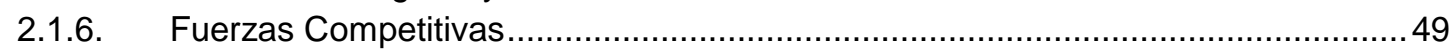

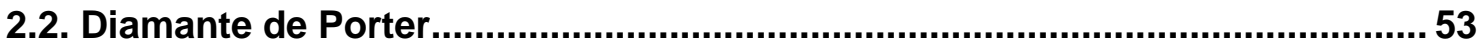

2.2.1. Poder de Negociación de los Proveedores.................................................................54 
2.2.2. Poder de Negociación de los Compradores …….........................................................

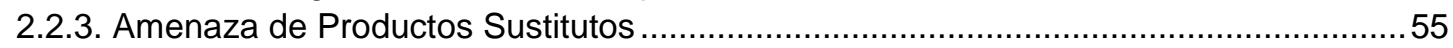

2.2.4. Amenaza de Entrada de Nuevos Competidores........................................................56

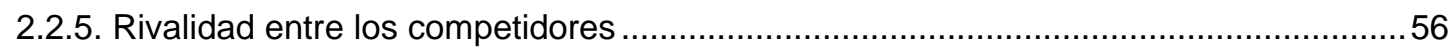

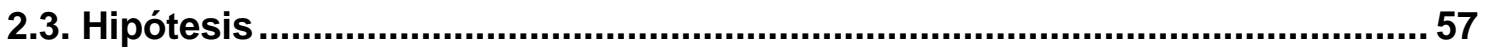

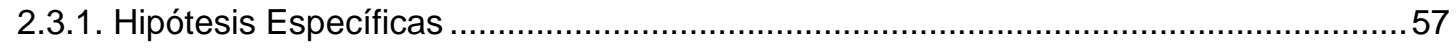

CAPITULO III: ESTUDIO DE MERCADO ……........................................... 58

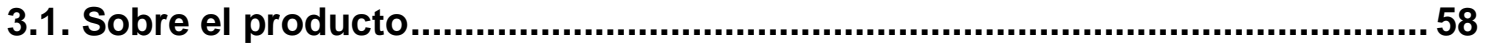

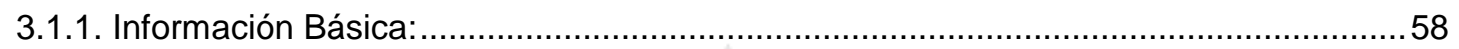

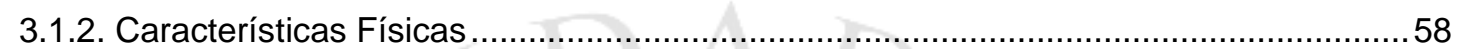

3.1.3. Propiedades Nutritivas y Beneficios para la Salud .....................................................59

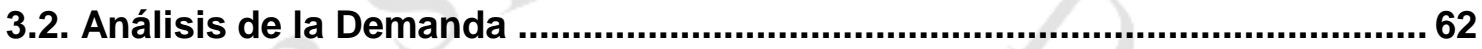

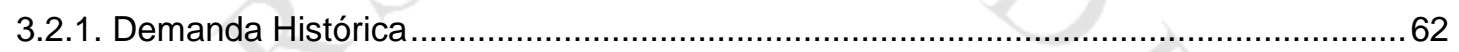

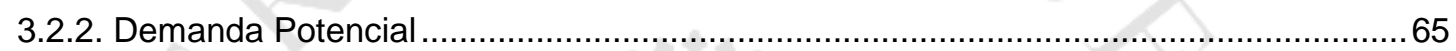

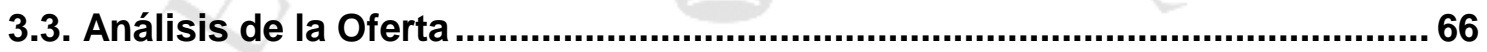

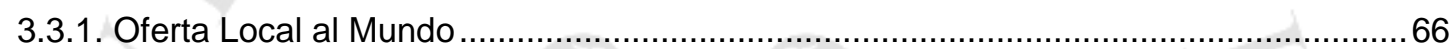

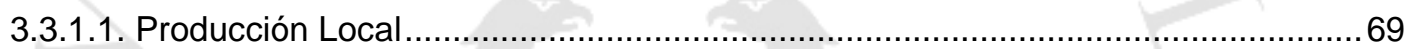

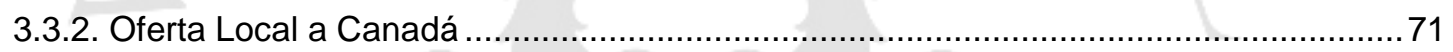

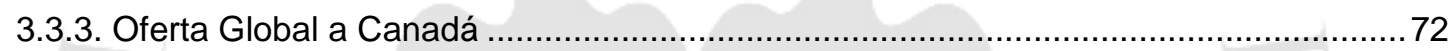

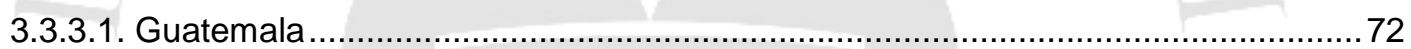

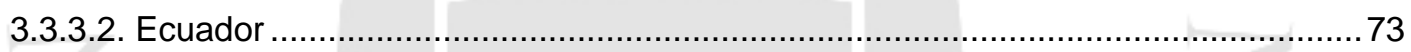

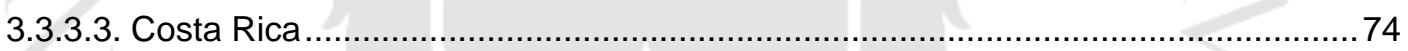

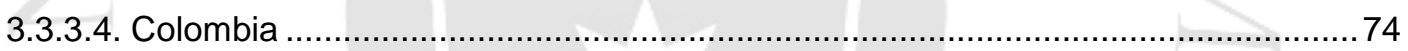

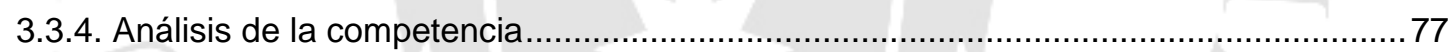

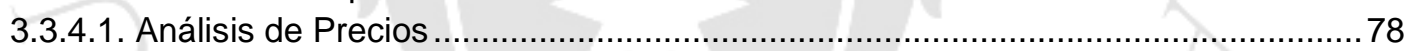

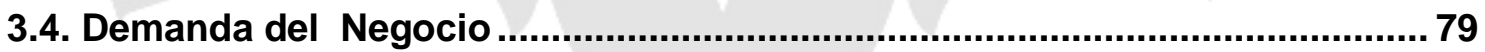

3.4.1. Perfil y Comportamiento del Consumidor Canadiense ............................................ 80

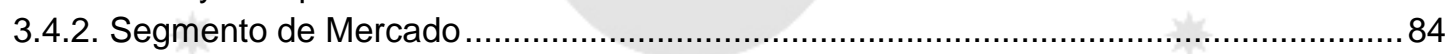

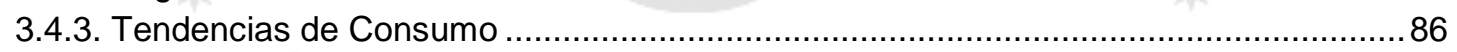

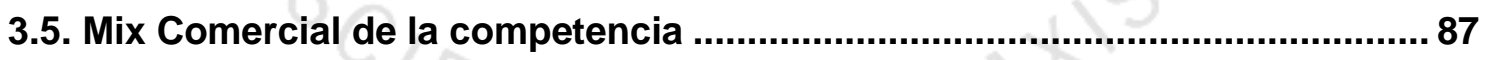

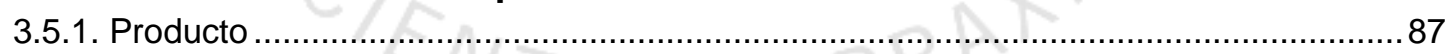

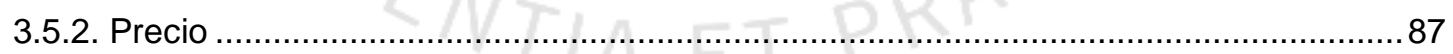

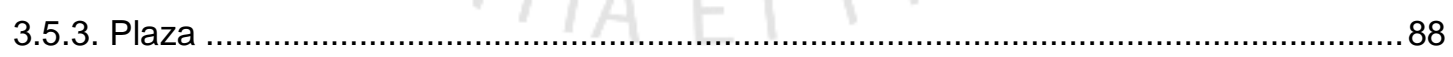

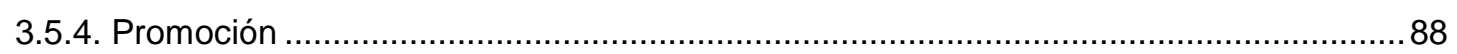

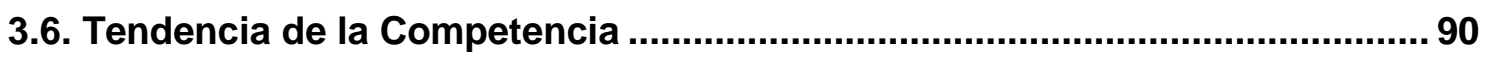

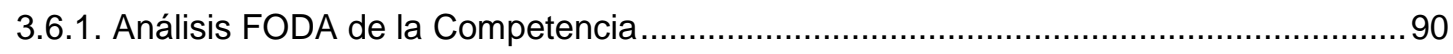

3.7. Mix Comercial Propuesto.......................................................................... 91

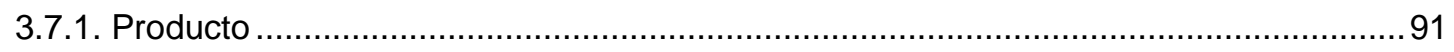

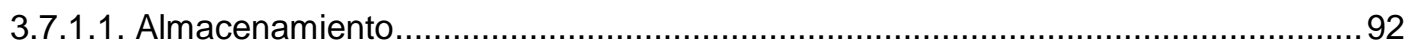

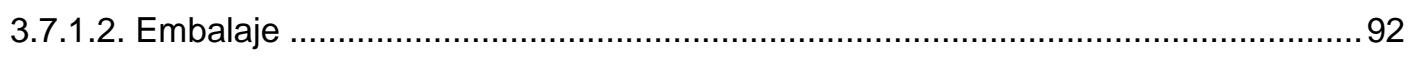

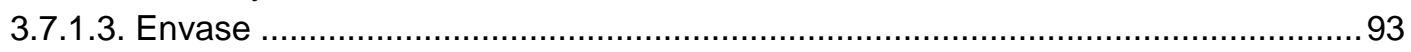

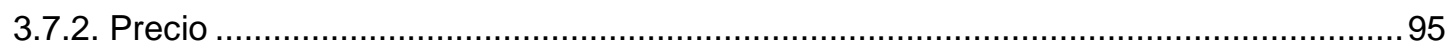

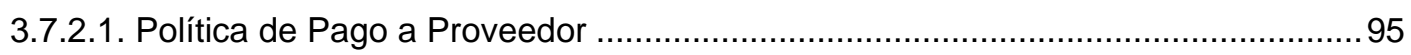




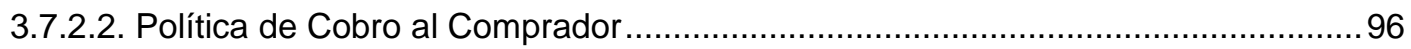

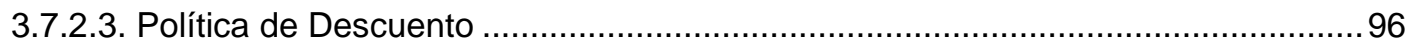

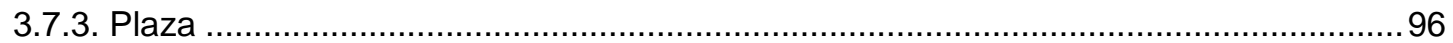

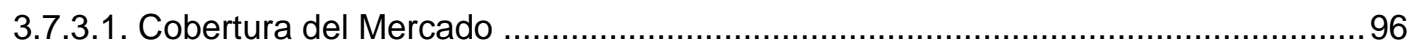

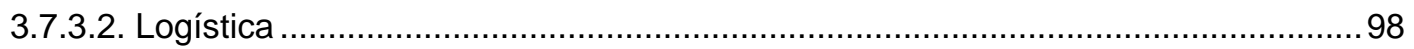

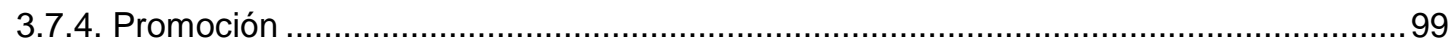

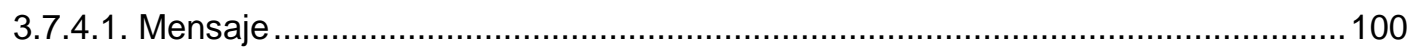

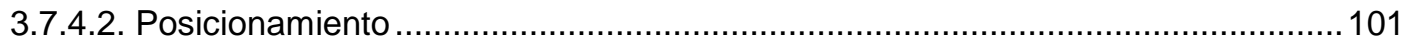

3.8. Requisitos de Acceso al Mercado Canadiense .......................................... 101

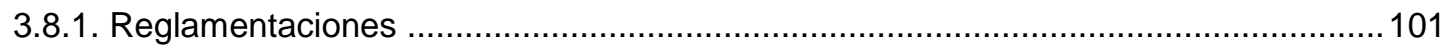

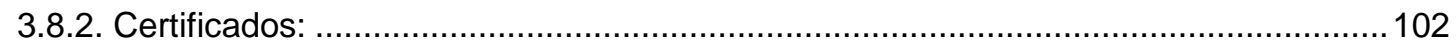

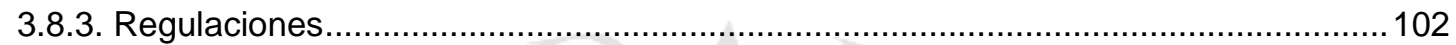

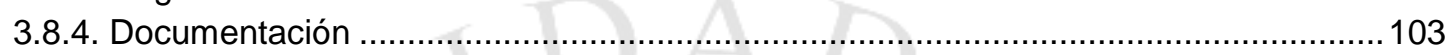

3.9. Pautas de Negociación entre Perú y Canadá ................................................ 104

3.9.1. Análisis de las cinco variables del modelo de clasificación cultural ............................104

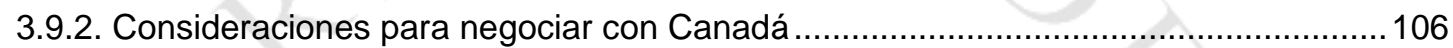

3.9.3. Conocimientos Básicos del Mercado Canadiense....................................................... 106

3.10. Potencial Punto de Negociación ................................................................... 107

CAPITULO IV: ESTUDIO TÉCNICO …................................................... 109

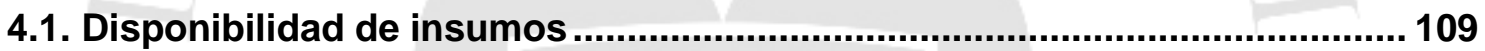

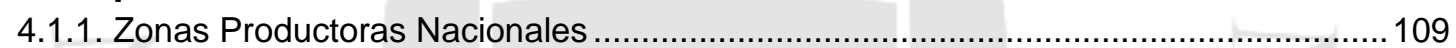

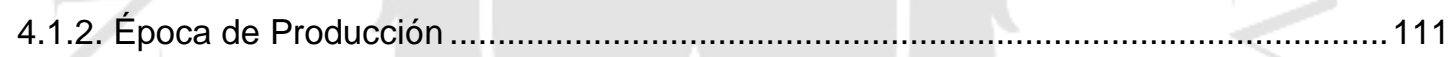

4.2. Proceso de producción de la exportación del Banano Orgánico .................. 112

4.3. Requerimientos Medio Ambientales ......................................................... 115

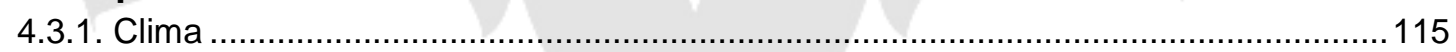

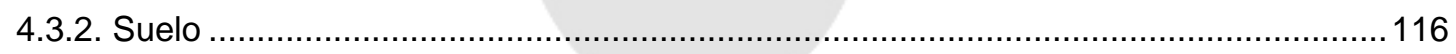

4.4. Requerimiento de Equipos de Oficina .................................................... 117

4.5. Requerimiento de Mobiliario de Oficina ..................................................... 120

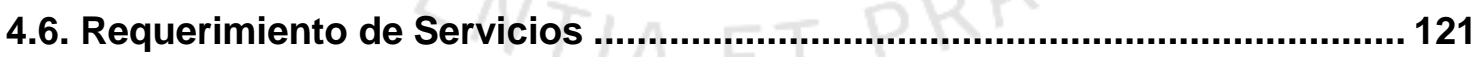

CAPITULO V: ORGANIZACIÓN DEL NEGOCIO .......................................123

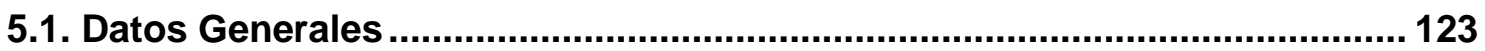

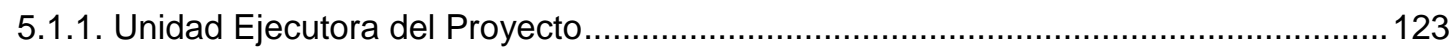

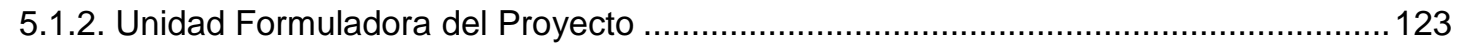

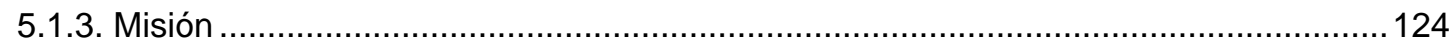

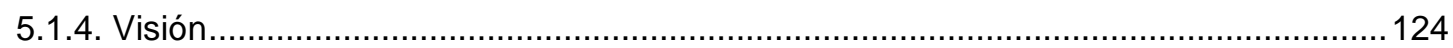

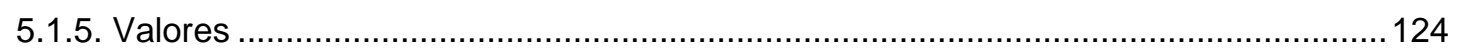

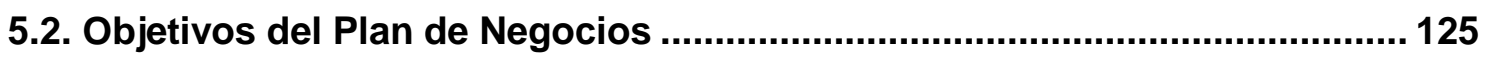

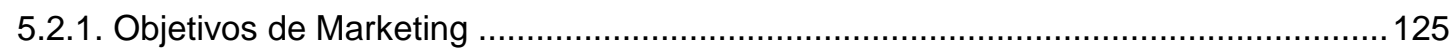




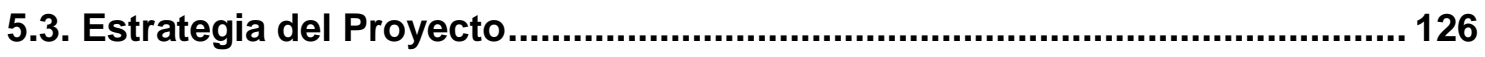

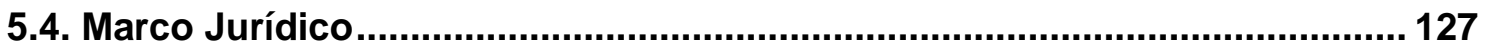

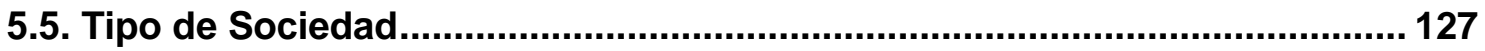

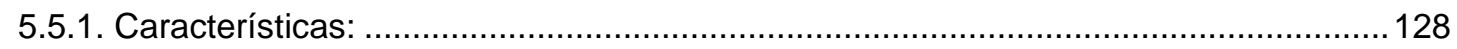

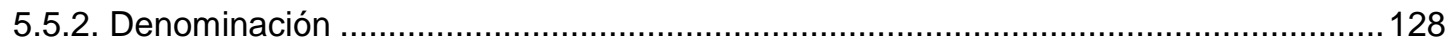

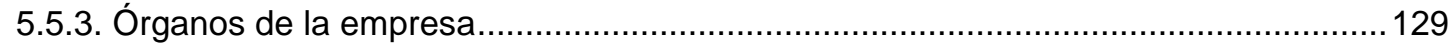

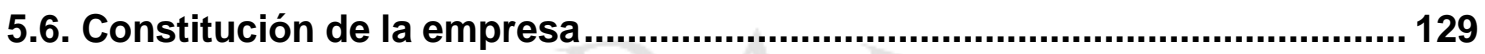

5.7. Minuta de Constitución de la Empresa ......................................................... 133

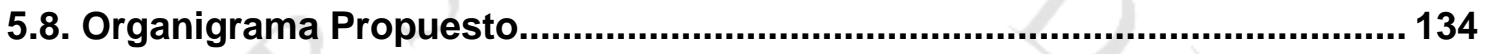

5.9. Análisis de los puestos de trabajo .............................................................. 136

CAPITULO VI: FUNDAMENTO FINANCIERO........................................... 138

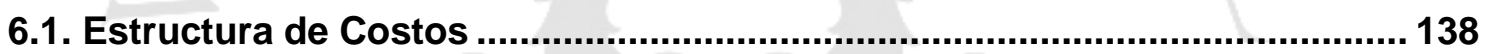

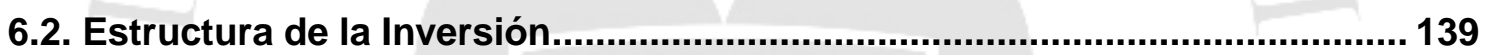

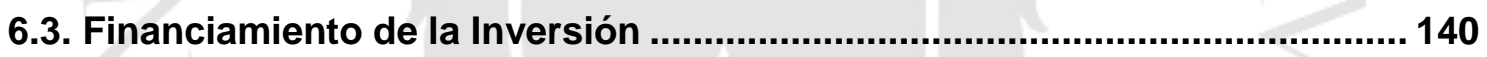

6.4. Determinación del Punto de Equilibrio ........................................................ 141

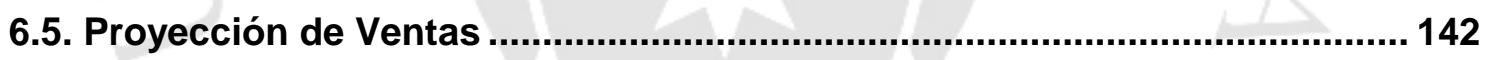

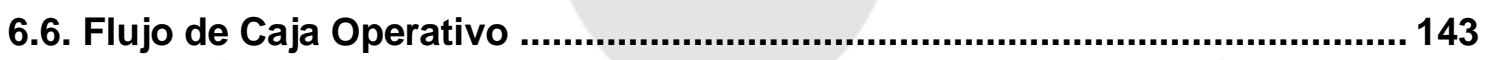

6.7. Flujo de Caja Económico .................................................................... 1487

6.8. Estado de Situación Financiera................................................................ 151

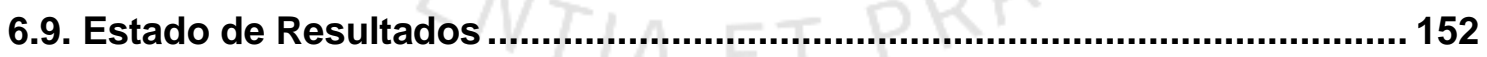

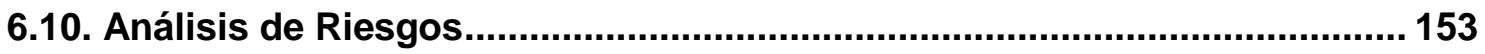

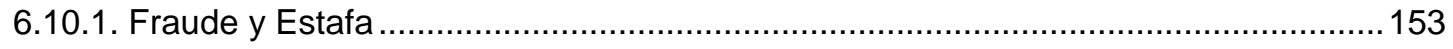

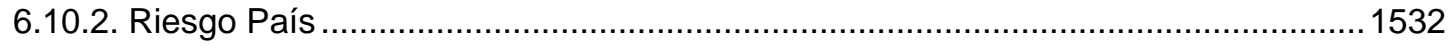

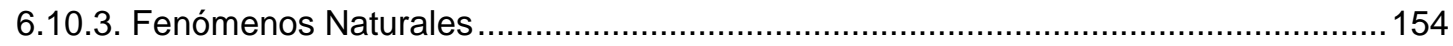

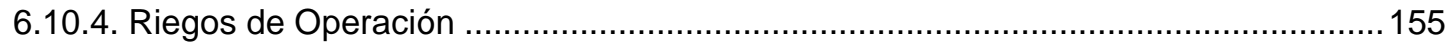

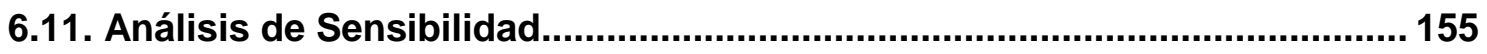

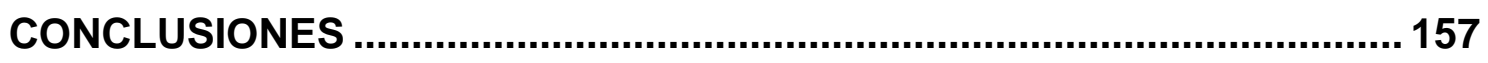

RECOMENDACIONES ........................................................................ 159 
BIBLIOGRAFÍA

ANEXOS 


\section{ÍNDICE DE CUADROS}

Cuadro N01.1: Principales Partidas Exportadas 2015............................................... 26

Cuadro N¹.2: Exportaciones e Importaciones Totales Canadá ............................... 30

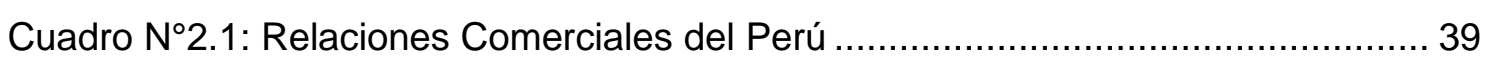

Cuadro N².2: Clima de Inversión en Latinoamérica ............................................... 41

Cuadro N².3: Posición Según Pilares ICR 2015 ...................................................... 52

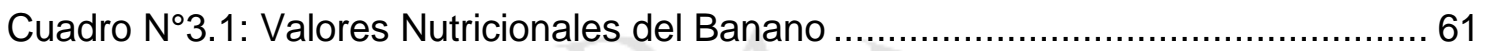

Cuadro N`3.2: Código Arancelario del Banano y sus Derivados ................................62 62

Cuadro N`3.3: Exportaciones de Banano Peruano 2005-2015 ............................... 67

Cuadro N`3.4: Distribución de Hectáreas por Zona ................................................ 70

Cuadro N`3.5: Exportaciones Históricas Anuales de Perú a Canadá de Banano ........ 71

Cuadro N`3.6: Empresas Peruanas Exportadoras de Banano Orgánico a Canadá.... 71

Cuadro N`3.7: Arancel de los Principales Proveedores de Banano a Canadá............. 77

Cuadro N`3.8: Precio Unitario del Banano 2011-2015............................................ 79

Cuadro N`3.9: Gastos del Consumidor en Canadá para el 2005, 2010-2015............. 83

Cuadro N`3.10: Gastos del Consumidor Canadiense en Alimentos .......................... 84

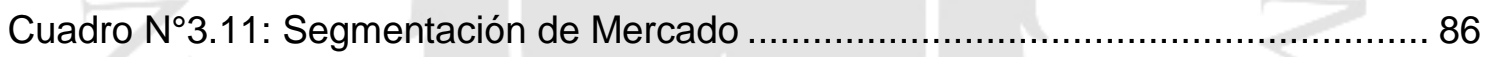

Cuadro $N^{\circ} 3.12$ : Dimensiones del Embalaje......................................................... 93

Cuadro N`3.13: Especificaciones de Fundas Plásticas .......................................... 95

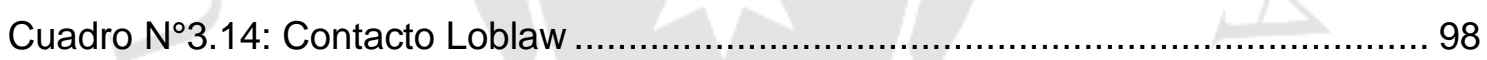

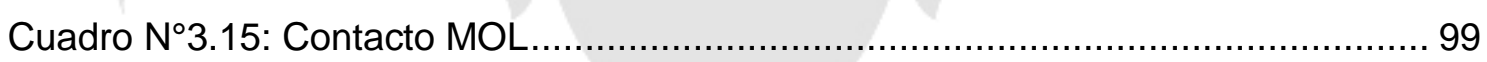

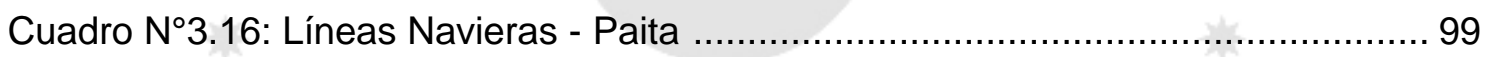

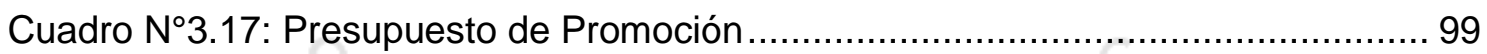

Cuadro N`3.18: Principales Días Festivos ......................................................... 106

Cuadro N4.1: Requerimiento de Equipos de Oficina .......................................... 117

Cuadro N4.2: Requerimiento de Mobiliario de Oficina........................................ 120

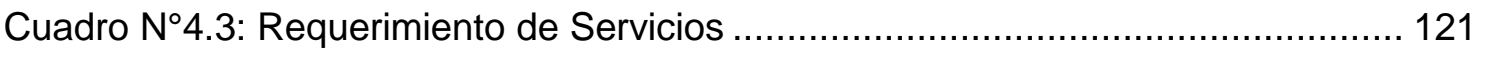

Cuadro N`4.4: Plan Dúo Movistar................................................................. 121

Cuadro N`5.1: Análisis de Puestos de Trabajo.................................................. 136

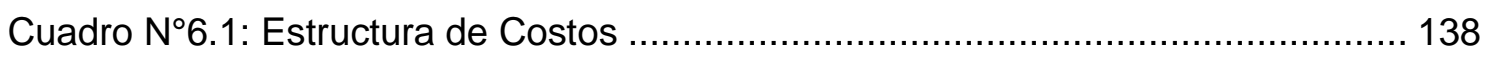

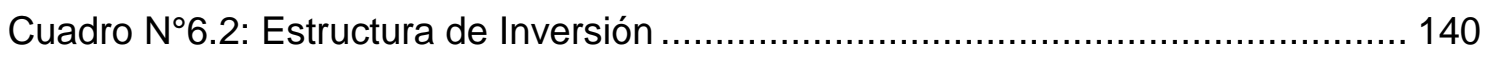

Cuadro Nº.3: Determinación del Punto de Equilibrio ............................................. 141

Cuadro N6.4: Proyección de Ventas ..................................................................... 142

Cuadro N6.5: Flujo de Caja Operativo ................................................................ 143 
Cuadro N6.6: Flujo de Caja Económico

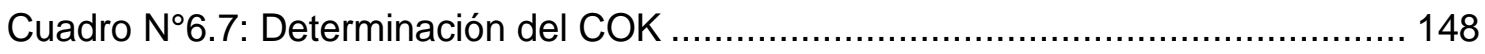

Cuadro N6.8: Estado de Situación Financiera.................................................... 150

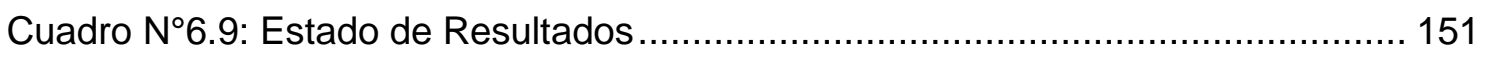

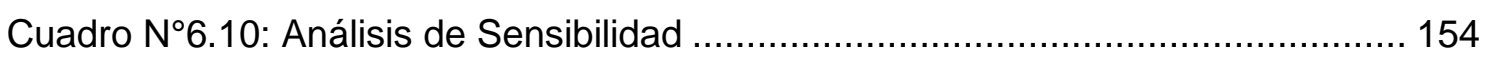




\section{ÍNDICE DE GRÁFICOS}

Gráfico №1.1: Evolución de las Exportaciones Peruanas 2005-2015........................ 21

Gráfico N¹.2: Composición de las Exportaciones 2015........................................ 22

Gráfico N¹.3: Exportaciones No Tradicionales 2015 ........................................... 23

Gráfico N¹.4: Evolución de las Exportaciones del Sector Agroindustrial .................... 24

Gráfico N`1.5: Evolución de los Indicadores del Sector Agroindustrial ...................... 25

Gráfico ํo1.6: Sectores Agrícolas Canadá 2015............................................... 28

Gráfico N`1.7: Composición de la Población por Grupos Étnicos ............................. 33

Gráfico No3.1: Demanda Histórica Mensual de Banano en Canadá ............................63

Gráfico N`3.2: Demanda Histórica Trimestral de Banano en Canadá........................... 63

Gráfico N`3.3: Demanda Histórica Anual de Banano en Canadá ..............................6 64

Gráfico N`3.4: Demanda Potencial de Banano en Canadá ...................................... 65

Gráfico N`3.5: Exportaciones de Banano Peruano ............................................. 68

Gráfico N`3.6: Principales Países de Destino del Banano Peruano 2015.................. 69

Gráfico N`3.7: Participación de la Competencia en el Mercado Canadiense de Banano

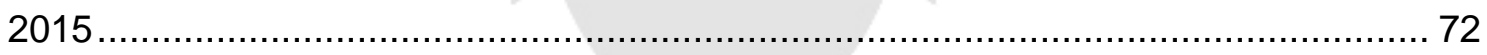

Gráfico N`3.8: Importaciones Canadienses de Banano por País................................ 76

Gráfico N³.9: Importaciones Canadienses de Banano por País.............................. 77 


\section{ÍNDICE DE IMÁGENES}

Imagen $N^{\circ} 1.1$ : Posición Mundial Según Cantidad Exportada ................................. 27

Imagen N¹.2: Pirámide Poblacional Canadá 2015 ............................................ 34

Imagen N`1.3: Guía de Alimentación de Canadá .............................................. 36

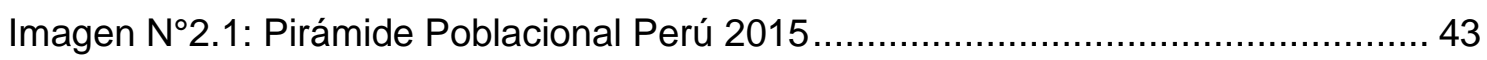

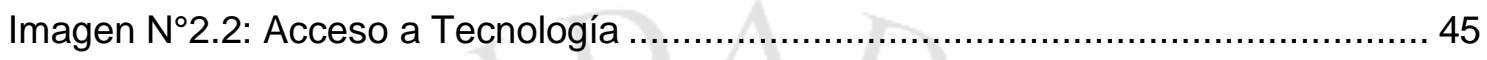

Imagen N².3: Índice de Competitividad Regional 2015 ................................... 51

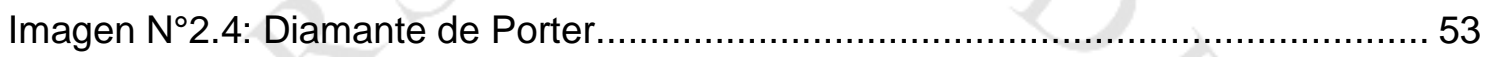

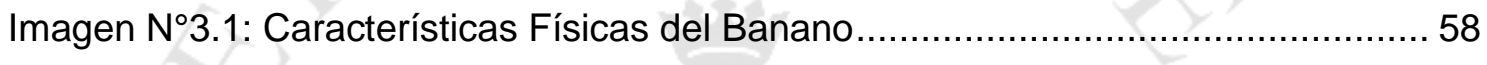

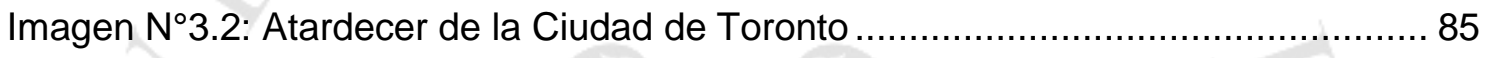

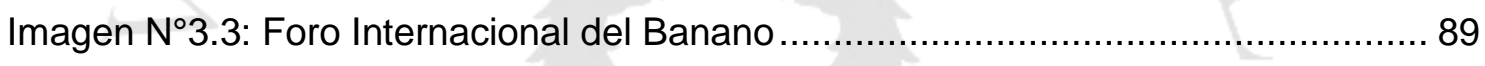

Imagen N`3.4: Análisis FODA de la Competencia .......................................... 91

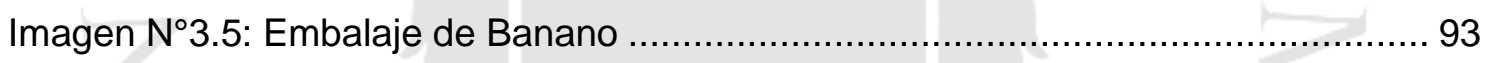

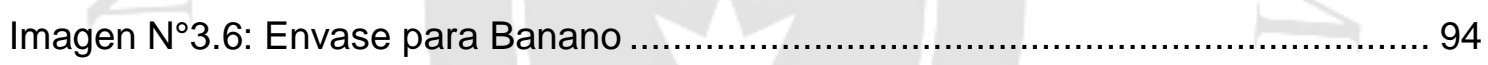

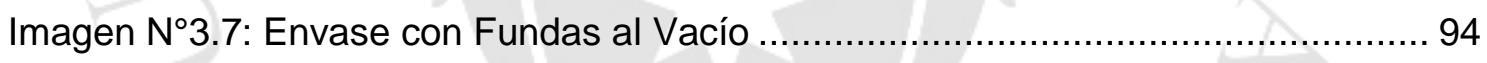

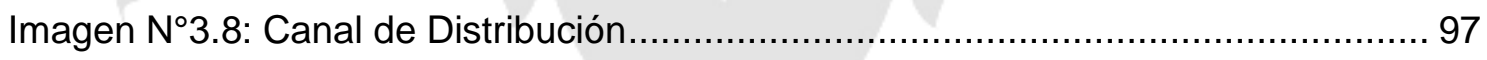

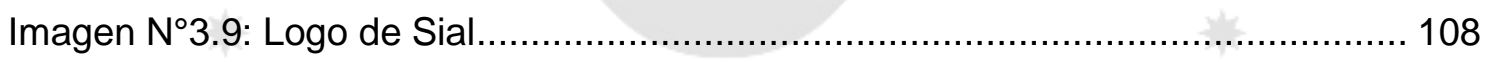

Imagen N4.1: Zona de Producción de Banano en Perú ...................................... 109

Imagen $\mathrm{N}^{\circ} 4.2$ : Nivel de Producción por Mes .................................................. 111

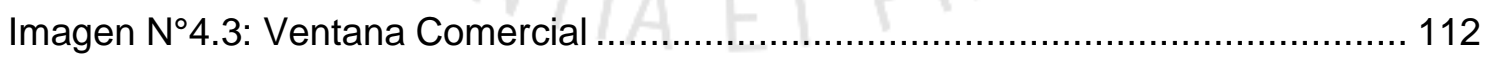

Imagen N4.4: Flujograma del Proceso de Producción ......................................... 114

Imagen N`5.1: Flujograma de Constitución de la Sociedad .................................. 132

Imagen N`5.2: Organigrama de Golden Banana S.A.C ................................... 134 


\section{INTRODUCCIÓN}

El comercio exterior ha demostrado ser uno de los pilares principales para el desarrollo de un país, por eso, en vista de que el Perú cuenta con las condiciones necesarias para triunfar en mercados internacionales, ha aprovechado las oportunidades comerciales que se le han presentado y ha dado continuidad a una política exterior con el fin de mejorar la calidad de vida de la población mediante el aprovechamiento con inclusión social.

Debido a sus políticas basadas en la liberalización de mercados, hoy, Perú cuenta con múltiples acuerdos multilaterales, que ha contribuido a beneficiarse de los resultados provenientes de un creciente dinamismo en lo que respecta al intercambio comercial. Esto, junto con diversas condiciones favorables, como políticas macroeconómicas coherentes, aprovechamiento de la apertura comercial, crecimiento y diversificación de exportaciones, constituyen el marco en el que el Perú se ha posicionado como un país apto para enfrentarse de manera competitiva a los desafíos y exigencias del dinamismo del mundo globalizado del siglo XXI.

Las exportaciones tienen una participación sobresaliente en el PBI nacional. Del mismo modo, se ha experimentado un crecimiento de las mismas de un $565 \%$ en la última década y las exportaciones no tradicionales representan un nada despreciable $32 \%$ del total exportado, con perspectivas de crecimiento.

En la actualidad, Perú, es el líder en crecimiento de exportaciones en la región latinoamericana, por encima de países como Colombia, Chile, Brasil y México; y el segundo, con mayor incremento de la IED en la última década.

A lo largo del presente estudio se describirán la oportunidad y la viabilidad de la exportación de banano orgánico al mercado canadiense, al mismo tiempo que se propone una alternativa estratégica para su exitosa inserción.

En el primer capítulo, denominado Planteamiento del Problema se detallará el proceso de delimitación del tema y se describirá el problema central, el cual constituirá el eje del desarrollo de la investigación. Asimismo, se identificará de la oportunidad del negocio y se expondrán las razones que han llevado a 
seleccionar el tema. La finalidad del proyecto de negocio se articulará en el planteamiento de los objetivos, a través de los cuales se platearán soluciones para las carencias encontradas. Todo esto, en conjunto, diseñará la orientación y el sesgo de la investigación al tema seleccionado.

El capítulo II expone el análisis de las variables importantes en el análisis del entorno, así como las fuerzas que influyen en el desarrollo del plan de negocios. Las hipótesis serán contrastadas luego de realizar un análisis de los indicadores que se presentarán a lo largo del trabajo.

En el tercer capítulo, nombrado Estudio de Mercado, se brindan características y conocimientos indispensables sobre el producto objeto de exportación. La demanda del mercado canadiense de banano orgánico y el segmento, específicamente la ciudad de Toronto; y la oferta nacional del mismo, que constituirá la base para el aprovisionamiento de dicho producto al mercado de destino. Una vez que el usuario se haya identificado con el producto y con la situación y entorno actual, se procederá a explicar los requisitos fundamentales de acceso al mercado y a evaluar el mix de marketing que permitirá arribar con éxito al mercado elegido.

A través del Estudio Técnico se determinarán los requerimientos necesarios para que la empresa opere de manera eficiente, refiriéndose a los activos fijos propios de la compañía, así como la disponibilidad de insumos para abastecer al mercado canadiense del producto elegido.

El capítulo V presenta la descripción de la organización del negocio, en el cual se detallará cómo se encuentra conformada la empresa y cuáles son las funciones y responsabilidades de cada uno de los miembros. Estos temas se encuentran envueltos en el marco jurídico dentro del cual se desarrolla la actividad comercial de la empresa, la cual se explica, también, en este acápite.

En el último capítulo se explorarán las implicancias del análisis en los fundamentos financieros. Se analizarán las cifras obtenidas luego de la evaluación correspondiente, brindando el último elemento decisivo en cuanto a la viabilidad del proyecto. 
Para finalizar, se presentan conclusiones y recomendaciones vinculadas a los temas tratados de acuerdo al alcance del estudio, que servirán de utilidad para el lector en la síntesis y análisis del caso orientado a la exportación de banano orgánico en el ámbito internacional, específicamente, en el mercado canadiense. 


\section{CAPÍTULO I: Planteamiento del Problema}

\subsection{Planteamiento del problema}

En los últimos años, la demanda de productos orgánicos ha sido protagonista de la nueva tendencia de consumo, debido a la creciente preocupación por los problemas de salud y la conservación del medio ambiente, sobre todo en países desarrollados.

El problema central de este estudio parte de la premisa de que, a pesar de que se trata de un producto orgánico, reconocido por su excelente calidad debido al país de procedencia, hasta el momento la estrategia empleada por los exportadores nacionales parece no ser la adecuada, ya que el consumidor canadiense parece preferir el banano orgánico de otros países sobre el peruano. En base a esto se plantea la pregunta correspondiente: ¿Será factible aplicar una estrategia competitiva que permita exportar un mayor volumen de banano orgánico peruano al mercado canadiense y obtener una mejor ubicación en la lista de principales proveedores?

El problema central ampara los siguientes problemas específicos:

- A pesar del mayor consumo que se ha presentado durante los últimos años de productos orgánicos, Canadá no registra un volumen de compra tan alto como otros países. Canadá importa el 3\% del banano mundial, cifra cuyo valor no es muy significativo comparado con el $18.8 \%$ del banano mundial importado por Estados Unidos o un $8.5 \%$ de Bélgica ${ }^{1}$. Al respecto se plantea la primera pregunta específica del estudio: ¿Es rentable exportar banano orgánico a Canadá?

- Hasta el momento, la estrategia de distribución del banano orgánico en Toronto, no ha permitido un mayor posicionamiento en el mercado de destino. Bajo esta premisa se cuestiona lo siguiente: ¿Es viable diseñar una estrategia de distribución que logre que el producto en mención llegue una mayor cantidad de consumidores canadienses?

\footnotetext{
${ }^{1}$ Trade Map, "Importaciones Mundiales de Banano".
} 
- Las actividades de promoción internacional no han tenido el impacto esperado en cuanto al posicionamiento en la mente del consumidor. ¿Cómo deben ser enfocadas estas actividades para lograr que los consumidores relacionen el concepto de banano orgánico con el concepto de producido en el Perú?

Estos son los problemas que forman el eje central del presente estudio de investigación, el cual tiene como objetivos responder a las preguntas antes mencionadas y demostrar la factibilidad del proyecto a través de los mecanismos considerados como los más adecuados.

\subsection{Justificación}

Las razones que han llevado a seleccionar como tema "La Exportación de Banano Orgánico a Canadá" para la elaboración del presente estudio se fundamenta, principalmente por el interés propio en el comercio exterior peruano y por la creciente predisposición de muchos habitantes por las modalidades de consumo de alimentos cada vez más saludable y por un negocio sostenible que contribuya a la preservación de los recursos naturales.

Este Plan de Negocios contribuirá a profundizar y obtener un mayor conocimiento de la especialidad en productos orgánicos y las nuevas tendencias del mercado mundial, así como una guía de inserción exitosa en este ámbito en el comercio.

Durante los últimos años, se ha presenciado una modificación en el consumo mundial de alimentos en cuanto a hábitos y gustos, orientados una mayor preocupación por la ingesta de productos naturales.

Por ello, se han desarrollado nichos de mercado para productos orgánicos, que atraen una demanda creciente al mejorar las dietas alimenticias, lo que permite reducir la obesidad y problemas de salud.

El banano orgánico se presenta como una alternativa interesante de exportación para el Perú, por lo tanto es necesario realizar una investigación 
exhaustiva para aprovechar la demanda canadiense existente y tendencia al alza de productos orgánicos. Las comunidades rurales dependen de su actividad económica relacionada al sector agropecuario para su bienestar y desarrollo.

Partiendo de este enfoque, este documento podría constituir un instrumento dinámico y viable, que contribuya al desarrollo económico y a la calidad de vida de las comunidades de las regiones de Piura, generando empleo y bienestar, a través del aumento de la producción y exportaciones.

\subsection{Objetivos}

- Objetivo General

Desarrollar un Plan de Negocios viable para la exportación de un producto nutritivo, exótico y de calidad, que es el banano orgánico, al mercado canadiense.

- Objetivos Específicos

- Analizar las fluctuaciones de la demanda histórica y diagnosticar la demanda proyectada canadiense de banano en comparación a la oferta histórica y proyectada de banano orgánico de Perú.

- Evaluar los principales factores que afectan la exportación del producto a Canadá, a través del análisis del diamante de competitividad de Porter.

- Definir la ruta logística adecuada para la exportación de banano orgánico a Canadá, con el fin de que el producto llegue en condiciones óptimas incurriendo en el menor costo logístico posible.

- Demostrar la viabilidad del proyecto, a través de un análisis financiero en términos de costo-beneficio. 


\subsection{Delimitación del tema de investigación}

En cuanto al periodo de tiempo, se recopilaron datos de la última década hasta el 2015. Esto brinda una perspectiva amplia de cómo ha evolucionado importación de Canadá de banano. En el análisis de las exportaciones de Perú de banano orgánico a Canadá se compilaron datos del 2009 al 2015, ya que durante los años anteriores no se exportaba este producto a dicho mercado.

En relación a la localización geográfica, el estudio se concentrará en Canadá, específicamente la ciudad de Toronto, que será el destino de las exportaciones debido a la concentración poblacional y a la multiculturalidad que caracteriza a esta región.

Para efectos de delimitación, el Plan de Negocios se restringirá al sector agroindustrial, ya que es el sector que representa un mayor aporte en las exportaciones no tradicionales y el cual comprende al producto objeto de exportación.

Finalmente, es necesario mencionar que la investigación se limitará a estudiar la viabilidad estratégica, financiera y comercial de la oportunidad de negocio internacional específicamente la cual será detallada más adelante, mas no entrará al detalle en la exportación del producto a otros mercados. Tampoco enfocará la problemática relacionada al agro ni a las materias primas para la producción del banano.

\subsection{Relevancia del tema para el usuario, organización o país}

El estudio de investigación tiene una justificación práctica como modelo y guía técnica de referencia para la exportación de banano orgánico al mercado canadiense.

En primer lugar, será de gran utilidad para los actores de esta rama productiva, como una valiosa fuente de información estratégica, comercial y financiera para mejorar la toma de decisiones de las empresas productoras de banano orgánico, contribuyendo al incremento del nivel de ingresos de las familias. Del 
mismo modo, se espera generar oportunidad de lograr el desarrollo sostenible del Valle de Chira y dinamizar la economía local, buscando ampliar la participación del Perú en los mercados internacionales, empezando por fortalecer nuestra oferta en Canadá.

Además, el estudio servirá a los futuros inversionistas para conocer la evolución de las exportaciones de banano orgánico peruano, las características más resaltantes de la actividad productiva, y el enfoque adecuado de la oportunidad de negocio internacional que representa.

Las instituciones públicas y privadas como PROMPERÚ, Ministerio de Comercio Exterior y Turismo, MINAGRI, SENASA, Gobierno Regional de Piura, ADEX, Asociación de Gremios Productores Agrarios del Perú, entre otras encontraran valor en la realización de este estudio dado que promueve un modelo exportador basado en el emprendimiento de los productores y/o comercializadores, a quienes este estudio ayudará a que encuentren nuevas alternativas de negocios en el comercio exterior.

Además, el estudio pretende servir como guía a los alumnos de nuestra universidad no solo de la Carrera Negocios Internacionales, sino también a estudiantes de todas las carreras, en su esfuerzo por realizar estudios de mercado e investigaciones exitosas.

Finalmente, el presente estudio parte de un interés personal de poner en práctica los conocimientos adquiridos en la carrera de Negocios Internacionales a lo largo de estos años y de concretizar en un emprendimiento sustentable y financiable que sea exitoso en el tiempo.

\subsection{Descripción del Entorno}

El escenario en el cual se despliega el presente estudio de investigación es el mercado de productos orgánicos, específicamente el de banano en el mercado canadiense. Se ha elegido este producto debido a la creciente preocupación de la población en relación con este tipo de productos y por ser el banano una 
fruta con potencial exportador para satisfacer las necesidades del mercado en lo referente a nutrición y demanda por productos exóticos.

La exportación de banano constituye una importante fuente de ingresos para el Perú y se espera que con las nuevas tendencias del mercado, el concepto de "orgánico" tome protagonismo dentro de las exportaciones peruanas, ya que contamos con adecuadas condiciones climatológicas para el cultivo de este producto.

Por otro lado, el Perú, dentro de sus políticas comerciales busca incentivar la producción y exportación de productos no tradicionales, con el fin de generar un mayor bienestar en la población mediante la generación de empleos. Asimismo, el objetivo es reducir dependencia de los commodities, cuyos precios fluctúan de manera volátil y así mantener el comercio exterior lo más estable posible.

La perspectiva de la economía mundial no ha sido del todo favorable en los últimos años después de la crisis financiera, lo que ha afectado las ventas totales de productos peruanos al exterior. Sin embargo, aquellos de origen no tradicional continúan creciendo a ritmos interesantes.

Ese es el caso del banano fresco tipo cavendish valery, resalta la Sociedad de Comercio Exterior (ComexPerú). En los últimos años, las exportaciones peruanas de esta variedad se han mostrado bastante dinámicas.

\subsubsection{Exportaciones Peruanas al Mundo}

El presente acápite ha sido elaborado con el objetivo de dar una visión general de la situación comercial actual del Perú, analizando la evolución de las exportaciones, enfocándonos en el sector agro exportador, debido a la estrecha relación con el producto objeto de exportación. 
Las exportaciones totales sumaron US\$33.5 millones, lo que significó una contracción del $13.07 \%$ respecto al 2014 , como resultado de las menores envíos de productos tradicionales y no tradicionales. ${ }^{2}$

El descenso que experimentaron las ventas peruanas se debió a la menor demanda de países como Estados Unidos, Canadá, Japón, España, Corea del Sur y Brasil.

\section{Gráfico N¹.1}

Evolución de las Exportaciones Peruanas 2005-2015

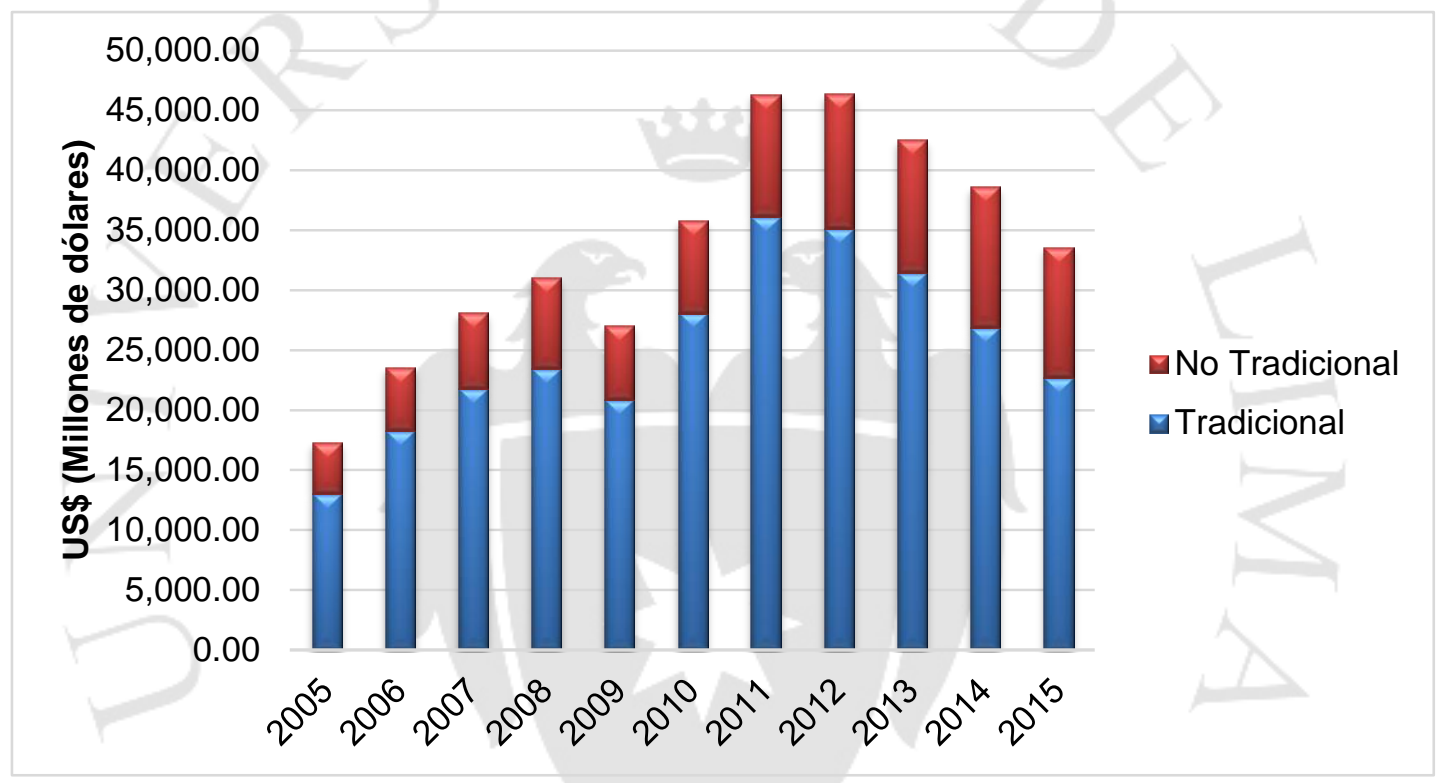

Fuente: InfoTrade

En cuanto a mercados de destino, en el 2015, las exportaciones peruanas se dirigieron a 183 países, es decir, 7 países menos con respecto al periodo enero-diciembre 2014. China fue el principal mercado de destino de las exportaciones peruanas al explicar el $22 \%$ del total exportado y un crecimiento de $11.31 \%$. Otros destinos importantes fueron Estados Unidos (15\%), Suiza (8\%), Canadá (7\%) y Japón (3\%).

Al cierre del año se registraron 4,609 partidas, que simboliza una disminución de 15 con respecto al año anterior; y de empresas exportadoras, que disminuyó a 7,597, en una cuantía de 630 en comparación con el 2014.

\footnotetext{
2 Trade Map, "Exportaciones peruanas en el 2015".
} 
Gran parte de las exportaciones peruanas corresponde al sector tradicional, como se muestra en el siguiente gráfico. El principal sector de este rubro es el minero, el cual representó el 54\% del total de exportaciones del 2015 y cerca del $80 \%$ de las exportaciones tradicionales. ${ }^{3}$

\section{Gráfico N¹.2}

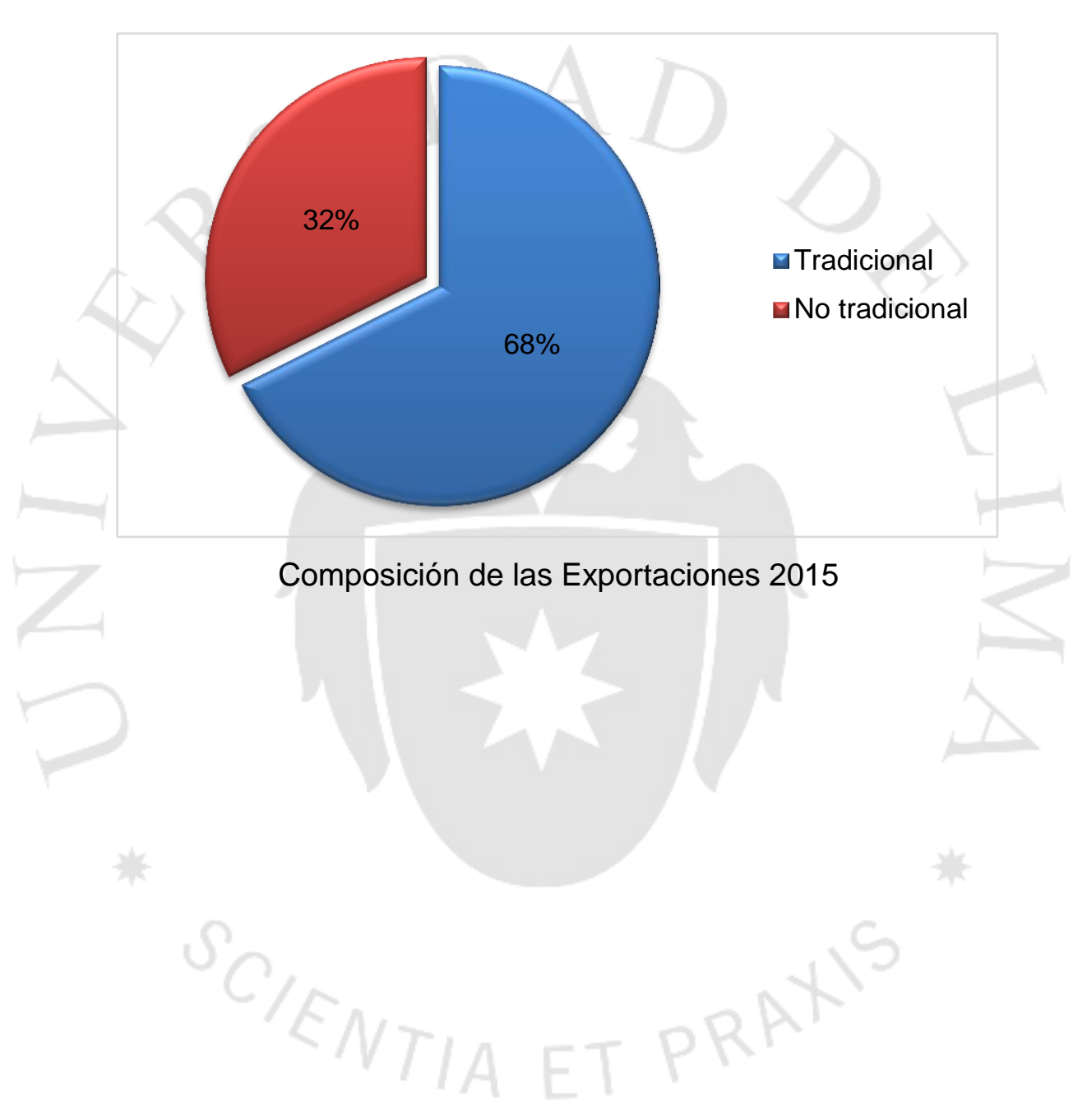

Fuente: InfoTrade

\subsubsection{Exportaciones Peruanas No Tradicionales}

Como se expuso en el gráfico anterior las exportaciones de productos no tradicionales representa un todavía bajo porcentaje dentro de las exportaciones

\footnotetext{
${ }^{3}$ InfoTrade, "Composición de las exportaciones peruanas 2015".
} 
totales, posicionándonos como un país exportador de materias primas. Debido a la gran dependencia económica de este tipo de productos, el gobierno peruano impulsará la exportación de productos no tradicionales para compensar la caída de los precios de los commodities y reducir la concentración en productos inherentes a este sector ${ }^{4}$.

Entre enero y diciembre, las exportaciones no tradicionales lograron ventas por US $\$ 10,893$ millones lo que equivale una contracción del $7.64 \%$, debido al retroceso de las exportaciones de casi todos los sectores productivos. Por otro lado, sectores como el agropecuario (US\$ 4345 millones de exportaciones y $3,4 \%$ de variación) y la minería no metálica (US\$ 697 millones y 4,6\%) registraron mayores exportaciones.

A nivel de mercados, Estados Unidos lideró el ranking de destinos, seguido por Países Bajos, Chile, Colombia, Ecuador y Bolivia.

La agroindustria (US\$ 4,345 millones) fue el sector más importante, seguido por textiles y confecciones (US\$1,324 millones), pesquero (US\$949 millones) y químico (US\$ 1,393 millones).

Gráfico №1.3

Exportaciones No Tradicionales 2015

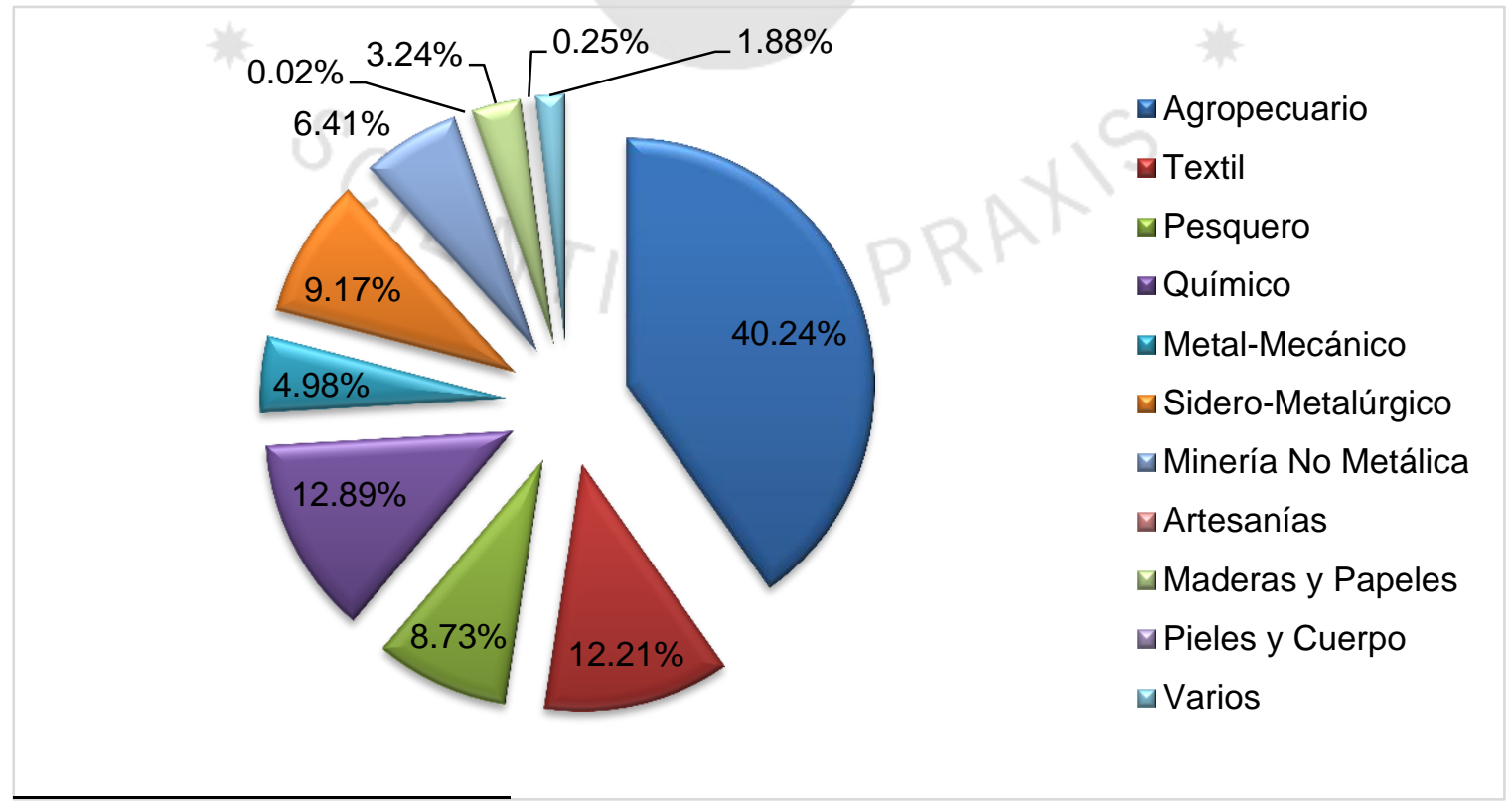

${ }^{4}$ Diario Gestión. "Se impulsan exportaciones no tradicionales para reducir efecto de caída en commodities". 


\subsubsection{Sector Agroindustrial Peruano}

Como se mencionó en la sección anterior, la agroindustria representa un gran motor dinamizador para la economía del país, además de ser una de las mayores fuentes de generación de trabajo y tiene una participación de $8 \%$ en las exportaciones totales.

Dentro del rubro, los alimentos frescos son los que lideran las principales exportaciones, específicamente las frutas, siendo las bananas, la cuarta fruta más exportada, luego de las uvas, la palta y el mango.

A continuación se presenta un gráfico que refleja la evolución de no solo de las exportaciones de productos agroindustriales totales en los últimos 10 años, sino también otros indicadores de que éstas han prosperado con el paso del tiempo.

\section{Gráfico №1.4}

Evolución de las Exportaciones del Sector Agroindustrial 2005-2015

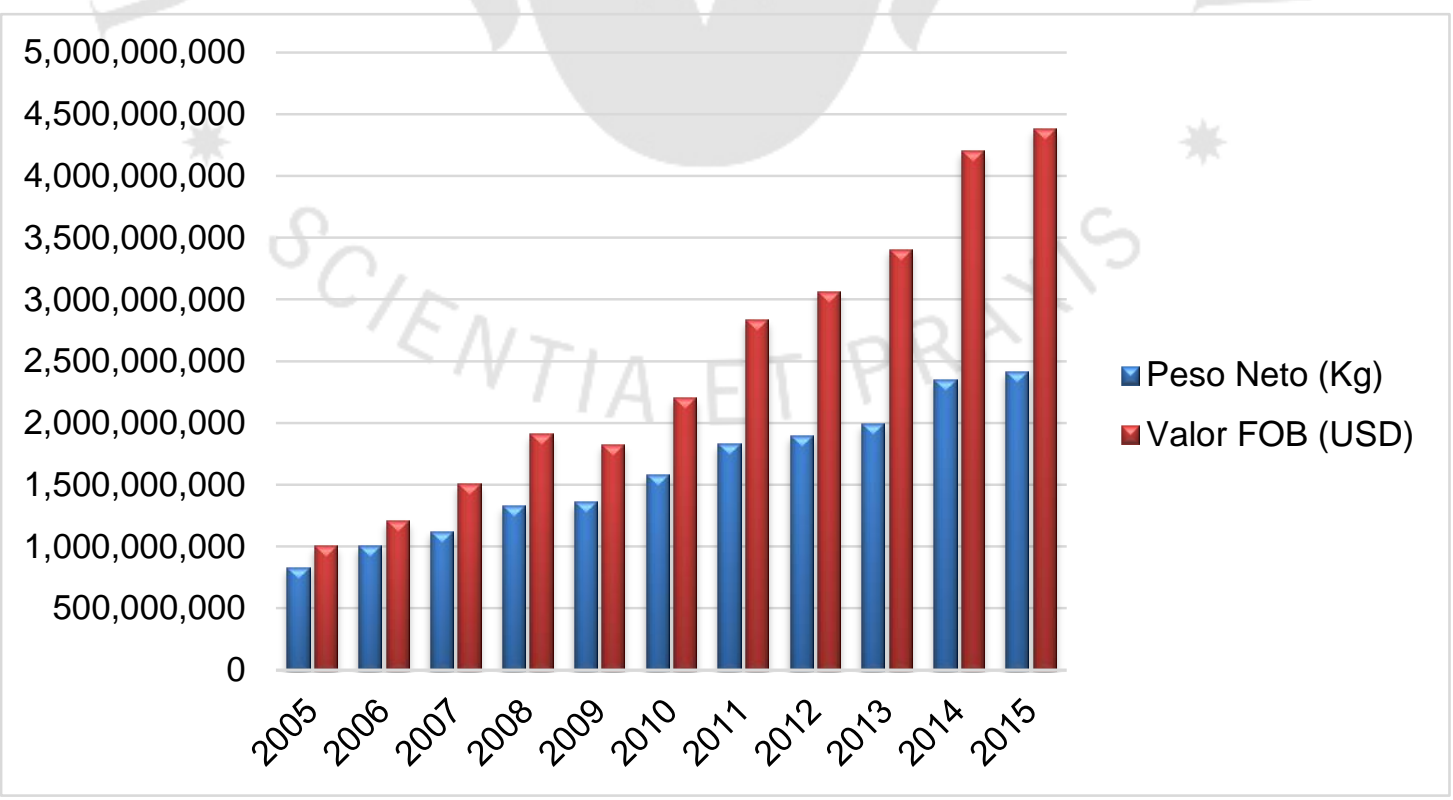

Fuente: InfoTrade 
Evolución de Indicadores Sector Agroindustrial 2005-2015

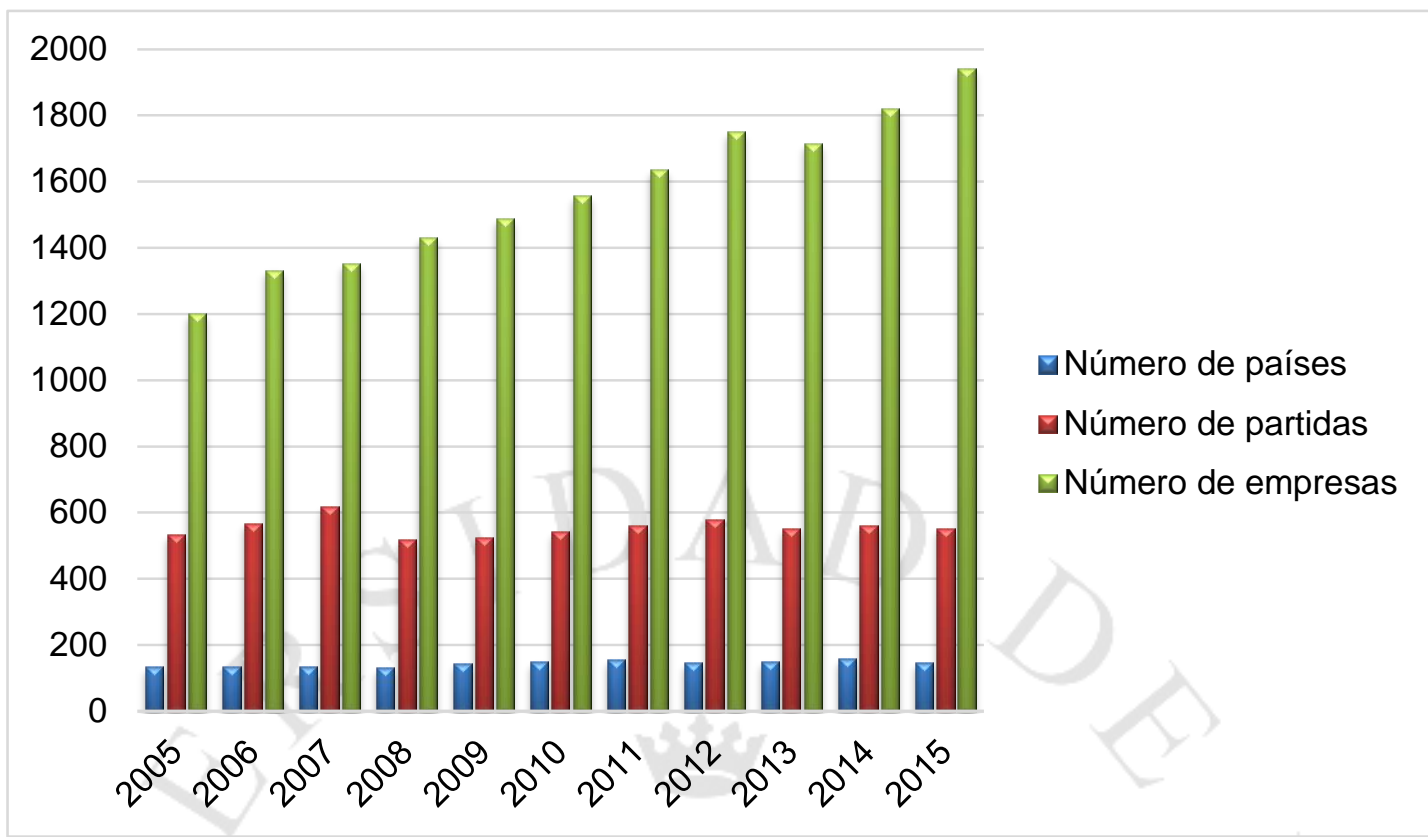

Fuente: InfoTrade

En lo que comprende al mercado de destino, en el 2015, las exportaciones de productos agropecuarios se dirigieron a 146 países, 11 menos que el año pasado. El número de partidas también presento una disminución de 9 con respecto al 2014 y, por el contrario, la cantidad de empresas exportadoras aumentaron en 75 .

EEUU se mantiene como principal destino y registra una tasa positiva de crecimiento, seguido por Países Bajos, España y luego Reino Unido. Entre estos cuatro principales países se concentra el $58.77 \%$ de las exportaciones de productos agropecuarios. Canadá se encuentra en el puesto 8 dentro de los principales destinos de este rubro.

A nivel de regiones, los tres principales departamentos exportadores representan el $69 \%$ del total colocado en el exterior. Lima lidera con el $32 \%$ del total, seguido por Ica con el $21 \%$ y La Libertad con $16 \%{ }^{5}$.

\footnotetext{
${ }^{5}$ Sistema Integrado de Información de Comercio Exterior (SIICEX). "Informe mensual de exportaciones (Acumulado) 2015".
} 
Cuadro $\mathrm{N}^{\circ} 1.1$

Principales partidas exportadas 2015

\begin{tabular}{|c|c|c|c|}
\hline NRO & PARTIDA & DESCRIPCIÓN & $\begin{array}{c}\text { VALOR FOB } \\
\text { US } \$\end{array}$ \\
\hline $\mathbf{1}$ & 0806100000 & Uvas frescas & $704,378,748.43$ \\
\hline $\mathbf{2}$ & 0709200000 & Espárragos, frescos o refrigerados & $421,318,290.65$ \\
\hline $\mathbf{3}$ & 0804400000 & Aguacates (Paltas), frescas o secas & $304,969,649.91$ \\
\hline $\mathbf{4}$ & 0804502000 & Mangos y Mangostanes, Frescos o Secos & $196,126,956.39$ \\
\hline $\mathbf{5}$ & 1801001900 & Cacao Crudo excepto para siembra & $183,167,785.84$ \\
\hline $\mathbf{6}$ & 0803901100 & Banano Tipo «Cavendish Valery» & $145,159,965.96$ \\
\hline $\mathbf{7}$ & 1008509000 & Los demás Quinua excepto para siembra & $144,225,920.72$ \\
\hline $\mathbf{8}$ & 2309909000 & Demás preparaciones utilizadas para la & $133,127,964.38$ \\
\hline $\mathbf{9}$ & 2005600000 & $\begin{array}{c}\text { Espárragos preparados dos animales } \\
\text { congelar }\end{array}$ & $131,834,660.06$ \\
\hline $\mathbf{1 0}$ & $\mathbf{0 4 0 2 9 1 1 0 0 0}$ & Leche Evaporada Sin Azúcar Ni Edulcorante & $98,839,280.14$ \\
\hline
\end{tabular}

Fuente: InfoTrade

Como se puede observar en la tabla presentada, el banano es uno de los 10 principales productos exportados del sector agropecuario y 4ta fruta más exportada, representando el $3.31 \%$ de las exportaciones totales de este sector.

\subsubsection{Panorama Nacional del Banano}

El Perú ha experimentado un avance en cuanto a posicionamiento en el mercado mundial en cuando a exportación de banano. Hasta el año pasado, nuestro país se encontraba en el puesto 14 dentro de los principales proveedores de este producto, pese a que cerca del $100 \%$ del banano exportado por Perú es banano orgánico.

A continuación se presenta la Imagen № 1.1 que muestra la evolución del tema recién expuesto. 


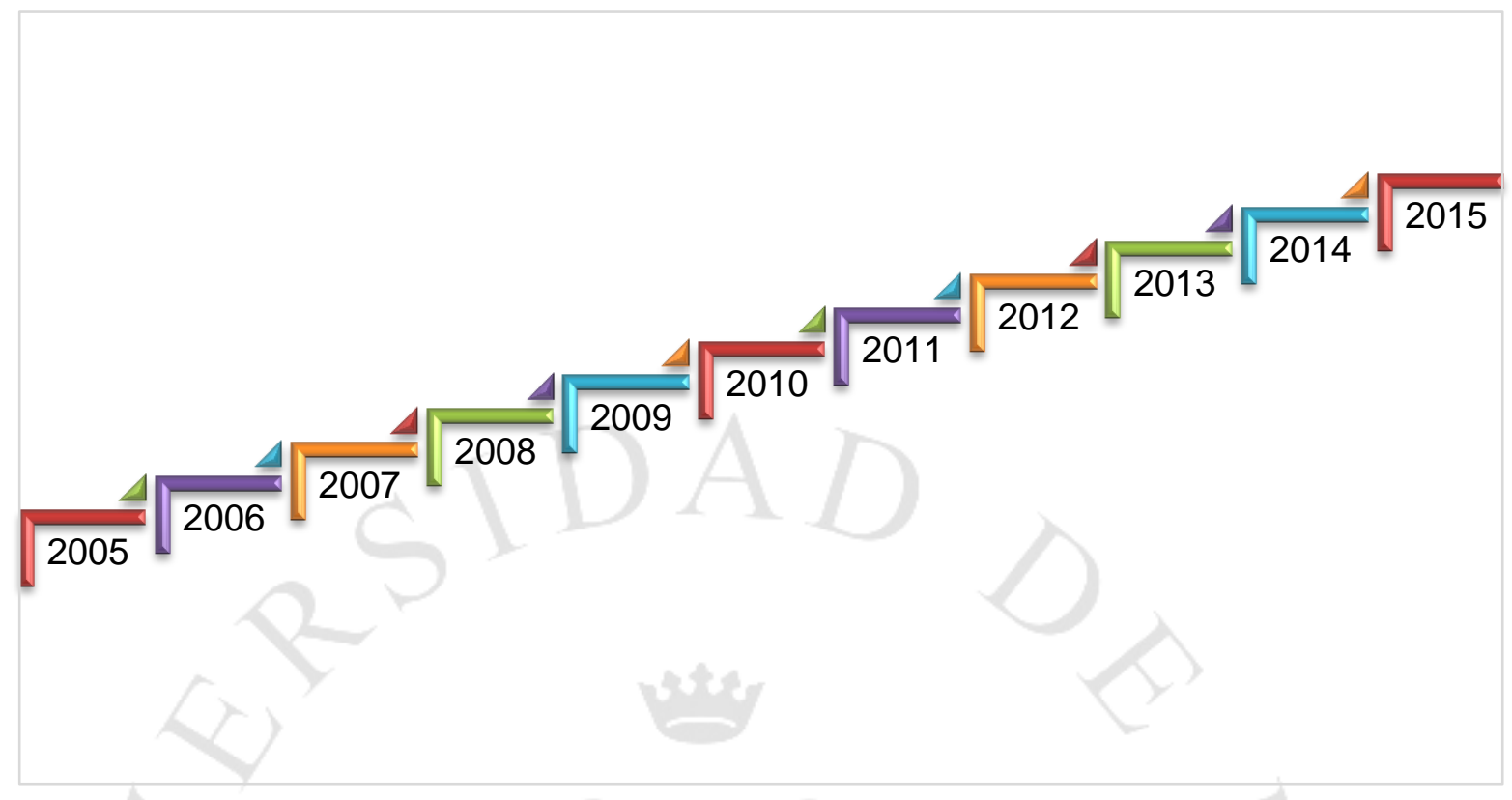

Fuente: Trade Map

Como se puede observar, hemos alcanzado 12 puestos por encimą de $\mathrm{la}^{\mathbf{1 4}}$ posición que nos caracterizaba hace una década. Esto rofleja e l $^{13}$ dinamismo de la exportación de banano, que se manifiessta en una mayor participación en el abastecimiento mundial. Simo olvidar que detrás de esto, se encuentraun cadena productiva ${ }_{2 ̧}$ ada vez más fortalecida y con mayor capacidad de producción.

26

\subsubsection{Sector Agroindustrial Canadá}

El principal cultivo exportado por Canadá es el trigo, el cual crece en las más importantes zonas trigueras del mundo, las provincias de Alberta, Manitoba y Saskatchewan y supone el $16 \%$ de la producción global. Otros principales cultivos son los cereales, la cebada, el lino, el tabaco y las hortalizas ${ }^{6}$.

El sector agroindustrial del mercado Canadiense no posee gran variedad de cultivos de frutas frescas y vegetales dado que no posee la capacidad de tierra de sembrío suficiente para realizarlo, ya que solo el $5 \%$ del total de su territorio es apto para realizar esta actividad. Cabe mencionar que Canadá no puede

\footnotetext{
${ }^{6}$ Euromonitor.
} 
producir banano debido a que no cuenta con la tierra adecuada para hacerlo ni tampoco con las condiciones climáticas apropiadas ${ }^{7}$.

Gráfico №1.6

Sectores Agrícolas Canadá 2015

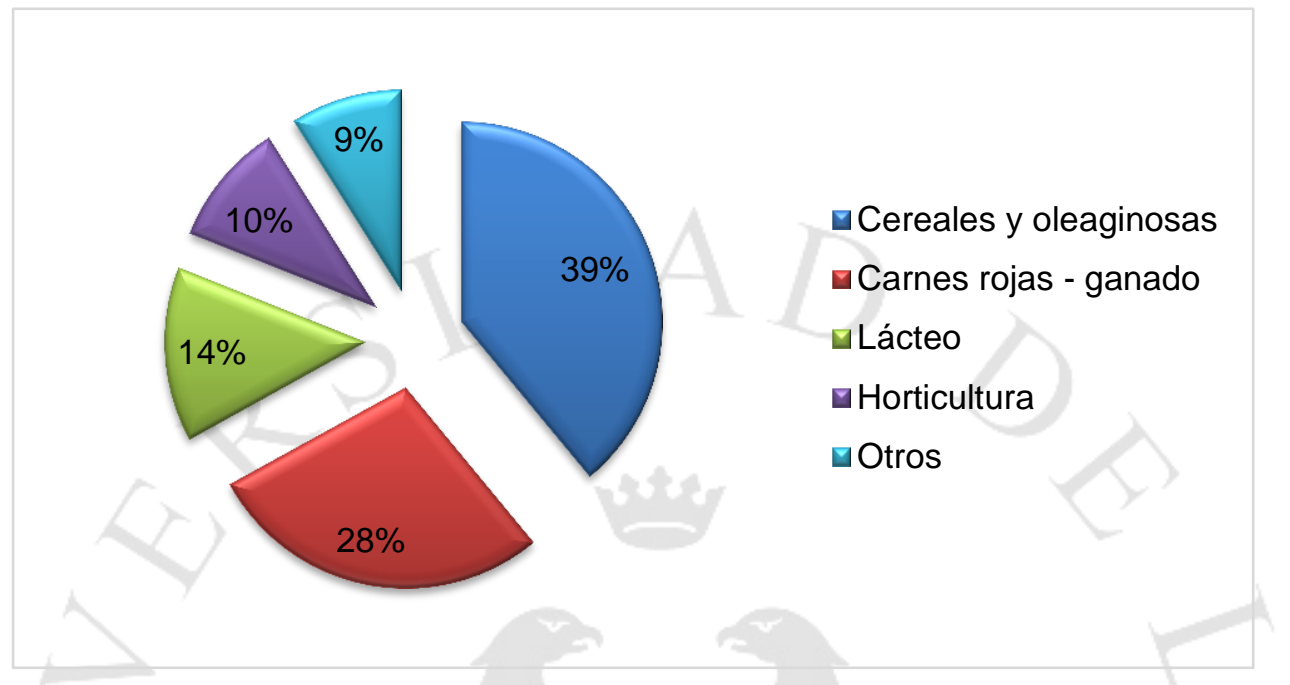

Fuente:

Agriculture Canadá

\subsubsection{Cooperación Perú - Canadá}

Uno de los factores más beneficiosos para establecer una relación comercial con Canadá, es la existencia de un Tratado de Libre Comercio entre ambos países. Este acuerdo se firmó en Lima el 29 de mayo de 2008 y entró en vigencia el $1^{\circ}$ de agosto de 2009. Este tiene como objetivo lograr procedimientos comerciales más eficaces y reducir las formalidades y los costos en los que incurren las empresas cuando buscan ingresar a nuevos mercados.

Los beneficios para ambos países han sido notables, ya que en el 2010 Canadá fue el cuarto mercado de destino de las exportaciones peruanas, aumentando en $44 \%$ con respecto a las del año anterior. De este incremento, el $18 \%$ proviene de las exportaciones no tradicionales, como lo son las frutas frescas o congeladas. ${ }^{8}$

\footnotetext{
${ }^{7}$ Ministerio de Agricultura y Agroalimentación de Canadá. "Servicio de Exportación Agroalimentaria".

${ }^{8}$ Trade Map, "Destino de las exportaciones peruanas".
} 


\subsection{Análisis de Canadá como potencia mundial}

Canadá es una de las naciones más ricas del mundo, con un alto ingreso per cápita y economía competitiva caracterizada por una amplia apertura comercial, alcanzando los casi 826 billones de dólares en el 2015.

Asimismo, desempeña un rol muy importante en organismos internacionales que llevan la batuta del desarrollo mundial, como la Organización Mundial de Comercio (OMC), el G-8, en otros. Posee una economía con un crecimiento constante y sostenido, en la cual todos los sectores aprovechan el poder de las nuevas tecnologías del comercio e inversión internacional.

El PBI de Canadá ha experimentado un aumento en los últimos 5 años, alcanzando los 1'566,901.28 millones de dólares en el año $2015^{9}$. Los positivos indicadores económicos y sus previsiones a mediano y largo plazo auguran que la economía canadiense continuará bien encaminada.

Su economía se ha mantenido firme, beneficiándose de un fuerte compromiso con las políticas de libre comercio que facilitan los flujos de bienes y servicios e inversión global.

Su principal socio comercial es Estados Unidos, mientras que Perú es el décimo séptimo en cuanto a proveedores. Los principales productos comercializados entre Perú y Canadá son perlas finas, minerales, frutos comestibles y vegetales, café, yerba y mate, siguiendo el orden de prioridad. ${ }^{10}$

Debido a las crisis que han afectado a Estados Unidos, desacelerando su actividad económica, Canadá está buscando diversificar los proveedores, mostrando un creciente interés por nuevos socios comerciales en el mundo o intensificar las relaciones con proveedores que mantengan una economía estable.

Cuadro $N^{\circ} 1.2$

Exportaciones e Importaciones Totales Canadá

\footnotetext{
9 Datos Macro, "El PBI subió un $1.2 \%$ en Canadá".

${ }^{10}$ Trade Map. "Importaciones canadienses de Perú”.
} 


\begin{tabular}{|c|c|c|c|c|c|}
\hline & $\mathbf{2 0 1 1}$ & $\mathbf{2 0 1 2}$ & $\mathbf{2 0 1 3}$ & $\mathbf{2 0 1 4}$ & $\mathbf{2 0 1 5}$ \\
\hline EXPORTACIONES & $450,430,008$ & $454,098,967$ & $456,605,444$ & $473,556,513$ & $407,140,011$ \\
\hline IMPORTACIONES & $450,579,509$ & $462,366,181$ & $461,764,140$ & $463,029,337$ & $418,801,083$ \\
\hline $\begin{array}{c}\text { SALDO } \\
\text { COMERCIAL }\end{array}$ & $-149,501$ & $-8,267,214$ & $-5,158,696$ & $-10,527,176$ & $-11,661,072$ \\
\hline
\end{tabular}

Fuente: Trade Map

En cuanto al índice de libertad económica, según el Instituto Fraser, Canadá obtuvo el 10mo lugar en el ranking mundial, lo cual significa que es un país con bastante libertad económica y que brinda oportunidades a sus ciudadanos ${ }^{11}$.

\subsection{Potencial de Consumo}

La convergencia dietética es bastante elevada entre los países de ingresos altos pertenecientes a la OCDE, de la cual Canadá es miembro activo.

Últimamente, los alimentos orgánicos han empezado a tener una fuerte presencia en la alimentación infantil. Los padres preocupados procuran adquirir productos que consideran saludables y sanos para sus hijos, limitando la exposición innecesaria a químicos.

Un estudio publicado por la Asociación de Comercio Orgánico Canadá (COTA) revela que la industria orgánica de Canadá está creciendo sostenidamente. El mercado de productos orgánicos alcanzó los \$ 3.5 mil millones en 2014, con unas ventas de alimentos y bebidas no alcohólicas orgánicas certificadas de US \$ 3 mil millones, y ahora es el triple del valor del mercado en 2006. El estudio también encontró que más de la mitad de los canadienses compran productos orgánicos por lo menos una vez cada semana.

El mercado de alimentos orgánicos en Canadá ha registrado una impresionante expansión durante la última década, logrando una relativa estabilidad en el consumo de fruta fresca, siendo este de $80 \mathrm{Kg}$ per cápita aproximadamente.

\footnotetext{
${ }^{11}$ NM Noticias, "Canadá en el top 10 de los países con mayor libertad económica del mundo, según el instituto Fraser".
} 
Es importante mencionar que el $80 \%$ de los alimentos orgánicos vendidos al consumidor final son importados, siendo 61 países en total los que participan de este proceso. Los favorables artículos de prensa sobre los beneficios en la salud del consumo de frutas frescas (tanto los orgánicas como los convencionales) continuarán promoviendo las ventas futuras.

La industria de productos orgánicos ha experimentado un rápido crecimiento en todo el mundo en las últimas décadas. $Y$ los productos frescos seguirán dominando el mercado y cada vez más personas optarán por empezar a realizar sus compras bajo esta nueva tendencia.

El consumidor canadiense en general es un comprador altamente sensibilizado en relación a los beneficios de una alimentación sana, saludable y respetuosa del medio ambiente, de tal manera que están dispuestos a pagar más por un producto de mayor calidad. $^{12}$

Dentro de las importaciones de Canadá al 2015 las frutas en general se ubicaron en el puesto 19 dentro de las principales importaciones, alcanzando los 4 mil 506 millones de dólares. En relación a la importación de frutas, el banano fue la quinta fruta más importada con un valor FOB de 414 mil 920 millones de dólares.

Por otro lado, las exportaciones canadienses de este producto suman solo 113 mil dólares, con lo que se puede concluir que existe una demanda interna insatisfecha que puede ser satisfecha solo mediante compras del exterior.

En base al análisis realizado hasta el momento, los productos orgánicos cuentan con un mercado cautivo en Canadá y el Perú puede beneficiarse de su reconocimiento internacional como productor de frutas de calidad y ganar terreno en esta industria. Además, el mercado de productos orgánicos es descrito por analistas como la industria más dinámica y de mayor crecimiento en el sector de la industria de alimentos.

\footnotetext{
${ }^{12}$ Comisión Interamericana de Agricultura Orgánica, "Estudio de Mercado: Arándanos Frescos Orgánicos, Canadá".
} 


\subsubsection{Producción de banano en Canadá}

Norteamérica cuenta con 2.7 millones de hectáreas destinadas a cultivos de productos orgánicos, lo que representa aproximadamente el $0.7 \%$ de toda el área agrícola de la región y $7 \%$ del área agrícola orgánica del mundo ${ }^{13}$. De esta cantidad, solo 700 mil se encuentran en Canadá.

Las limitaciones productivas de Canadá se derivan del hecho de no contar con las condiciones idóneas en materia de clima para el cultivo de este producto. Los largos y crudos inviernos canadienses permiten únicamente una agricultura estacional. La producción nacional de frutas y vegetales se reduce a productos como la col, las cebollas, el maíz, tomates, zanahorias, manzanas, uvas arándanos.

\subsubsection{Entorno Cultural}

Canadá cuenta con una extensión geográfica de $9,984,670 \mathrm{~km}^{14}$, posicionándolo como el segundo país más grande el mundo, luego de Rusia y con una población de aproximadamente $36,048,521$ habitantes ${ }^{15}$. Esta última cifra constituye uno de los factores que convierten a este país en un mercado atractivo para la exportación de banano orgánico, no solo por su ubicación en el puesto 39 dentro de los países con mayor población, sino también por su composición multicultural.

En el Gráfico №1.7 se puede apreciar la composición de la población por grupos étnicos y sus respectivos porcentajes de participación.

\footnotetext{
${ }^{13}$ Organic World, "Key Indicators and Leading Countries".

${ }^{14}$ Central Intelligence Agency. "World Factbook".

${ }^{15}$ Statistics Canada.
} 
Composición de Población por Grupos Étnicos

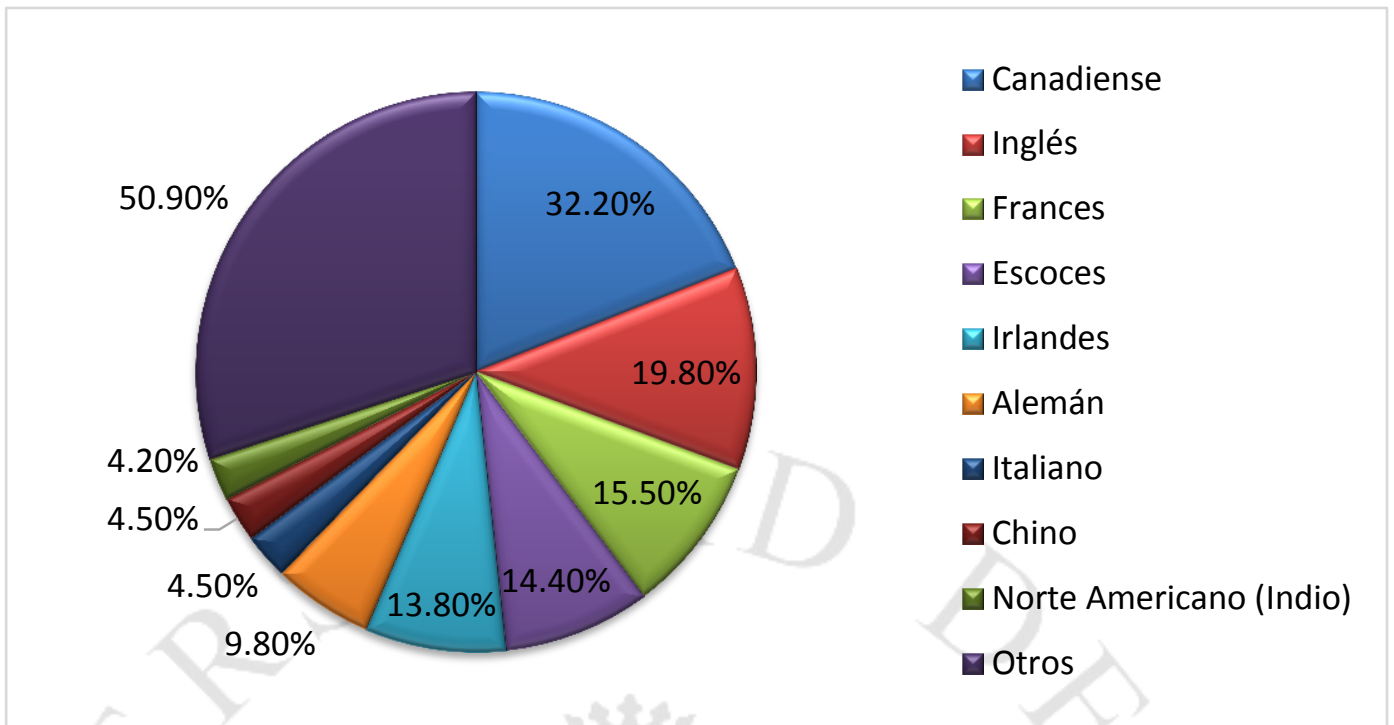

Nota: Porcentajes suman más de $100 \%$ porque los encuestados fueron capaces de identificar más de un origen étnico

Fuente: World Factbook - CIA

Las sucesivas olas migratorias provenientes de diversas partes el mundo han protagonizado la transición de la población canadiense a la multiculturalidad, razón por la cual estos nuevos residentes han tendido a ubicarse en grandes centros urbanos, como Toronto, dentro de las cuales se han creado mercados especializados para satisfacer la demanda de estos nichos étnicos por alimentos exóticos.

Un poco más del $80 \%$ de la población se concentra en las ciudades, por lo que se considera que este país es altamente urbano, siendo Toronto, Montreal y Vancouver las ciudades con mayor número de habitantes del país. Estas ciudades cuentan con la presencia de 6.1, 4 y 2.5 millones de habitantes respectivamente, confirmando que la ciudad objetivo del presente estudio es la más poblada de Canadá ${ }^{16}$. 
Imagen $\mathrm{N}^{\circ} 1.2$

Pirámide Poblacional Canadá 2015

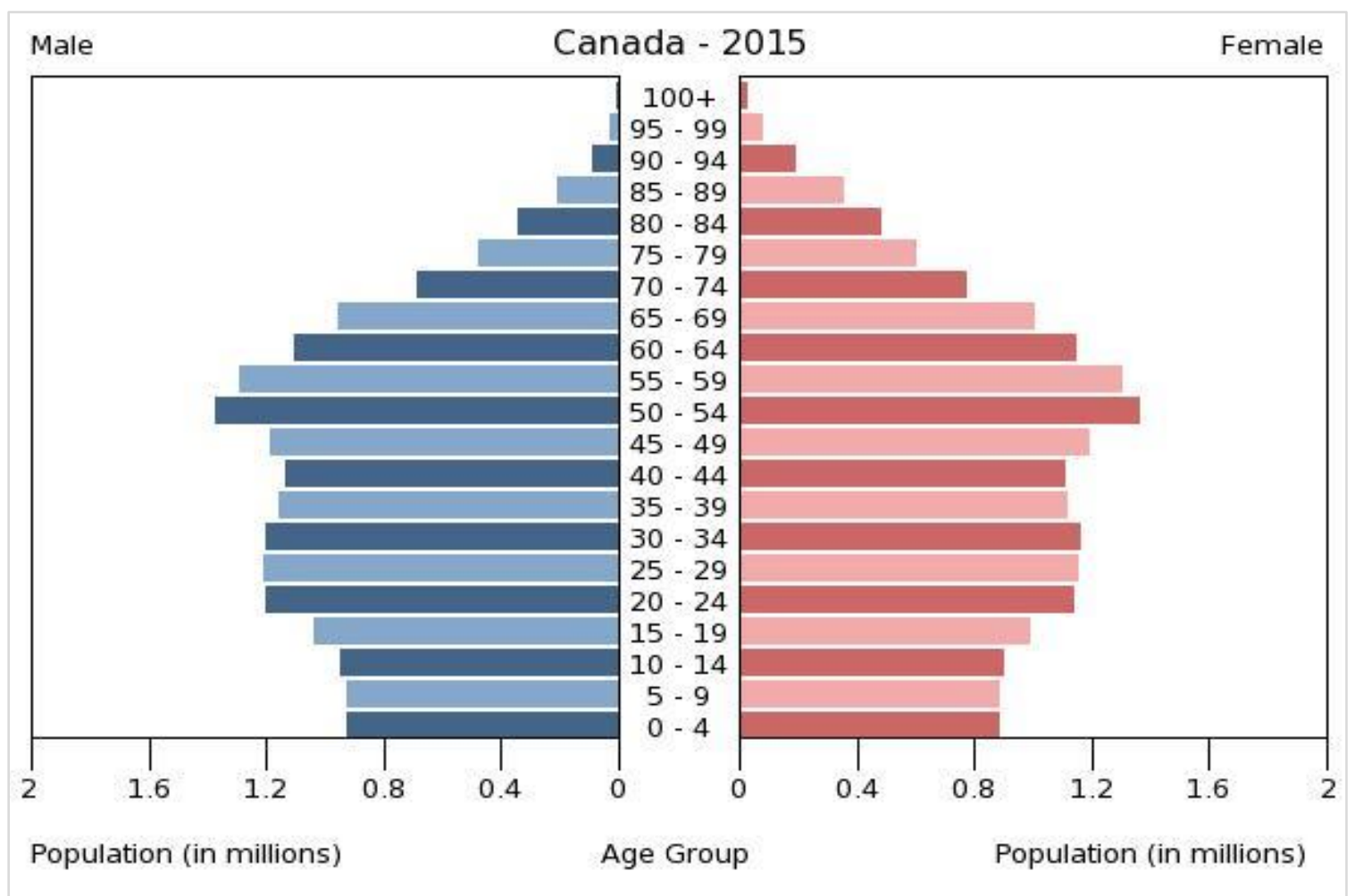

Fuente: World Factbook - CIA

La pirámide de la Imagen N¹.2 muestra la estructura de la población de acuerdo a género y edad, mostrando un balance entre géneros y una leve concentración en personas alrededor de los 50 años, principalmente como resultado de la baja tasa de fertilidad y el incremento de la expectativa de vida.

\subsubsection{El problema de la obesidad}

Una preocupación que acecha tanto a las familias como a los gobernantes es la alta tasa de obesidad que ha alcanzado el mayor porcentaje en la historia de este país. Este es un problema mundial que inquieta, sobre todo a los países desarrollados, como es el caso de Canadá, el cual junto con EEUU, Australia y Reino Unido presentan los índices más altos de obesidad.

La situación actual de Canadá en cuanto a obesidad es un importante factor de riesgo, ya que podría traducirse en un mayor desencadenamiento de 
enfermedades crónicas, debido a que las altas tasas de obesidad se han relacionado con enfermedades como la diabetes, problemas cardiovasculares e incluso cáncer de mama, colon y próstata. ${ }^{17}$

Se estima que estas enfermedades puedan prevenirse en un $90 \%, 82 \%$ y $70 \%$ de los casos respectivamente, si las personas mejoran su estilo de vida, lo cual implica una mejor alimentación ${ }^{18}$.

Las cifras muestran que $52 \%$ de adultos tienen sobrepeso y/o obesidad y el $20.4 \%$ los jóvenes entre 12 y 17 años presentan el mismo problema. ${ }^{19}$ Cabe mencionar que el $75 \%$ de los niños obesos sufren de este problema cuando llegan a la adultez.

La obesidad ha tomado un lugar central como un importante factor de riesgo de enfermedades crónicas, por lo que el gobierno ha tomado medidas y ha elaborado la "Guía alimenticia de Canadá", que recomienda a la población ingerir entre 5 y 10 porciones de frutas y verduras cada día. En el siguiente punto se expone con más detalle el alcance de esta guía.

\subsubsection{Acciones Gubernamentales}

Los departamentos de Salud y Servicios Comunitarios y Educación han estado trabajando estrechamente con los distintos colegios y autoridades regionales con la finalidad de ayudar a crear entornos saludables para los estudiantes.

En el 2006, se lanzó un documento para ayudar a los proveedores de alimentación escolar a vender y/o servir comidas y bocadillos saludables en las escuelas. Este documento se ha sometido a actualizaciones para reflejar las nuevas recomendaciones de la Guía de Alimentos de Canadá. Además, se han desarrollado criterios nutricionales sobre la grasa, sodio, azúcar, fibra, calcio y hierro.

\footnotetext{
17 The Star. "Adult obesity rates in Canada reaching historic highs, UBC study warns".

${ }^{18}$ Best Health Magazine. "Are Canadians too fat?"

${ }^{19}$ CBC News. "31\% of Canadian kids are overweight or obese."
} 
Imagen $\mathrm{N}^{\circ} 1.3$

Guía de Alimentación de Canadá

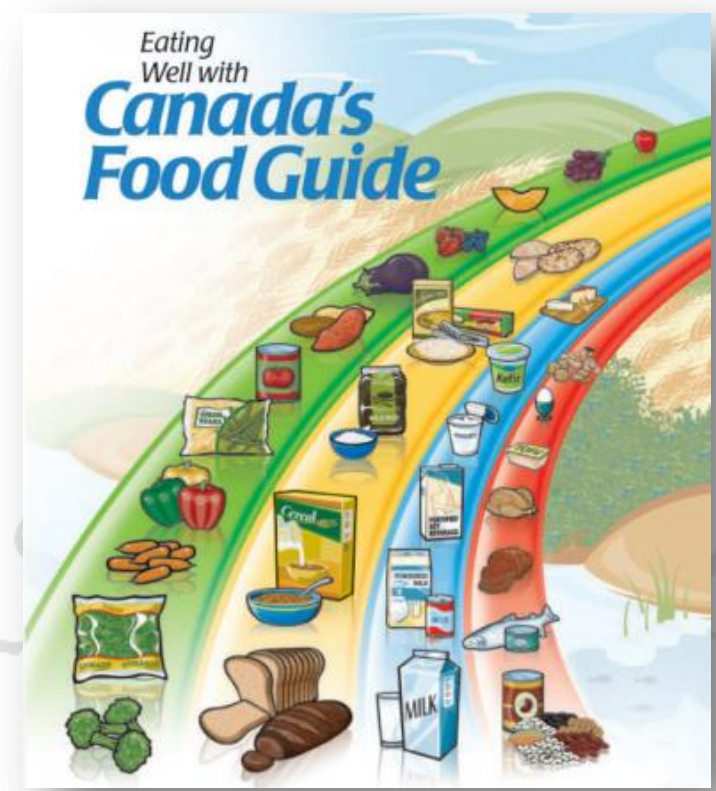

Esta guía provee de opciones tanto para desayunos como para almuerzos y cenas. Dentro de la dieta recomendada figura, evidentemente, el banano, debido a que se trata de una importante fuente de energía y nutrientes, como se explicará más adelante cuando se detallen las propiedades y beneficios derivados del consumo del banano.

Está orientada a que los estudiantes reciban una alimentación adecuada basada en las vitaminas y minerales necesarios para mantenerlos saludables y proveer de la energía necesaria para desempeñarse y obtener un rendimiento óptimo en las distintas actividades a las que se someten los niños y adolescentes.

Esta regulación, no solo brindará estos beneficios a los estudiantes, sino que también se convertirá en un modelo de alimentación que, al inculcarse desde una temprana edad, perdurará hasta la adultez, convirtiéndose en parte de un estilo de vida que favorece la inserción del producto en el mercado.

Asimismo, en octubre del 2012 la Asociación Médica de Ontario dio a conocer un plan para adoptar medidas para combatir este problema a través de campañas que impulsan el consumo de productos saludables, lo que 
constituye un elemento importante en la inserción de nuestro producto en la región de Toronto, capital del estado de Ontario.

\subsection{Ventajas Comerciales}

La diversidad de sus pisos ecológicos y microclimas le da al Perú la ventaja de poder cultivar banano durante todo el año y ofrecer este producto en contrastación al mundo, además de una baja incidencia de Sigatoka Negra, que ataca a este cultivo, reduciendo las mermas de exportación. Se estima que en Ecuador y Colombia dicho costo representa aproximadamente $12 \%$ de los costos de producción.

Otra ventaja para la producción de banano orgánico es la importante reserva del guano de isla, insumo orgánico de gran demanda para la fertilización de los suelos. Pese a que su precio es percibido por los productores como alto, resulta $50 \%$ menor que en otros países, donde este insumo tiene que ser importado.

Las zonas de donde se acopiará el producto tienen ventajas competitivas debido a la ubicación en la costa del Perú, que permite beneficiarse de mejores propiedades organolépticas. Entre estas ventajas se pueden destacar el clima favorable y estable con relación a otros productores en el mundo que se ven frecuentemente afectados por huracanes, lluvias torrenciales e inundaciones con efectos sobre la producción; además de las buenas condiciones de suelo y menor incidencia de plagas y enfermedades. Asimismo, se encuentran en zonas estratégicas debido a la cercanía a los puertos de Paita-Perú.

Actualmente, Perú se posiciona como el primer exportador y el quinto productor mundial de banano orgánico. A diferencia de otros proveedores importantes, la exportación de banano orgánico en el Perú representa la totalidad de la exportación de banano. 


\section{CAPÍTULO II: Marco Legal}

\subsection{Análisis PESTEC de PerúFuerzas Políticas, Legales y Gubernamentales}

Como resultado del proceso de globalización, se han creado mayores espacios de comercio internacional, por lo que el Estado peruano viene enfocando sus energías en una mayor integración con el mundo, punto mencionado en el discurso del 28 de julio del presidente Humala, siendo este el punto de partida para que los países del mundo vean que el Perú quiere continuar beneficiándose de una mayor libertad comercial. Esto se refleja en el aumento sustancial de las exportaciones de los últimos años, pasando de US $\$ 7,000$ millones registrados en el 2001 a más de US $\$ 33,000$ millones en el 2015. ${ }^{20}$

Actualmente, Perú tiene acuerdos con sus principales socios comerciales, siendo uno de los países con más tratados de libre comercio en vigencia en América Latina, cubriendo todos los continentes menos África. Además, tiene una visión de integración regional a través de dos iniciativas en las cuales participa activamente: El "Trans Pacific Partnership" (TPP) y la Alianza del Pacífico. El estado actual de las relaciones comerciales del Perú se presenta a continuación:

${ }^{20}$ Trade Map, “Exportaciones peruanas en el 2015”, op cit. 
Cuadro $\mathrm{N}^{\circ} 2.1$

Relaciones Comerciales del Perú

\begin{tabular}{|c|c|c|}
\hline ÁMBITO & SOCIO COMERCIAL & ESTATUS \\
\hline \multirow{2}{*}{ MULTILATERAL } & OMC & Vigente \\
\hline & DOHA & En Negociaciones \\
\hline \multirow{8}{*}{ REGIONAL } & APEC & Vigente \\
\hline & CAN & Vigente \\
\hline & APEC & Vigente \\
\hline & EFTA & Vigente \\
\hline & MERCOSUR & Vigente \\
\hline & UE & Vigente \\
\hline & TPP & Por entrar en vigencia \\
\hline & Alianza del Pacífico & Por entrar en vigencia \\
\hline \multirow{17}{*}{ BILATERAL } & Chile & Vigente \\
\hline & Estados Unidos & Vigente \\
\hline & Canadá & Vigente \\
\hline & China & Vigente \\
\hline & México & Vigente \\
\hline & Cuba & Vigente \\
\hline & Tailandia & Vigente \\
\hline & Corea del Sur & Vigente \\
\hline & Japón & Vigente \\
\hline & Panamá & Vigente \\
\hline & Singapur & Vigente \\
\hline & Venezuela & Vigente \\
\hline & Costa Rica & Vigente \\
\hline & Guatemala & Por entrar en vigencia \\
\hline & Honduras & Por entrar en vigencia \\
\hline & El Salvador & En negociaciones \\
\hline & Turquía & En negociaciones \\
\hline
\end{tabular}

Fuente: Acuerdos Comerciales del Perú

El Tratado de Libre Comercio entre Perú y Canadá, que entró en vigencia el $1^{\circ}$ de Agosto del 2009, ha beneficiado a todos los sectores al incluirse el $96.9 \%$ de líneas en desgravación inmediata, particularmente los sectores textil y agroexportador, y el $1.8 \%$ de líneas en plazos de hasta 7 años.

Por otro lado, el Congreso de la República ha promulgado una ley de promoción del sector agrario, el cual persigue la formalización del empleo y el acceso a la seguridad sociales de los pequeños productores. Además, aplica 
una tasa de $15 \%$ para efecto del Impuesto a la Renta a las personas naturales o jurídicas comprendidas en las actividades de desarrollo de cultivos. ${ }^{21}$

\subsubsection{Fuerzas Económicas y Financieras}

La economía peruana ha presentado un desempeño estable durante los últimos años y se espera que registre un crecimiento del $3.7 \%$ durante el próximo año, lo cual posicionaría al Perú como la segunda economía que más crecerá en América Latina, luego de Bolivia.

EI BCR destacó que las expectativas de inflación del presente año y de los dos siguientes continúan disminuyendo gradualmente y mantienen una senda decreciente desde una tasa esperada de 3,4\% para este año a 2,9\% al 2017 y a $2,5 \%$ al $2018 .^{22}$

Por otro lado, los bancos proyectan que la cotización del dólar continuará subiendo este año en relación al nuevo sol, pero de una manera más gradual.

De acuerdo al informe de la CEPAL, "La inversión extranjera directa en América Latina y el Caribe 2015", los ingresos por este concepto sumaron US\$ 6,861 millones, lo que representa una disminución del $13 \%$ con respecto al año anterior. Aun así, esta cifra representa el sexto valor anual más alto de la historia del país. En este sentido, el Perú se constituyó como el quinto receptor de IED de América del Sur, luego de Brasil, Chile, Colombia y Argentina y el quinto a nivel latinoamericano.

Una de las compañías más importantes que miden el riesgo de inversión y de desarrollo de países, ha calificado al Perú como el quinto país a nivel latinoamericano y el tercero a nivel sudamericano que es idóneo en proyectos de inversión extranjera, lo cual mejora el entorno competitivo internacional del país; permitiría atraer un mayor flujo de inversión en los diversos sectores económicos nacionales. Véase el siguiente cuadro.

\footnotetext{
${ }^{21}$ Congreso de la República del Perú. "Ley de Promoción del Sector Agrario № 27360".

${ }^{22}$ El Comercio. "BCR ve la inflación estable y deja tasa de interés en 4.25\%".
} 
Cuadro $\mathrm{N}^{\circ} 2.2$

Clima de Inversión en Latinoamérica

\begin{tabular}{|c|c|c|}
\hline $\begin{array}{c}\text { POSICIÓN } \\
\text { SUDAMÉRICA }\end{array}$ & PAÍS & POSICIÓN MUNDIAL \\
\hline $\mathbf{1}$ & Chile & 30 \\
\hline $\mathbf{2}$ & Uruguay & 51 \\
\hline $\mathbf{3}$ & Costa Rica & 52 \\
\hline $\mathbf{4}$ & México & 53 \\
\hline $\mathbf{5}$ & Perú & 55 \\
\hline $\mathbf{6}$ & Panamá & 56 \\
\hline $\mathbf{7}$ & Jamaica & 59 \\
\hline $\mathbf{8}$ & Colombia & 65 \\
\hline $\mathbf{9}$ & El Salvador & 86 \\
\hline $\mathbf{1 0}$ & República Dominicana & 87 \\
\hline
\end{tabular}

Fuente: FORBES Magazine

En cuanto al sector financiero, el Perú es uno de los más competitivos de toda América Latina. Esto permite que los costos de los créditos sigan disminuyendo y beneficiando, principalmente a las pequeñas y micro empresas.

Asimismo, si bien se observa dispersión en las tasas de interés, según el tipo de crédito, de consumo, hipotecario, de capital de trabajo entre otros; hay mucho espacio para que las tasas de interés sigan bajando con la mayor competencia que se da en el sistema financiero peruano.

El representante del Banco Interamericano del Desarrollo (BID) en el Perú, Fidel Jaramillo, expresó que el sistema financiero peruano se caracteriza por su enorme solidez, mucha liquidez y gran vocación para financiar una serie de proyectos en diferentes áreas no sólo corporativo sino proyectos de infraestructura.

El reto del país es mantenerse como la economía de mayor crecimiento en la región y de mayor reducción en la tasa de pobreza e inequidad. ${ }^{23}$ El desafío es asegurar que el país continúe creciendo a tasas sostenidas por encima de seis por ciento por lo menos durante los próximos 15 años.

${ }^{23}$ RPP Noticias. "Economía peruana será la más estable de la región hasta el 2015". 
El departamento de Piura es un importante punto de desarrollo nacional, ya que centra su economía en la agricultura, pesca, hidrocarburos y el comercio.

Los productos agropecuarios son producidos mayormente en los valles formados por los ríos Chira y Piura, cuya área cultivable ha sido aumentada gracias a diversas obras de irrigación. En la serranía piurana, los valles interandinos producen alimentos que mayormente son destinados al autoconsumo.

\subsubsection{Fuerzas Sociales, Culturales y Demográficas}

Debido a las olas migratorias y a la conquista española, la sociedad peruana está conformada por personas de distintas razas, blanca, negra, china, japonesa, mestizos, etc.

Según el último reporte del INEI, los habitantes del Perú ascendían a 31 millones 151 mil 643 personas, presentando una concentración del $31.57 \%$ en la capital. Esto se traduce en una densidad poblacional de $24.5 \mathrm{hab} / \mathrm{km}^{2}$.

En base al ritmo de crecimiento que se ha presentado durante los años, se prevé que para el año 2021 la población incremente a más de 33 millones y en el 2050, el Perú superaría los 40 millones de habitantes.

La ciudad de Piura es la quinta en cuanto a mayor población, con un registro de $1,844,129$ habitantes, de la cual 317,443 se encuentran en la provincia de Sullana. 
Imagen $\mathrm{N}^{\circ} 2.1$

Pirámide Poblacional Perú 2015

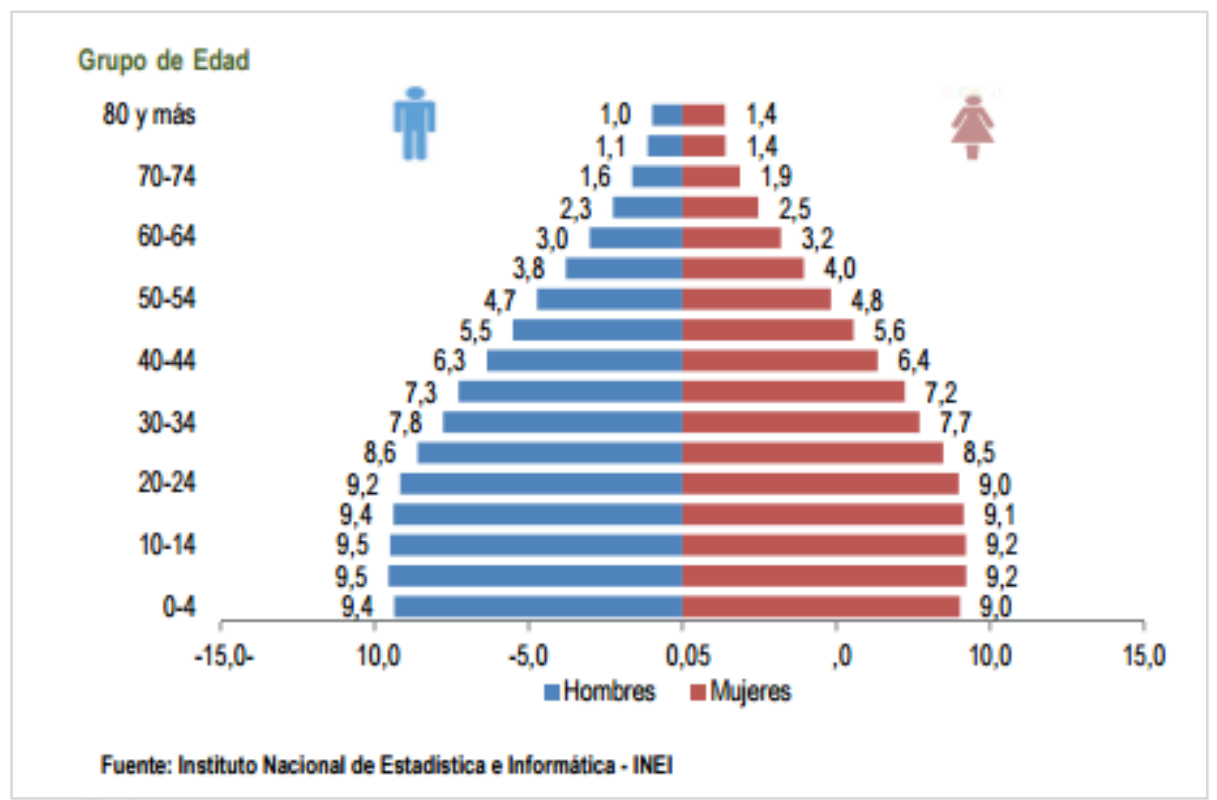

Fuente: INEI - Perú: Síntesis Estadística 2015

Se muestra que la población joven y en edad de trabajar seguirá constituyendo el segmento más grande de la población. Es importante que este segmento disponga de una formación y posibilidades de desarrollo apropiadas, ya que, durante esta etapa, se adquieren los conocimientos y habilidades de los cuales dependerán sus condiciones de vida futuras.

Además el tradicional problema de la pobreza, el Perú se caracteriza por una grave situación de exclusión social de las poblaciones indígenas y afroperuanas. Estas poblaciones son más pobres y tienen menor acceso a la educación, la salud y el crédito que la población no indígena.

El Perú ha tenido una larga historia de pobreza que todavía está en pie. A pesar de la disminución que se ha presentado, existe un indicador preocupante: la desigualdad. Si bien la pobreza ha bajado tanto en zonas urbanas como rurales, sigue siendo tres veces mayor en la parte urbana.

Evidentemente, existe una relación entre la pobreza y la educación, ya que el $67 \%$ de los pobres extremos solo tiene primaria o ninguna educación y un $2.8 \%$ accede a la educación superior. 
El último presidente de la república sostiene que la educación para todos es la clave para lograr un desarrollo integral. Para lograrlo implementó un programa llamado "Beca 18" con el fin de dar oportunidad a personas de bajos recursos de que gocen de carreras profesionales técnicas y universitarias a nivel de pregrado. Además, se inició una convocatoria de becas integrales en el extranjero. Se espera que para finales del 2016, el número de becas otorgadas aumente a 25 mil.

Por otro lado, se espera que a finales del 2016 el programa "JUNTOS" cuente con una cobertura del $100 \%$ de la educación inicial.

Asimismo, se entregaron bicicletas a los estudiantes en zonas alejadas, con el objetivo de facilitar el acceso a sus centros educativos.

Se ha presentado al congreso un Proyecto Ley de Desarrollo Docente, mediante el cual se incluirán mejoras remunerativas, ya que los profesores son actores clave en esta mejora educativa.

Ya que los beneficios deben ser percibidos por todos, se ha definido la "Educación Intercultural Bilingüe", de modo que los maestros estén debidamente formados para dar educación de calidad a estudiantes quechuas, aymaras y amazónicos.

Todas estas medidas implementadas o en proceso de implementación se ejecutan velando siempre por la salud física y mental de los estudiantes, protegiéndolos contra el acoso y violencia en las escuelas.

\subsubsection{Fuerzas Tecnológicas y Logísticas}

La situación tecnológica del Perú ha seguido presentando indicadores poco favorables. Uno de los factores de mayor influencia en la evolución y progreso del país es el desarrollo de las famosas Tecnologías de Información y Comunicación (TIC).

En el ranking mundial proporcionado por el informe Global sobre Tecnología, realizado por el Foro Económico Mundial, el Perú se encuentra detrás de los 
11 países de América Latina y debido a las limitaciones de ciertas barreras, se mantiene en el puesto 90 en cuanto a competitividad tecnológica a nivel mundial. ${ }^{24}$

Según estadísticas del Instituto Nacional de Estadísticas e Informática (INEI) el acceso de la población peruana a las nuevas tecnologías varía significativamente en función del área de residencia.

El porcentaje de hogares que tienen acceso a al menos una Tecnología de Información y Comunicación ha aumentado en 1 punto porcentual, al pasar de $88,9 \%$ a $89,9 \%$, es decir, de cada 100 hogares 90 tienen al menos uno de estos servicios: teléfono fijo, teléfono móvil, televisión por cable o Internet.

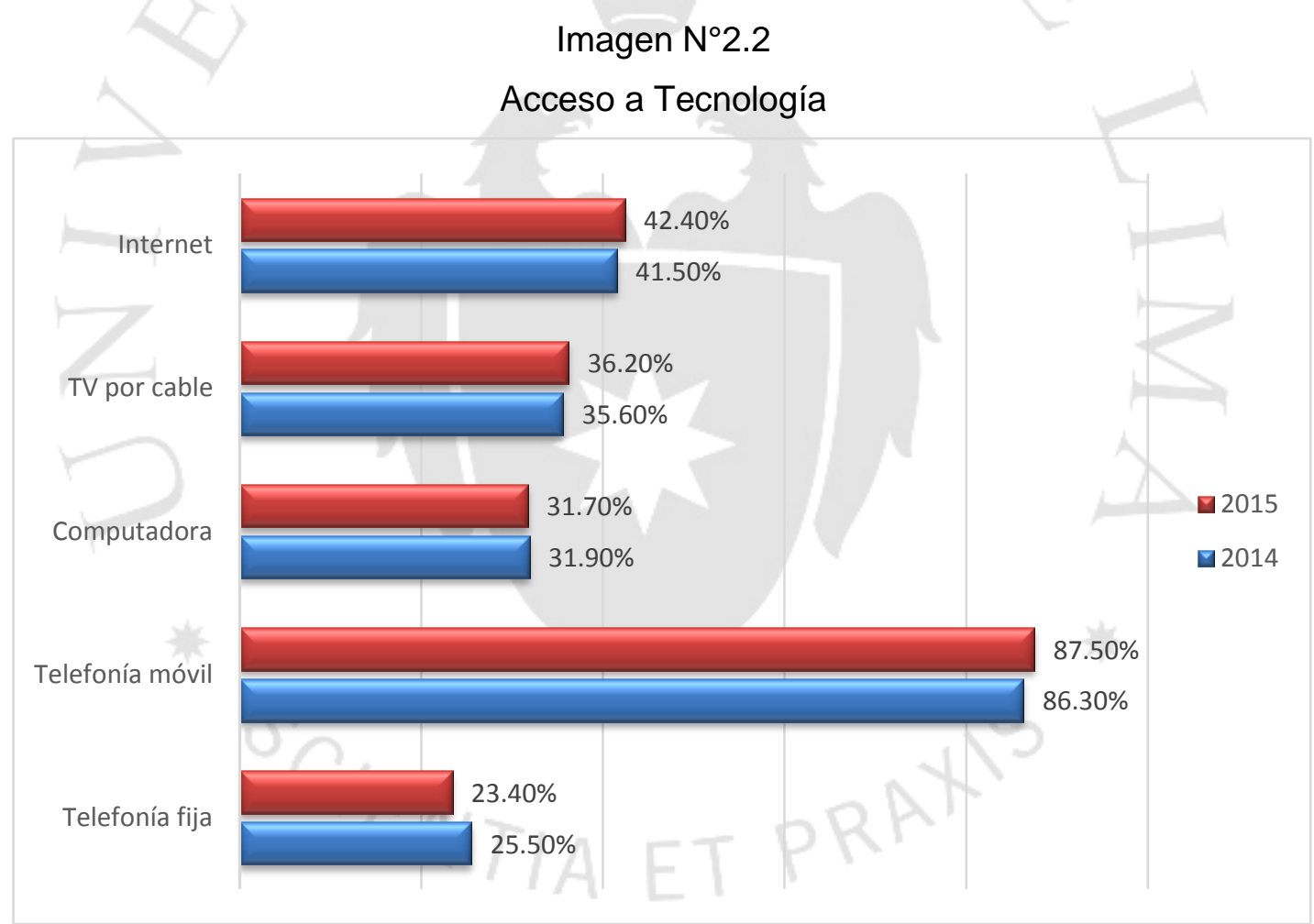

Fuente: INEI - Estadísticas de las Tecnologías de Información y Comunicación en los Hogares

A pesar de que en el gráfico anterior se ve un avance en cuanto a distintos dispositivos tecnológicos en los últimos años, este progreso se ha dado de manera paulatina reflejando aún bajos niveles de acceso incluso a medios de comunicación. Sin embargo, como consecuencia de un mayor poder

${ }^{24}$ The World Economic Forum (WEF). "The Global Information Techonology Report 2015” 
adquisitivo y la explosión comercial de aparatos tecnológicos que proporciona un gama cada vez más amplia de productos a precios competitivos, se pueden pronosticar indicadores más favorables para los próximos años.

Actualmente se presenta una demanda insatisfecha de tecnología que se manifiesta a través del aumento del número de maquinarias que se adquieren cada año. Con el paso del tiempo se hace mayor la necesidad de incorporar innovaciones tecnológicas para adaptarse a los nuevos requerimientos relacionados a la competitividad que el mercado del siglo XXI demanda.

Se debe promover una mayor participación del sector privado en el desarrollo de las actividades de ciencia y tecnología a través de la inversión, ya que los costos derivados de ésta son muy altos para los agricultores y son indispensables para alcanzar altos niveles de desarrollo y productividad.

Asimismo, es necesario impulsar la innovación en infraestructura de riego, ya que muchas de las productoras de la región de Piura no aplican la técnica de riego por goteo, lo cual reduciría sus costos debido a un uso más eficiente del agua y contribuiría al uso sostenible de este recurso natural.

El Instituto Nacional de Innovación Agraria (INIA), realizó en Piura, un curso de capacitación denominado: "Tecnologías de manejo del cultivo de banano orgánico" con el objetivo de difundir las tecnologías generadas por el INIA sobre el manejo agronómico de este cultivo.

En lo que respecta a la logística, en el caso de la región de Piura, el transporte del banano no ha sido un obstáculo, ya que el camino al puerto de Paita se encuentra en buenas condiciones y proporcionan una conexión directa a la carretera que llega al puerto.

El puerto de Paita, cuyo operador y concesionario es "Terminales Portuarios Euroandinos" ha sido banco de inversiones que suman varios millones de dólares. ${ }^{25}$

En la actualidad, este puerto ya inició el uso de dos grúas móviles que permiten la recepción de hasta 50 mil TM de capacidad en comparación de las

\footnotetext{
${ }^{25}$ Iniciativa para la Integración de la Infraestructura Regional Suramericana (IIRSA).
} 
30 mil TM que manejaba cuando se construyó. La adquisición de éstas y otras inversiones han permitido una gestión eficiente a través de mejor infraestructura que ha permitido un mayor tráfico de contenedores y barcos y un menor tiempo de estadía de la mercadería en el puerto.

"Con estas grúas se puede atender a barcos Panamax y Post Panamax, buques de gran tamaño, lo que a su vez dinamiza toda la actividad comercial asociada al puerto", manifestó Carlos Vargas Loret de Mola, Presidente del directorio de TPE. ${ }^{26}$

\subsubsection{Fuerzas Ecológicas y Ambientales}

El Perú es un país con un patrimonio natural tan importante, que lo convierte en uno de los países con mayor diversidad biológica a nivel mundial, la cual engloba las múltiples especies de flora y fauna y ecosistemas presentes. En este sentido, es evidente que estos recursos ofrecen muchas oportunidades de desarrollo, siempre y cuando los recursos sean aprovechados de manera sostenible.

La relevancia del enfoque medioambiental en el Perú se materializa en la existencia del Ministerio del Ambiente, creado en el año 2008.

De dicho ente institucional se despliega una Política Nacional del Ambiente, cuyo objetivo es servir como herramienta del proceso estratégico de desarrollo del país en la integración de las fuerzas sociales, económicas y por supuesto, ambientales, velando por la preservación de los recursos naturales para la satisfacción de las necesidades de las futuras generaciones.

sta política es un instrumento de cumplimiento obligatorio tanto para entidades públicas como privadas y considera los lineamientos en diversos ámbitos, siendo uno de ellos el "aprovechamiento de los recursos naturales", con la cual se busca promover la agricultura orgánica, articulando las cadenas productivas mediante una participación activa de las poblaciones locales. ${ }^{27}$

\footnotetext{
${ }^{26}$ Andino Investment Holding. "Puerto de Paita comienza a atender con grúas móviles".

${ }^{27}$ Ministerio del Ambiente. "Política Nacional del Ambiente".
} 
La Ley $N^{\circ} 28611$ que es la Ley General del Ambiente (LGA), es uno de los lineamientos sobre la cual se sustenta la Política Nacional del Ambiente y tiene por objetivo mejorar la calidad de vida de las personas y el desarrollo sostenible del país, mediante el aprovechamiento responsable de los recursos $y$ el respeto de los derechos fundamentales de la persona ${ }^{28}$. Existe una estrecha vinculación entre el ambiente y la calidad de vida, en la medida en que las condiciones del ambiente físico permitan las mejores condiciones posibles de salud para las personas y que, además, propicien su desenvolvimiento social.

La ley LGA es una de las principales políticas ambientales que tiene el gobierno peruano para hacer frente a actividades que tienen un impacto negativo en el medioambiente. Sin embargo, no es la única ley que regula el impacto ambiental, a la vez, existen otros temas que se complementan con la LGA, Integración de la Legislación Ambiental y Responsabilidad por daño Ambiental.

El sector agrícola es uno de los principales sectores productivos afectados por la contaminación ambiental por parte de empresas extractivas de minerales dado que los desechos tóxicos son la principal fuente de contaminación del agua de los ríos que nutren a los sembríos. Se busca prevenir la contaminación del suelo que está apto para el cultivo, a la vez, reducir su pérdida y deterioro por erosión o contaminación producto de actividades industriales $\mathrm{y} / \mathrm{o}$ extractivas.

En la región Piura se presente una gran variedad de producción de frutas y cereales tales como el banano, mango, arroz, naranja y entre otros. Además, está región posee su propia Gerencia de Recursos Naturales y Gestión del Medio Ambiente para preservar la calidad ambiental que puede ser afectada por actividades extractivas, productivas y de servicios, tales como vertimiento industriales y domésticos sin tratamiento ${ }^{29}$.

\footnotetext{
${ }^{28}$ Ibíd.

${ }^{29}$ Gobierno Regional de Piura.
} 
El objetivo de la Política Ambiental Regional de Piura está alineada a la Política Nacional del Medio Ambiente, en su búsqueda por la mejora continua de la calidad de vida de las personas mediante la protección, conservación y recuperación del ambiente y sus componentes e impulsando actividades productivas y extractivas sostenibles que permitan el aprovechamiento sostenible de los recursos naturales de la región, incluyendo la participación ciudadana en los procesos de toma de decisiones ${ }^{30}$.

Dentro de esta definición se mueven los ejes políticos ambientales de la región para un mayor cuidado del medio ambiente. Uno de los principales problemas es la carencia de agua en zonas de cultivo.

El cultivo del banano orgánico en la región Piura se está impulsando por el gobierno regional, dado a las actividades que practica que no repercuten de manera dañina al medioambiente; son actividades que impulsan el desarrollo económico en la región y la preservación del medio ambiente a través de los cultivos libres de químicos.

\subsubsection{Fuerzas Competitivas}

El Perú ha experimentado un crecimiento continuo, lo cual ha venido de la mano con un nivel más elevado de competitividad.

Los principales factores que han impulsado esta mejora en el nivel de competitividad comprenden la mayor facilidad para hacer negocios, menores barreras para el comercio internacional y el manejo responsable del gasto y endeudamiento, entre otros. Esto nos permite contar con un marco económico sólido, que sea la base para que el país tenga un desenvolvimiento próspero en un contexto internacional volátil e incierto.

En el ranking del Reporte de Competitividad Global, elaborado por el Foro Económico Mundial, Perú desciende a la posición 69 de 137 países analizados.

\footnotetext{
${ }^{30}$ Ibíd.
} 
A pesar de que el Perú sigue favoreciéndose de los beneficios de las políticas de liberalización comercial; sin embargo, todavía se enfrenta a retos importantes como deficiencias en el funcionamiento de instituciones públicas y del gobierno y, como se mencionó en el punto anterior, el bajo acceso a la utilización de las TIC y baja capacidad tecnológica para innovar y desarrollar actividades con valor añadido.

Gracias a esta posición, el Perú es el sexto país más competitivo en Latinoamérica, luego de Chile, quien encabeza la lista, seguido de Panamá, Costa Rica, México y Colombia en orden de posiciones.

En el marco de la Ley 27867 "Ley Orgánica de Gobiernos Regionales", la función de gestionar la competitividad regional corresponde a los gobiernos regionales. En este sentido, en los últimos años se puede identificar una serie de iniciativas destinadas a fomentar de la competitividad en las regiones.

Para realizar el análisis competitivo de la región de Piura, se utilizará como marco de referencia el Índice de Competitividad Regional (ICR) para determinar su grado de desempeño en comparación con las demás regiones del país y a la vez tener una visión general de cuál es el desenvolvimiento del país.

Perú en términos de los 6 pilares que se consideran en éste índice. 
Imagen $\mathrm{N}^{\circ} 2.3$

Índice de Competitividad Regional 2015

\section{Índice de Competitividad Regional 2015*}

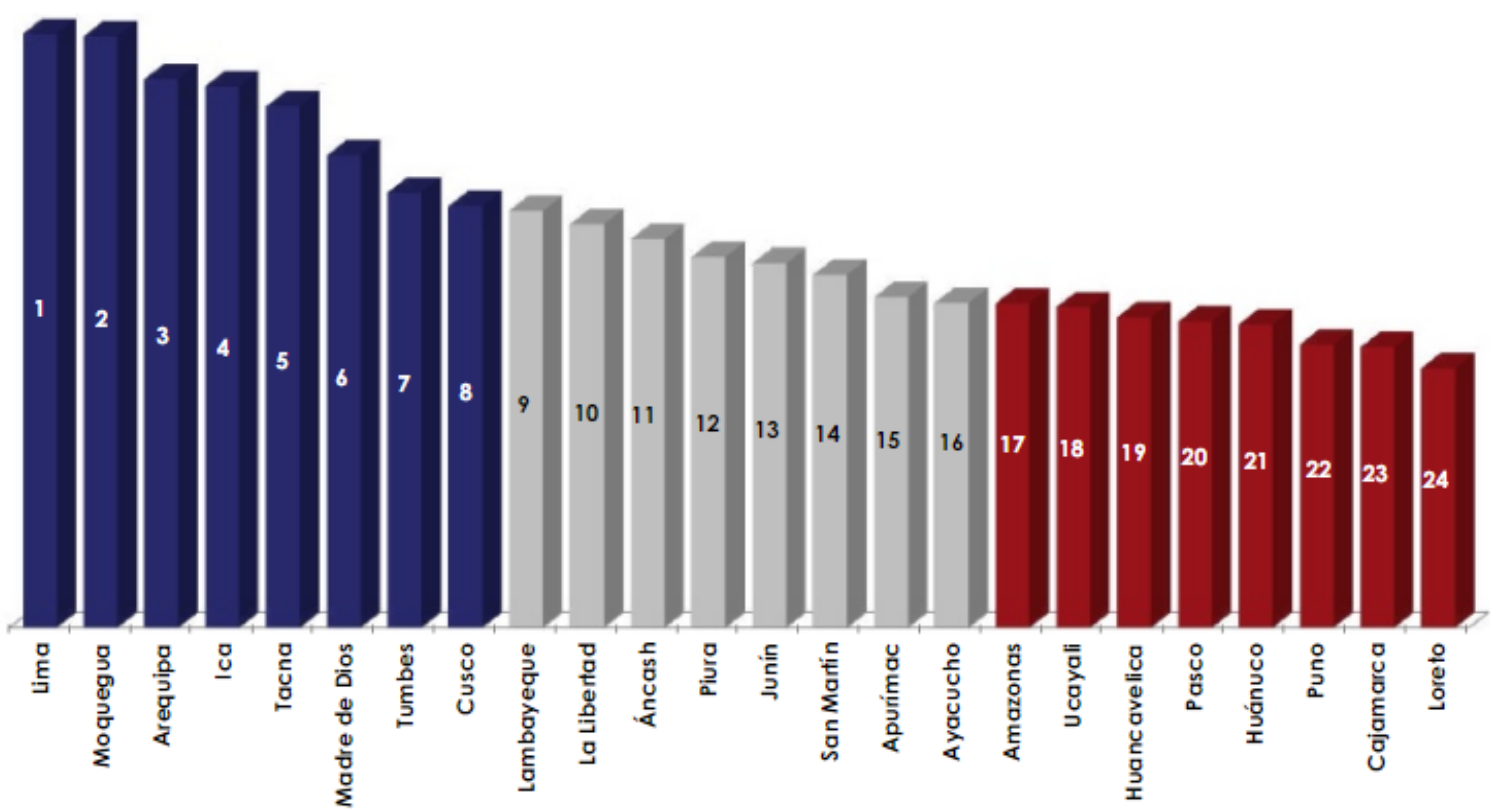

Fuente: Índice de Competitividad Regional

La imagen recién mostrada indica que las regiones más competitivas con aquellas ubicadas en la costa del país. Si analizamos los 10 primeros puestos, podemos observar que 8 de ellos pertenecen a esta zona geográfica. 
Cuadro $\mathrm{N}^{\circ} 2.3$

Posición según Pilares ICR 2015

\begin{tabular}{|c|c|c|c|c|c|c|}
\hline & $\begin{array}{c}\text { Entorno } \\
\text { Económico }\end{array}$ & Infraestructura & Salud & Educación & Laboral & Instituciones \\
\hline Lima & $1^{\circ}$ & $1^{\circ}$ & $1^{\circ}$ & $4^{\circ}$ & $1^{\circ}$ & $22^{\circ}$ \\
\hline Moquegua & $2^{\circ}$ & $8^{\circ}$ & $4^{\circ}$ & $1^{\circ}$ & $4^{\circ}$ & $1^{\circ}$ \\
\hline Arequipa & $3^{\circ}$ & $2^{\circ}$ & $2^{\circ}$ & $5^{\circ}$ & $5^{\circ}$ & $14^{\circ}$ \\
\hline Ica & $7^{\circ}$ & $4^{\circ}$ & $3^{\circ}$ & $3^{\circ}$ & $2^{\circ}$ & $8^{\circ}$ \\
\hline Tacna & $6^{\circ}$ & $3^{\circ}$ & $8^{\circ}$ & $2^{\circ}$ & $6^{\circ}$ & $11^{\circ}$ \\
\hline Tumbes & $11^{\circ}$ & $7^{\circ}$ & $6^{\circ}$ & $6^{\circ}$ & $14^{\circ}$ & $21^{\circ}$ \\
\hline La Libertad & $12^{\circ}$ & $11^{\circ}$ & $7^{\circ}$ & $13^{\circ}$ & $11^{\circ}$ & $17^{\circ}$ \\
\hline Lambayeque & $10^{\circ}$ & $6^{\circ}$ & $5^{\circ}$ & $7^{\circ}$ & $18^{\circ}$ & $24^{\circ}$ \\
\hline Piura & $13^{\circ}$ & $13^{\circ}$ & $10^{\circ}$ & $12^{\circ}$ & $20^{\circ}$ & $16^{\circ}$ \\
\hline Junín & $14^{\circ}$ & $12^{\circ}$ & $18^{\circ}$ & $9^{\circ}$ & $10^{\circ}$ & $23^{\circ}$ \\
\hline Ancash & $9^{\circ}$ & $9^{\circ}$ & $14^{\circ}$ & $11^{\circ}$ & $17^{\circ}$ & $20^{\circ}$ \\
\hline $\begin{array}{c}\text { Madre de } \\
\text { Dios }\end{array}$ & $4^{\circ}$ & $10^{\circ}$ & $9^{\circ}$ & $8^{\circ}$ & $3^{\circ}$ & $15^{\circ}$ \\
\hline Cusco & $5^{\circ}$ & $5^{\circ}$ & $13^{\circ}$ & $16^{\circ}$ & $9^{\circ}$ & $12^{\circ}$ \\
\hline Pasco & $19^{\circ}$ & $22^{\circ}$ & $19^{\circ}$ & $10^{\circ}$ & $22^{\circ}$ & $6^{\circ}$ \\
\hline San Martin & $18^{\circ}$ & $16^{\circ}$ & $15^{\circ}$ & $18^{\circ}$ & $7^{\circ}$ & $5^{\circ}$ \\
\hline Ucayali & $8^{\circ}$ & $18^{\circ}$ & $22^{\circ}$ & $24^{\circ}$ & $8^{\circ}$ & $9^{\circ}$ \\
\hline Ayacucho & $23^{\circ}$ & $15^{\circ}$ & $11^{\circ}$ & $17^{\circ}$ & $21^{\circ}$ & $10^{\circ}$ \\
\hline Puno & $15^{\circ}$ & $21^{\circ}$ & $24^{\circ}$ & $14^{\circ}$ & $19^{\circ}$ & $19^{\circ}$ \\
\hline Cajamarca & $21^{\circ}$ & $19^{\circ}$ & $20^{\circ}$ & $21^{\circ}$ & $23^{\circ}$ & $4^{\circ}$ \\
\hline Apurímac & $16^{\circ}$ & $14^{\circ}$ & $12^{\circ}$ & $19^{\circ}$ & $15^{\circ}$ & $18^{\circ}$ \\
\hline Huánuco & $20^{\circ}$ & $20^{\circ}$ & $16^{\circ}$ & $23^{\circ}$ & $12^{\circ}$ & $7^{\circ}$ \\
\hline Amazonas & $24^{\circ}$ & $23^{\circ}$ & $17^{\circ}$ & $20^{\circ}$ & $13^{\circ}$ & $3^{\circ}$ \\
\hline Loreto & $17^{\circ}$ & $24^{\circ}$ & $23^{\circ}$ & $22^{\circ}$ & $16^{\circ}$ & $13^{\circ}$ \\
\hline Huancavelica & & $17^{\circ}$ & $21^{\circ}$ & $15^{\circ}$ & $24^{\circ}$ & $2^{\circ}$ \\
\hline
\end{tabular}

Fuente: Índice de Competividad Regional

El cuadro mostrado evidencia el puesto de cada una de las regiones según los 6 pilares tomados en cuenta. Piura ha mostrado un cambio favorable con el paso de los años, ya que de encontrarse en el puesto 12, ha pasado a la posición $n^{\circ} 11$ en este ranking.

Los pilares en los que más destaca la región analizada son instituciones y laboral. La primera toma en consideración la ejecución de la inversión pública, 
contrataciones, percepción de la gestión pública, conflictos sociales, entre otros. El segundo pilar se focaliza en el nivel de ingresos por trabajo, la brecha de género en ingresos, creación de empleo, por nombrar algunas.

En este sentido, hablamos de una región competitiva a nivel de ICR y de las más competitivas en cuanto al tema laboral e institucional de todo el territorio peruano.

\subsection{Diamante de Porter}

Existen 5 fuerzas que influyen en la competitividad del producto. Estas son las amenazas por la entrada de nuevas empresas al mercado, la rivalidad entre los competidores, el poder de negociación de los proveedores, el poder de negociación de los compradores y las amenazas de los productos sustitutos.

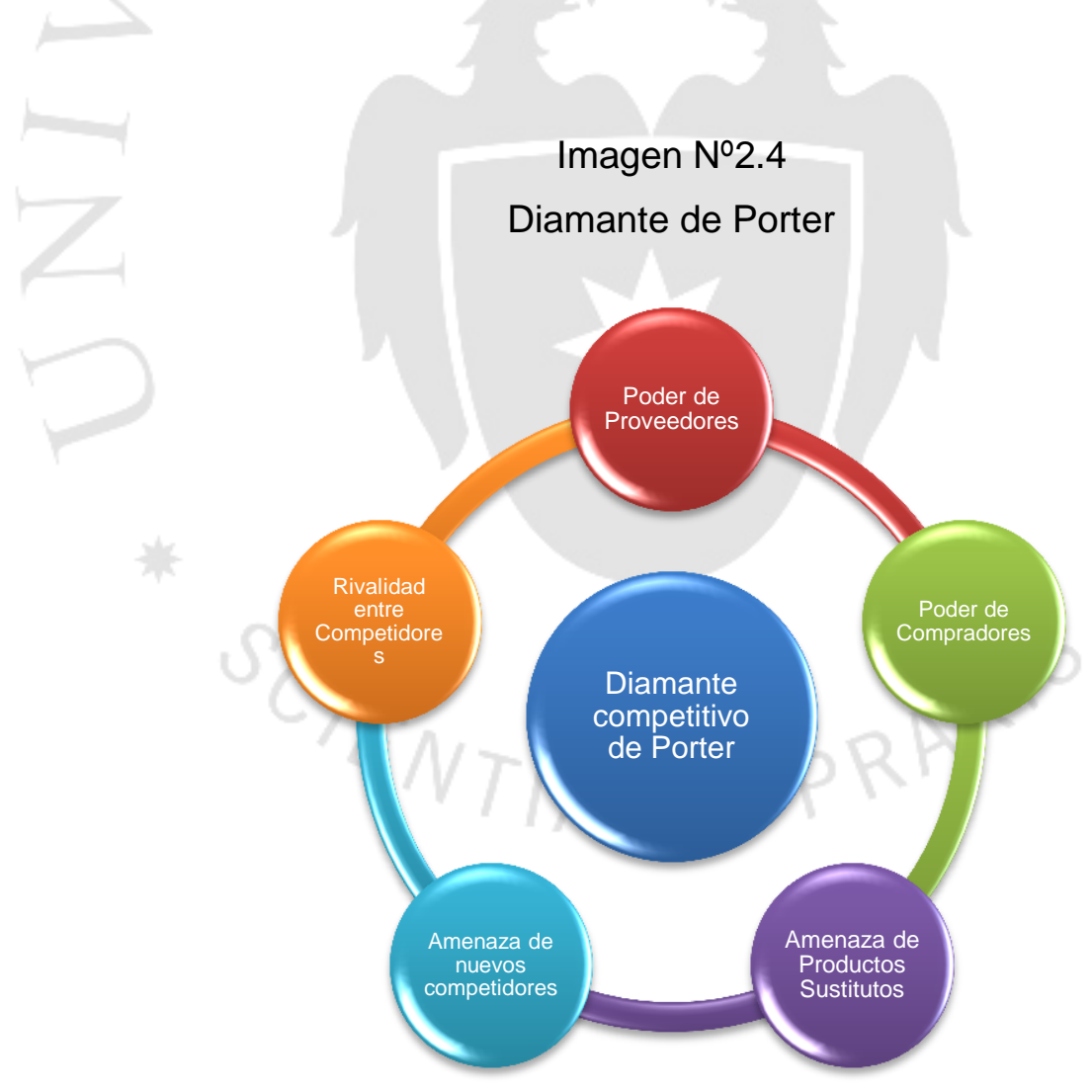




\subsubsection{Poder de Negociación de los Proveedores}

Dado que la mayor parte del cultivo de banano orgánico se encuentra en la zona de Piura, se limitará a realizar el análisis de los proveedores ubicados en ésta área geográfica.

La transición significativa del cultivo de arroz a la producción de banano orgánico, debido al crecimiento mundial por el consumo de productos orgánicos y mayor rentabilidad, ha resultado en un mayor número de empresas dedicadas a ésta actividad. Sin embargo, aproximadamente el $20 \%$ de los productores no se encuentran certificados.

A pesar de que estas empresas operan en asociaciones conjuntas para lograr sinergias y que podría dar a pensar que tienen un fuerte poder de negociación, existe una deficiencia en la gestión de mercados, que resulta en una baja capacidad de estas organizaciones de exportar directamente a países del exterior. Por lo que al momento de convertirse en acopiador, los proveedores visualizan esto como una oportunidad para insertarse en el mercado internacional.

Se planea establecer contratos con los productores para asegurar la oferta de este producto y establecer relaciones comerciales a largo plazo.

\subsubsection{Poder de Negociación de los Compradores}

El segmento al cual se apunta se caracteriza por una alta capacidad adquisitiva debido a que su economía lo permite. Ello implica que opten por un producto de calidad y estén dispuestos a pagar el precio mayor. El factor clave es establecer un precio acorde a la calidad del producto, ya que existe una oferta variada proveniente de diversos países.

Canadá importa la totalidad de su consumo en banano; por tal motivo, existen diversas empresas de distintos países que poseen un precio diferente de una a otra, siendo la calidad (textura y sabor) uno de los factores claves importantes para la elección del consumidor. 
El comprador posee un gran poder de negociación porque de la preferencia por el producto peruano depende el éxito del banano orgánico.

\subsubsection{Amenaza de Productos Sustitutos}

La disposición de banano convencional se considera como el producto sustito más cercano, ya que satisface los mismos requerimientos alimenticios en cuanto a valor nutricional. Sin embargo, el banano orgánico permite distinguirse positivamente frente al producto sustituto gracias a su valor agregado y a la satisfacción de necesidades que este último no compete.

A los consumidores de productos orgánicos les tiende a importar mucho los valores nutricionales de la comida por encima de los aumentos en el precio de ésta. Claramente, los consumidores que son leales a los productos orgánicos que van de compras a las tiendas de comidas especializadas opinan que los precios de la comida orgánica están justificados por sus atributos superiores. En varios países, la diferencia de precios entre la comida orgánica y la convencional se está disminuyendo. Esto sucede a medida que se exportan mayores volúmenes de productos orgánicos y los distintos participantes de las cadenas de distribución comienzan a aprovechar los beneficios de economías de escala.

Otros productos sustitutos son las demás frutas tropicales orgánicas, como la mandarina orgánica o la palta orgánica, que poseen altos beneficios nutritivos y son del agrado del consumidor canadiense. Esto afectaría las ventas del banano orgánico, ya que muchas veces el consumidor opta por comprar una 0 pocas variedades de frutas debido al alto precio de las mismas. 


\subsubsection{Amenaza de Entrada de Nuevos Competidores}

En los últimos años, la producción del banano orgánico ha sustituido a la producción convencional y a cultivos como el arroz y algodón, convirtiéndose en una alternativa de generación de mejores y más estables ingresos para el agricultor.

Esto indica que no hay altas barreras que restrinjan la incursión de nuevas empresas en este ámbito y que productores de otros cultivos puedan dar un vuelco a la producción de esta fruta si se consolida su exportación.

En la actualidad existen empresas emergentes que debido al incremento por la preocupación de la salud y demanda de productos orgánicos y con alto valor nutricional, optan por la comercialización de este tipo de producto.

\subsubsection{Rivalidad entre los competidores}

Desde un punto de vista local, la mayor rivalidad es entre los productores que exportan directamente y los que exportan a través de intermediarios.

Por otro lado, a partir de una perspectiva global, se percibe una gran competencia, siendo el principal competidor del banano ecuatoriano, ya que poseen ventajas en cuanto a precio, debido a que mayor parte de su exportación de banano consiste en el tipo convencional. Las empresas ecuatorianas abarcan la mayor parte del mercado, convirtiendo a este país en uno de los principales proveedores de Canadá.

Sin embargo, a pesar de que Ecuador presenta las condiciones climatológicas necesarias para el cultivo del banano, algunos factores como la humedad impiden desarrollar con facilidad una agricultura orgánica, al presentar una mayor incidencia de Sigatoka Negra. Por ello, el 60\% del tratamiento contra esta enfermedad consiste en la aplicación de productos químicos, lo que representa una conducta contraria a la tendencia de demanda orgánica.

En conclusión, no hay muchos países que puedan tener un origen orgánico y ciertamente mucho menos que puedan ser fuente de comercio justo, lo que representa una ventaja para las empresas peruanas. 


\subsection{Hipótesis}

Un plan de negocios de exportación de banano orgánico a Canadá constituye un instrumento dinámico de gran utilidad, que servirá como guía técnica de referencia para cualquier empresa con potencial exportador y; asimismo, permitirá el incremento de las exportaciones de este producto.

\subsubsection{Hipótesis Específicas}

- Las empresas de abastecimiento en Canadá estarán interesadas en adquirir el banano orgánico directamente del Perú al contar con las condiciones necesarias para cosechar un producto de calidad con valor agregado que satisfaga las necesidades del mercado.

- La elaboración de un plan de marketing mix para la exportación de banano orgánico permitirá a la empresa cumplir con los objetivos propuestos a través de una estrategia de diferenciación.

- La utilización de la ruta Paita-Toronto permitirá a la empresa incurrir en el menor costo logístico posible y lograr colocar el producto en las condiciones óptimas de calidad. 


\section{CAPITULO III: Estudio de Mercado}

\subsection{Sobre el producto}

3.1.1. Información Básica ${ }^{31}$ :

- Nombre Comercial: Organic Banana

- Nombre Científico: Musa Acuminata (group AAA)/ Musa Paradisiaca, Musa cavendishii

- Nombre Común: Organic Banana

\subsubsection{Características Físicas}

En lo que respecta a la forma natural de la fruta esta es carnosa y tiene una forma alargada, oblonga y algo curvada. Nace del árbol del banano, en el cual crece en racimos que pueden contener de 2 a 20 frutos. El tamaño y peso de los racimos que se comercializan internacionalmente suelen ajustarse a normas de calidad que determinan el peso y el tamaño medio de los frutos; estos tendrán en promedio una longitud de 7.5" y un peso por unidad de aproximadamente 200 gramos. En cuanto al color, éste está cubierto por una cáscara amarillo-verdosa que luego se torna amarilla o amarillo-rojiza con manchas negras conforme la maduración va tomando curso. El interior está determinado por una pulpa con tonalidad blanca o ligeramente amarillenta, caracterizada por un sabor dulce y olor agradable.

Imagen $\mathrm{N}^{\circ} 3.1$

Características Físicas del Banano

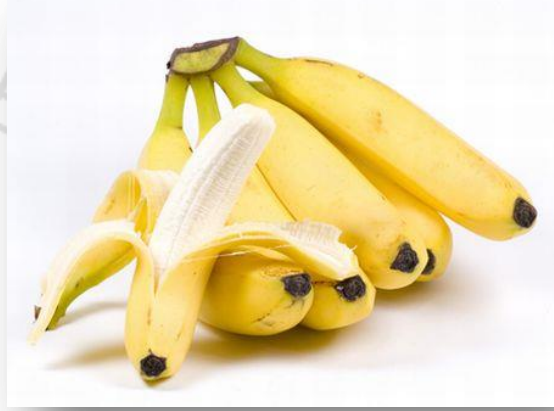

Fuente: http://www.adelgaceenlinea.com/el-banano-y-los-beneficios-para-la-salud.html

\footnotetext{
${ }^{31}$ Sistema Integrado de Información de Comercio Exterior (SIICEX). "Ficha Técnica Banano".
} 


\subsubsection{Propiedades Nutritivas y Beneficios para la Salud}

Dentro de los cultivos más importantes del mundo, tenemos el banano, que se encuentra en el cuarto puesto, luego del arroz, trigo y maíz. Asimismo, debido a su excelente combinación de minerales, vitaminas y energía y a ser uno de los alimentos con mayor valor nutricional, es una fruta de amplio consumo en todo el mundo. Existe una presencia casi nula de grasas y un contenido bajo en proteínas.

Dentro de los numerosos minerales que contiene el banano, podemos destacar el potasio, hierro, fósforo y calcio, siendo estos minerales los que presentan en una cantidad superior a los demás minerales contenidos en la fruta. En adición a esto, también podemos nombrar las vitaminas más representativas, siendo estas la vitamina B1, B2, B6 y C.

Debido a su alto contenido energético, la variedad "Cavendish" es consumida por personas con mucha actividad física, como los deportistas, al contener 3 tipos de azúcares naturales (sacarosa, fructosa y glucosa), que incrementan la energía y al mismo tiempo que previene la aparición de calambres.

Del mismo modo, dado su bajo contenido de sal, es recomendado para regular la presión arterial, reduciendo así, el riesgo de probabilidades de infarto e hipertensión arterial.

Sin embargo, estas no son las únicas maneras en la que el banano proporciona beneficios para la salud. También es efectivo en la prevención y tratamiento de un número exorbitante de enfermedades y problemas de salud.

A continuación se nombran algunos de los usos curativos del fruto objeto de estudio.

- Acidez estomacal

- Anemia

- Artritis

- Cálculos renales

- Depresión

- Estreñimiento 
- Picaduras de mosquitos

- Retención de líquidos

- Síndrome pre-menstrual

- Tabaquismo

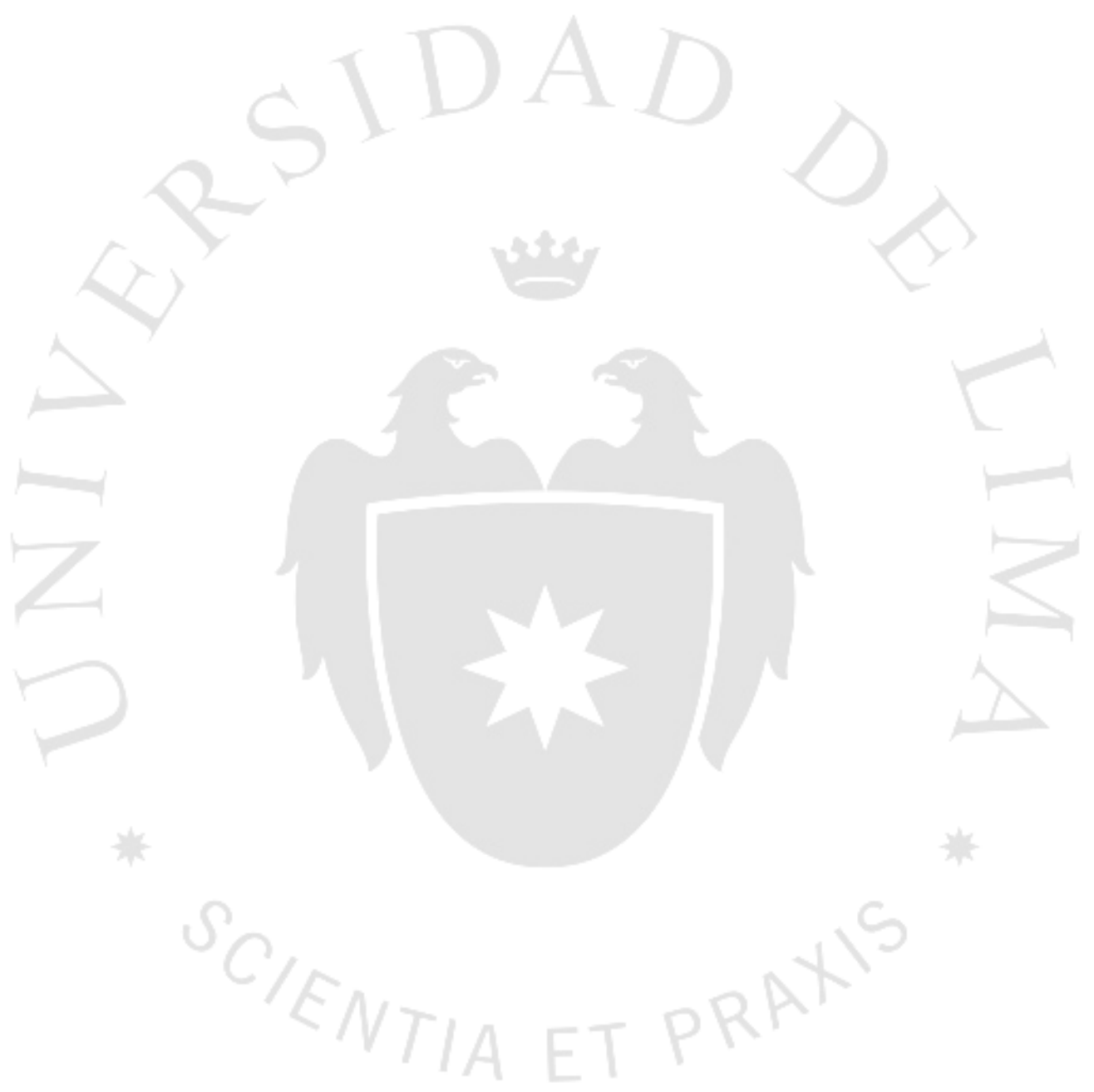

Cuadro N³.1

Valores Nutricionales del Banano 


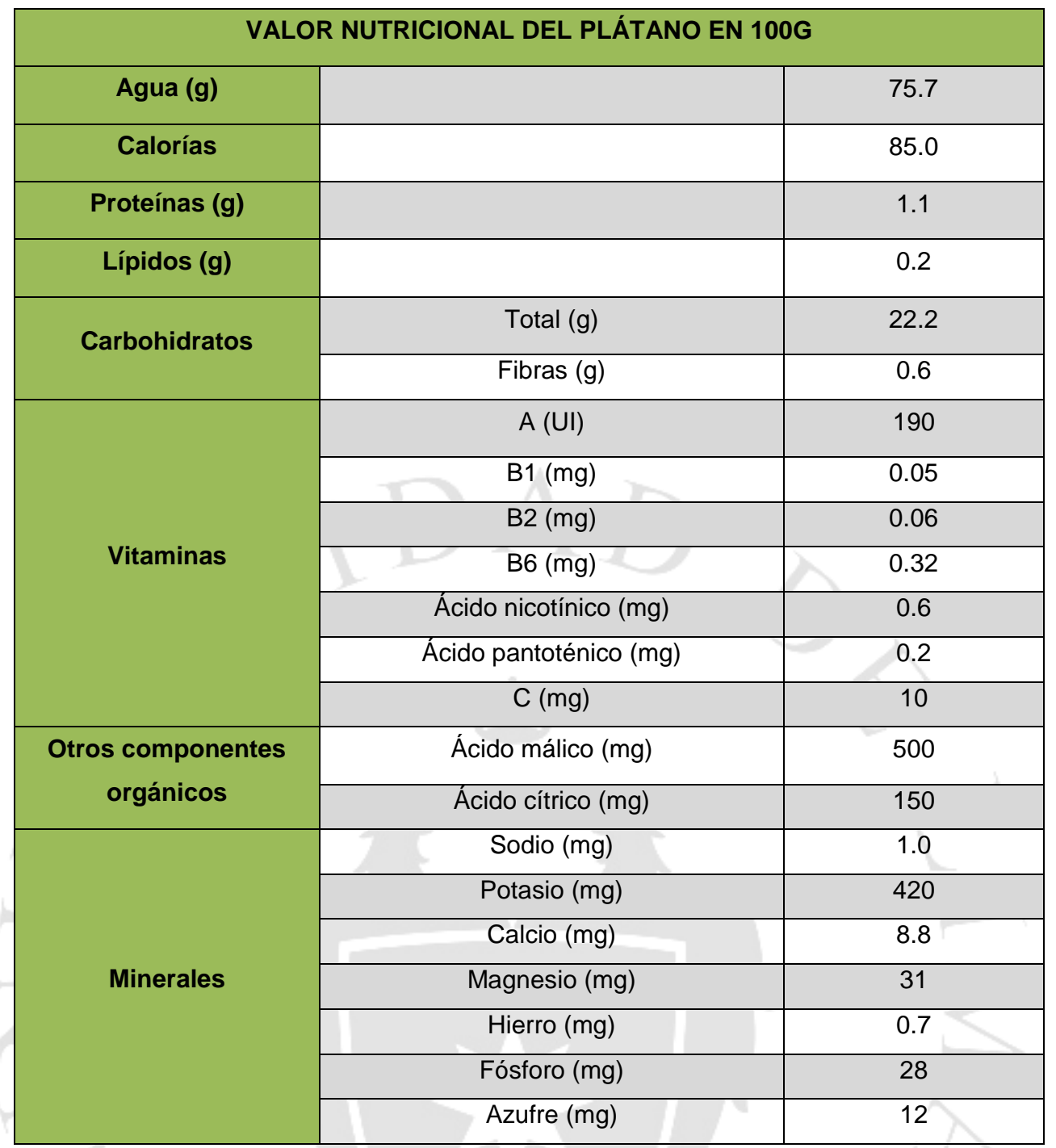

Fuente: Sistema Integrado de Información de Comercio Exterior (SIICEX) y Zona Diet

En el siguiente cuadro figura la partida arancelaria del banano según el Arancel de Aduanas. Para efectos de este estudio se considerará la partida 0803.90.11.00, la cual entró en vigencia a inicios del 2012. Años posteriores, el producto se encontraba bajo la partida 0803.00.12.00. 
Cuadro №3.2

Código Arancelario del Banano y sus Derivados

\begin{tabular}{|c|c|}
\hline PARTIDA ARANCELARIA & DESCRIPCIÓN \\
\hline 0803.10 .10 .00 & Frescos \\
\hline 0803.10 .20 .00 & Secos \\
\hline 0803.90.11.00 & Tipo Cavendish Valery \\
\hline 0803.90 .12 .00 & $\begin{array}{c}\text { Bocadillo (Manzanito, Orito) (Musa } \\
\text { Acuminata) }\end{array}$ \\
\hline 0803.90.19.00 & $\begin{array}{l}\text { Las demás bananas o plátanos } \\
\text { frescos }\end{array}$ \\
\hline 0803.90 .20 .00 & Secos \\
\hline
\end{tabular}

Fuente: Sistema Integrado de Información de Comercio Exterior (SIICEX)

3.2. Análisis de la Demanda

\subsubsection{Demanda Histórica}

Para analizar la demanda de banano en el mercado canadiense se recopiló información de las importaciones realizadas por Canadá, de la partida 0803, generando así una demanda histórica espejo del producto investigado. 
Gráfico №3.1

Demanda Histórica Mensual de Banano en Canadá 2010-2015

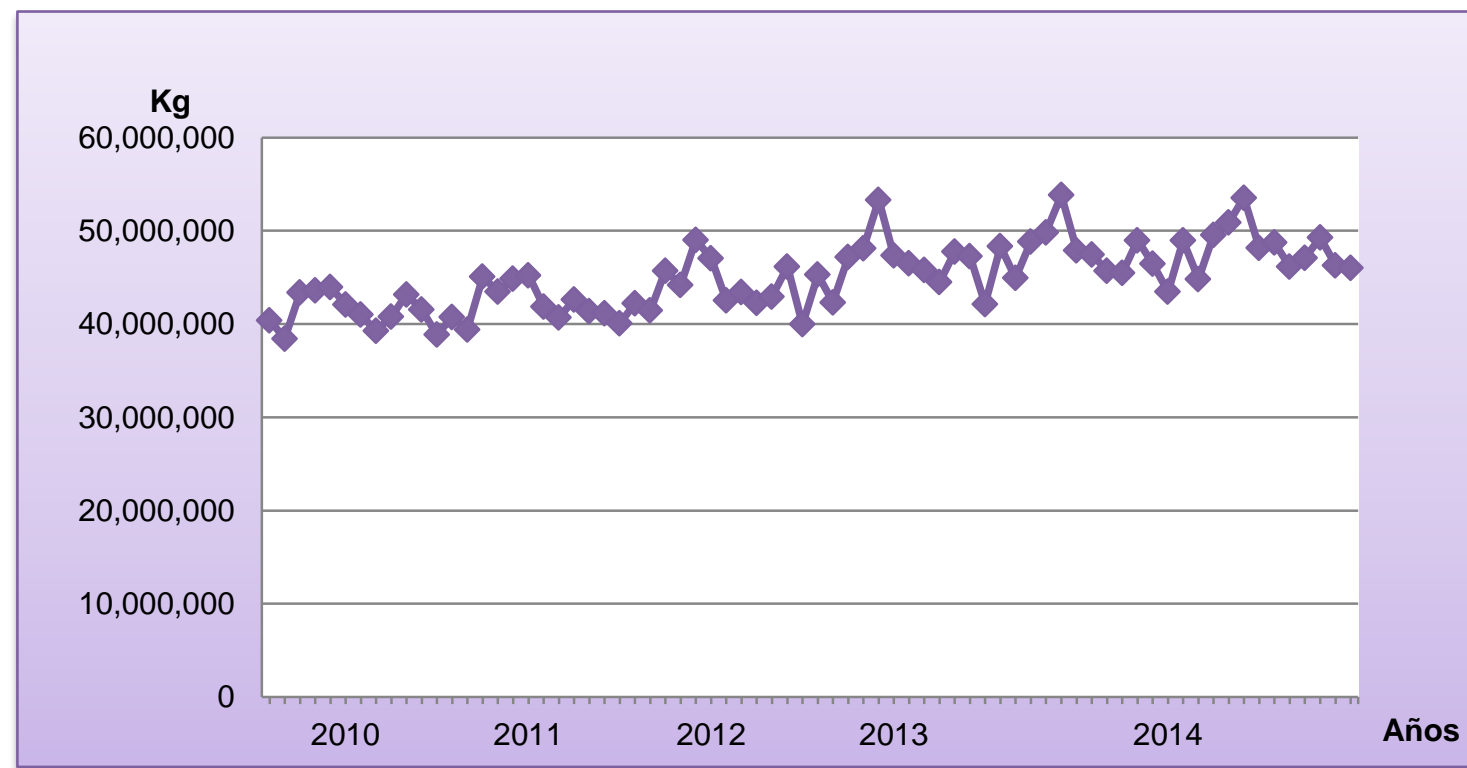

Fuente: Trade Map

\section{Gráfico N³.2}

Demanda Histórica Trimestral de Banano en Canadá 2010-2015

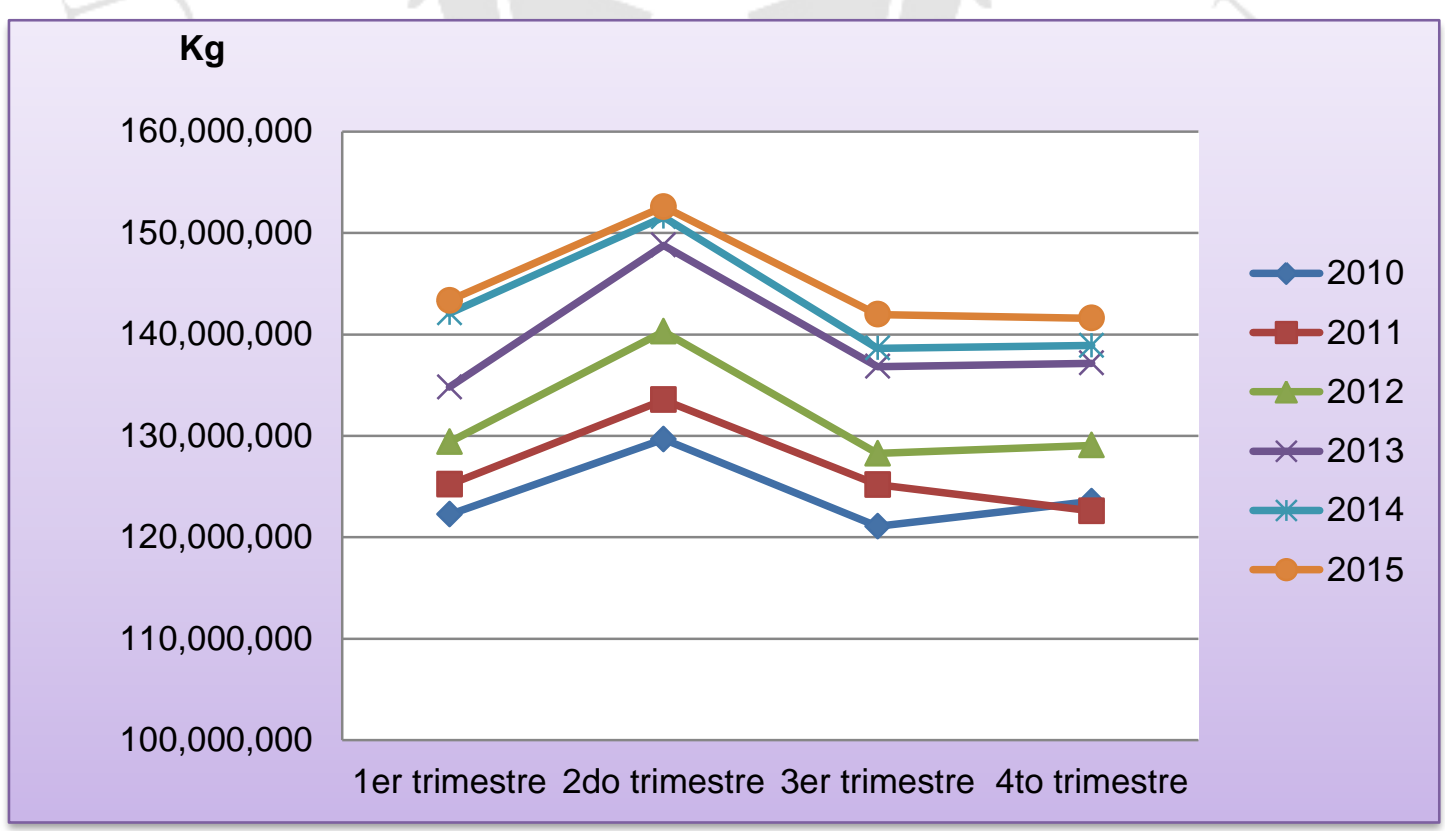

Fuente: Trade Map 
El presente gráfico muestra que la mayor demanda de banano se registra durante el segundo trimestre de cada año, del 2010 al 2015 habiendo una notable diferencia con otros trimestres. Asimismo, se ve una tendencia al alza, ya que tanto los puntos de mayor demanda como los de menor, correspondientes a cada uno de los años analizados, presentan incremento con respecto a años anteriores.

Gráfico №3.3

Demanda Histórica Anual de Banano en Canadá 2005-2015

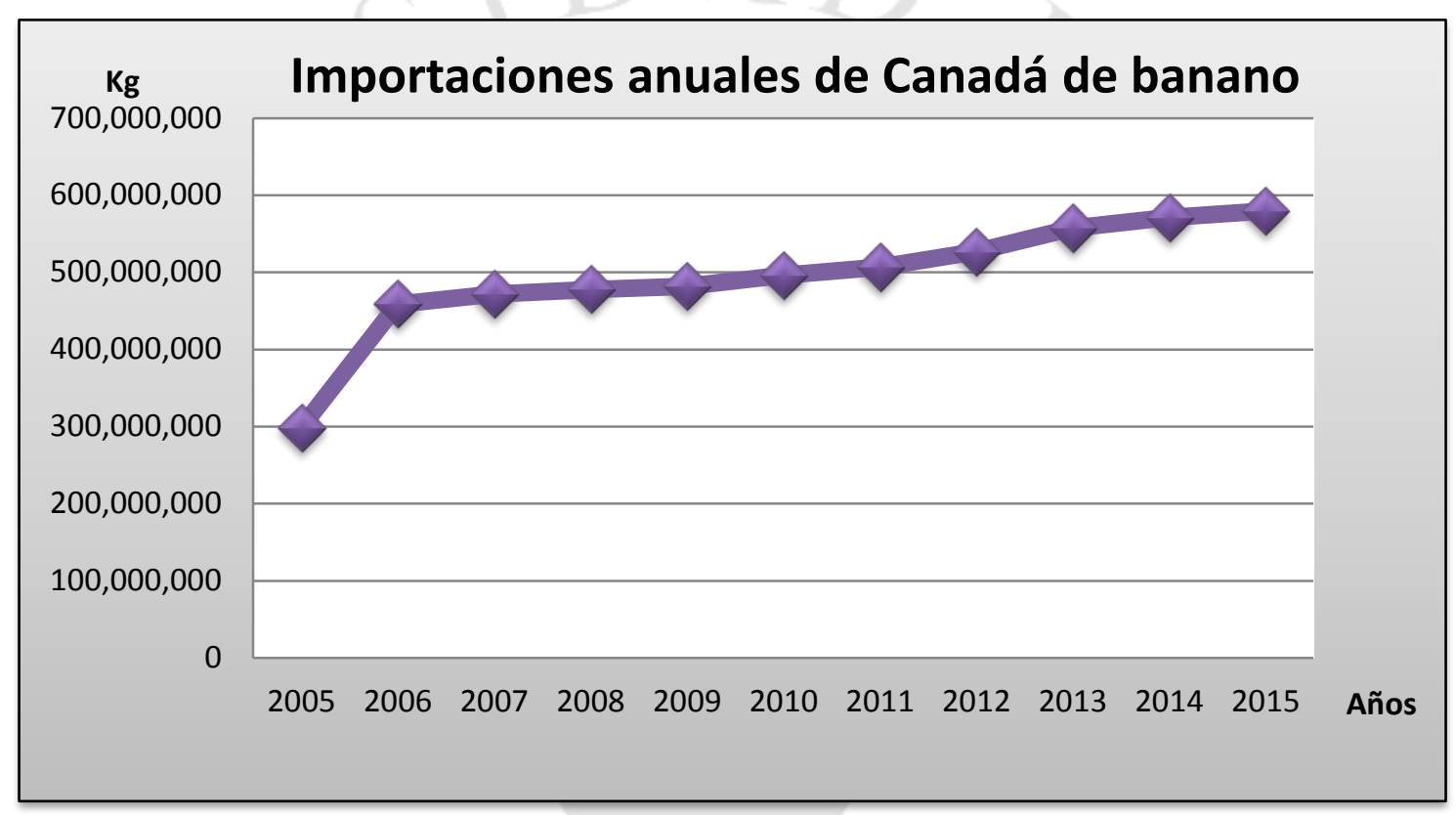

Fuente: Trade Map

A partir del gráfico, se puede concluir que existe una relación lineal positiva entre las variables a partir del año 2005, presentándose un aumento de la demanda de un año a otro. En el 2006, se registró un fuerte aumento de $159,919,000 \mathrm{~kg}$, representando un incremento del $53.50 \%$ con respecto al año 2005. Por otro lado, la cantidad demanda en el año 2015 presentó un incremento de $1.44 \%$ y de $93.98 \%$ en razón a los años 2014 y 2005, respectivamente.

La base de datos utilizada fue TRADE MAP: estadísticas de comercio para el desarrollo internacional de las empresas. Esta fuente sintetiza los cálculos 
realizados por la Cámara de Comercio Internacional basados en estadísticas de UN COMTRADE.

Cabe resaltar que, para obtener la demanda histórica real presentada, se analizaron las cantidades demandadas en kilos; mas no en dólares, con ello se buscó no incorporar cualquier incremento del precio reflejado en el crecimiento de la demanda.

\subsubsection{Demanda Potencial}

Para el análisis de la demanda potencial del banano se manejó como base la demanda histórica determinada en el punto 3.2.1. El método de proyección utilizado fue el de la media móvil; el cual contempla como principal variable la evolución del producto analizado en el tiempo, dejando de lado las demás variables.

Se realizó la proyección de la demanda hasta el 2017 por medio del análisis de series de tiempo del programa Minitab. El método utilizado fue el modelo multiplicativo debido a que presentó un menor margen de error que el modelo aditivo.

\section{Gráfico №3.4}

Demanda Potencial de Banano en Canadá

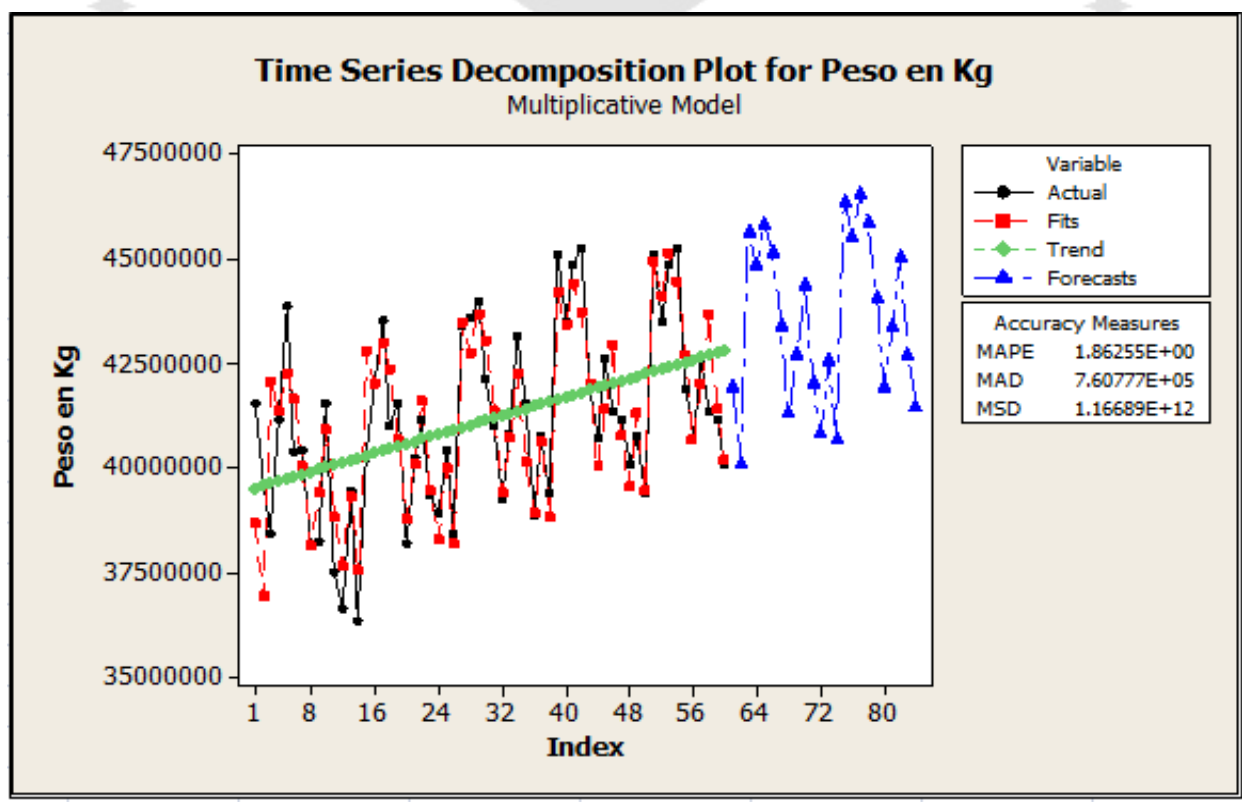

Fuente: Trade Map 
El gráfico obtenido muestra la existencia una tendencia al alza de la cantidad de banano importado por Canadá, siendo promedio de más de 43 millones de $\mathrm{kg}$ para los dos años proyectados, que presentan un aumento del $3 \%$ aproximadamente con respecto al año 2015.

Tanto la demanda histórica como la potencial se complementan con la demanda cualitativa. En cuanto a esta última se puede mencionar que los países desarrollados, como es el caso de Canadá, el concepto de alimentos orgánicos se encuentra arraigado a su cultura, ya que la preferencia por estos productos tiene origen en la teoría de que el cáncer surgió como consecuencia de la utilización de productos químicos, luego de la revolución industrial, con el fin de acelerar la producción agrícola; y, además, está convencida de que estos productos otorgan ventajas que permiten vivir más años como producto de una mejor calidad de vida.

\subsection{Análisis de la Oferta}

\subsubsection{Oferta Local al Mundo}

En el 2015 las exportaciones peruanas de banano totalizaron más de US\$145 millones, lo que representó un crecimiento de $21.66 \%$ respecto al año anterior. A pesar de que en el año 2010 se registró una variación poco favorable sobre las exportaciones mencionadas, se muestra una tendencia creciente en los últimos años, que se puede apreciar con mayor claridad en el Cuadro №3.3. 
Cuadro №3.3

Exportaciones de banano peruano 2005-2015

\begin{tabular}{|c|c|c|c|c|}
\hline \multirow{2}{*}{ AÑ } & \multicolumn{3}{|c|}{ EXPORTACIONES AL MUNDO } \\
\cline { 2 - 5 } & $\begin{array}{c}\text { VALOR } \\
\text { FOB } \\
\text { (US\$) }\end{array}$ & VAR. $\%$ & $\begin{array}{c}\text { PESO } \\
\text { NETO } \\
\text { (KG) }\end{array}$ & VAR. \% \\
\hline 2005 & $17,588,701$ & - & $42,851,942$ & - \\
\hline 2006 & $26,142,560$ & $48.63 \%$ & $56,305,776$ & $31.40 \%$ \\
\hline 2007 & $31,227,957$ & $19.45 \%$ & $65,495,004$ & $16.32 \%$ \\
\hline 2008 & $45,553,148$ & $45.87 \%$ & $78,162,586$ & $19.34 \%$ \\
\hline 2009 & $51,322,040$ & $12.66 \%$ & $82,510,391$ & $5.56 \%$ \\
\hline 2010 & $49,519,405$ & $-3.51 \%$ & $78,783,054$ & $-4.52 \%$ \\
\hline 2011 & $64,474,333$ & $30.20 \%$ & $100,319,805$ & $27.34 \%$ \\
\hline 2012 & $80,366,111$ & $24.65 \%$ & $117,677,818$ & $17.30 \%$ \\
\hline 2013 & $88,985,417$ & $10.73 \%$ & $124,122,837$ & $5.48 \%$ \\
\hline 2014 & $119,348,044$ & $34.12 \%$ & $159,602,807$ & $28.58 \%$ \\
\hline 2015 & $145,159,966$ & $21.63 \%$ & $191,418,243$ & $19.93 \%$ \\
\hline
\end{tabular}

Fuente: Infotrade

En base al presente gráfico, se puede concluir de que tanto el valor FOB como el peso neto en kilogramos de las exportaciones peruanas de banano han registrado una tendencia a la alza durante los años que se tomaron como muestra para el análisis de la evaluación de las exportaciones de banano (a excepción del 2010, cuando lo presentaron ambas variables), siendo la tasa promedio de crecimiento de $23.56 \%$ y de $17.34 \%$ para el valor FOB y el peso neto, respectivamente. 
Gráfico №3.5

Exportaciones de Banano Peruano 2005-2015

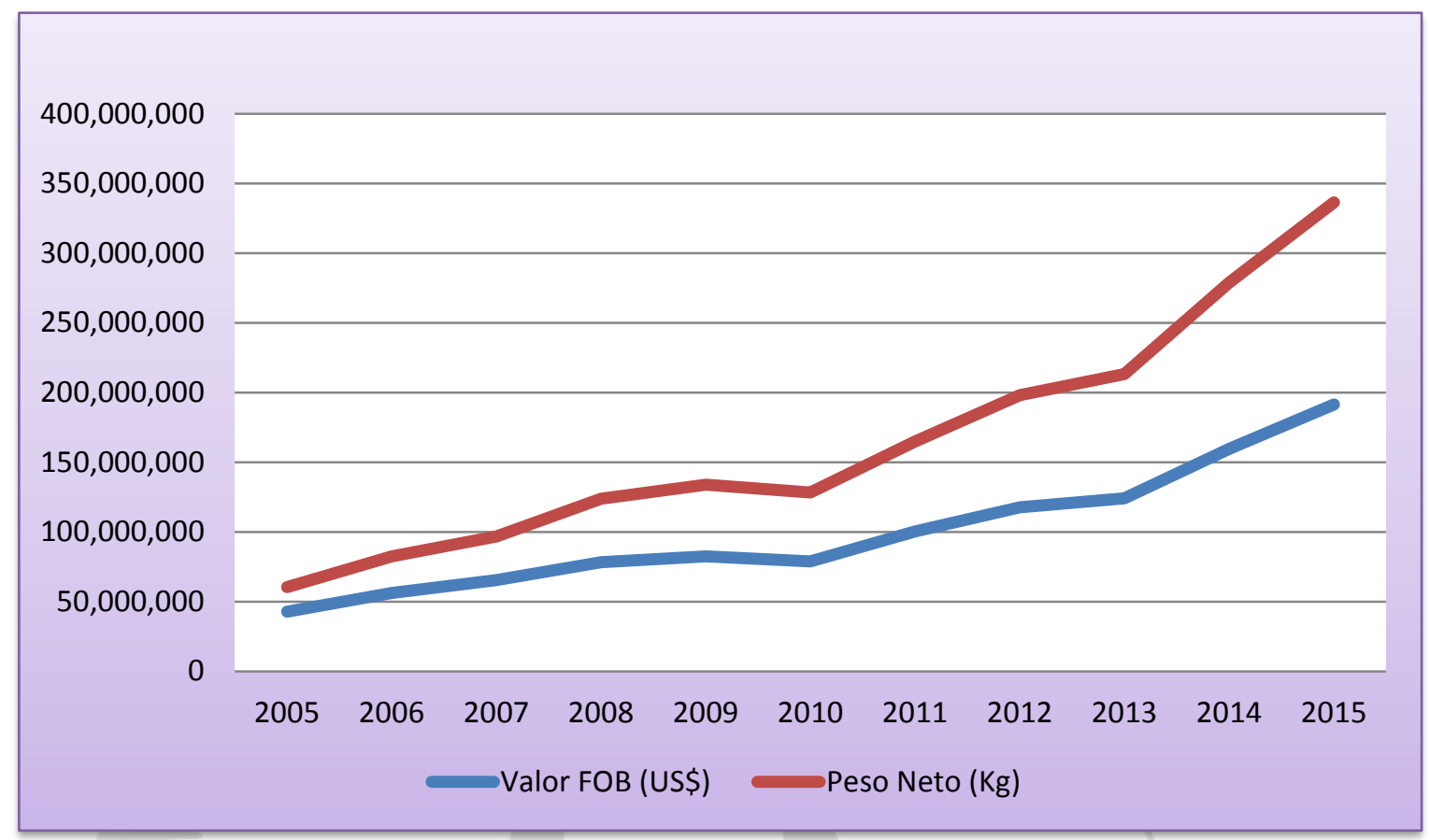

Fuente: Infotrade

Por otro lado, al analizar los principales mercados de destino de las exportaciones de banano peruano, tenemos que desde el año 2009, Países Bajos se ha consolidado como el principal país de destino, a excepción del año 2015, cuando fue desplazado al segundo lugar por Estados Unidos. Estos países se han mantenido entre los cinco principales mercados de destino durante los últimos cinco años, junto con Alemania y Bélgica. Esta es una prueba cabal de que existe una gran fidelidad por parte de países del exterior por el banano peruano. 


\section{Gráfico N³.6}

\section{Principales Países de Destino del Banano Peruano 2015}

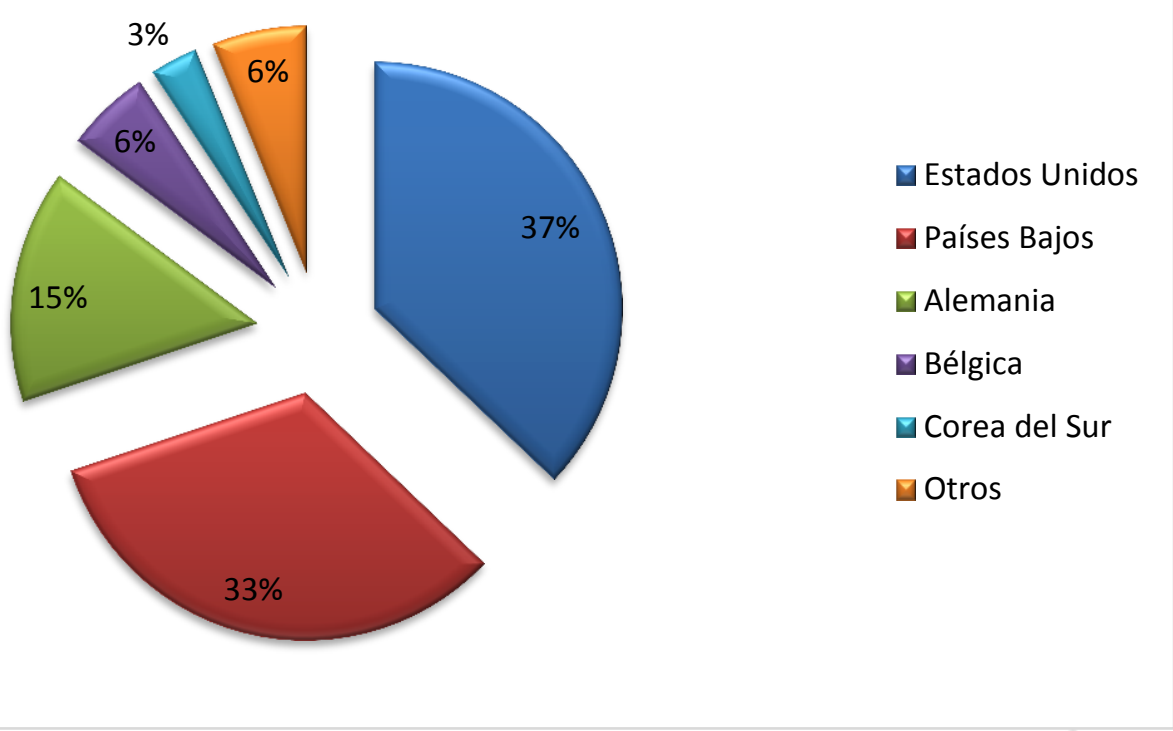

Fuente: Promperú Stat

\subsubsection{Producción Local}

"El Perú lidera a nivel mundial las exportaciones de (...) banano orgánico (...)", así lo informó la Asociación de Exportadores (ADEX).32

La producción de banano orgánico se concentra en el departamento de Piura, donde se dispone de más de 5 mil hectáreas para el cultivo de este producto ${ }^{33}$.

Los productores de esta zona cuentan con gran experiencia en la producción de banano orgánico, ya que han venido trabajando en las técnicas de cultivo desde hace 14 años.

La Dirección Regional de Agricultura de Piura invertirá más de 9 millones de soles en un proyecto denominado: "Mejoramiento de la competitividad de la cadena productiva del banano orgánico para mejorar la oferta exportable en la región de Piura". A través de esta iniciativa se incentivará la siembra en zonas

\footnotetext{
${ }^{32}$ América Economía. "Perú es el primer exportador mundial de quinua, banano orgánico y espárragos"

${ }^{33}$ Radio Programas del Perú (RPP) "Piura: Impulsan producción de banano orgánico en el Valle de Chira"
} 
aptas para el cultivo como el Valle de Chira, San Lorenzo, Morropón, Medio Piura y Bajo Piura, teniendo como resultado el incremento de la producción, la cual pasaría de 1,200 cajas por hectárea al año, a 3,000. ${ }^{34}$

Cuadro $N^{\circ} 3.4$

Distribución de hectáreas por zona

\begin{tabular}{|c|c|}
\hline PROVINCIA & HECTÁREAS (Ha) \\
\hline Valle de Chira & $4,790.80$ \\
\hline San Lorenzo & 255.00 \\
\hline Alto Piura & 136.00 \\
\hline Medio y Bajo Piura & 47.42 \\
\hline TOTAL & $\mathbf{5 , 2 2 9 . 2 2}$ \\
\hline
\end{tabular}

Fuente: Ministerio de Agricultura

El presente cuadro muestra la cantidad de hectáreas disponibles para el cultivo de banano orgánico en el departamento de Piura. En base a la producción total, sostenida por el viceministro de Políticas Agrarias del Ministerio de Agricultura y Riego (MINAGRI), César Sotomayor se ha estimado el porcentaje de la demanda requerida en razón a la producción local, siendo esta de $0.07 \%$ Esto muestra que el acopio necesario para abastecer al mercado canadiense de banano orgánico no distorsionaría la oferta peruana.

Como se ha hecho mención a lo largo de esta investigación, el Perú, al encontrarse en una zona estratégica del hemisferio sur, goza de condiciones climáticas que le permiten beneficiarse de una producción de banano durante todos los meses del año, lo que constituye una ventaja importante frente a los países abastecedores de banano a nivel mundial.

Actualmente, se busca la modernización de las áreas de cultivo, así como la implementación de tecnologías, que permitan a los agricultores aprovechar las oportunidades y superar los desafíos que se presentan debido al dinamismo que presenta la economía actual.

\footnotetext{
${ }^{34}$ Radio Programas del Perú (RPP). "Agricultura impulsa productividad de banano orgánico".
} 


\subsubsection{Oferta Local a Canadá}

Cerca del 1\% de las exportaciones peruanas de banano tienen como destino el mercado canadiense y se encuentra en el séptimo puesto dentro de los principales proveedores a este mercado.

\section{Cuadro N³.5}

Exportaciones Históricas Anuales de Perú a Canadá de Banano 2009-2015

\begin{tabular}{|c|c|c|c|c|}
\hline \multicolumn{5}{|c|}{ PERÚ-CANADÁ } \\
\hline AÑO & $\begin{array}{c}\text { VALOR } \\
\text { FOB (USD) }\end{array}$ & VAR. (\%) & $\begin{array}{c}\text { PESO NETO } \\
\text { (KG) }\end{array}$ & VAR. (\%) \\
\hline $\mathbf{2 0 0 9}$ & 296,396 & - & 524,470 & - \\
\hline $\mathbf{2 0 1 0}$ & 728,010 & 146 & $1,212,100$ & 131 \\
\hline $\mathbf{2 0 1 1}$ & $1,083,648$ & 49 & $1,689,816$ & 39 \\
\hline $\mathbf{2 0 1 2}$ & 971,521 & 10 & $1,488,989$ & 12 \\
\hline $\mathbf{2 0 1 3}$ & 660,962 & -32 & 994,404 & -33 \\
\hline $\mathbf{2 0 1 4}$ & 968,628 & 47 & $1,274,646$ & 28 \\
\hline $\mathbf{2 0 1 5}$ & $1,423,488$ & 47 & $1,802,390$ & 41 \\
\hline
\end{tabular}

Fuente: Infotrade

En el año 2015 se registraron 15 empresas exportadoras de banano a nivel mundial, de las cuales sólo 2 exportaron a Canadá.

Cuadro N³.6

Empresas Peruanas Exportadoras de Banano Orgánico a Canadá 2015

\begin{tabular}{|c|c|c|c|}
\hline \multicolumn{3}{|c|}{ PERÚ-CANADÁ } \\
\hline EMPRESA & RUC & $\begin{array}{c}\text { PESO NETO } \\
\text { KG }\end{array}$ & VALOR FOB \\
\hline $\begin{array}{c}\text { Asociación de Pequeños } \\
\text { Productores de Banano } \\
\text { Orgánico de Saman y } \\
\text { Anexos }\end{array}$ & 20484062031 & $1,724,025$ & $1,368,192$ \\
\hline $\begin{array}{c}\text { Asociación de Bananeros } \\
\text { Orgánicos Solidarios Salitral }\end{array}$ & 20484149748 & 78,364 & 55,296 \\
\hline TOTAL & & $\mathbf{1 , 8 0 2 , 3 9 0}$ & $\mathbf{1 , 4 2 3 , 4 8 8}$ \\
\hline
\end{tabular}

Fuente: Infotrade 


\subsubsection{Oferta Global a Canadá ${ }^{35,36}$}

Los principales países proveedores de banano a Canadá son Guatemala, Ecuador, Costa Rica y Colombia en orden de posiciones.

\section{Gráfico N³.7}

Participación de la Competencia en el Mercado Canadiense de Banano 2015

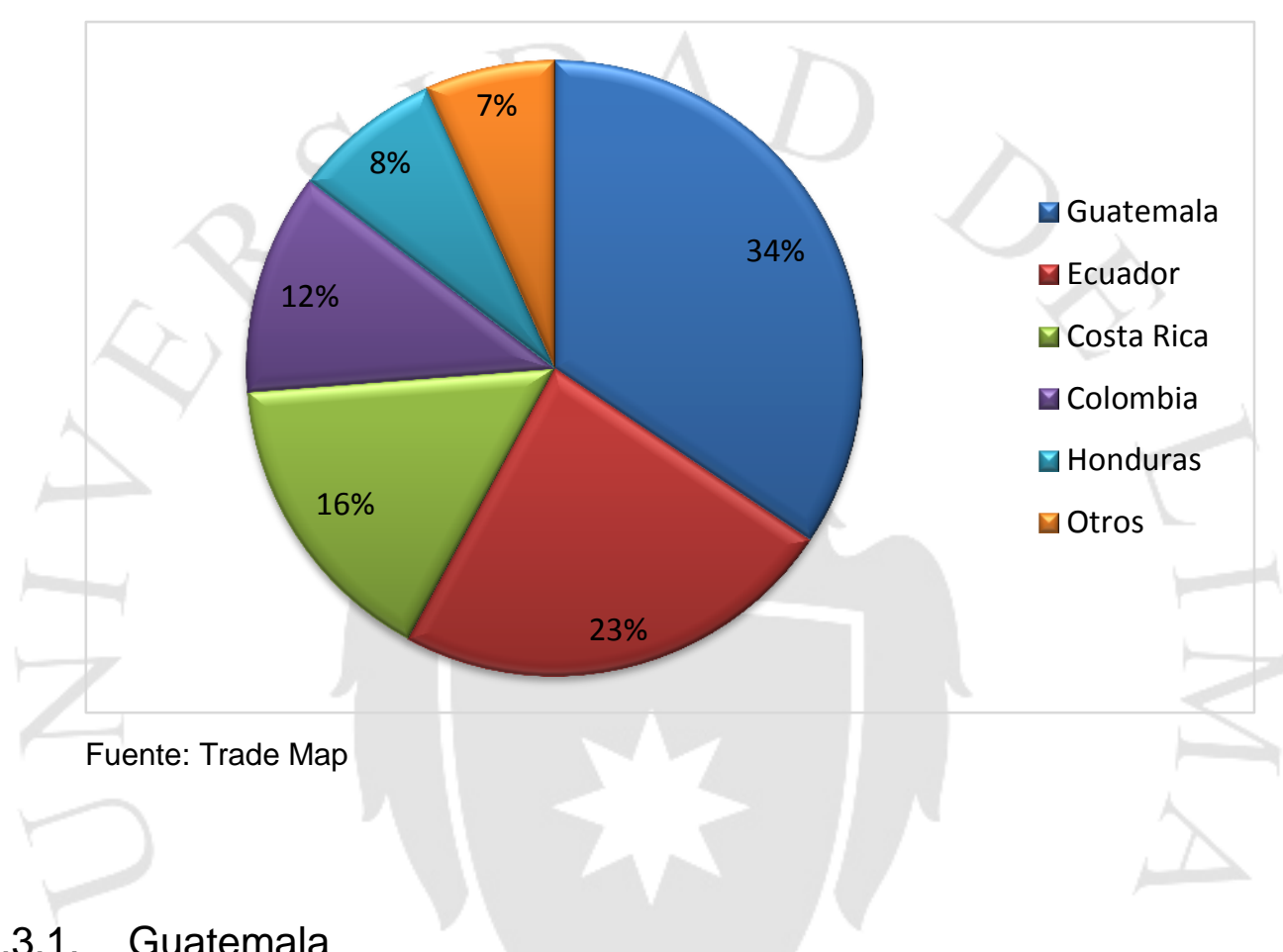

\subsubsection{Guatemala}

Guatemala es el mayor exportador de banano al mercado canadiense y el cuarto exportador de este producto al mundo en cuanto a valor FOB y el segundo en cuanto a cantidad, contando con una participación del $7.83 \%$ en las exportaciones mundiales de banano en cuanto a valor.

Este producto agrícola representa una importante fuente de ingresos de exportación y de empleo (después del café y el azúcar), ya que se estima que da empleo a 62 mil personas de forma directa y poco menos de 10 mil de manera indirecta, contribuyendo a la economía del país.

\footnotetext{
35 Trade Map.

${ }^{36}$ Sistema Integrado de Información de Comercio Exterior (SIICEX).
} 
En el 2009, se registraron 66,500 hectáreas de superficie plantada para el cultivo de banano.

Como veremos más adelante, los principales países proveedores de banano a Canadá cuentan con ventajas competitivas debido a las condiciones climatológicas que favorecen el cultivo del mismo; sin embargo, Guatemala puede verse influenciada de manera perjudicial con fenómenos relacionados al clima que pueden afectar su producción, como fue en 1998 cuando esta zona fue azotada por el Huracán Mitch ${ }^{37}$.

Asimismo, en el primer trimestre del presente año, la producción guatemalense se presentó más baja en comparación con el resto del año, debido a que desde el mes de diciembre hasta el mes de febrero, se registran las temperaturas más bajas del año, además de menos horas de luz, lo que contribuye a una considerable disminución su oferta de banano.

\subsubsection{Ecuador}

Ecuador es el segundo proveedor de Canadá de banano en cuanto a valor FOB y a cantidad y el mayor exportador de banano del mundo y su presencia en el comercio mundial va en aumento. Su participación en las exportaciones mundiales de este producto, representaron el $26.46 \%$ en el 2015.

Como consecuencia de las excelentes condiciones climatológicas y ecológicas que tiene este país, pequeños, medianos y grandes productores han podido beneficiarse de las potencialidades provenientes de estas ventajas competitivas en cuanto a la producción de bananos. Asimismo, estas condiciones ambientales permiten que la oferta ecuatoriana de banano sea constante durante todo el año.

Este país cuenta con 175 mil hectáreas, de las cuales el $91.22 \%$ se encuentra concentrada en las provincias de El Oro, Guayabas y Los Ríos.

Este sector es uno de los más importantes de este país debido a la fuerte inversión que recibe, siendo esta, en promedio, de 4 millones de dólares.

\footnotetext{
${ }^{37}$ Food and Agriculture Organization of the United Nations (FAO)
} 


\subsubsection{Costa Rica}

Con un valor FOB de $65,912,000$ dólares y una cantidad de 101,849,000 kilogramos, Costa Rica es el tercer país exportador de banano a nivel mundial (después de Ecuador y Guatemala) tanto a valor FOB como a cantidad.

El banano es el principal producto agrícola de exportación. En el 2015, según cifras del Banco Central de Costa Rica (BCCR), la participación de las exportaciones de banano dentro del total de exportaciones nacionales representó el $7.88 \%$ de éstas.

Además, es una importante fuente de empleo, ya que, en el 2011, los empleos directos generados por la industria ascendieron a 40,000 y los indirectos, a 100,000 .

En cuanto al mercado canadiense, las exportaciones costarricenses de este producto presentaron un decrecimiento, en el 2015, tanto en valor como en volumen, siendo esta de $16.46 \%$ y de $10.75 \%$, respectivamente.

Costa Rica cuenta con 42,017 hectáreas destinadas al cultivo de banano, las cuales se encuentran, principalmente, en la región del Caribe, donde puede beneficiarse de las condiciones climáticas y de los suelos, debido a la ubicación privilegiada donde se encuentra, que lo convierte en una de las mejores áreas de América del Centro para la producción del banano.

\subsubsection{Colombia}

Colombia ocupa el cuarto lugar dentro de los principales proveedores de banano a Canadá de banano en cuanto a valor FOB y a cantidad; y es el cuarto mayor exportador de banano del mundo en cuanto a cantidad y el quinto en cuanto a valor FOB. 
Las hectáreas de cultivo de banano ascendieron a, aproximadamente, 46,500 en el 2010, concentrándose principalmente en las zonas de Urabá y Magdalena, las cuales albergaron el $72 \%$ y el $28 \%$ del total de área sembrada para producción de banano.

Según la Asociación de Bananeros de Colombia, esta industria genera cerca de 30,000 empleos directos y 80,000 indirectos.

Debido al relieve y a los diferentes climas que posee Colombia, este es rico en un gran número de productos y variedad de los mismos, siendo el banano uno de los productos agrícolas más importantes desde el punto de vista económico, ya que representa el $0.4 \%$ del PBI y el $3 \%$ de las exportaciones totales y $6 \%$ de las no tradicionales 38

En el 2015, las exportaciones colombianas de banano al mercado canadiense presentaron una disminución del $20.32 \%$ y $17.55 \%$ en cuanto a valor FOB y cantidad exportada, respectivamente.

El siguiente gráfico muestra el porcentaje de participación de los principales proveedores de banano en las importaciones de este producto por parte del mercado canadiense para el año 201539.

Los cuatro principales países proveedores concentran el $85.41 \%$ del mercado canadiense.

Dentro de los otros países se encuentra Honduras, en el quinto lugar con un porcentaje de participación del $7.80 \%$, luego se encuentra México con un $3.47 \%$ y le sigue Perú con un $2.23 \%$.

\footnotetext{
${ }^{38}$ Ministerio de Agricultura y Desarrollo Rural. Sistema de Información de Gestión y Desempeño de Organizaciones de Cadenas

${ }^{39}$ Los valores tomados como referencia para el cálculo de los porcentajes de participación fueron en cuanto al valor FOB exportado.
} 


\section{Gráfico N³.8}

Importaciones Canadienses de Banano por País 2011-2015

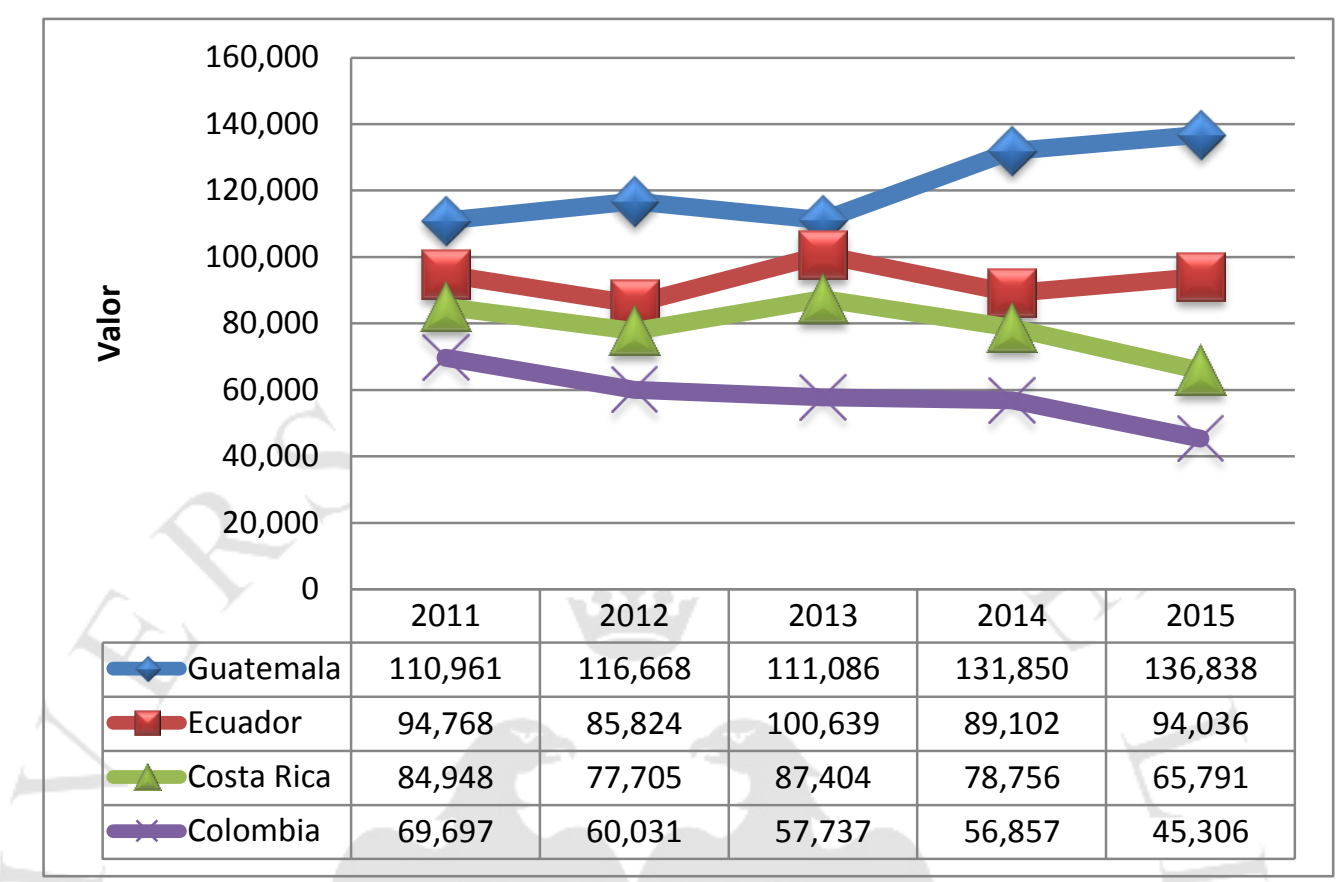

Fuente: Trade Map 
Gráfico ํ⒊9

Importaciones Canadienses de Banano por País 2011-2015

\section{Importaciones Canadienses de Banano}

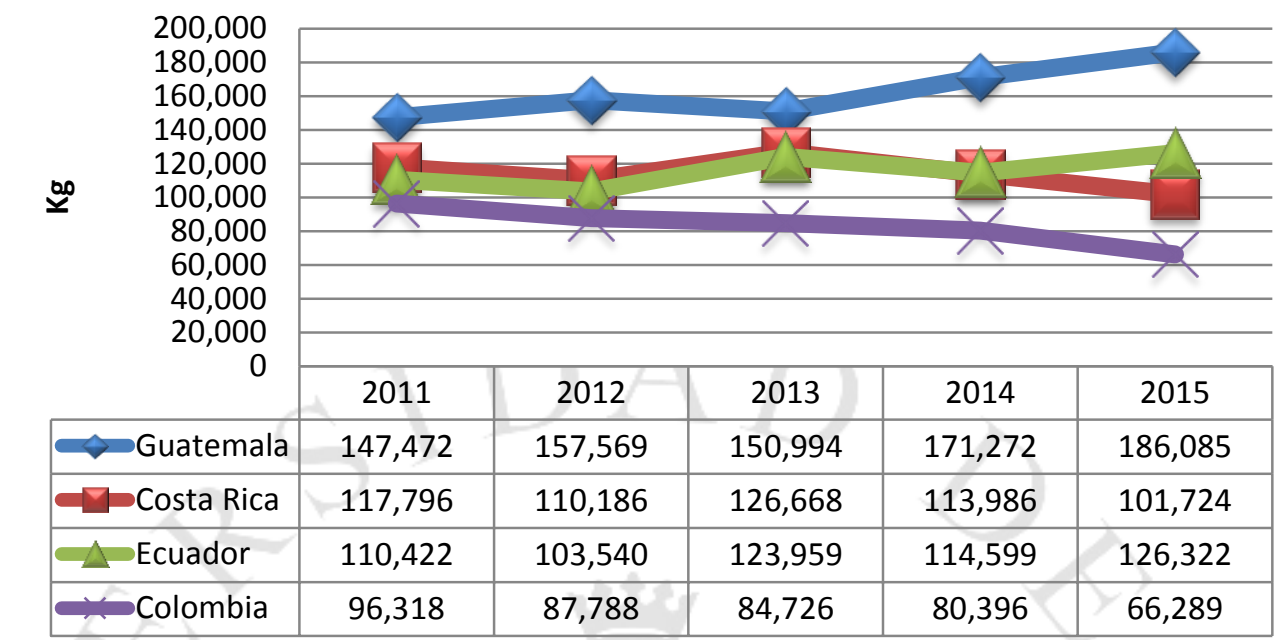

Fuente: Trade Map

\subsubsection{Análisis de la competencia}

Como países competidores de la oferta peruana de banano, se consideran los principales proveedores de este producto al mercado canadiense, estudiados en el punto anterior.

A continuación se presenta el arancel vigente en Canadá para el ingreso del producto en mención, tanto para Perú como para los países analizados en el punto anterior.

\section{Cuadro $\mathrm{N}^{\circ} 3.7$}

Arancel de los Principales Proveedores de Banano a Canadá

\begin{tabular}{|c|c|c|c|c|c|}
\hline & Guatemala & Ecuador & $\begin{array}{c}\text { Costa } \\
\text { Rica }\end{array}$ & Colombia & Perú \\
\hline $\begin{array}{c}\text { Régimen } \\
\text { Tarifario }\end{array}$ & MNF & MNF & MNF & MNF & MNF \\
\hline $\begin{array}{c}\text { Tarifa } \\
\text { Aplicada }\end{array}$ & $0 \%$ & $0 \%$ & $0 \%$ & $0 \%$ & $0 \%$ \\
\hline $\begin{array}{c}\text { Ad } \\
\text { Valorem }\end{array}$ & $0 \%$ & $0 \%$ & $0 \%$ & $0 \%$ & $0 \%$ \\
\hline
\end{tabular}

Fuente: Trade Map - Market Access Map 
En cuanto a relaciones comerciales, Colombia, Costa Rica y Perú disponen de un Tratado de Libre Comercio con Canadá, mientras que en el caso de Honduras, las negociaciones han concluido pero todavía no entra en vigencia.

Al mismo tiempo, Canadá otorga ventajas arancelarias a países en desarrollo como Guatemala y Ecuador bajo el esquema del GSP (por sus siglas en inglés) por lo que los principales países proveedores de banano a este mercado de destino se encuentran en igualdad de condiciones en cuanto a barreras arancelarias.

La producción de banano orgánicos ecuatorianos corresponde a una fracción pequeña de las exportaciones de bananos totales ${ }^{40}$. Esta parece ir en aumento, no obstante, este crecimiento podría ser mitigado por la propagación de plagas y enfermedades, ya que a diferencia de las zonas de Piura y Tumbes, en Perú, que cuentan con una gran ventaja competitiva, debido que las condiciones de los suelos y del clima propician una baja incidencia de la Sigatoka Negra ${ }^{41}$, en Ecuador el $60 \%$ del tratamiento contra esta enfermedad consiste en la aplicación de productos químicos, lo que representa una conducta contraria a la tendencia de demanda orgánica.

Desde hace ya varios años, Guatemala se ha posicionado como el principal protagonista en el abastecimiento de banano en el mercado canadiense.

Como se mencionó anteriormente, Perú se posiciona como el primer exportador y el quinto productor mundial de banano orgánico, además, a diferencia de otros proveedores importantes, la exportación de banano orgánico representa prácticamente la totalidad de la exportación de banano.

\subsubsection{Análisis de Precios}

Al cierre del año 2015, Guatemala registra los precios unitarios más bajos entre los principales países ofertantes al mercado canadiense. Como se aprecia en el siguiente cuadro, todos estos países han presentado un aumento en el

\footnotetext{
${ }^{40}$ Organización de las Naciones Unidas para la Alimentación y la Agricultura (FAO)

${ }^{41}$ Enfermedad causada por un hongo que ataca a las plantaciones de banano. Debido a que presenta una maduración prematura, reduce la calidad de la fruta, ocasionando pérdidas en el rendimiento de entre $50 \%$ y $100 \%$, por lo que se considera altamente destructiva.
} 
precio con respecto al año 2014, sin embargo, Perú se destaca entre estos ya que a su precio se ha mantenido como el más elevado durante los últimos 6 años. Esto se debe, principalmente, a que la exportación de banano peruano está compuesta, casi en tu totalidad, por banano orgánico, el cual, al ser un producto con valor agregado, goza de un precio mayor en el mercado internacional.

Cuadro $\mathrm{N}^{\circ} 3.8$

Precio Unitario del Banano 2011-2015

(US $\$ / \mathrm{Kg})$

\begin{tabular}{|c|c|c|c|c|c|}
\hline \multirow{2}{*}{ PAís } & \multicolumn{5}{|c|}{ VALOR UNITARIO USD/KG } \\
\cline { 2 - 6 } & $\mathbf{2 0 1 1}$ & $\mathbf{2 0 1 2}$ & $\mathbf{2 0 1 3}$ & $\mathbf{2 0 1 4}$ & $\mathbf{2 0 1 5}$ \\
\hline Guatemala & 0.305 & 0.304 & 0.311 & 0.321 & 0.328 \\
\hline Ecuador & 0.389 & 0.400 & 0.427 & 0.435 & 0.449 \\
\hline Costa Rica & 0.376 & 0.375 & 0.404 & 0.418 & 0.422 \\
\hline Colombia & 0.426 & 0.448 & 0.465 & 0.464 & 0.477 \\
\hline Honduras & 0.375 & 0.313 & 0.372 & 0.348 & 0.391 \\
\hline Perú & 0.633 & 0.687 & 0.717 & 0.748 & 0.760 \\
\hline
\end{tabular}

Fuente: Trade Map

Los precios del banano orgánico en Canadá varían de acuerdo al peso. Por ejemplo, en el supermercado Loblaws $1 \mathrm{~kg}$ de este producto se vende a 1.74 dólares canadienses, que equivale al mismo precio en dólares. (Ver Anexo $\left.\mathrm{N}^{\circ} 6\right)$

\subsection{Demanda del Negocio $^{42}$}

Existe un futuro promisorio para alimentos orgánicos, frescos y naturales en el mercado canadiense. El banano figura como uno de los productos identificados con potencial exportador y se clasifica como un producto estrella, ya que, a través de la metodología de la CEPAL, tanto la tasa de crecimiento como la

\footnotetext{
${ }^{42}$ Ministerio de Comercio Exterior y Turismo. "Plan Operativo de Mercado Canadá"
} 
participación en las importaciones de Canadá son positivas. El consumo de los productos orgánicos está vinculado al creciente interés de la población por adquirir alimentos saludables y por disponer de una mayor variedad de productos orgánicos en el mercado. Cabe indicar que en Canadá, las frutas orgánicas tienen gran acogida, entre las favoritas están las fresas, bananos, kiwis, naranjas y manzanas ${ }^{43}$.

Debido a las condiciones climatológicas que se presentan en Canadá, que solo permiten una producción estacional, y al escaso número de empresas dedicadas a la producción de productos orgánicos (el número de empresas productoras de este tipo de productos representan solo el $1.3 \%$ del total de granjas del país), el suministro interno es insuficiente para satisfacer la demanda, por lo que, aproximadamente, el $70 \%$ y $80 \%$ de productos orgánicos consumidos son importados.

Es importante señalar que las importaciones de Canadá de banano representan el $2.95 \%$ de las importaciones mundiales de este producto, siendo su posición relativa en las importaciones mundiales $9 .{ }^{44}$

Los alimentos étnicos han desarrollado un fuerte crecimiento, y se han ido configurando como la principal tendencia.

\subsubsection{Perfil y Comportamiento del Consumidor Canadiense}

En cuanto al perfil del consumidor canadiense se puede afirmar que los factores determinantes en la decisión de compra de alimentos son, en primer lugar, la salud, en segundo lugar, el sabor y en tercer lugar la seguridad, seguida por el medio ambiente.

Las frutas peruanas cumplen con todos estos requisitos. Además, al ser el Perú uno de los principales proveedores de verduras de Canadá, este último conoce y confía en sus productos, por lo que las frutas objeto de exportación,

\footnotetext{
${ }^{43}$ Promoción de Turismo, Inversión y Exportación (PROEXPORT COLOMBIA). "Oportunidades en Canadá"

44 Trade Map
} 
son productos potencialmente atractivos para este mercado, ya que, en un futuro, el Perú podría posicionarse como uno de los principales proveedores de frutas.

A continuación se nombran algunas de las características más importantes del consumidor canadiense:

- Los hogares disponen de altos ingresos, siendo el ingreso per cápita de USD 47,500 para el año 2015. ${ }^{45}$ Algunos de ellos disponen, incluso, de doble ingreso.

- El consumidor es exigente en cuanto a la presentación exterior del producto, información nutricional y formas de utilización del mismo.

- El mercado está dominado por los baby boomers, los cuales representan el mayor grupo, en cuanto a tamaño, de la población canadiense. Se espera que con el envejecimiento de este segmento de la población, se incremente la demanda de productos saludables, ya que muchos de los que hoy son adultos, llegan a los 60 años con problemas de salud debido al sobrepeso y al sedentarismo. Por eso, la generación del Baby Boom está consciente de la salud y puede darse el lujo de pagar precios más altos.

- El consumidor canadiense destina alrededor del $10 \%$ de su ingreso en alimentos y bebidas (Ver Cuadro №3.9)

- Los canadienses muestran preocupación por el comercio justo y el medio ambiente, por lo que busca envases fáciles y cómodos, al mismo tiempo que ecológicos. Además, se preocupa también por la salud y la nutrición.

- Existe un creciente interés por productos orgánicos, debido a consumidor valora cada vez más el uso de productos completamente naturales, ya que contienen vitaminas y otras propiedades antioxidantes.

- El consumidor es consciente del precio, el cual es un factor importante en la decisión de compra.

\footnotetext{
${ }^{45}$ Banco Mundial.
} 
- Sobre los gustos, podemos afirmar que el consumidor canadiense está abierto a sabores exóticos y étnicos ${ }^{46}$.

- El $58 \%$ de las familias canadienses compra alimentos orgánicos al menos una vez a la semana.

- El consumidor toma en cuenta la historia detrás del producto (cómo se hizo, de dónde provienen los cultivos, tradición de lleva el producto, etc)

El criterio predominante en la decisión de compra de productos orgánicos es la apariencia, la cual debe ser atractiva, la calidad aparente y la uniformidad en el tamaño.

${ }^{46}$ Oficina Económica y Comercial de la Embajada de España en Toronto. "El Mercado de Alimentación en Canadá 2012" 
Cuadro №3.9

Gastos del Consumidor en Canadá para el 2005, 2010 y 2015 (millones de dólares)

\begin{tabular}{|c|c|c|c|c|c|}
\hline \multirow{2}{*}{ RUBRO } & \multicolumn{3}{|c|}{ AÑO } & \multirow{2}{*}{ PART. 2010\% } & \multirow{2}{*}{ PART. 2015\% } \\
\hline & 2005 & 2010 & 2015 & & \\
\hline $\begin{array}{l}\text { Alimentos y } \\
\text { bebidas no } \\
\text { alcohólicas }\end{array}$ & 67,362 & 75,690 & 85,513 & 9.90 & 9.95 \\
\hline $\begin{array}{c}\text { Bebidas } \\
\text { alcohólicas y } \\
\text { tabaco }\end{array}$ & 26,870 & 31,125 & 35,509 & 4.07 & 4.13 \\
\hline $\begin{array}{c}\text { Prendas de } \\
\text { vestir y calzado }\end{array}$ & 34,811 & 40,189 & 47,159 & 5.26 & 5.49 \\
\hline Vivienda & 157,510 & 164,330 & 183,540 & 21.49 & 21.35 \\
\hline $\begin{array}{c}\text { Artículos del } \\
\text { hogar y } \\
\text { servicios }\end{array}$ & 48,848 & 53,478 & 58,608 & 6.99 & 6.82 \\
\hline $\begin{array}{l}\text { Art. salud y } \\
\text { servicios } \\
\text { médicos }\end{array}$ & 32,141 & 37,983 & 44,442 & 4.97 & 5.17 \\
\hline Transporte & 103,101 & 114,243 & 130,173 & 14.94 & 15.15 \\
\hline Comunicaciones & 16,799 & 19,411 & 21,243 & 2.54 & 2.47 \\
\hline $\begin{array}{c}\text { Ocio y } \\
\text { recreación }\end{array}$ & 75,399 & 84,337 & 96,923 & 11.03 & 11.28 \\
\hline Educación & 9,540 & 11,024 & 12,822 & 1.44 & 1.49 \\
\hline $\begin{array}{l}\text { Hoteles y } \\
\text { catering }\end{array}$ & 53,186 & 59,634 & 62,739 & 7.80 & 7.30 \\
\hline $\begin{array}{c}\text { Art. diversos y } \\
\text { servicios }\end{array}$ & 68,363 & 73,299 & 80,801 & 9.58 & 9.40 \\
\hline TOTAL & 693,930 & 764,744 & 859,472 & 100 & 100 \\
\hline
\end{tabular}

Fuente: Euromonitor

En base al siguiente cuadro, se puede concluir que el gasto en frutas seguirá ganando terreno frente a los vegetales. 
Cuadro №3.10

Gastos del Consumidor Canadiense en Alimentos para el 2010, 2015 y 2020 (millones de dólares)

\begin{tabular}{|c|c|c|c|c|c|}
\hline \multirow{2}{*}{ RUBRO } & \multicolumn{3}{|c|}{ AÑO } & \multirow{2}{*}{$\begin{array}{c}\text { PART. \% } \\
2010\end{array}$} & \multirow{2}{*}{$\begin{array}{c}\text { PART. \% } \\
2020\end{array}$} \\
\hline & 2010 & 2015 & 2020 & & \\
\hline $\begin{array}{c}\text { Pan y } \\
\text { cereales }\end{array}$ & 13,320 & 14,756 & 15,803 & 17.2 & 18.2 \\
\hline Carne & 17,384 & 18,614 & 19,263 & 22.4 & 22.2 \\
\hline $\begin{array}{l}\text { Pescado y } \\
\text { mariscos }\end{array}$ & 4,202 & 5,602 & 7,215 & 5.4 & 8.3 \\
\hline $\begin{array}{l}\text { Leche, } \\
\text { queso y } \\
\text { huevos }\end{array}$ & 12,168 & 12,870 & 12,870 & 15.7 & 14.8 \\
\hline $\begin{array}{c}\text { Aceites y } \\
\text { grasas }\end{array}$ & 1,031 & 1,104 & 1,143 & 1.3 & 1.3 \\
\hline Frutas & 10,244 & 11,394 & 12,132 & 13.3 & 14.0 \\
\hline Vegetales & 8,420 & 8,859 & 9,008 & 10.8 & 10.4 \\
\hline $\begin{array}{l}\text { Azúcar y } \\
\text { pastelería }\end{array}$ & 3,459 & 3,997 & 4,466 & 4.5 & 5.1 \\
\hline $\begin{array}{c}\text { Otros } \\
\text { alimentos }\end{array}$ & 7,283 & 6,154 & 5,018 & 9.4 & 5.8 \\
\hline TOTAL & 77,611 & 83,209 & 86,920 & 100.0 & 100.0 \\
\hline
\end{tabular}

Fuente: Euromonitor

\subsubsection{Segmento de Mercado}

El segmento de mercado seleccionado, basado en la demanda de negocio, es Toronto, para lo cual se entrará en más detalle en esta ciudad a continuación:

Toronto es la capital de la provincia de Ontario y es la ciudad más grande de Canadá. Se encuentra ubicada al sureste de Canadá y es considerada el centro financiero e industrial del país. También se considera como una zona primaria de comercialización, ya que es el mayor centro de comercio mayorista de Canadá. Un gran número de importadores y departamentos de compra se ubican aquí, convirtiéndola en la ciudad clave para los proveedores extranjeros. 
Gran parte de la distribución e importación se concentra en la región de Ontario, teniendo esta última una participación del $58.43 \%$ de las importaciones totales del país. Además, esta provincia, junto con Quebec y British Columbia, concentra el $80 \%$ de las ventas de productos orgánicos. Por otro lado, Ontario es una de las provincias con mayor volumen de ventas en supermercados. Esto se explica debido a su tamaño, ya que ésta provincia supone el $38.78 \%$ de la población canadiense, además de contar con una distribución desarrollada y competitiva con el mayor número de establecimientos, los cuales alcanzan los 6,262, en comparación con las provincias restantes ${ }^{47}$.

Imagen $\mathrm{N}^{\circ} 3.2$

Atardecer de la Ciudad de Toronto

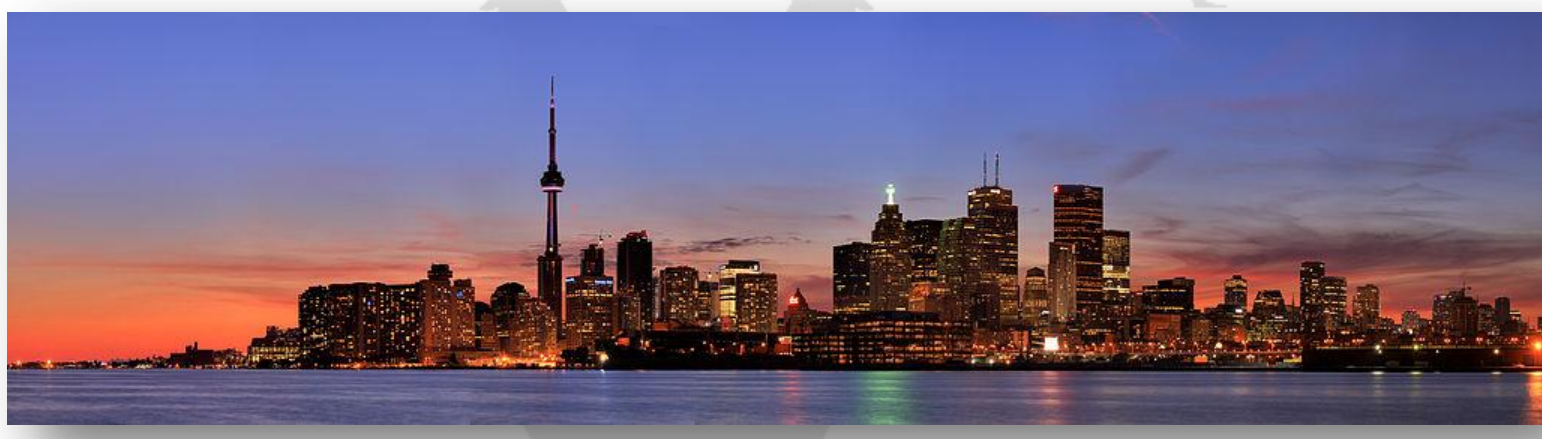

Fuente: http://es.wikipedia.org/wiki/Toronto

Su clima está caracterizado por veranos templados e inviernos fríos, en los cuales la temperatura máxima puede encontrarse debajo de los $-10^{\circ} \mathrm{C}$, por lo que el banano es una opción bastante atractiva, al ser una fuente de calorías que ayudaría a hacer frente a los fríos intensos por los que atraviesa la población canadiense.

Los habitantes de Toronto son sensibles a las tendencias americanas, por lo cual no dudarán en gastar más dinero en un producto de calidad.

47 Oficina Económica y Comercial de la Embajada de España en Toronto. "El Mercado Alimentos en Canadá". 
El $80 \%$ de la población mayor a 65 años vive en centros urbanos, siendo uno de ellos Toronto, la cual se caracteriza por un gran interés hacia productos saludables, siendo un nicho potencial para la exportación de banano orgánico. Además de contar con un alto nivel poblacional, esta ciudad se caracteriza por una creciente mezcla étnica que incluye inmigrantes procedentes de Europa, Asia y América Latina.

Toronto cuenta con el puerto de Toronto, localizado próximo al centro de la ciudad.

Cuadro N³.11

Segmentación de Mercado

\begin{tabular}{|c|c|}
\hline \multicolumn{2}{|c|}{ SEGMENTACIÓN } \\
\hline GEOGRÁFICA & \multicolumn{1}{c|}{ Zona urbana de Toronto } \\
\hline DEMOGRÁFICA & $\begin{array}{c}\text { Hombres y Mujeres entre } 30 \text { a } 50 \text { años que } \\
\text { tengan problemas de obesidad o cuyos hijos } \\
\text { los tengan, así también como deportistas }\end{array}$ \\
\hline SOCIO ECONÓMICA & $\begin{array}{c}\text { Profesionales o amas de casa con un ingreso } \\
\text { de USD 56,000 y de los sector A y B }\end{array}$ \\
\hline CONDUCTUAL & $\begin{array}{c}\text { Personas con problemas de sobrepeso u } \\
\text { obesidad, o preocupados por mantener una } \\
\text { buena salud, ya sea la del mismo individuo o } \\
\text { la de sus familiares }\end{array}$ \\
\hline PSICOGRÁFICA & $\begin{array}{c}\text { Estilo de vida sedentario, preocupados por la } \\
\text { conservación del ecosistema }\end{array}$ \\
\hline
\end{tabular}

\subsubsection{Tendencias de Consumo}

Se considera que el mercado de alimentos orgánicos en Canadá ha crecido en la última década a un ritmo del 15-20\% anual, por lo que, se concluye que definitivamente existe un número creciente de canadienses, quienes se preocupan cada vez más por los beneficios de las dietas saludables y nutricionales. Esta tendencia incrementará la demanda por alimentos que contribuyan al bienestar y a mejorar la salud. 
Aproximadamente el $64 \%$ de los consumidores considera que los productos orgánico son mejores; y el $68 \%$ está dispuesto a pagar por ellos un sobreprecio de por lo menos $10 \%$, ya que este tipo de productos tienen un precio superior al de los mismos elaborados de manera convencional, justificados por las características y beneficios de los mismos.

El consumidor canadiense está bien informado, debido a que la educación está relacionada con la salud por medio de los conocimientos de los efectos de la dieta en la salud, por lo que existe una tendencia de compra hacia productos menos manipulados industrialmente y cuyos valores nutritivos sean evidentes al tacto, vista y sabor ${ }^{48}$.

\subsection{Mix Comercial de la competencia}

\subsubsection{Producto}

Ecuador cuenta con plantaciones propias de banano orgánico y convencional, cuyos cultivos son trabajados directamente por los agricultores. Se estima que la mayor parte de la superficie cosechada de banano posee plantaciones tecnificadas y con certificaciones de estándares internacionales de calidad como las normas ISO, HACCPP, Rainforest Alliance y GLOBALGAP.

En cuanto a la presentación, el banano es embalado en cajas de cartón, politubo y/o cluster bag con un peso neto por caja de $18.14 \mathrm{~kg}$ y un peso bruto de $20 \mathrm{~kg}$.

Las dimensiones de las cajas son de $35 \mathrm{~cm}, 40 \mathrm{~cm}$ y $51 \mathrm{~cm}$ de altura, ancho y largo, respectivamente.

Ecuador cuenta con una disponibilidad de oferta exportable de banano durante todo el año.

\subsubsection{Precio}

El precio en el mercado de destino depende de varios factores, entre ellos: la lejanía o cercanía al mercado exportador, del cual depende el costo de flete y

\footnotetext{
${ }^{48}$ Ministerio de Comercio Exterior y Turismo. "Plan Operativo de Mercado Canadá".
} 
transporte, los aranceles, los trámites legales y fitosanitarios, entre otros. Además, influye la valorización que vaya adquiriendo el producto ante los consumidores en vista de sus factores nutricionales, sociales, étnicos, etc. $Y$ por supuesto, depende también del volumen de producto que se exporte.

El valor de la caja de banano ecuatoriano de $18,4 \mathrm{~kg}$ en el mercado internacional preocupa al sector exportador, que lo cataloga de muy alto frente a los de sus competidores, y por ello pide una revisión de precios de la fruta con toda la cadena productiva y el gobierno. ${ }^{49}$

\subsubsection{Plaza}

Actualmente el $50 \%$ del banano se comercializa a través de supermercados, mientras hace 9 años solo era el 13\%. Este porcentaje puede cambiar fácilmente.

El mercado canadiense cuenta con distintos puntos de venta, a través de los cuales se suministran productos alimenticios. Sin embargo, se hace énfasis en los supermercados, debido a la estrategia de distribución de Ecuador.

Los supermercados disponen de un gran número y variedad de productos adaptados a las necesidades de los consumidores. Estos pueden ser cadenas (4 o más establecimientos) o pueden ser de carácter independiente. A diferencia de la segunda, la primera cuenta con marcas propias, servicios adicionales y un tamaño superior. Asimismo, en el año 2015, el 82\% de las ventas totales en alimentación tuvieron lugar en este canal.

\subsubsection{Promoción}

Se programa la llegada de misiones de compradores canadienses, quienes se reúnen con comerciantes ecuatorianas para visitar las plantaciones y constatar las capacidades productivas.

\footnotetext{
${ }^{49}$ Diario El Universo. "Exportadores de banano pìden revisión de precio".
} 
Además de esto, ProEcuador, junto con AEBE, organiza una Rueda de Negocios del Foro Internacional del Banano, en la cual se reúne a exportadores de banano. Dicho Foro se llevó a cabo del 12 al 15 de Mayo del 2015, en la ciudad de Guayaquil.

El objetivo del foro es promover la colaboración entre las múltiples partes implicadas de forma que se produzcan resultados prácticos para la mejora de la industria bananera.

La Asociación de Exportadores de Banano del Ecuador (AEBE) indica que estuvieron presentes productores, exportadores ecuatorianos y extranjeros, empresas de cartón y de plástico, certificadoras e insumos agrícolas; además de compañías navieras, importadores y representantes de cadenas internacionales de supermercados.

Esta edición contó con la participación de compradores de diversos países, entre los cuales estaba Canadá.

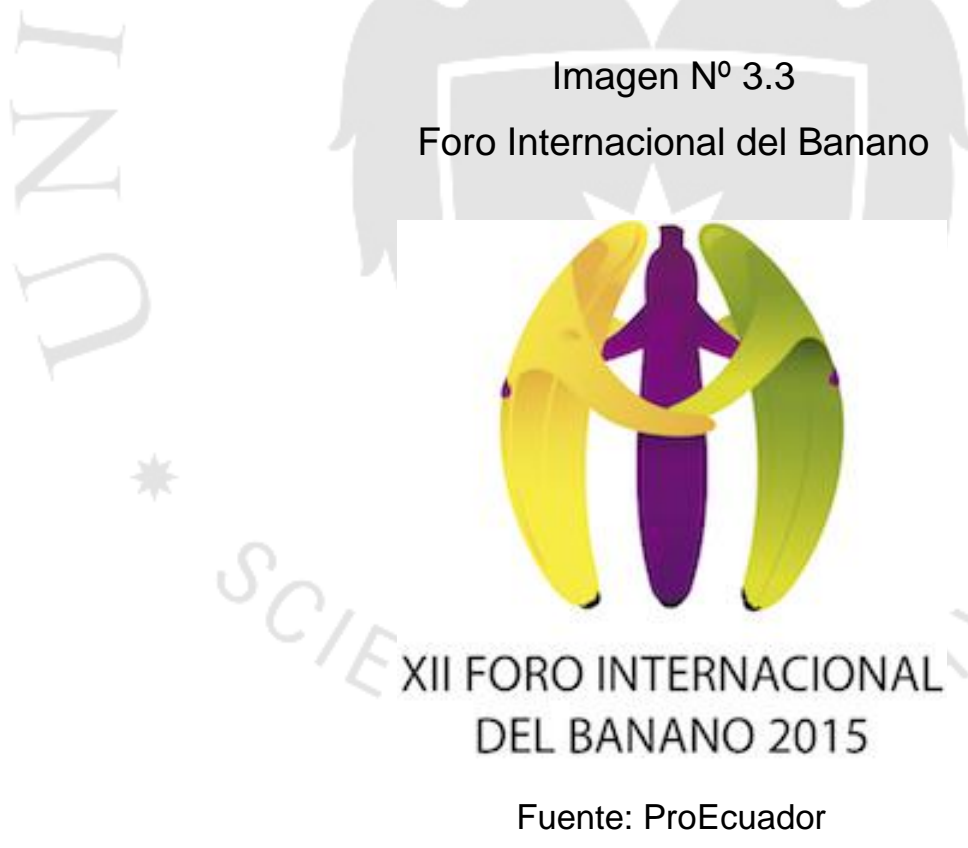

AEBE cuenta con una página web, en la cual los usuarios pueden hacer publicaciones sobre su empresa, la cual está relacionada con el cultivo, importación, exportación y comercialización del banano. El portal atrae un promedio de 10 mil usuarios por mes, tanto de Ecuador como del extranjero y cuenta con noticias diarias del ámbito nacional e internacional, estadísticas bananeras nacionales, publicaciones para el gremio bananero, listado de 
oportunidades de negocio, y demás artículos de interés para los socios de AEBE y usuarios que visitan diariamente el portal en busca de información precisa y útil.

\subsection{Tendencia de la Competencia}

En busca de mejorar las ventas al exterior de pequeños y medianos productores de banano y la iniciativa de estos por consolidarse, ProEcuador está impulsando la creación de un consorcio de exportadores con certificaciones de Comercio Justo como manera alternativa de comercio.

Esto representa una oportunidad para que los productores consoliden tanto el volumen de la oferta exportable y la estructura organizacional. Además, brinda la opción de expandir sus mercados, buenas condiciones de trabajo y costos de producción sostenible.

De este modo, y gracias a las certificaciones de Fair Trade, más de dos mil familias de las provincias de El Oro, Azuay y Guayas serán beneficiadas, ya que el acuerdo se enfoca en proporcionar un mejor nivel de vida.

La productividad pasó de 1300 a 1700 cajas por hectárea, porque los pequeños y medianos productores están aplicando técnicas de renovación de suelo y plantando variedades de banano más productivas.

Cuando comenzó el 2015, los bananeros no esperaban un buen año. Las ventas habían caído en relación al año anterior. Sin embargo, el escenario se tornó positivo debido a que en la temporada alta el comportamiento de la demanda sobrepasó la expectativa de los comercializadores.

Distintos medios señalan que el 2016 será un año complicado para la exportación de este producto en Ecuador, como consecuencia de la debilidad del mercado ruso (al cual destina el $95 \%$ de sus bananos) y la amenaza por el fenómeno del Niño.

\subsubsection{Análisis FODA de la Competencia}


Imagen № 3.4

Análisis FODA de Ecuador

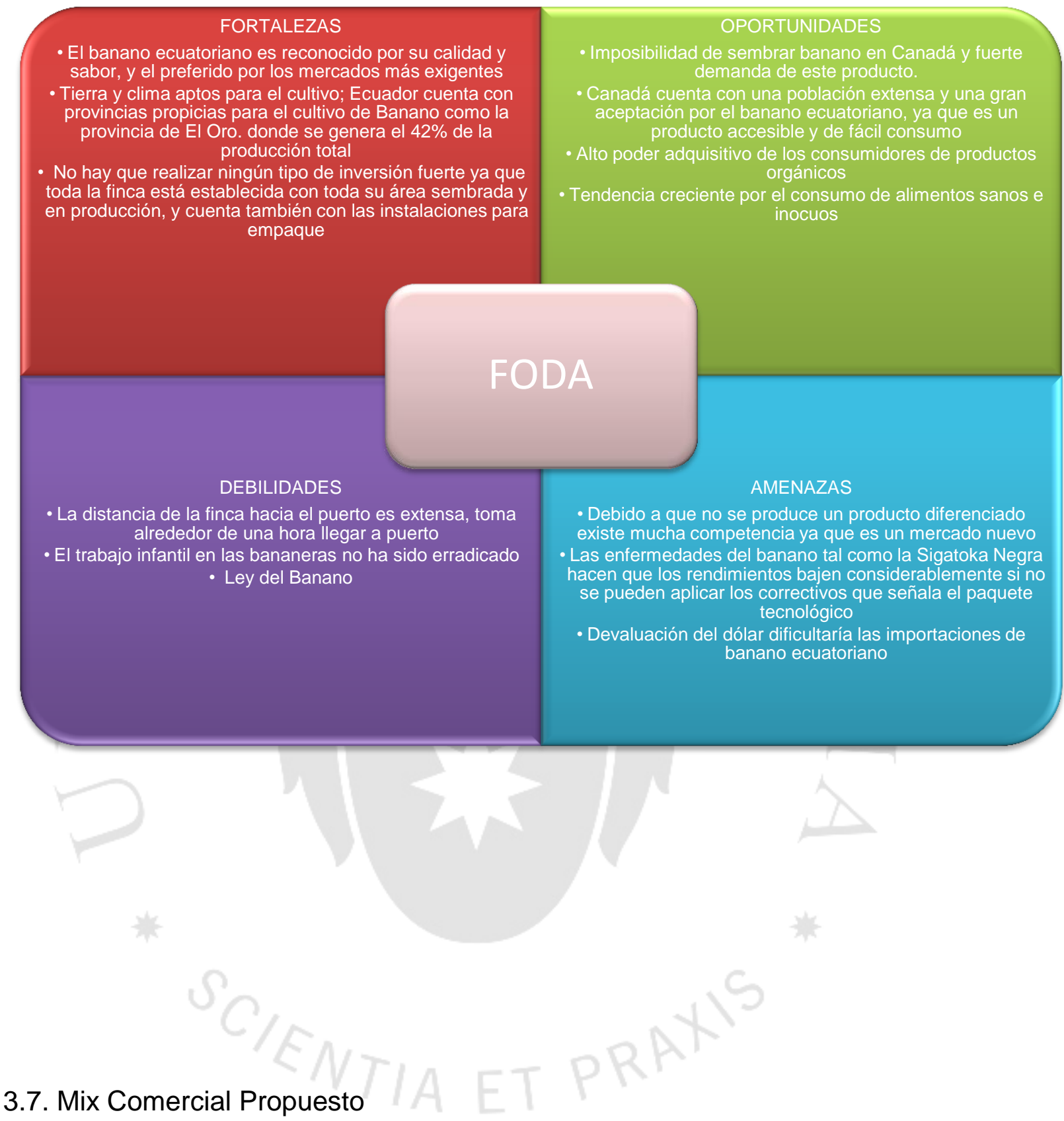

\subsubsection{Producto}

Dentro de la amplia variedad de banano, el plan de negocios contempla la viabilidad de exportar banano orgánico, como respuesta a la creciente demanda del mercado internacional por productos que impacten de manera positiva en la preservación del medio ambiente. Éste contará con certificación orgánica y de comercio justo, diferenciándose así de la competencia. 
Se exportarán bananos orgánicos en un contenedor de 40 pies, el cual contendrá 1080 cajas de cartón corrugado, 20 pallets estándar debidamente certificados, 54 cajas por pallet, cada caja tendrá un peso aproximado promedio de 18 kilogramos, lo que equivale a 19,440 kilogramos por contenedor.

\subsubsection{Almacenamiento}

Las condiciones óptimas de almacenamiento en cuanto a temperatura y nivel de humedad relativa son de $14^{\circ} \mathrm{C}$ y $85 \%-90 \%$, respectivamente.

\subsubsection{Embalaje}

Para el embalaje de la fruta se utilizan cajas de cartón, las cuales cuentan con unos orificios estratégicamente ubicados a fin de facilitar la circulación de aire frío en los contenedores.

Estas deben cumplir con los siguientes criterios de calidad:

- Cajas de cartón triple corrugado de $18.4 \mathrm{~kg}$. Incluye una lámina de papel kraft y una funda de polietileno.

- Cajas de cartón de tipo telescópico con un peso aproximado de $18 \mathrm{~kg}$. 
Imagen $\mathrm{N}^{\circ} 3.5$

Embalaje de Banano

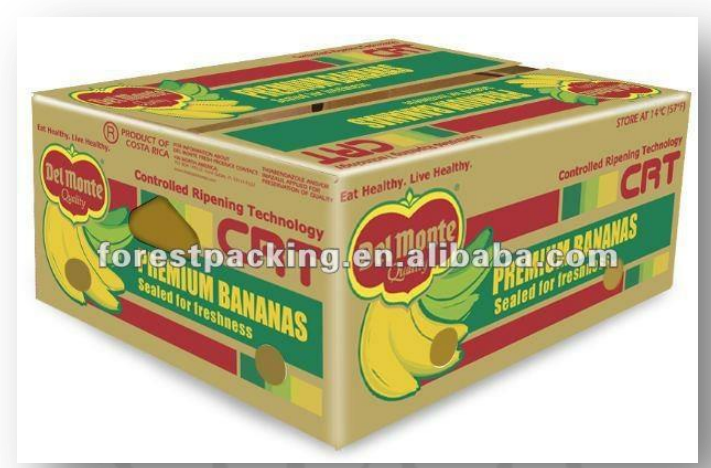

Fuente: Alibaba

Las ventajas de este embalaje es que permite brindar el peso exacto del producto debido a lo ligero que son las cajas, pueden ser recicladas al $100 \%$, protegen al producto de los posibles daños que podrían ocurrir en la manipulación y no son costosas, ya que existe un gran número de proveedores de las mismas.

El tamaño de las cajas será de 50 centímetros de largo por 40 centímetros de ancho por 40 centímetros de alto, de esta manera calzan 6 embalajes en la base de cada pallet, con lo que se aprovecha el $100 \%$ de la superficie disponible.

Cuadro $\mathrm{N}^{\circ} 3.12$

Dimensiones del Embalaje

\begin{tabular}{|c|c|c|}
\hline CALIBRE & MÍNIMO & MÁXIMO \\
\hline Diámetro (grados) & 39 grados & 46 grados \\
\hline Longitud (pulgadas) & $8 "$ & $11 "$ \\
\hline
\end{tabular}

Fuente: Sistema Integrado de Información de Comercio Exterior (SIICEX)

\subsubsection{Envase}

El tipo de fundas más utilizado es al vacío con el fin de disminuir la tasa de respiración de la fruta durante el transporte marítimo. 


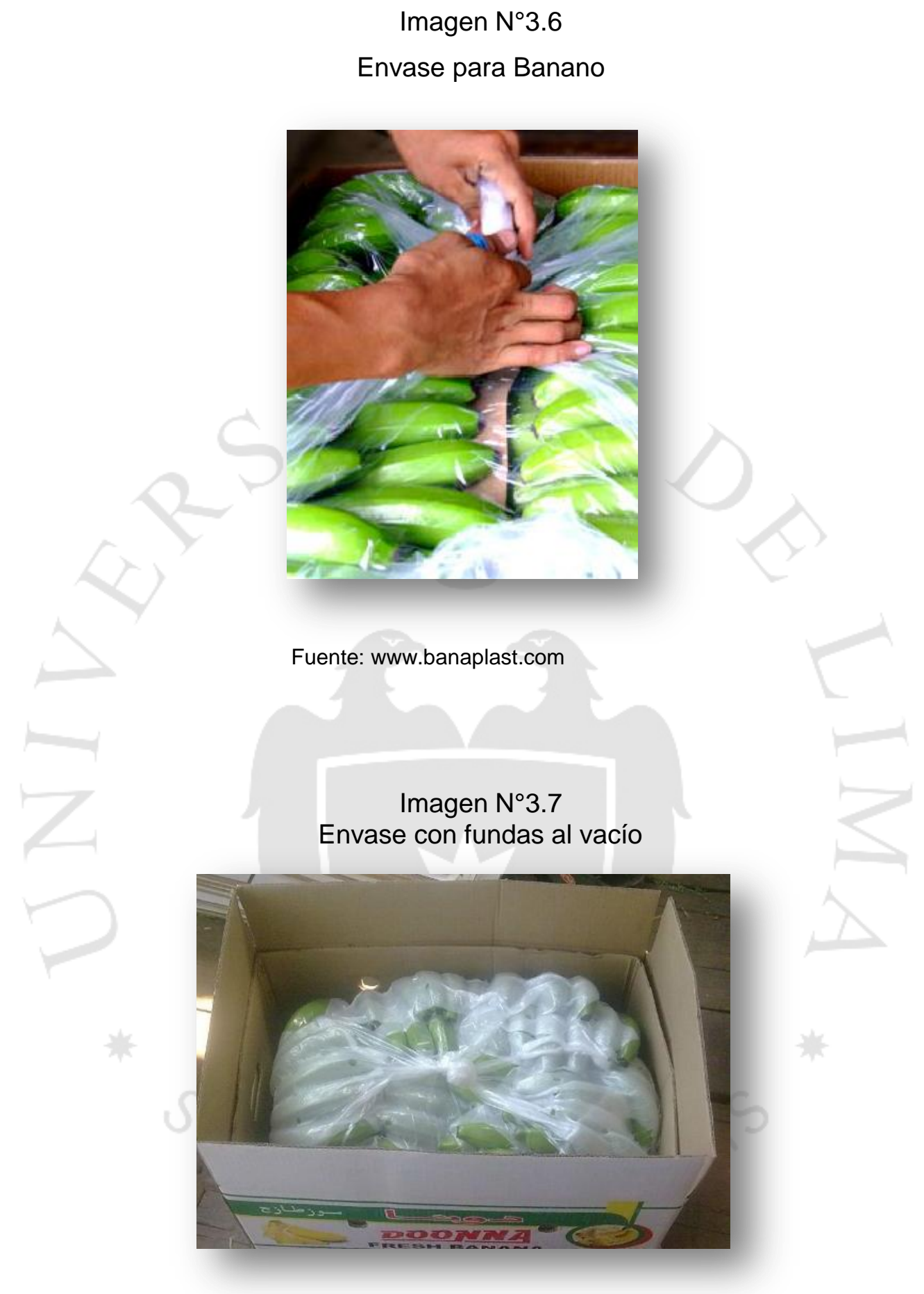

Fuente: www.solostocks.cl

A continuación se detallan las especificaciones referentes al tipo de fundas plásticas, ya sean al vacío, politubo o polipack. 


\section{Cuadro №3.13}

Especificaciones de Fundas Plásticas

\begin{tabular}{|c|c|c|c|}
\hline $\begin{array}{c}\text { ESPECIFICACIONES } \\
\text { (PULGADAS) }\end{array}$ & POLITUBO & POLIPACK & $\begin{array}{c}\text { AL VACíO (22 X } \\
\text { U) }\end{array}$ \\
\hline Ancho & $38.50 "$ & $38.50 "$ & $38.50 "$ \\
\hline Largo & $52.00 "$ & $50.00 "$ & $48.00 "$ \\
\hline Grosor & $0.0007 "$ & $0.0007 "$ & $0.0015^{\prime \prime}$ \\
\hline
\end{tabular}

Fuente: Sistema Integrado de Información de Comercio Exterior (SIICEX)

\subsubsection{Precio}

La estrategia de precio que se empleará será la de descreme, que, con un precio alto trata de obtener mejores beneficios a corto plazo. Esta estrategia es la más adecuada, ya que se trata de un producto exclusivo y existe un segmento dispuesto a pagar un precio alto.

La estrategia de precio será complementada con la estrategia de fijación del precio de exportación, cuyo precio parte de los precios de mercado, con el objetivo de no brindar el banano a un precio mayor que el del mercado.

Al calcular el precio FOB, se determinó que éste será de USD 0.758 por caja.

\subsubsection{Política de Pago a Proveedor}

El pago al productor de banano orgánico, CEPIBO, se realizará al contado, proporcionándole un adelanto del $30 \%$ del valor de la mercadería y el resto se abonará entre 15 y 20 días posteriores a dicho adelanto, sujeto a las negociaciones que se efectúen con el proveedor. 


\subsubsection{Política de Cobro a Comprador}

Al tratarse de mercadería perecible, le medio de cobro más conveniente es un adelanto parcial o total de parte del comprador; sin embargo, al todavía no consolidarse una relación entre comprador y vendedor, puede que no se logre acordar utilizar este medio de pago.

En caso de que esto ocurriese, la segunda opción más favorable en términos de seguridad de recibir el pago correspondiente por la venta del producto sería una cobranza documentaria, con la cual el pago se realiza contra documentos.

La siguiente opción en orden de prioridad y grado de riesgo es el pago por parte de Loblaw a través de una transferencia telegráfica, también conocida como transferencia internacional $u$ orden de pago. Este medio constituye el medio de pago más riesgoso para "Golden Banana S.A.C", por lo que la empresa definirá sus esfuerzos por llegar a un consenso con el comprador por escoger como medio de pago una cobranza documentaria, lo cual es lo más factible en un escenario realista.

\subsubsection{Política de Descuento}

La empresa "Golden Banana S.A.C" no aplicará políticas de descuento durante los 5 años de funcionamiento, debido a que primero enfocará sus esfuerzos en recuperar la inversión y luego comenzar a tener utilidades.

\subsubsection{Plaza}

\subsubsection{Cobertura del Mercado}

El producto se comercializará específicamente en la ciudad de Toronto, debido a que se considera a esta ciudad como un mercado potencial, debido a los 
altos índices de obesidad y problemas de salud, además de ser un mercado relativamente nuevo y de contar con acciones gubernamentales que promuevan el consumo de este producto.

El sistema de distribución, que logrará insertarnos en puntos clave de venta, será la venta directa al supermercado "Loblaw", debido a que es uno de los grandes protagonistas de la expansión de la venta de orgánicos en las grandes cadenas de distribución en Canadá y cuenta con una línea de productos orgánicos "President's Choice Organic", sobre todo en las zonas del centro y el este del país. Precisamente en el este del país el $85 \%$ de la distribución de productos orgánicos se encuentra concentrado en dos grande cadenas de alimentación: Loblaw y Sobey. Loblaw se constituyó como empresa en el año 1919 y en la actualidad presenta ventas anuales de USD 32 billones y cuenta con 135, 000 empleados.

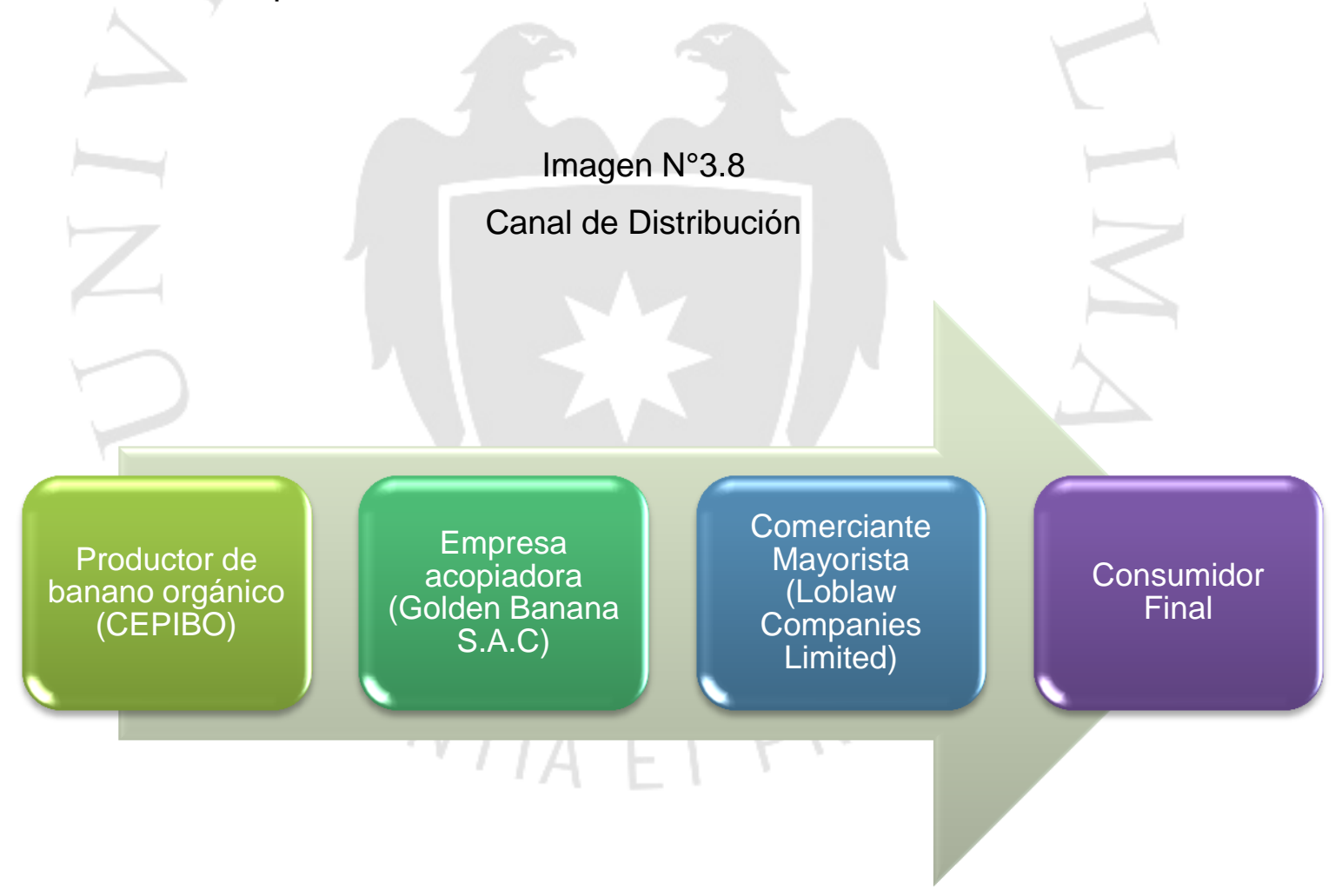


Cuadro N`3.14

Contacto Loblaw

\begin{tabular}{|c|c|}
\hline \multicolumn{2}{|c|}{ INFORMACIÓN DEL CONTACTO } \\
\hline Nombre de Contacto & Jorge Ciurlizza \\
\hline Cargo & Senior Manager Offshore Procurement \\
\hline Teléfono & 9054592500 Ext. 613521 \\
\hline E-mail & jorge.ciurlizza@loblaw.ca \\
\hline Página Web & www.loblaw.ca \\
\hline
\end{tabular}

\subsubsection{Logística}

El banano orgánico se enviará a Canadá por vía marítima en un contenedor refrigerado (Reefer), siendo esta la principal vía de transporte de exportación de banano del Perú al mundo. El transporte marítimo albergó, en el 2014, USD $118,085,000$ y un peso neto de 157,973 toneladas, presentando un incremento de $32.81 \%$ en cuanto a valor FOB y de $27.36 \%$ en cantidad, con respecto al 2013. Estas cifras revelan que el $99 \%$ de las exportaciones peruanas en el 2014 se concentraron en la vía marítima como medio de transporte.

El puerto de embarque será el puerto de Paita ubicado en el departamento de Piura, debido a la cercanía que mantiene con el Valle de Chira, la cual es de aproximadamente de $50 \mathrm{~km}$.

El puerto de destino recomendado es Toronto, Canadá.

La línea naviera Hamburg Sud cuenta con salidas del puerto de Paita a Toronto cada 7 días sin transbordo, motivo por el cual se recomienda contratar a esta empresa. El flete correspondiente asciende a USD 2,412.

En el caso de que el comprador elija esta opción, podrá contactarse directamente con el siguiente contacto: 
Cuadro N`3.15

Contacto Hamburg Sud

\begin{tabular}{|c|c|}
\hline \multicolumn{2}{|c|}{ INFORMACIÓN DEL CONTACTO } \\
\hline Nombre de Contacto & Rafael del Solar \\
\hline Cargo & Sales Manager \\
\hline Teléfono & $(51$ 1) 610-7500 ext: 518 \\
\hline Página Web & www.hamburgsud-line.com \\
\hline
\end{tabular}

Por otro lado, se dispone de una serie de navieras que también salen del puerto de Paita y que llegan a Toronto de manera semanal. A continuación se hace referencia a ellas y su página web.

Cuadro №3.16

Líneas Navieras - Paita

\begin{tabular}{|c|c|}
\hline LÍNEA NAVIERA & PÁGINA WEB \\
\hline CMA CGM & hwww.cma-cgm.com \\
\hline EverGreen & www.greenandes.com.pe \\
\hline MAERSK & www.maerskline.com \\
\hline
\end{tabular}

Fuente: http://www.siicex.gob.pe/rutas/frmRutasSimulador.aspx

3.7.4. Promoción

Cuadro № 3.17

Presupuesto de Promoción

\begin{tabular}{|c|c|c|c|c|c|c|}
\hline \multicolumn{6}{|c|}{ PRESUPUESTO DE PROMOCIÓN DE VENTAS DE BANANO ORGÁNICO } \\
\hline Instrumento/Año & 0 & 1 & 2 & 3 & 4 & 5 \\
\hline Identidad Visual & 300 & 0 & 0 & 0 & 0 & 0 \\
\hline Publicidad & 900 & 700 & 700 & 700 & 700 & 700 \\
\hline RRPP & 0 & 0 & 0 & 0 & 16,255 & 20,000 \\
\hline TOTAL & $\mathbf{1 , 2 0 0}$ & $\mathbf{7 0 0}$ & $\mathbf{7 0 0}$ & $\mathbf{7 0 0}$ & $\mathbf{1 6 , 9 5 5}$ & $\mathbf{2 0 , 7 0 0}$ \\
\hline
\end{tabular}


La identidad visual se refiere a la estética de la comunicación y será la manifestación física de la marca. El nombre del producto es un elemento básico de identidad y en este caso cuenta con las características de un buen nombre, debido a que es breve, fácil de recordar y con connotaciones positivas.

El logotipo proyecta una imagen con la que se identifica el producto y se diferencia de la competencia. Se busca que la marca contribuya a mejorar la imagen del país.

El monto destinado por concepto de publicidad corresponde tanto a la creación de la página web, como al "hosting".

El gasto en relaciones públicas está compuesto por el desembolso correspondiente a las ferias a las que se participará. Durante el segundo y tercer año se participará en la feria Expo Alimentaria y en el cuarto y quinto se proyecta la asistencia a SIAL Canadá.

Este centro de contactos comerciales permitirá un número de encuentros con clientes potenciales, difíciles de alcanzar por otro medio.

\subsubsection{Mensaje}

El mensaje de la promoción del producto se dirige principalmente a transmitir tanto a los consumidores regulares como a los potenciales, los beneficios del consumo de banano como una fuente importante de vitaminas y minerales indispensables para el buen funcionamiento y desarrollo del cuerpo humano, además de presentarlo como un método para la prevención de enfermedades.

Asimismo, el mensaje tiene un enfoque hacia una nueva dieta más saludable que contribuya a reducir los índices de obesidad que se presencian en Canadá. 


\subsubsection{Posicionamiento}

Golden Banana S.A.C busca posicionarse en el mercado canadiense bajo la imagen de una empresa confiable que brinda un producto de calidad que cumple con las normas y regulaciones estipuladas por parte del mercado de destino, satisfaciendo y superando las expectativas de los clientes.

Así, logrará ocupar un lugar distintito en la mente de los consumidores con relación a la competencia.

Por otro lado, se busca posicionar al banano orgánico como un elemento indispensable de la dieta de los consumidores a través de una promoción enfocada en el consumo de productos sin químicos y en la responsabilidad ambiental.

3.8. Requisitos de Acceso al Mercado Canadiense ${ }^{50}$

La Canadian Food Inspection Agency es la institución encargada de aplicar los requerimientos necesarios para que los alimentos ingresen al mercado de Canadá. A continuación se detallan las reglamentaciones, certificados y documentos que constituyen un requerimiento necesario para el acceso al mercado canadiense.

\subsubsection{Reglamentaciones}

Las reglamentaciones que debe cumplir el banano orgánico son las siguientes:

\footnotetext{
50 Sistema Integrado de Información de Comercio Exterior (SIICEX). "Estudio para la Identificación de Requisitos, Acceso a Mercado y Regulaciones para el Ingreso de Productos Alimenticios a Canadá"
} 
- Reglamentación para Productos Fresco de la Ley de Productos Agrícolas de Canadá

- Reglamentación para empaquetado y etiquetado de la Ley Consumer Packaging and Labelling Act

- Reglamentación de Alimentos y Medicamentos de la Ley Food and Drugs Act

Estas regulaciones cubren aspectos de calidad, etiquetado, empaquetado, clasificación, requisitos de salud y de seguridad.

\subsubsection{Certificados:}

Los certificados con los que se debe contar para la exportación del producto son:

- Certificado de Origen: emitido por la Cámara de Comercio de Lima, que acredita y garantiza la procedencia de las mercancías, permitiendo acogerse a los beneficios derivados de las preferencias arancelarias que otorga Canadá en virtud del TLC.

- Certificado Fitosanitario: el banano orgánico está sujeto a la presentación de dicho certificado, ya que es una medida aplicada por el mercado de destino para prevenir el ingreso de plagas.

- Certificado del Régimen Orgánico Canadiense: Confirmación de Equivalencia que permite a los productos certificados ingresar a Canadá utilizando la denominación "orgánico" y el logo "bio" de Canadá.

- Certificado de Inspección: requisito indispensable emitido por la CFIA con el fin de comprobar que los productos que ingresan al territorio canadiense cumplen con los requisitos mínimos de ingreso. Dentro de los aspectos que se evalúan se encuentran la calidad, el etiquetado y embalaje, y si el producto está libre de plagas o enfermedades.

\subsubsection{Regulaciones}


En cuanto a las regulaciones de etiquetado de productos frescos, se presentan las exigencias más importantes a considerar tanto para el etiquetado como para el embalaje, estos son:

Etiquetado de productos fresco pre-empacados:

- La información debe presentarse tanto en inglés como en francés

- Nombre genérico del producto y variedad.

- Cantidad neta por número, peso o volumen. En Canadá se utiliza el sistema métrico internacional.

- Nombre y dirección del productor o de la persona que comercializa el producto en Canadá.

- País de origen.

- Tabla de contenido nutricional.

- Fecha de caducidad

Embalaje de productos frescos:

- La información puede presentar en inglés o en francés.

- Nombre común del producto.

- Cantidad neta.

- Nombre completo y dirección del productor o empacador del producto.

- País de origen.

\subsubsection{Documentación}

La documentación requerida para poder realizar la operación de exportación se detalla a continuación:

- Factura comercial

- Conocimiento de embarque

- Certificado de origen

- Certificado fitosanitario

- Certificado sanitario 
- Lista de Empaque o "packing list"

- Declaración de Aduanas

- Orden de Embarque

3.9. Pautas de Negociación entre Perú y Canadá ${ }^{51}$

Cualquiera que realice una negociación por primera vez con un país extranjero, experimentará un sentimiento de desorientación, que se explica sobre todo por las diferencias culturales.

Para poder entablar negociaciones de manera correcta con Canadá, es propicio conocer la cultura y los factores que influyen en la negociación de manera íntegra. No basta con saber negociar precios y cantidades, se requiere de conocimiento sobre modales y costumbres, actitudes y valores, educación, etc.

El desconocimiento perjudica la capacidad negociadora, pudiendo condicionar el éxito de la negociación.

Por eso, se analizará el modelo de clasificación cultural cuyo objetivo es familiarizarse con los aspectos culturales que más afectan a una negociación entre personas de diferentes países, desarrollando un estilo de negociación adaptado a estos diferentes factores.

Este modelo presenta las cinco variables consideradas como las más significativas en una negociación, las cuales se expondrán en el siguiente punto.

3.9.1. Análisis de las cinco variables del modelo de clasificación cultural ${ }^{52}$

En cuanto al uso del tiempo, los canadienses lo consideran un recurso muy limitado, que debe utilizarse de manera eficaz y rentable - "Time is Money" es una frase acuñada ahí, por lo que se requiere ser puntual. Por otro lado, las agendas de los ejecutivos están llenas de citas y plazos que deben cumplirse inexorablemente.

\footnotetext{
${ }^{51}$ Linklater, Diana. Apuntes de clase del curso Taller de Negociación. 52 lbíd.
} 
En lo que respecta a las relaciones personales y profesionales, las reuniones empiezan con una breve conversación informal en la que se tocan temas personales y en seguida se pasa a temas profesionales. Establecer relaciones personales más estrechas no se considera un método efectivo para mejorar la posición negociadora, ya que estas reciben poca atención y son difíciles de mantener. Por otra parte, los negociadores canadienses buscan proveedores confiables, con experiencia y capacidad de mantener relaciones a largo plazo.

La tercera variable corresponde a las pautas de comunicación, en la que es sustancial resaltar el valor otorgado a la libertad de opinión y a la aceptación de posturas enfrentadas y desacuerdos. El lenguaje utilizado se caracteriza por ser claro y directo, tratando de ser precisos y obtener resultados rápidos y por predominar la comunicación verbal sobre la no verbal. Es recomendable utilizar objetivos que resalten aspectos como la calidad o garantía y mantener contacto directo a los ojos, ya que es apreciado como un signo de sinceridad, interés y honradez. Por lo general, los canadienses no hacen interrupciones y tienen mucho sentido del humor.

Debido al elevado nivel de competitividad existente en la cultura canadiense, los negociadores se jactan de ceder lo menos posible. El enfoque de la negociación es secuencial, es decir, una vez que se ha tomado una decisión sobre un aspecto del acuerdo, se pasa al siguiente, negociando los temas a tratar uno por uno. Estas particularidades conciernen al cuarto factor: Concesiones y Acuerdos.

La última variable a describir es la "Toma de Decisiones" en la que se puede concluir que el perfil de los empleados de una empresa de Canadá se asocia a un área o función específica para la que se definen objetivos y responsabilidades, presentando una ventaja para el negociador extranjero, porque tendrá la posibilidad de establecer relación con la persona que tiene capacidad de negociar los asuntos acordados. Sin embargo, el poder de decisión se encuentra bastante descentralizado, ya que las estructuras empresariales tienden a ser planas con el fin de eliminar procedimientos burocráticos y dar poder a los empleados. 


\subsubsection{Consideraciones para negociar con Canadá}

En cuanto a las negociaciones, al momento de presentarse o referirse a alguna persona durante la negociación, no se acostumbra a emplear los títulos profesionales, más bien se utiliza Mr. o Ms, seguido del apellido. Por el contrario, en una conversación telefónica es habitual utilizar el nombre propio. ${ }^{53}$ En lo que respecta a la vestimenta, los canadienses son conservadores; por consiguiente, no se aconseja utilizar ropa de última moda ni tampoco gran cantidad de accesorios. ${ }^{54}$

\section{Cuadro N`3.18}

Principales Días Festivos

\begin{tabular}{|c|c|}
\hline Fecha & Festivos \\
\hline Enero 1 & Año Nuevo \\
\hline Abril 10 & Viernes Santo \\
\hline Mayo 18 & Fiesta de la Reina \\
\hline Julio 1 & Día de Canadá \\
\hline Septiembre 7 & Día del Trabajo \\
\hline Octubre 12 & Acción de Gracias \\
\hline Noviembre 11 & Día del Recuerdo \\
\hline Diciembre 25 & Día de Navidad \\
\hline Diciembre 26 & Día de San Esteban \\
\hline
\end{tabular}

Fuente: World Travel Guide

\subsubsection{Conocimientos Básicos del Mercado Canadiense $e^{55,56}$}

\footnotetext{
${ }^{53}$ Ministerio de Comercio Exterior y Turimo. "Plan Operativo de Mercado Canadá".

${ }^{54}$ Promoción de Turismo, Inversión y Exportaciones (PROEXPORT COLOMBIA). "Guía para exportar a Canadá".

${ }^{55}$ Ministerio de Comercio Exterior y Turismo. "Plan Operativo de Mercado Canadá".
} 
Canadá es el país con mayor extensión territorial del mundo luego de Rusia con casi 10 millones de $\mathrm{km}^{2}$. Sin embargo, con una densidad promedio de 3.6 habitantes por $\mathrm{km}^{2}$, es el país que presenta la densidad poblacional más baja de todos los países industrializados, situándose en el puesto $36 .{ }^{57}$ La moneda oficial es el dólar canadiense, que equivale a 0.77 dólares americanos.

Ha sido el primer país del mundo en adoptar una política de multiculturalismo, ya que su población ha experimentado un crecimiento continuo debido a las olas sucesivas de inmigrantes, que se han instalado en el país. Los idiomas oficiales son el inglés y el francés, siendo el primero la lengua materna de una mayor parte de la población en comparación de la segunda. Entre los idiomas no oficiales más hablados se encuentran el chino, italiano, alemán y el español. ${ }^{58}$

La religión predominante es el cristianismo, seguida por el agnosticismo y luego por el islamismo y el judaísmo. ${ }^{59}$

Canadá tiene una economía de mercado caracterizada por un alto nivel de comercio exterior, debido a sus políticas basadas la liberalización comercial, y por un sólido marco institucional junto con una gran estabilidad política y altos niveles de transparencia, lo que se traduce en una baja corrupción ${ }^{60}$.

\subsection{Potencial Punto de Negociación ${ }^{61}$}

La feria líder SIAL celebrada todos los años, desde el 2001, es el principal encuentro internacional de comercio exterior del sector alimentos.

En promedio, esta feria cuenta con la participación de 700 expositores representantes de 50 países y la visita de más de 13,000 interesados

\footnotetext{
${ }^{56}$ Promoción de Turismo, Inversión y Exportaciones (PROEXPORT COLOMBIA). "Guía para exportar a Canadá".

${ }^{57}$ lbíd.

${ }^{58}$ Stadistics Canada.

${ }^{59}$ lbíd.

${ }^{60}$ Foro Económico Internacional. "Reporte de Competitividad".

${ }^{61}$ Feria Sial Canadá.
} 
provenientes de 60 países durante los 3 días de duración. Esto contribuirá a la expansión de la red de contactos, ya que permite desarrollar nuevas relaciones comerciales a través del contacto directo con contrapartes potencialmente interesadas en el producto.

Debido a su envergadura, esta feria ofrece una excelente plataforma para iniciar negocios, una excelente oportunidad para hacer contactos de negocios en todo el mundo y una oportunidad única que permite distinguirse de la competencia a medida que se aprende de las ideas innovadores a la vez que se obtiene una visión sobre las últimas tendencias y los últimos avances de la industria.

Imagen $\mathrm{N}^{\circ} 3.9$

Logo de SIAL

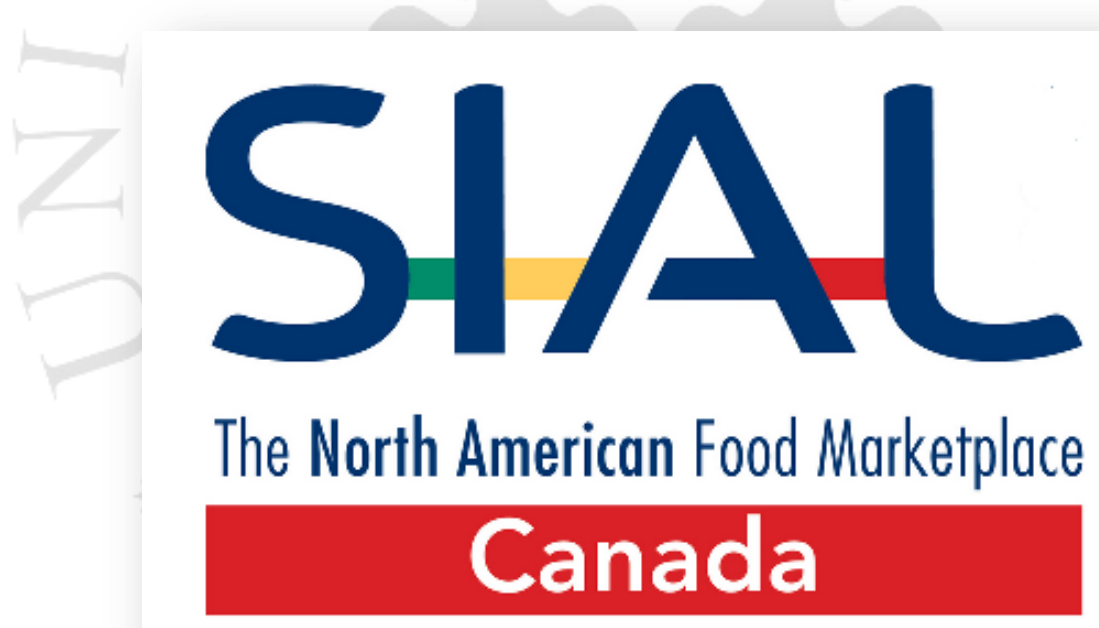

Fuente: www.sialcanada.com 


\section{CAPITULO IV: ESTUDIO TÉCNICO}

\subsection{Disponibilidad de insumos}

\subsubsection{Zonas Productoras Nacionales}

La producción de banano en sus distintas variedades se ubica en los departamentos de Lambayeque, La Libertad y Piura, sin embargo, las áreas de producción de banano orgánico tienen lugar, esencialmente en el Valle de Chira, provincia de Sullana (Piura), donde se concentra el $40 \%$ del total producido.

\section{Imagen №4.1}

Zona de Producción de Banano en Perú

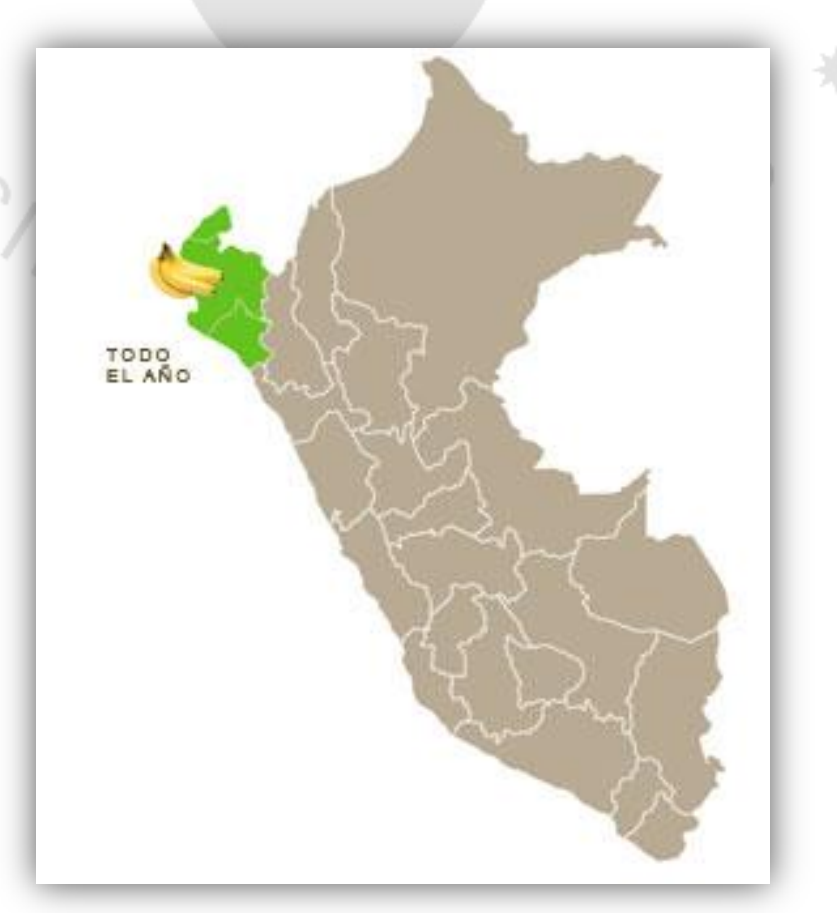


Estas zonas tienen ventajas competitivas debido a la ubicación en la costa del Perú, que permite beneficiarse de mejores propiedades organolépticas. Entre estas ventajas se pueden destacar el clima favorable y estable con relación a otros productores en el mundo que se ven frecuentemente afectados por huracanes, lluvias torrenciales e inundaciones con efectos sobre la producción; además de las buenas condiciones de suelo y menor incidencia de plagas y enfermedades.

Asimismo, se encuentran en zonas estratégicas debido a la cercanía a los puertos de Paita-Perú y Bolivar-Ecuador.

En Piura existen 4 mil 505 hectáreas de banano orgánico y más de 7 mil 413 hectáreas de plátano convencional.

Para efectos de acopio, se ha elegido, entre los productores certificados de banano orgánico del departamento de Piura, a la "Asociación de Pequeños Productores de Banano Orgánico, más conocida como CEPIBO. Esta empresa se encuentra conformada por 1,350 productores que trabajan desde el año 2003 bajo este mecanismo, en que cada agricultor trabaja un promedio de una hectárea y cuyo producto luego es exportado.62

Las exportaciones de esta asociación empezaron en el 2008, siendo estas de un contenedor mensual. Sin embargo, con el paso de los años esta cantidad se incrementó, tanto en número de contenedores, como en periodo de tiempo, que fue semanal, pasando así, en el 2009, a seis contenedores y en el 2010, entre ocho y nueve. Durante el 2011, las exportaciones de banano orgánico alcanzaron un número de entre 20 y 22 contenedores semanales ${ }^{63}$. Su participación en el último año, es decir, en el 2015 fue de $5.12 \%{ }^{64}$, lo que la

\footnotetext{
${ }^{62}$ Radio Programas del Perú (RPP) “El banano orgánico, una experiencia de exportación en Piura” 63 lbíd.

${ }^{64}$ Sistema Integrado de Información de Comercio Exterior (SIICEX)
} 
posiciona en el segundo puesto en cuanto a empresas peruanas exportadoras de banano orgánico.

Por otro lado, esta asociación fue declarada en el 2010, la Empresa Agroexportadora del Año y cuenta con certificaciones bajo los esquemas de producción orgánica y de comercio justo, como Fair Trade y GlobalGap, las cuales garantizan y refuerzan la calidad del banano no solo en el mercado local, sino también en mercados extranjeros. ${ }^{65}$

\subsection{2. Época de Producción}

El período de producción del banano orgánico se realiza todo el año, sin embargo, este periodo se puede dividir en tres etapas dependiendo del nivel de producción como se muestra a continuación.

\section{Imagen $\mathrm{N}^{\circ} 4.2$}

Nivel de Producción por Mes

\begin{tabular}{|c|c|c|c|c|c|c|c|c|c|c|c|c|}
\hline & Ene & Feb & Mar & Abr & May & Jun & Jul & Ago & Sep & Oct & Nov & Dic \\
\hline $\begin{array}{c}\text { Nivel de } \\
\text { Producción }\end{array}$ & & & & & & & & & & & & \\
\hline
\end{tabular}

\begin{tabular}{|l|l|}
\hline & Meses de alta producción \\
\hline & Meses de moderada producción \\
\hline & Meses de baja producción \\
\hline
\end{tabular}

\footnotetext{
${ }^{65}$ Ministerio de Agricultura. "Ministerio de Agricultura mejora la oferta tecnológica del banano orgánico".
} 
A pesar de que el mes de menor producción es el mes de julio $(5.9 \%$ de la producción total) $^{66}$, se tiene disponibilidad de bananos orgánicos durante los doce meses del año tanto para exportación como para consumo nacional.

Imagen $\mathrm{N}^{\circ} 4.3$

Ventana Comercial

\begin{tabular}{|c|c|c|c|c|c|c|c|c|c|c|c|}
\hline Ene & Feb & Mar & $A b r$ & May & Jun & Jul & Ago & Sep & Oct & Nov & Dic \\
\hline$\checkmark$ & $\nabla$ & $\nabla$ & $\nabla$ & $\nabla$ & $\nabla$ & $\nabla$ & $\checkmark$ & $\nabla$ & $\nabla$ & $\checkmark$ & $\nabla$ \\
\hline
\end{tabular}

Fuente: Sistema Integrado de Información de Comercio Exterior (SIICEX)

4.2. Proceso de producción de la exportación del Banano Orgánico

i) Cultivo: Exige características especiales de suelo y climatología que se presentan en el siguiente punto:" Requerimientos medioambientales".

ii) Siembra: Listo el terreno se elige el tipo de semilla y se determina la densidad con la que se quiere sembrar. Luego, se hace un hoyo donde se coloca la semilla y se aplican abonos y materia orgánica y se riega.

iii) Protección de la fruta

- Deshije: Dejar a cada planta con su hijo y su nieto (unidad de producción completa) para garantizar que el número y tamaño de los racimos por hectárea sea optimo y que la plantación se mantenga como un cultivo perenne.

- Embolse: Consiste en proteger el racimo con una funda o bolsa plástica de polietileno del ataque de plagas y resguardarlo de los cambios bruscos de temperatura.

- Desflore: Una vez que las manos cambian de posición hacia arriba, las flores blandas son retiradas de la punta del dedo.

\footnotetext{
${ }^{66}$ Ministerio de Agricultura.
} 
- Identificación de la edad de la fruta: consiste en utilizar una cinta del color correspondiente a la semana y amarrarla al racimo para poder llevar un inventario de la fruta.

- Desmane: Consiste en separar la mano más pequeña para que las demás se desarrollen mejor para cumplir las calidades exigidas.

- Desbacote: Consiste en retirar de la punta del vástago o raquis las flores masculinas para contribuir a aumentar la longitud, grosor y peso de los dedos de las manos restantes y también a la sanidad del racimo.

- Amarre: Consiste en amarrar dos cuerdas denominadas "vientos" de cada mata que tenga racimo, con el objetivo de evitar la caída de la planta por acción del viento o peso del racimo.

- Desvío del hijo: separar el hijo de la planta madre para evitar cualquier daño que pueda producrise por el roce de sus hojas.

- Deshoje: Consiste en eliminar las hojas secas, viejas y/o quebradas que puedan causar un deterioro en la calidad del racimo, o ser fuente de propagación de enfermedades y plagas.

- Recolección: El promedio de días para recolección se calcula en función de la lejanía entre el destino y el lugar de producción:

i. Cerca: se recolecta el producto pocos días antes de la maduración plena.

ii. Distancia intermedia: se recolecta racimo todavía verde y completamente crecidos.

iii. Lejos o periodo hasta comercialización amplio: se recolecta el producto cuando los dedos han llegado a $3 / 4$ del fruto.

- Procesamiento del banano para su comercialización.

- Garruchar: Etapa en donde llega la fruta que viene del campo a través del cable vía desde los lotes. Los racimos son 
contados y calibrados para verificar si la fruta tiene el grado de madurez necesario.

- Desflore: Proceso de quitar la flor del racimo para que la fruta no pase con ningún residuo de flor a la próxima etapa.

- Área de selección: seleccionar y clasificar la fruta con estrictos parámetros de calidad para poder cumplir con las necesidades de los clientes.

- Desmane: eliminan dedos que presentan defectos de calidad.

- Lavado: primero se procede a lavar cuidadosamente cada mano y se eliminan las defectuosas, luego permanece de 12 a 20 minutos dentro del agua para que se elimine todo látex 0 leche.

- Área de sello: proceso para etiquetar la fruta.

- Pesado: la mercadería es puesta sobre una balanza electrónica para calcular el peso exacto antes de pasar a embalarla.

- Área de empaque: la fruta es empacada en cajas de cartón corrugado elaborado bajo especificaciones y dimensiones convenientes. En esta fase se colocan el número de flete, el código de barra y otros.

Imagen $\mathrm{N}^{\circ} 4.4$

Flujograma del Proceso de Producción 

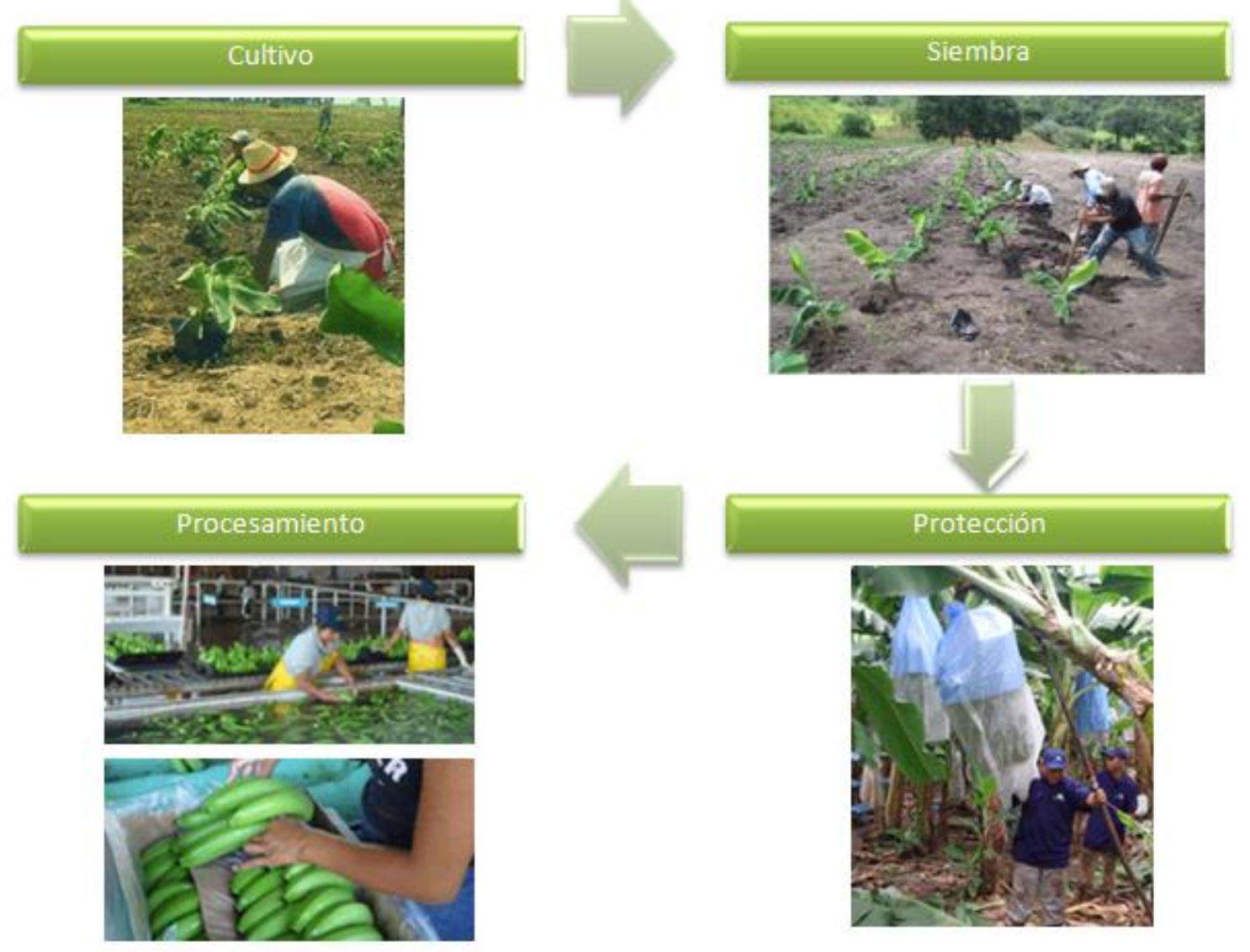

4.3. Requerimientos Medio Ambientales

\subsubsection{Clima}

- Altitud: Las zonas adecuadas para el desarrollo del cultivo son las comprendidas entre los 0 y $30 \mathrm{msnm}$. Sin embargo, el banano se adapta a alturas que alcanzan hasta los 2,200 msnm.

- Agua: Las necesidades de agua son elevadas. Aproximadamente, el 85-88\% del peso del banano está constituido por agua; por lo tanto requiere un suministro mensual de 1,200 a 1,300 m3/ha. De no ser suministrada por la lluvia, han de ser aportadas por riegos regulares y constantes. En el Valle del Chira, se realiza el riego entre los meses de abril y noviembre, periodo en que se presentan condiciones de sequía. 
- Temperatura: La temperatura óptima para el cultivo es de $25^{\circ} \mathrm{C}$. Un rango de temperaturas entre 25 a $30^{\circ} \mathrm{C}$ favorece su desarrollo. Cuanto más baja sea la temperatura, más prolongado es el ciclo vegetativo del banano.

- Luminosidad: El banano se cultiva en condiciones de variada iluminación. Sin embargo, se prefiere zonas de sol y despejadas de nubes, ya que bajo condiciones de baja luminosidad y frío; el ciclo vegetativo pasa de 8.5 meses a 14 meses.

- Vientos: Las zonas propicias son aquellas que están expuestas a velocidades de viento mayores a $20 \mathrm{~km} / \mathrm{hora}$.

\subsubsection{Suelo}

Los mejores suelos son los que se encuentran en los valles costeros, de textura arenosa y gran porosidad y que posean un buen drenaje para favorecer el desarrollo del cultivo. El exceso de humedad produce un mal desarrollo y la pudrición de las raíces. El banano ofrece una gran tolerancia orgánica, pues vegeta sobre suelos cuya reacción varía de pH 4.5 a pH 8. La condición ideal de $\mathrm{pH}$ es 6.5 . 


\subsection{Requerimiento de Equipos de Oficina}

\begin{tabular}{|c|c|c|c|c|}
\hline ITEM & IMAGEN & CANTIDAD & CARACTERÍSTICAS & DESCRIPCIÓN \\
\hline $\begin{array}{c}\text { Impresora } \\
\text { Multifuncional }\end{array}$ & & 1 & $\begin{array}{l}\text { - Marca: HP } \\
\text { - Modelo: Ink Advantage } 5525 \text { e-All-in-One } \\
\text { - Tipo: Multifuncional } \\
\text { - Tecnología: Inyección térmica de tinta HP } \\
\text { - Velocidad máxima de impresión en negro (ppm): } \\
\text { Hasta } 11 \\
\text { - Velocidad máxima de impresión a colores (ppm): } \\
\text { Hasta } 8 \\
\text { - Resolución de la impresión en negro: Hasta } 1200 \text { x } \\
1600 \text { dp } \\
\text { - Resolución de la impresión en colores: Hasta } 4800 \\
\text { x } 1200 \text { dpi } \\
\text { - Capacidad de papel (hojas): Hasta } 80 \\
\text { - Impresión máxima por mes (pág.): } 1000 \\
\text { - Resolución escáner (ppp): Hasta } 1200 \text { x } 2400 \\
\text { - Resolución de la fotocopiadora (ppp): Hasta } 600 \\
\text { - Velocidad de la fotocopiadora a blanco y negro: } 6.5 \\
\text { cpm } \\
\text { - Velocidad de la fotocopiadora a colores: } 5.5 \mathrm{cpm} \\
\text { - Copias múltiples: Hasta } 9.999 \\
\text { - Consumo de energía en funcionamiento (kW/h): } \\
14.64 \text { watts } \\
\text { - Consumo de energía en espera: } 4.75 \text { watts } \\
\text { - Compatible con Windows: Sí } \\
\text { - Compatible con Mac: Sí } \\
\text { - Tipo de conexión: USB } 2.0 \\
\text { - Red inalámbrica: WiFi } 802.11 \text { b/g/n } \\
\text { - Impresión sin computadora: Sí } \\
\text { - Térensiones (cm): } 44.4 \times 14.4 \times 54.5 \mathrm{~cm} \text { de la garantía - Respuestos: } 1 \text { año } \\
\text { - Términos de la garantía - Mano de obra: } 1 \text { años }\end{array}$ & $\begin{array}{l}\text { Con esta impresora será posible } \\
\text { imprimir, escanear y fotocopiar de } \\
\text { forma inalámbrica. Cuenta con } \\
\text { pantalla táctil, velocidad de } \\
\text { impresión en negro de hasta } 11 \\
\text { páginas por minuto (ppm), a color de } \\
\text { hasta } 22 \text { ppm y de copia en negro de } \\
\text { hasta } 6.5 \text { copias por minuto (cpm). } \\
\text { Gracias a su bandeja de entrada } \\
\text { podrás imprimir hasta } 80 \text { hojas, } \\
\text { además podrás que acceder a tus } \\
\text { documentos desde este equipo } \\
\text { gracias a su pantalla táctil }\end{array}$ \\
\hline
\end{tabular}




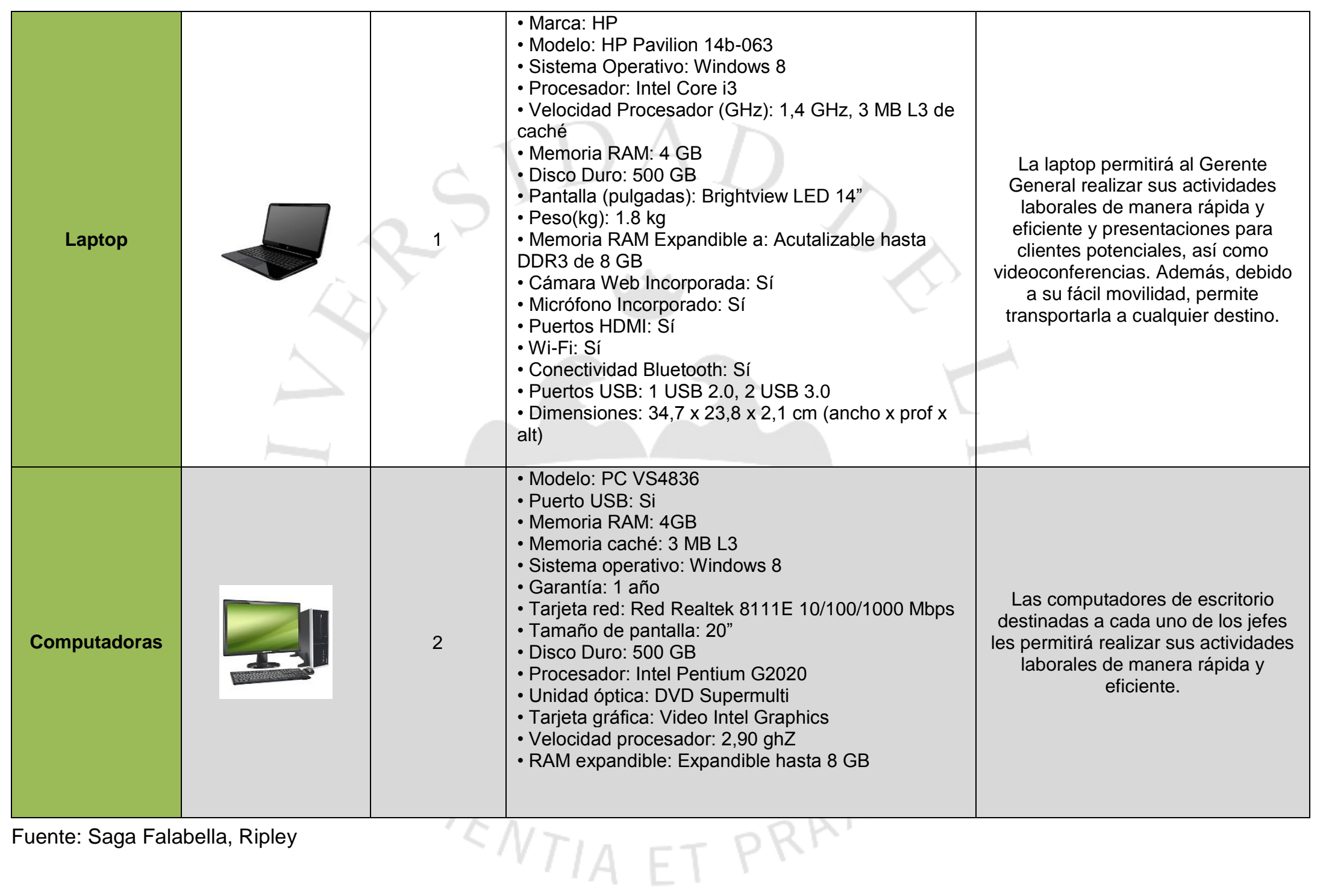


Adicionalmente, se requiere de un router que permite la conectividad a internet a través de una red inalámbrica desde cualquier punto de la oficina y un teléfono fijo para recibir y realizar llamadas, con el fin de mantenerse en contacto con los grupos de interés. Dichos equipos no figuran en el cuadro debido a que se incluyen en el servicio que brindará la empresa Movistar de telefonía fija e internet, el cual se detallará en el siguiente punto.

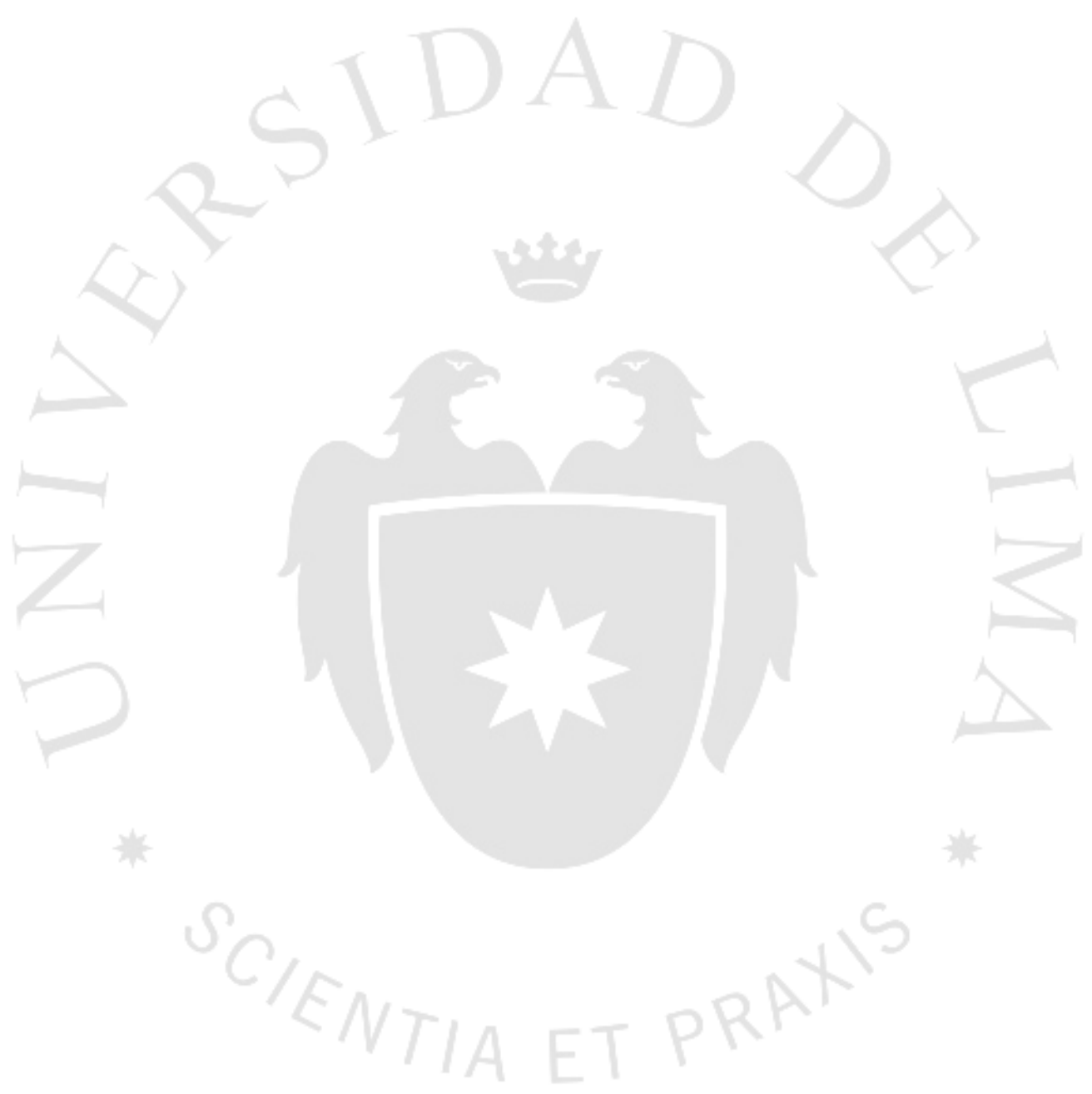




\subsection{Requerimiento de Mobiliario de Oficina}

Cuadro №4.2

Requerimiento de Mobiliario de Oficina

\begin{tabular}{|c|c|c|c|c|}
\hline ITEM & IMAGEN & CANTIDAD & CARACTERÍSTICAS & DESCRIPCIÓN \\
\hline Escritorio & & 2 & $\begin{array}{l}\text { - Espacio para monitor de 19" } \\
\text { - Portateclado y espacio para } \\
\text { CPU } \\
\text { - Estante para almacenaje. } \\
\text { - Color:Wengue } \\
\text { - Marca:Moduart } \\
\text { - Medidas: } 142 \text { x } 50 \text { x } 121 \mathrm{~cm} \\
\text { - Procedencia:Colombia }\end{array}$ & $\begin{array}{c}\text { Entre los muebles de } \\
\text { mayor importancia en } \\
\text { la oficina podemos } \\
\text { encontrar a los } \\
\text { Centros de Cómputo, } \\
\text { el más importante para } \\
\text { la realización de } \\
\text { trabajos en la mayoría } \\
\text { de casos, aparte de } \\
\text { ser reconocido por su } \\
\text { multifuncionalidad, } \\
\text { siendo también útil } \\
\text { para instalar una } \\
\text { computadora, guardar } \\
\text { toda clase de archivos } \\
\text { y libros, etcétera. }\end{array}$ \\
\hline Escritorio & & 1 & $\begin{array}{l}\text { - Incluye:Portateclado con } \\
\text { correderas metálicas } \\
\text { - Material del producto:Metal } \\
\text { con cristal templado } \\
\text { - Medidas: } 165 \times 75 \times 60 \mathrm{~cm} \\
\text { - Procedencia:China }\end{array}$ & $\begin{array}{c}\text { Exclusivo modelo con } \\
\text { un respaldar alto y } \\
\text { reclinable, además de } \\
\text { un asiento con tejido } \\
\text { de relieve que evita el } \\
\text { rebote del calor } \\
\text { corporal y te hará } \\
\text { sentir siempre fresco. } \\
\text { Elegante, moderna y } \\
\text { extremadamente } \\
\text { cómoda, esta silla es } \\
\text { perfecta para } \\
\text { combinarla tanto en } \\
\text { estudios como en } \\
\text { oficinas }\end{array}$ \\
\hline $\begin{array}{l}\text { Sillas de } \\
\text { Cómputo }\end{array}$ & & 3 & - Color: Negro & $\begin{array}{l}\text { Una de las principales } \\
\text { piezas del centro } \\
\text { laboral, este producto } \\
\text { armoniza tres factores } \\
\text { básicos: estética, } \\
\text { resistencia y } \\
\text { comodidad. }\end{array}$ \\
\hline $\begin{array}{c}\text { Sillas de } \\
\text { Visita }\end{array}$ & & $1 / 7$ & $\begin{array}{l}\text { - Asiento y respaldo en malla } \\
\text { - Base cromada. } \\
\text { - Marca:ASENTI } \\
\text { - Color:Negro }\end{array}$ & $\begin{array}{c}\text { Estas piezas } \\
\text { permitirán la visita de } \\
\text { clientes y clientes } \\
\text { potenciales, } \\
\text { brindándoles un } \\
\text { ambiente cómodo para } \\
\text { llevar a cabo } \\
\text { conversaciones } \\
\text { comerciales. }\end{array}$ \\
\hline
\end{tabular}

Fuente: Sodimac, Ripley, Saga 
Cuadro №4.3

Requerimiento de Servicios

\begin{tabular}{|c|c|c|c|}
\hline ÍTEM & $\begin{array}{c}\text { UNIDAD DE } \\
\text { MEDIDA }\end{array}$ & DESCRIPCIÓN & PROVEEDOR \\
\hline Luz & kWh & Consumo de energía eléctrica & Luz del Sur \\
\hline Agua & Metros Cúbicos & Consumo de agua potable & Sedapal \\
\hline Plan Dúo & Tarifa Plana & Internet Móvil y Telefonía Fija & Movistar \\
\hline
\end{tabular}

Cuadro №4.4

Plan Dúo Movistar

\begin{tabular}{|c|c|}
\hline \multicolumn{2}{|c|}{ PLAN DUO MOVISTAR } \\
\hline Internet & $6 \mathrm{Mbps}$ \\
\hline Navegación ilimitada & \\
\hline $\begin{array}{c}\text { Zona de Seguridad Gratis por } \\
\text { 3 meses }\end{array}$ & \\
\hline Línea & Plana Nacional \\
\hline $\begin{array}{c}\text { Llamadas locales ilimitadas } \\
\text { (Red Movistar) }\end{array}$ & Todo el día \\
\hline Minutos Multidestino & 150 \\
\hline
\end{tabular}

Fuente: Movistar

El plan dúo contratado permite realizar llamadas a nivel nacional de manera ilimitada las 24 horas a 100 destinos fijos locales, facilitando la comunicación con los proveedores del producto ubicados en la región de Piura.

Asimismo, incluye 150 minutos para llamadas a larga distancia internacional (LDI) o móvil de cualquier operador. Los minutos de LDI aplican sólo para los siguientes destinos:

- Fijo y Móviles de USA, Canadá y China

- Fijos de Alemania, Argentina, Brasil, Chile, España, Francia e Italia 


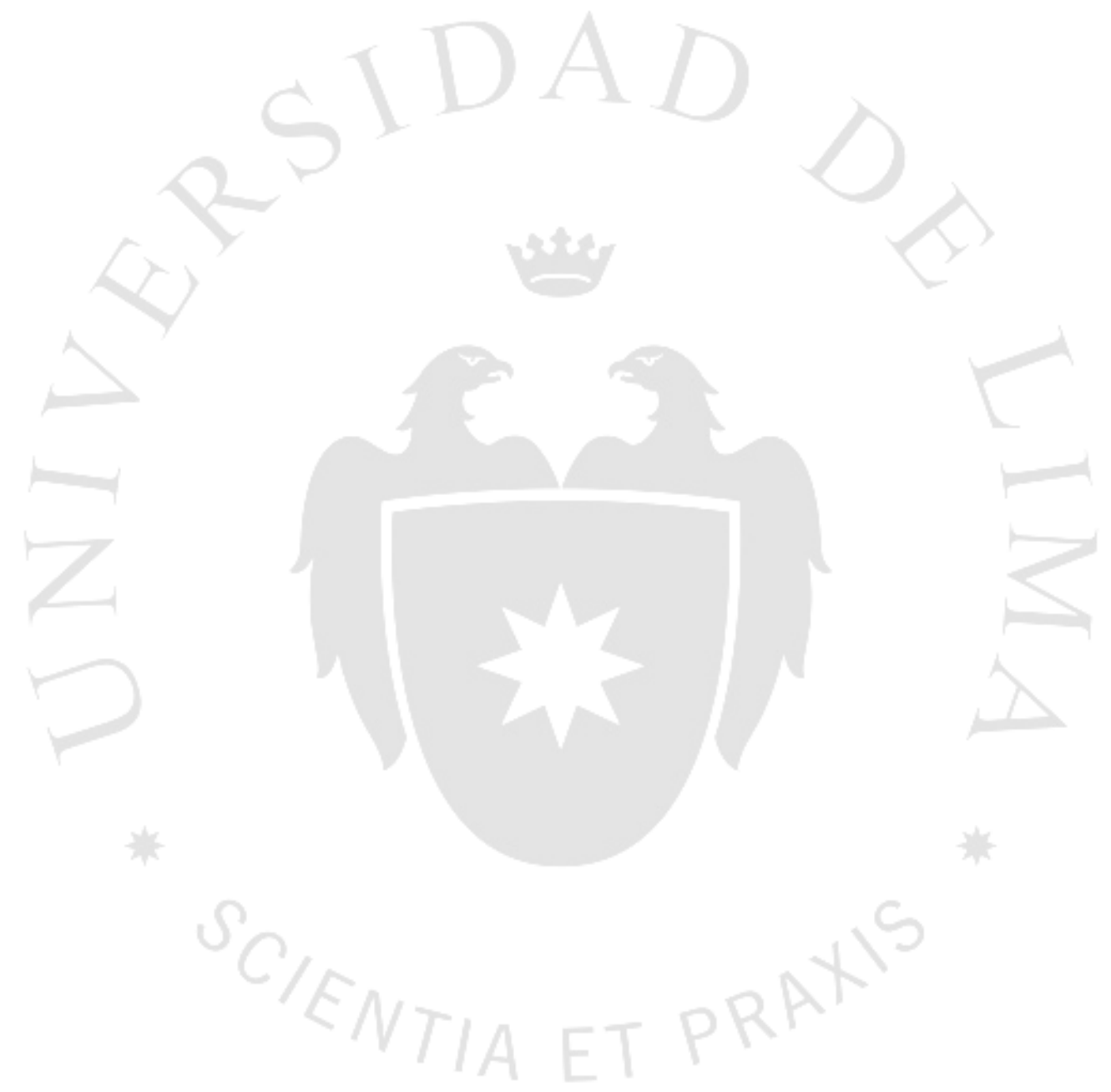




\section{CAPITULO V: ORGANIZACIÓN DEL NEGOCIO}

\subsection{Datos Generales}

Golden Banana S.A.C se dedica al acopio y exportación de banano orgánico al mercado canadiense. El producto proviene del norte del Perú, específicamente de la región de Piura.

La empresa basa sus operaciones en la orientación al cliente exterior, buscando satisfacer sus necesidades y superando las expectativas del consumidor.

- Horario de atención: 9am - 18:00pm

- Teléfono: (01-511) 436-6441

- Dirección: Pasaje Antonio Moro Nro 150 Of. 511, Distrito de San Borja, Provincia de Lima, Departamento de Lima

\subsubsection{Unidad Ejecutora del Proyecto}

- Cynthia Pilar La Rosa Duarte (D.N.I 46641613): Gerente General de la Empresa Golden Banana S.A.C.

- Javier Adolfo La Rosa Duarte (D.N.I 47345622): Jefe de Operaciones y Logística de la Empresa Golden Banana S.A.C.

- Gianfranco Camaiora Castañeda (D.N.I 71258922): Jefe de Administración y Finanzas de la Empresa Golden Banana S.A.C.

\subsubsection{Unidad Formuladora del Proyecto}

- Cynthia Pilar La Rosa Duarte (D.N.I 46641613): persona natural y Bachiller en Negocios Internacionales de la Universidad de Lima.

- Javier Adolfo La Rosa Duarte (D.N.I 47345622): persona natural y Bachiller

en Ingeniería Industrial de la Universidad de Lima, con Diplomado en Gerencia de Proyectos. 
- Gianfranco Camaiora Castañeda (D.N.I 71258922): persona natural y Licenciado de la carrera de Administración y Negocios Internacionales de la Universidad Peruana de Ciencias Aplicadas.

\subsubsection{Misión}

Servir al mercado internacional de un producto exótico y deleitarlo con la alta calidad peruana, cumpliendo con los términos de costo y tiempo acordados y satisfaciendo sus necesidades y expectativas de acuerdo a los estándares que el mercado demanda.

\subsubsection{Visión}

Ser una empresa altamente competitiva en el ámbito nacional e internacional, respondiendo de manera confiable a la demanda del mercado y buscando sostenibilidad en el tiempo a través de una gestión eficiente y basada en valores.

\subsubsection{Valores}

Los siguientes valores definen lo que la empresa Golden Banana S.A.C representa como una institución dedicada al comercio exterior y ayudan a mantener alineado al equipo de trabajo en la búsqueda de objetivos, presentar un clima laboral adecuado y demostrando compromiso con la satisfacción de clientes.

- Integridad

- Responsabilidad

- Lealtad

- Calidad 
5.2. Objetivos del Plan de Negocios

5.2.1. Objetivos de Marketing

- Lograr la inserción en supermercados canadienses, empezando por Loblaws.

- Contribuir a un mejor posicionamiento del país a nivel mundial dentro de los principales proveedores de banano, alcanzando un puesto entre los 7 primeros abastecedores de este producto.

- Conseguir que la marca sea reconocida en el mercado por su calidad a través de controles continuos.

\subsubsection{Objetivo de Operaciones}

- Lograr la mayor eficiencia en gestiones, definiendo la política de personal y captando las personas adecuadas para ejercer los cargos establecidos

- Contar con las instalaciones física y equipos requeridos para que cada miembro de la organización lleve a cabo sus gestiones

- Controlar la calidad del producto mediante visitas a la zona de producción

- Optimizar el proceso de producción a través de la tercerización de la producción

- Invertir en actividades de promoción máximo 5\% sobre las ventas por año

\subsubsection{Objetivos Económicos y Financieros}

- Recuperar el capital invertido en un plazo no mayor a 4 años

- Obtener una Tasa Interna de Retorno (TIR) mayor al 10\% a los cinco años del inicio de operaciones de la empresa

- Presentar un crecimiento en la rentabilidad de un $10 \%$ por año 


\subsection{Estrategia del Proyecto}

Según Michael Porter, la estrategia competitiva es la manera en que una empresa compite frente a sus rivales en un determinado negocio o unidad estratégica de negocio. Por lo que se debe relacionar a la empresa con su entorno, y así concluir y elegir cuál será la mejor elección para competir en un determinado mercado. Es así como Porter contribuye con sus tres estratégicas competitivas genéricas: liderazgo en costos globales, liderazgo en la diferenciación y liderazgo por nicho.

De acuerdo a Porter, "la estrategia de segmentación se centra en un grupo de clientes, en un segmento sobre la línea de productos o un mercado en específico. La clave en este tipo de estrategia es encontrar un grupo con necesidades inusuales" 67

Ésta es la estrategia que se considera como la más adecuada, ya que, cuya definición, es la que mejor se ajusta al proyecto.

Es importante realizar un seguimiento cuidadoso a los factores determinantes que puedan poner en peligro la posición competitiva de la empresa. No se debe subestimar el poder de la innovación que actualmente emplean todas las empresas para mantener su posición en el mercado.

${ }^{67}$ Porter, Michael E., “Estrategia competitiva”. Piramide Ediciones Sa, 2009, pp.78 


\subsection{Marco Jurídico}

La ley General de Sociedades, ley N²6887, constituye el marco jurídico de la presente organización. Los Libros I y II son aplicables al modelo de empresa, dado que el primero contiene las reglas aplicables a todas las sociedades, y el segundo se enfoca directamente en la sociedad anónima.

En el Libro II, sección sétima, título I, se especifica la forma especial de sociedad anónima propuesta, la sociedad anónima cerrada. Al respecto se menciona los tres principales artículos:

- Artículo 234.- Requisitos

La sociedad anónima puede sujetarse al régimen de la sociedad anónima cerrada cuando tiene no más de veinte accionistas y no tiene acciones inscritas en el Registro Público del Mercado de Valores. No se puede solicitar la inscripción en dicho registro de las acciones de una sociedad anónima cerrada.

- Artículo 235.- Denominación

La denominación debe incluir la indicación "Sociedad Anónima Cerrada", o las siglas S.A.C.

- Artículo 236.- Régimen

La sociedad anónima cerrada se rige por las reglas de la presente Sección y en forma supletoria por las normas de la sociedad anónima, en cuanto le sean aplicables.

\subsection{Tipo de Sociedad ${ }^{68}$}

Las principales razones por la cual se optó por una Sociedad Anónima Cerrada se exponen a continuación:

- Son 3 el número de socios determinados para la constitución de la empresa; ajustándose la cantidad al rango de la sociedad anónima cerrada, la cual permite mínimo 2 y máximo 20 socios.

- La duración de la organización es indeterminada.

- La representación del capital es en acciones.

\footnotetext{
${ }^{68}$ Ministerio de Producción. "Guía de Constitución y Formalización de Empresas".
} 
- La responsabilidad del socio está limitada únicamente al monto aportado (salvo caso de fraude), por lo que no responden personalmente con su patrimonio por las deudas asumidas por la empresa.

- Puede adoptar cualquier denominación agregando S.A.C.

A continuación se detallaran las características, denominación y órganos de la empresa en base al tipo societario seleccionado:

\subsubsection{Características:}

- El número de accionistas no puede ser menor de dos ni mayor a 20.

- Se impone el derecho de adquisición preferente por los socios, salvo que el estatuto disponga lo contrario.

- El Capital Social está representado por acciones nominativas y se conforma con los aportes (en bienes y/o en efectivo) de los socios, quienes no responden personalmente por las deudas sociales.

- Es una persona jurídica de Responsabilidad Limitada.

- No puede inscribir sus acciones en el Registro Público del Mercado de Valores.

- Predomina el elemento personal, dentro de un esquema de sociedad de capitales.

\subsubsection{Denominación}

La denominación adoptada debe incluir la indicación: "Sociedad Anónima Cerrada" o estar acompañada de su abreviatura "S.A.C.". Haciendo referencia a lo anterior el nombre de la empresa es Golden Banana S.A.C. 


\subsection{3 Órganos de la empresa}

- Junta General de Accionistas: es el órgano supremo de la sociedad. Está integrada por el total de socios que conforman la empresa.

- Gerente: es la persona en quien recae la representación legal y de gestión de la sociedad. El Gerente convoca a la junta de accionistas.

- Sub-gerente: es la persona que reemplaza al Gerente en caso de ausencia.

- Directorio: el nombramiento de un Directorio por la Junta es facultativo (no es obligatorio).

\subsection{Constitución de la empresa ${ }^{69}$}

Para efectuar la constitución de la empresa será necesario realizar las siguientes etapas de manera consecutiva, tal como se detalla en la Guía de Constitución y Formalización de Empresas elaborada por el Ministerio de la Producción, las cuales se enumerarán a continuación:

i) Seleccionar la modalidad empresarial a adoptar Este paso se detalló en el punto 5.5 .

ii) Reserva del nombre en Registros Públicos

El primer trámite a realizarse es la Reserva de Nombre o Denominación Social ante Registro Públicos. Esta reserva se puede hacer por internet, lo cual facilita y agiliza el proceso. Reservar el nombre seleccionado para la empresa a constituir impide que cualquier otra empresa se inscriba adoptando una razón social o denominación completa o abreviada, igual o semejante al nombre elegido.

iii) Elaboración de la Minuta de Constitución de la Empresa

Es un documento que es redactado por un abogado que establece el pacto social, en el cual los miembros de sociedad manifiestan su voluntad de constituir la empresa, y en donde se señalan todos los 
acuerdos respectivos. La Minuta incluye los estatutos, designación de representantes y la duración de los cargos.

iv) Elaboración de Escritura Pública

Documento que se realiza ante un Notario Público en el que se incluye o inserta la Minuta de Constitución y los Estatutos. Se le conoce también como Testimonio de Constitución. Mediante este paso, se da formalidad a la Minuta para presentarla posteriormente en Registros Públicos.

Los documentos necesarios son:

- Minuta

- Pago de derechos notariales

v) Inscripción en Registros Públicos

Una vez obtenida la Escritura Pública, el notario, titular o socios deben inscribir a la empresa en la Oficina Registral competente en el Registro de Personas Jurídicas de la SUNARP. Para efectos de la empresa Golden Banana S.A.C se debe inscribir en el Registro de Sociedades, ya que éste corresponde a distintos tipos de sociedades entre las cuales se encuentra S.A.C.

Se deben presentar los siguientes documentos:

- Formato de solicitud de inscripción debidamente llenado y suscrito

- Copia de DNI de la persona que realiza el trámite

- Escritura Pública que contenga Pacto Social y Estatuto

- Comprobante de depósito por el pago de derechos registrales

vi) Inscripción en el Registro Único de Contribuyentes (RUC)

Inscrita la sociedad, se procede a solicitar la inscripción en la SUNAT para la obtención del R.U.C, la cual es otorgada de forma gratuita e inmediata. Mediante el número de RUC, que consta de once dígitos, se identifica a una persona jurídica ante la SUNAT para el pago de los impuestos. Para obtenerlo debemos acudir a la SUNAT, llenar un formulario de justificación, y esperar notificación. 
vii) Apertura de cuenta bancaria

Luego de la elaboración de la minuta, abrir una cuenta de custodia para el aporte en efectivo que se pueda realizar de capital como aporte de los accionistas.

viii) Licencia Municipal de Funcionamiento

La Licencia Municipal de Funcionamiento se requiere para que la sociedad pueda funcionar en un determinado local. Puede ser: Provisional o Indefinida.

Esta autorización tiene como objetivos evitar multas y/o cierre del establecimiento, con lo cual se permite el desarrollo de las actividades económicas en su normalidad. Además, constituye uno de los mecanismos de equilibrio entre el derecho de ejercer una actividad comercial privada y el respeto a la tranquilidad y seguridad de la comunidad.

Los documentos a presentar se mencionan a continuación:

- Fotocopia del RUC.

- Certificado de Zonificación (zona industrial, zona comercial, zona residencial, etc.).

- Croquis de la ubicación de la empresa.

- Copia de contrato de alquiler o título de propiedad.

- Fotocopia de la escritura pública.

- Recibos de pago por derecho por licencia.

- Formulario de solicitud.

ix) Certificado de Defensa Civil

Es una acción de prevención a solicitud de parte que comprende el conjunto de procedimientos y acciones efectuadas por los Órganos Ejecutantes, con la intervención de los Inspectores Técnicos de Seguridad en Defensa Civil autorizados por el INDECI, conducentes a verificar y evaluar el cumplimiento o incumplimiento de las normas de seguridad vigentes a fin prevenir $\mathrm{y} / \mathrm{o}$ reducir el riesgo debido a un peligro de origen natural o inducido por el hombre. 
Imagen $\mathrm{N}^{\circ} 5.1$

Flujograma de Constitución de la Sociedad

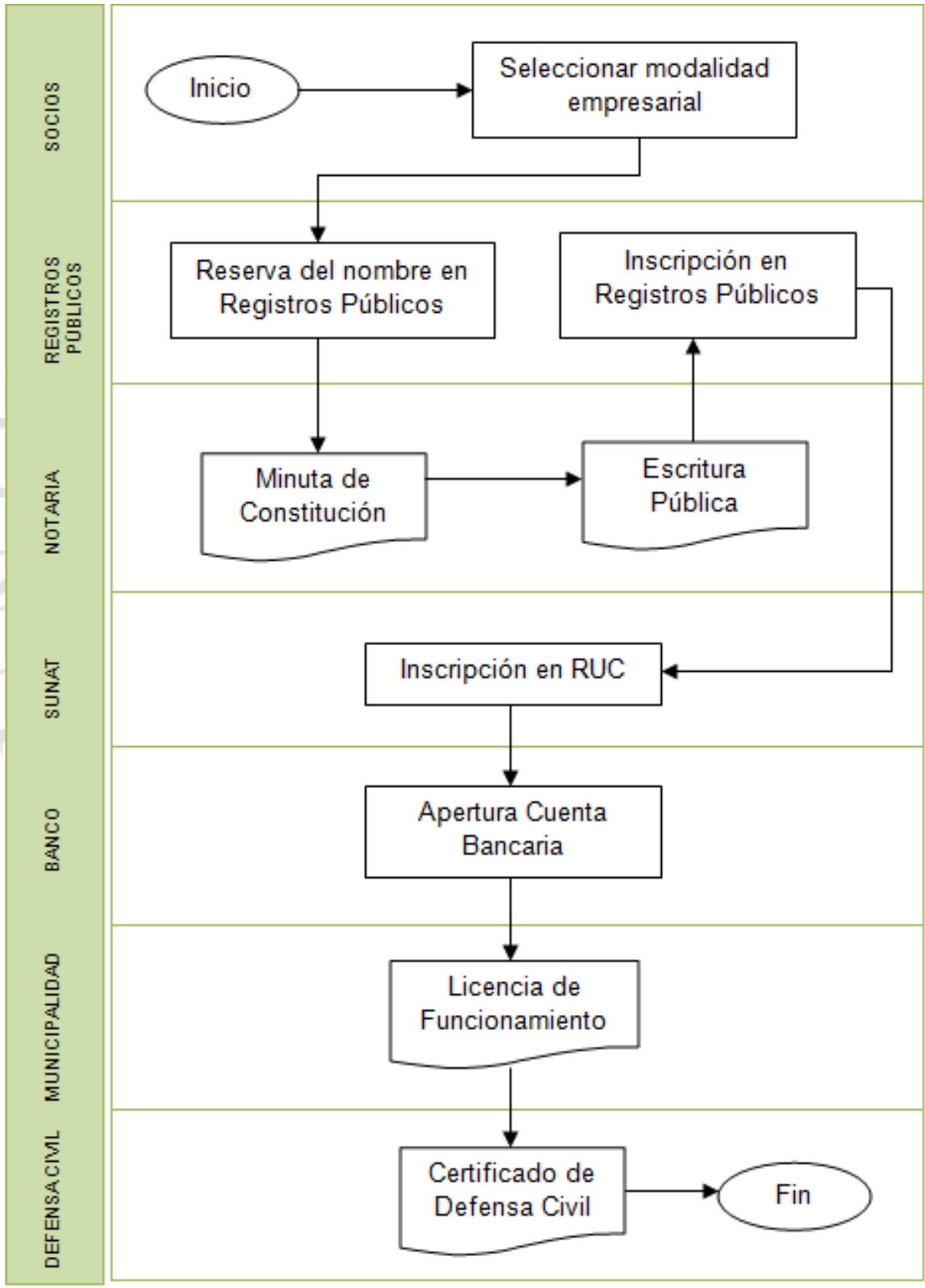

Fuente: Ministerio de Producción 


\subsection{Minuta de Constitución de la Empresa}

La elaboración de la Minuta de Constitución de la Empresa, fue explicada de manera general en el punto anterior, cuando se trató sobre los pasos a seguir para constituir una empresa. En este punto, se expondrá de manera más detallada.

Para llevar a cabo este paso de manera eficiente, se debe llevar consigo los documentos personales a presentar, como original y copia del DNI del titular o de los socios. Debido a que existe un socio extranjero, este debe presentar la copia de su carné de extranjería o visa de negocio.

Al tratarse de Golden Banana S.A.C, que es una micro empresa, ésta se beneficia de las ventajas otorgadas a las MYPE, por lo que todos los trámites correspondientes a este paso se puede completar en un tiempo breve, acercándose a las oficinas de atención a las MYPE de la Dirección Mi Empresa del Ministerio de Producción, que puede brindar asesoría especializada y sin ningún costo.

Para fines del estudio se tomará como referencia el modelo propuesto por la Superintendencia Nacional de Registros Públicos para la elaboración de la minuta de constitución. El capital social está representado por acciones y se integra por aportes de cada uno de los socios, que realizan con efecto de constituir la empresa. (Ver Anexo $\mathrm{N}^{\circ} 5$ ) 


\subsection{Organigrama Propuesto70}

Debido a que las organizaciones no tienen las mismas estructuras, se ha tomado la decisión, en cuanto al diseño organizacional, de adoptar el modelo genérico de la organización mecanicista, que presenta las siguientes características:

- Alto grado de especialización

- Departamentalización rígida

- Cadena de mando definida

- Tramo de control reducido

- Centralización

- Alto grado de formalidad

Imagen №5.2

Organigrama de Golden Banana S.A.C
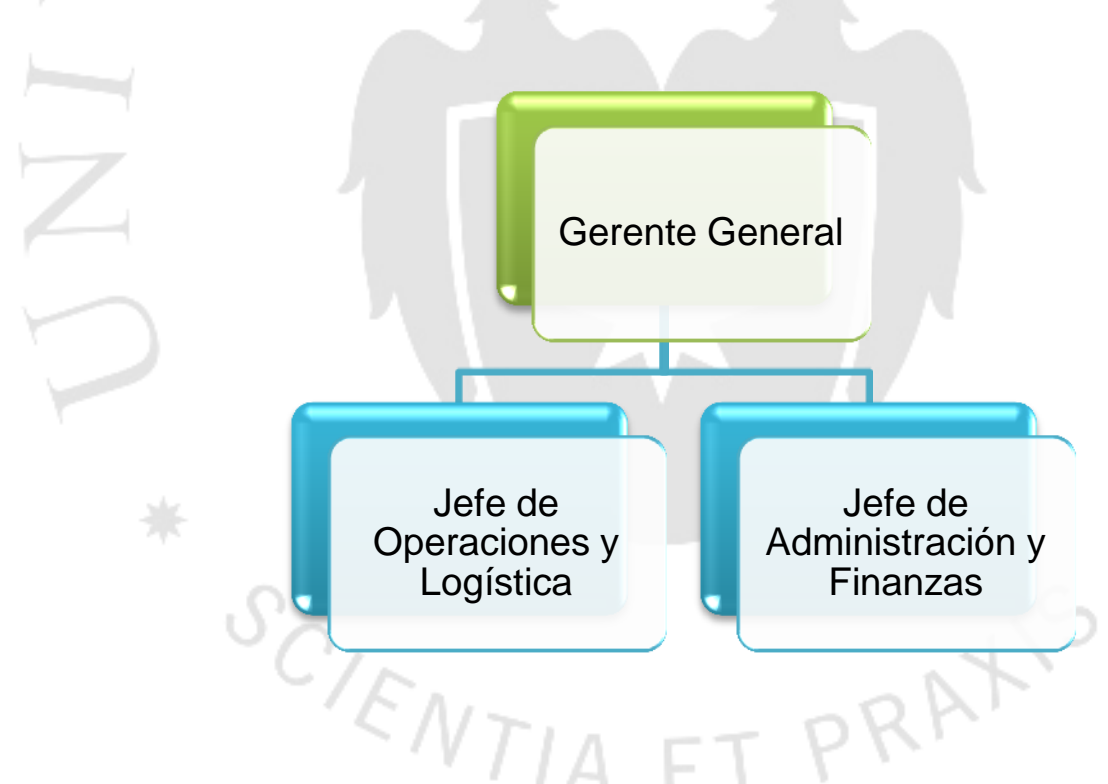

La estructura del organigrama propuesto muestra las relaciones jerárquicas entre las áreas de trabajo, representado por la posición de los cuadros, y las líneas muestran la comunicación forman entre éstas.

Éste organigrama es claramente vertical y cuenta con un grado de complejidad bajo, debido a la etapa en la que se encuentra la empresa y los pocos

${ }^{70}$ De la Puente, Julio. Apuntes de clase Gestión Empresarial I. 
trabajadores que la constituye. Por su extensión, puede ser clasificado como sintético, ya que contiene sólo las unidades básicas de la empresa.

El tipo de departamentalización escogida fue la funcional, agrupando las actividades y tareas de acuerdo con las principales funciones desarrolladas dentro de la empresa. Este diseño organizacional presenta ciertas ventajas, ya que reduce la duplicación de recursos entre áreas, facilita la coordinación interna del área, simplifica la capacitación y el control.

Además, la toma de decisiones se encuentra centralizada en el Gerente General. 


\subsection{Análisis de los puestos de trabajo}

En el cuadro 5.1 se sintetiza el análisis de puestos de trabajo considerado para las operaciones de la empresa Golden Banana S.A.C. En él se detalla el nombre del cargo, la cantidad de personas que ocuparan el puesto, las funciones que deberán realizar y el perfil de empleado que se requiere para cubrir con el cargo.

\section{Cuadro $N^{\circ} 5.1$}

\section{Análisis de Puestos de Trabajo}

\begin{tabular}{|c|c|c|c|}
\hline CARGO & $\begin{array}{c}\mathbf{N}^{\circ} \\
\text { PUESTOS }\end{array}$ & FUNCIONES & PERFIL \\
\hline \multirow{5}{*}{ Gerente General } & \multirow{5}{*}{1} & \multirow{5}{*}{$\begin{array}{l}\text { - Representar a la organización } \\
\text { - Establecer metas y objetivos de la } \\
\text { organización } \\
\text { - Controlar que las distintas jefaturas } \\
\text { funcionen correctamente } \\
\text { - Toma de decisiones } \\
\text { - Evaluar resultados obtenidos }\end{array}$} & $\begin{array}{l}{ }^{*} \text { Especialidad: Administración o } \\
\text { Negocios Internacionales. }\end{array}$ \\
\hline & & & $\begin{array}{l}\text { * Situación: Egresado con Título } \\
\text { Universitario }\end{array}$ \\
\hline & & & $\begin{array}{l}{ }^{*} \text { Conocimientos, competencias y } \\
\text { habilidades: } \\
\text { - Emprendedor, líder, proactivo. } \\
\text { - Tener alto grado de responsabilidad } \\
\text { e integridad ética y moral. } \\
\text { - Inglés Avanzado }\end{array}$ \\
\hline & & & $\begin{array}{l}\text { * Experiencia: Mínima } 2 \text { años en } \\
\text { cargos similares al puesto }\end{array}$ \\
\hline & & & * Disponibilidad: Tiempo Completo \\
\hline \multirow{5}{*}{$\begin{array}{l}\text { Jefe de } \\
\text { Operaciones y } \\
\text { Logística }\end{array}$} & \multirow{5}{*}{1} & \multirow{5}{*}{$\begin{array}{l}\text { - Coordinar la distribución del producto desde } \\
\text { el acopio hasta el embarque } \\
\text { - Análisis de costos logísticos y operacionales } \\
\text { de la empresa } \\
\text { - Informar a clientes sobre el estado de la } \\
\text { mercadería } \\
\text { - Llevar control de inventarios } \\
\text { - Generar órdenes de compra y de venta } \\
\text { Coordinación con almacén para despachos }\end{array}$} & $\begin{array}{l}{ }^{*} \text { Especialidad: Negocios } \\
\text { Internacionales }\end{array}$ \\
\hline & & & $\begin{array}{l}\text { * Situación: Egresado con Título } \\
\text { Universitario }\end{array}$ \\
\hline & & & $\begin{array}{l}\text { * Conocimientos, competencias y } \\
\text { habilidades: } \\
\text { - Liderazgo, } \\
\text { - MS Office Avanzado } \\
\text { - Inglés avanzado }\end{array}$ \\
\hline & & & $\begin{array}{l}{ }^{*} \text { Experiencia: Mínima } 2 \text { años en } \\
\text { Comercio Exterior, Logística }\end{array}$ \\
\hline & & & * Disponibilidad: Tiempo Completo \\
\hline \multirow{2}{*}{$\begin{array}{c}\text { Jefe de } \\
\text { Administración y } \\
\text { Finanzas }\end{array}$} & \multirow{2}{*}{1} & \multirow{2}{*}{$\begin{array}{l}\text { - Desarrollar políticas, promociones y } \\
\text { estrategias de ventas } \\
\text { - Controlar el cumplimiento del plan de trabajo } \\
\text { y establecer medidas correctivas }\end{array}$} & $\begin{array}{l}\text { *Especialidad: Administración, } \\
\text { Negocios Internacionales, Marketing }\end{array}$ \\
\hline & & & $\begin{array}{l}\text { * Situación: Egresado con Título } \\
\text { Universitario }\end{array}$ \\
\hline
\end{tabular}




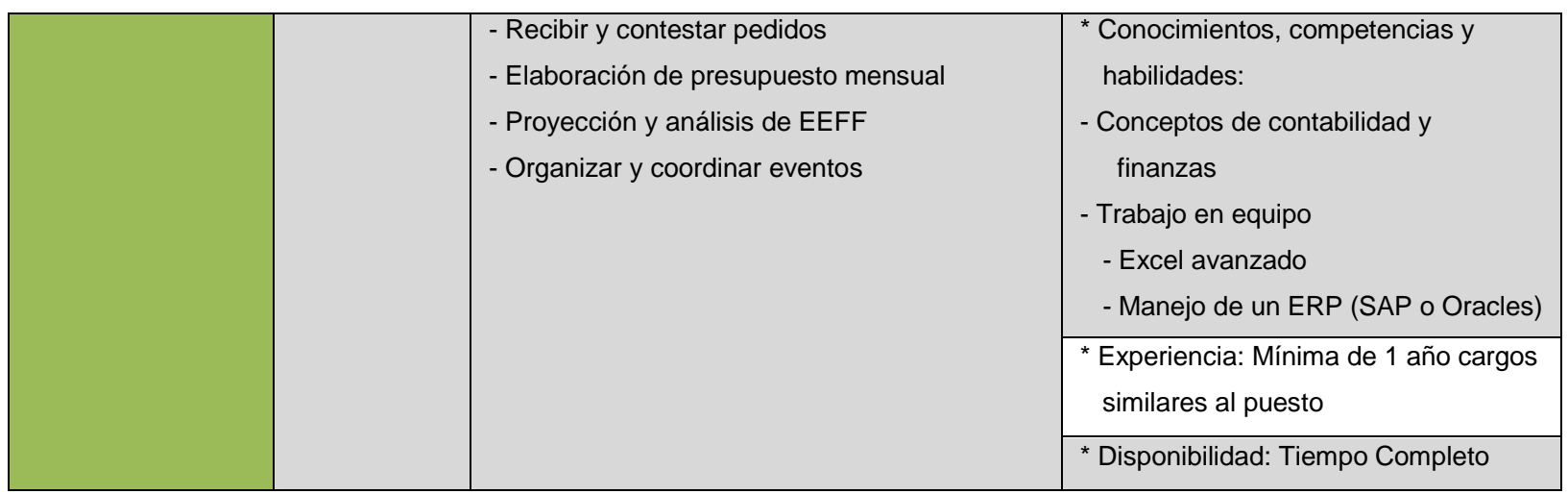

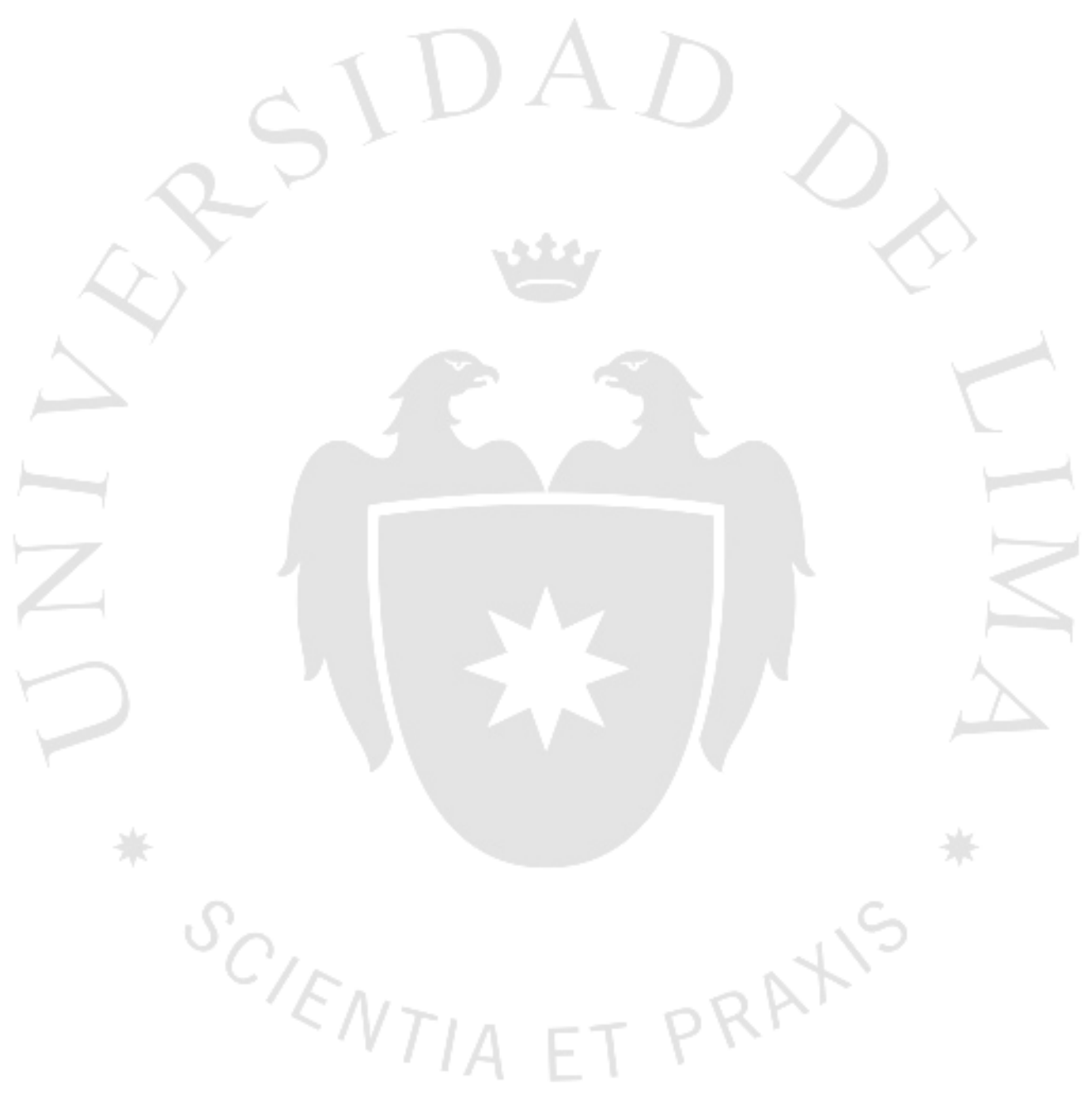




\section{CAPITULO VI: FUNDAMENTO FINANCIERO}

\subsection{Estructura de Costos}

La estructura de costos para la implementación del Plan de Negocios, se encuentra constituida por los costos fijos y variables. Los costos fijos son incurridos de manera mensual durante todo el periodo de funcionamiento de la empresa, independientemente de las ventas realizadas. En contraste, los costos variables son los que están relacionados directamente con el volumen de ventas, es decir, que se verán incrementados en función de la cantidad de producto que se oferte al mercado.

Cuadro $\mathrm{N}^{\circ} 6.1$

Estructura de Costos

(En Nuevos Soles)

\begin{tabular}{|l|c|c|c|c|}
\hline \multicolumn{1}{|c|}{ COSTOS VARIABLES } & \multicolumn{4}{|c|}{ CONTENEDOR 40} \\
\hline & U.M & Cantidad & $\begin{array}{c}\text { Valor } \\
\text { unitario }\end{array}$ & $\begin{array}{c}\text { Monto } \\
\text { Total }\end{array}$ \\
\hline Banano orgánico & $\mathrm{Kg}$ & 19,440 & 1.70 & $33,048.00$ \\
\hline Costos Variables Acumulados & $\mathrm{Kg}$ & $\mathbf{1 9 , 4 4 0}$ & $\mathbf{1 . 7 0}$ & $\mathbf{3 3 , 0 4 8 . 0 0}$ \\
\hline
\end{tabular}

\begin{tabular}{|l|c|c|c|}
\hline \multicolumn{1}{|c|}{ COSTOS FIJOS } & \multicolumn{3}{c|}{ COSTOS ADMINISTRATIVOS } \\
\hline & $\begin{array}{c}\text { Unidad } \\
\text { Meses }\end{array}$ & $\begin{array}{c}\text { Valor } \\
\text { Unitario }\end{array}$ & $\begin{array}{c}\text { Monto } \\
\text { Planilla }\end{array}$ \\
mes & $9,294.22$ & $9,294.22$ \\
\hline Alquiler & mes & $1,112.00$ & $1,112.00$ \\
\hline Servicios (agua, luz, internet) & mes & 599.00 & 599.00 \\
\hline Depreciación & mes & 118.05 & 118.05 \\
\hline \multicolumn{3}{|c|}{} & $\mathbf{1 1 , 1 2 3 . 2 8}$ \\
\hline
\end{tabular}

Es importante tener en cuenta que, Golden Banana S.A.C., es una empresa con una estructura simple, dedicada exclusivamente a la comercialización de banano orgánico, no altera ni modifica el producto que recibe del proveedor de 
Piura. El tipo de cambio considerado para los cálculos financieros es de S/. 3.30 nuevos soles por 1 dólar americano.

Costos fijos:

Los costos fijos contemplan el pago de planilla del personal indicado en el organigrama, durante los meses de funcionamiento del proyecto. La empresa funcionará en el quinto piso de un edificio destinado a la actividad empresarial y por el cual se asumirá un gasto por concepto de alquiler.

En lo que respecta a los servicios, entre los que podemos encontrar el agua, la energía eléctrica e internet, serán asumidos de forma mensual durante el periodo de operaciones de la empresa.

En el concepto gastos por llamadas nivel nacional o internacional relacionadas a la supervisión de la producción, monitoreo de pedidos y atención de potenciales clientes para la exportación se contempla dentro de los servicios, específicamente el plan dúo.

Costos variables:

Los costos variables fueron determinados básicamente mediante la entrevista a profundidad realizada, donde se pusieron en conocimientos los costos del producto.

\subsection{Estructura de la Inversión}

El cuadro $N^{\circ} 6.2$ puntualiza la estructura de inversión, la cual está constituida por inversiones en activos fijos, capital de trabajo y gastos pre-operativos. 
Cuadro $\mathrm{N}^{\circ} 6.2$

Estructura de Inversión

(En Nuevos Soles)

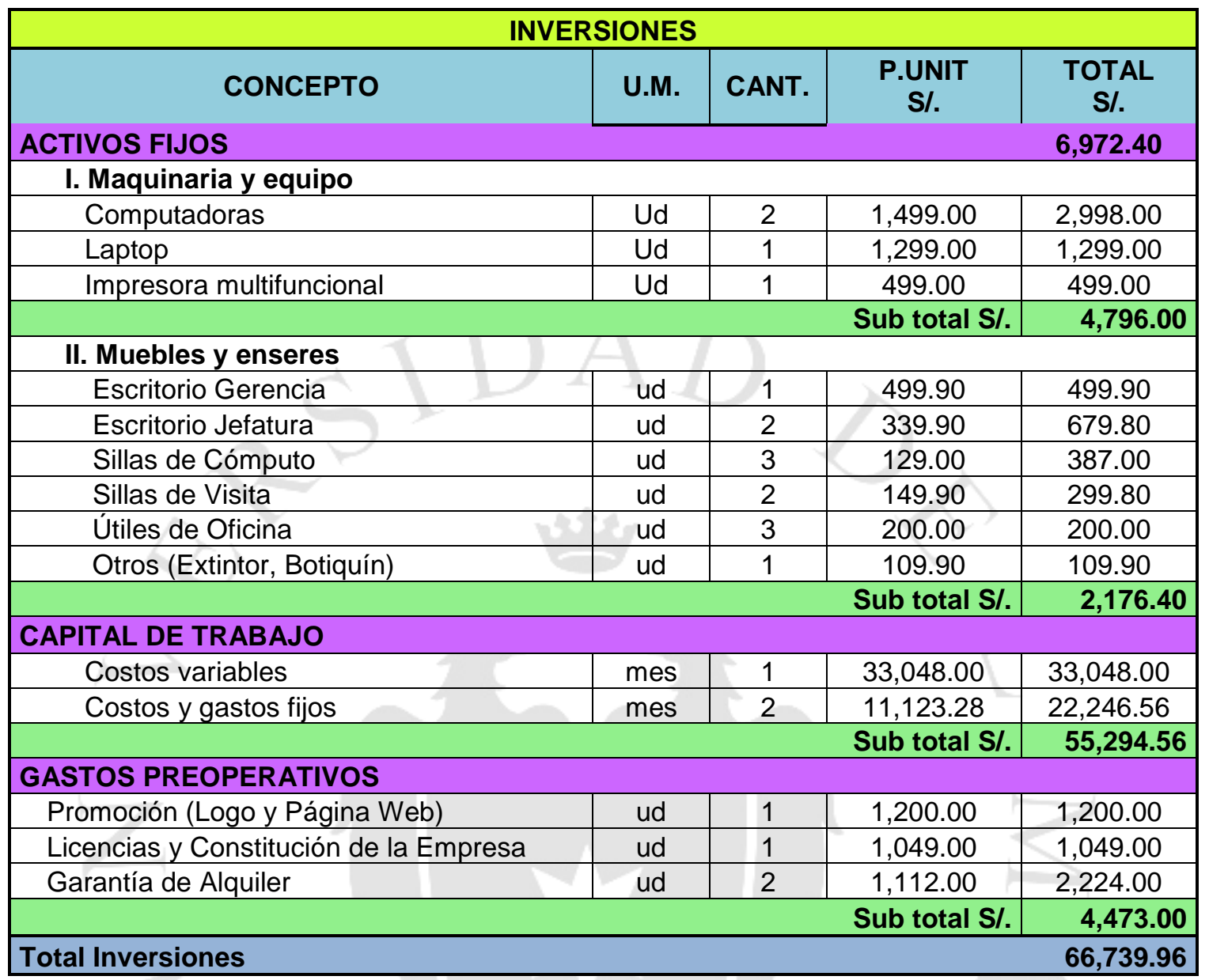

\subsection{Financiamiento de la Inversión}

La política de endeudamiento de la empresa se basa en el financiamiento a través de fondos propios y no por medio de algún instrumento de deuda bancaria, tratándose así de una empresa no apalancada.

Por lo tanto, la inversión se financiará en su totalidad por el aporte realizado por los accionistas. El total de esta inversión está destinada en un 10.45\% a activos fijos, $82.85 \%$ a capital de trabajo y $6.70 \%$ a gastos pre-operativos. 


\subsection{Determinación del Punto de Equilibrio}

Teniendo en consideración los costos fijos, los costos variables unitarios y precio de venta podemos determinar el punto de equilibrio para la empresa, los cuales cubrirá los costos fijos implicados en la operación. Se obtuvieron los siguientes puntos de equilibrio para cada año.

\section{Cuadro $\mathrm{N}^{\circ} 6.3$}

Determinación del Punto de Equilibrio

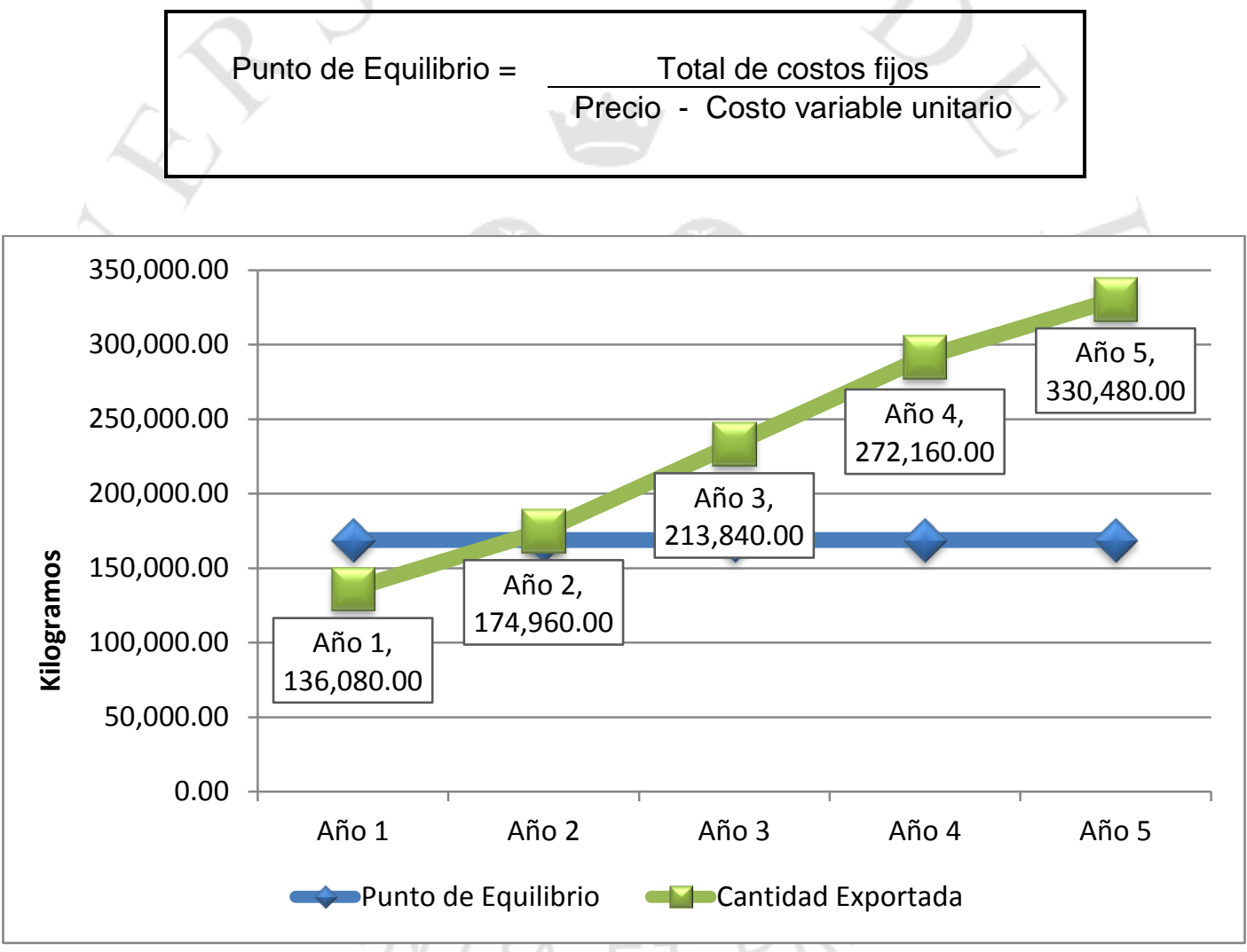

Debido a que no se presenta ningún cambio en los costos ni en el precio durante los años por los que pasa el proyecto, el punto de equilibrio se mantiene igual para todos los años. 


\subsection{Proyección de Ventas}

En el cuadro $N^{\circ} 6.4$, se muestra un resumen de la evolución de las ventas para los primeros cinco años de operación tanto en número de contenedores como en soles.

\section{Cuadro $N^{\circ} 6.4$}

Proyección de Ventas

\begin{tabular}{|l|l|l|l|l|l|}
\hline \multicolumn{1}{|l|}{ En unidades } \\
\hline \multicolumn{1}{|c|}{ Producto } & $\mathbf{1}$ & $\mathbf{2}$ & $\mathbf{3}$ & $\mathbf{4}$ & $\mathbf{5}$ \\
\hline $\begin{array}{l}\text { Contenedor de 40 pies } \\
\text { FOB }\end{array}$ & 7 & 9 & 11 & 14 & 17 \\
\hline
\end{tabular}

\section{En Nuevos Soles}

\begin{tabular}{|l|c|c|c|c|c|}
\hline \multicolumn{1}{|c|}{ Producto } & $\mathbf{1}$ & $\mathbf{2}$ & $\mathbf{3}$ & $\mathbf{4}$ & $\mathbf{5}$ \\
\hline $\begin{array}{l}\text { Contenedor de } 40 \text { pies } \\
\text { FOB }\end{array}$ & 340,200 & 437,400 & 534,600 & 680,400 & 826,200 \\
\hline
\end{tabular}




\subsection{Flujo de Caja Operativo}

Este estado financiero explica la variación de cuentas de efectivo y de cuentas denominadas equivalentes de efectivo, proporcionando la base sobre la cual se evaluará la capacidad de la empresa para generar flujos de fondos.

El flujo de caja operativo presenta los ingresos proyectados por la venta de banano orgánico y los costos incurridos por concepto de compra del producto a los agricultores de CEPIBO y costos y gastos diversos, en otras palabras, son los flujos provenientes de las transacciones que constituye la principal fuente de ingresos de la empresa junto con los gastos derivados de estas transacciones.

\section{Cuadro $\mathrm{N}^{\circ} 6.5$}

Flujo de Caja Operativo (en Nuevos Soles)

PRIMER AÑO

(Expresado en Nuevos Soles)

\begin{tabular}{|c|c|c|c|c|c|c|c|c|c|c|c|c|c|c|}
\hline CONCEPTO & 0 & 1 & 2 & 3 & 4 & 5 & 6 & 7 & 8 & 9 & 10 & 11 & 12 & Total \\
\hline INGRESOS (A) & & 0 & 48,600 & 48,600 & 48,600 & 48,600 & 48,600 & 48,600 & 0 & 48,600 & 0 & 0 & 0 & 340,200 \\
\hline Ventas & & 0 & 48,600 & 48,600 & 48,600 & 48,600 & 48,600 & 48,600 & 0 & 48,600 & 0 & 0 & 0 & \\
\hline EGRESOS (B) & & 11,123 & 40,283 & 40,283 & 40,283 & 40,283 & 40,283 & 40,283 & 11,123 & 40,283 & 11,123 & 11,123 & 11,123 & 337,599 \\
\hline Costos Fijos & & 11,123 & 11,123 & 11,123 & 11,123 & 11,123 & 11,123 & 11,123 & 11,123 & 11,123 & 11,123 & 11,123 & 11,123 & \\
\hline Costos Variables & & 0 & 29,160 & 29,160 & 29,160 & 29,160 & 29,160 & 29,160 & & 29,160 & 0 & 0 & & \\
\hline INVERSION & 55,295 & & & 7 & 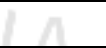 & $+\bar{T}$ & 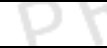 & 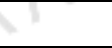 & & & & & & \\
\hline Saldo Inicial & 0 & & 44,171 & 52,488 & 60,805 & 69,121 & 77,438 & 85,755 & 94,072 & 82,948 & 91,265 & 80,142 & 69,019 & \\
\hline FLUJO NETO (A-B) & 55,295 & 44,171 & 52,488 & 60,805 & 69,121 & 77,438 & 85,755 & 94,072 & 82,948 & 91,265 & 80,142 & 69,019 & 57,895 & 2,601 \\
\hline
\end{tabular}




\section{SEGUNDO AÑO}

(Expresado en Nuevos Soles)

\begin{tabular}{|c|c|c|c|c|c|c|c|c|c|c|c|c|c|}
\hline CONCEPTO & 1 & 2 & 3 & 4 & 5 & 6 & 7 & 8 & 9 & 10 & 11 & 12 & Total \\
\hline INGRESOS (A) & 0 & 48,600 & 48,600 & 48,600 & 48,600 & 48,600 & 48,600 & 48,600 & 48,600 & 0 & 0 & 48,600 & 437,400 \\
\hline Ventas & 0 & 48,600 & 48,600 & 48,600 & 48,600 & 48,600 & 48,600 & 48,600 & 48,600 & 0 & 0 & 48,600 & \\
\hline EGRESOS (B) & 11,823 & 44,171 & 44,171 & 44,171 & 44,171 & 44,171 & 44,171 & 44,171 & 44,171 & 11,123 & 11,123 & 44,171 & 431,611 \\
\hline Costos Fijos & 11,123 & 11,123 & 11,123 & 11,123 & 11,123 & 11,123 & 11,123 & 11,123 & 11,123 & 11,123 & 11,123 & 11,123 & \\
\hline Costos Variables & 0 & 33,048 & 33,048 & 33,048 & 33,048 & 33,048 & 33,048 & 33,048 & 33,048 & & & 33,048 & \\
\hline Renovación Hosting & 700 & & & & & & & & & $A$ & & & \\
\hline $\begin{array}{l}\text { Pago de } \\
\text { Impuestos }\end{array}$ & 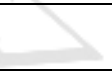 & & & & 7 & & & & & & & & \\
\hline Saldo Inicial & 57,895 & 46,072 & 50,501 & 54,929 & 59,358 & 63,787 & 68,216 & 72,644 & 77,073 & 81,502 & 70,378 & 59,255 & \\
\hline FLUJO NETO (A-B) & 46,072 & 50,501 & 54,929 & 59,358 & 63,787 & 68,216 & 72,644 & 77,073 & 81,502 & 70,378 & 59,255 & 63,684 & 5,789 \\
\hline
\end{tabular}

\section{TERCER AÑo}

(Expresado en Nuevos Soles)

\begin{tabular}{|c|c|c|c|c|c|c|c|c|c|c|c|c|c|}
\hline CONCEPTO & 1 & 2 & 3 & 4 & 5 & 6 & 7 & 8 & 9 & 10 & 11 & 12 & Total \\
\hline INGRESOS (A) & 0 & 0 & 48,600 & 48,600 & 97,200 & 97,200 & 48,600 & 48,600 & 48,600 & 0 & 48,600 & 48,600 & 534,600 \\
\hline Ventas & 0 & 0 & 48,600 & 48,600 & 97,200 & 97,200 & 48,600 & 48,600 & 48,600 & 0 & 48,600 & 48,600 & \\
\hline EGRESOS (B) & 11,823 & 11,123 & 44,484 & 44,171 & 77,219 & 77,219 & 44,171 & 44,171 & 60,426 & 11,123 & 44,171 & 44,171 & 514,275 \\
\hline Costos Fijos & 11,123 & 11,123 & 11,123 & 11,123 & 11,123 & 11,123 & 11,123 & 11,123 & 11,123 & 11,123 & 11,123 & 11,123 & \\
\hline Costos Variables & 0 & 0 & 33,048 & 33,048 & 66,096 & 66,096 & 33,048 & 33,048 & 33,048 & & 33,048 & 33,048 & \\
\hline Renovación Hosting & 700 & & 4 & $1=$ & & . & Q & & & & & & \\
\hline Pago de impuesto & & & 313 & & & & & & & & & & \\
\hline Saldo Inicial & 63,684 & 51,861 & 40,737 & 44,853 & 49,282 & 69,263 & 89,243 & 93,672 & 98,101 & 86,275 & 75,151 & 79,580 & \\
\hline FLUJO NETO (A-B) & 51,861 & 40,737 & 44,853 & 49,282 & 69,263 & 89,243 & 93,672 & 98,101 & 86,275 & 75,151 & 79,580 & 84,009 & 20,325 \\
\hline
\end{tabular}




\section{CUARTO AÑO}

(Expresado en Nuevos Soles)

\begin{tabular}{|c|c|c|c|c|c|c|c|c|c|c|c|c|c|}
\hline CONCEPTO & 1 & 2 & 3 & 4 & 5 & 6 & 7 & 8 & 9 & 10 & 11 & 12 & Total \\
\hline INGRESOS (A) & 48,600 & 48,600 & 48,600 & 48,600 & 97,200 & 97,200 & 48,600 & 48,600 & 48,600 & 48,600 & 48,600 & 48,600 & 680,400 \\
\hline Ventas & 48,600 & 48,600 & 48,600 & 48,600 & 97,200 & 97,200 & 48,600 & 48,600 & 48,600 & 48,600 & 48,600 & 48,600 & \\
\hline EGRESOS (B) & 44,871 & 44,171 & 50,002 & 97,219 & 77,219 & 77,219 & 44,171 & 44,171 & 44,171 & 44,171 & 44,171 & 44,171 & 655,730 \\
\hline Costos Fijos & 11,123 & 11,123 & 11,123 & 11,123 & 11,123 & 11,123 & 11,123 & 11,123 & 11,123 & 11,123 & 11,123 & 11,123 & \\
\hline Costos Variables & 33,048 & 33,048 & 33,048 & 66,096 & 66,096 & 66,096 & 33,048 & 33,048 & 33,048 & 33,048 & 33,048 & 33,048 & \\
\hline Renovación Hosting & 700 & & & $\bar{x}$ & 8 & 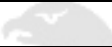 & & & 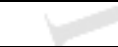 & 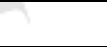 & & & \\
\hline Pago de Impuestos & & & 5,831 & & $z^{2}$ & 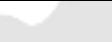 & 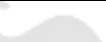 & & & & & & \\
\hline Saldo Inicial & 84,009 & 87,737 & 92,166 & 90,764 & 42,145 & 62,125 & 82,106 & 86,535 & 90,963 & 95,392 & 99,821 & 104,250 & \\
\hline FLUJO NETO (A-B) & 87,737 & 92,166 & 90,764 & 42,145 & 62,125 & 82,106 & 86,535 & 90,963 & 95,392 & 99,821 & 104,250 & 108,678 & 24,670 \\
\hline
\end{tabular}

\section{QUINTO AÑO}

(Expresado en Nuevos Soles)

\begin{tabular}{|c|c|c|c|c|c|c|c|c|c|c|c|c|c|}
\hline CONCEPTO & 1 & 2 & 3 & 4 & 5 & 6 & 7 & 8 & 9 & 10 & 11 & 12 & Total \\
\hline INGRESOS (A) & 48,600 & 48,600 & 48,600 & 97,200 & 97,200 & 97,200 & 97,200 & 97,200 & 48,600 & 48,600 & 48,600 & 48,600 & 826,200 \\
\hline Ventas & 48,600 & 48,600 & 48,600 & 97,200 & 97,200 & 97,200 & 97,200 & 97,200 & 48,600 & 48,600 & 48,600 & 48,600 & \\
\hline EGRESOS (B) & 44,871 & 44,171 & 52,961 & 77,219 & 77,219 & 77,219 & 77,219 & 77,219 & 44,171 & 44,171 & 44,171 & 44,171 & 704,785 \\
\hline Costos Fijos & 11,123 & 11,123 & 11,123 & 11,123 & 11,123 & 11,123 & 11,123 & 11,123 & 11,123 & 11,123 & 11,123 & 11,123 & \\
\hline Costos Variables & 33,048 & 33,048 & 33,048 & 66,096 & 66,096 & 66,096 & 66,096 & 66,096 & 33,048 & 33,048 & 33,048 & 33,048 & \\
\hline Renovación Hosting & 700 & & & 7 & 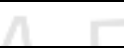 & $\bar{T}$ & $8+1$ & & & & & & \\
\hline Pago de Impuestos & & & 8,790 & 7 & 7 & 1 & & & & & & & \\
\hline Saldo Inicial & 108,678 & 112,407 & 116,836 & 112,474 & 132,455 & 152,436 & 172,417 & 192,397 & 212,378 & 216,807 & 221,236 & 225,664 & \\
\hline FLUJO NETO (A-B) & 112,407 & 116,836 & 112,474 & 132,455 & 152,436 & 172,417 & 192,397 & 212,378 & 216,807 & 221,236 & 225,664 & 230,093 & 121,415 \\
\hline
\end{tabular}




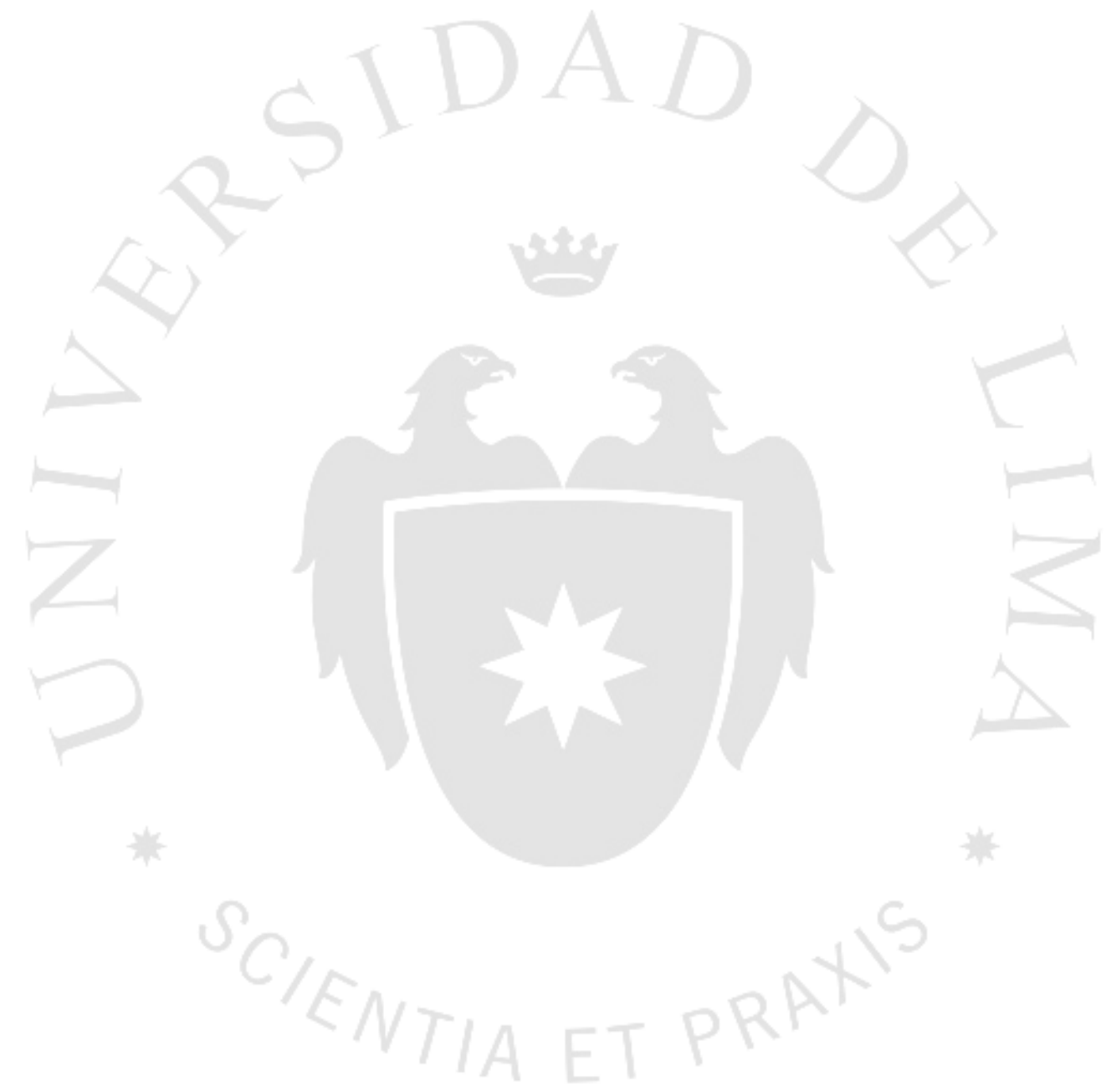


Como resultado, se obtienen flujos positivos a partir del segundo año y se registra un crecimiento constante, dada la mayor frecuencia de envíos a Canadá. Este flujo será un elemento fundamental, que se utilizará en el cálculo del valor presente neto del proyecto y la tasa interna de retorno, los cuales se presentarán en el siguiente punto. 


\subsection{Flujo de Caja Económico}

El flujo de caja económico se obtiene al combinar el flujo de caja operativo y el flujo de inversiones, aplicando el impuesto a la renta al resultado del EBITDA, que representa los ingresos y salidas de efectivo provenientes de la actividad del proyecto.

El flujo de inversiones está constituido por los flujos de efectivo a través de los cuales la entidad adquiere y enajena activos a largo plazo y otras inversiones.

\section{Cuadro $\mathrm{N}^{\circ} 6.6$}

Flujo de Caja Económico (en Nuevos Soles)

\begin{tabular}{|c|c|c|c|c|c|c|}
\hline \multicolumn{7}{|c|}{ FLUJO DE CAJA ECONÓMICO } \\
\hline & 0 & 1 & 2 & 3 & 4 & 5 \\
\hline INGRESOS & & 340,200 & 437,400 & 534,600 & 680,400 & 826,200 \\
\hline Ventas & & 340,200 & 437,400 & 534,600 & 680,400 & 826,200 \\
\hline \multicolumn{7}{|l|}{ EGRESOS } \\
\hline INVERSIÓN TOTAL & $(66,740)$ & & & & & \\
\hline Activo Fijo & $(6,972)$ & & 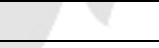 & & & \\
\hline Capital de Trabajo & $(55,295)$ & & & & & \\
\hline Gastos Pre-Operativos & $(4,473)$ & & & & 4 & \\
\hline COSTOS & & $(337,600)$ & $(430,912)$ & $(497,008)$ & $(629,200)$ & $(695,296)$ \\
\hline Costos Fijos & & $(133,480)$ & $(133,480)$ & $(133,480)$ & $(133,480)$ & $(133,480)$ \\
\hline Costos Variables & & $(204,120)$ & $(297,432)$ & $(363,528)$ & $(495,720)$ & $(561,816)$ \\
\hline GASTOS & & & $(1,013)$ & $(18,332)$ & $(26,532)$ & $(9,491)$ \\
\hline Participación en Feria & & & $\square$ & $(16,255)$ & $(20,000)$ & \\
\hline Hosting & 7 & A & $(700)$ & $(700)$ & $(700)$ & $(700.00)$ \\
\hline Pago de Impuestos & 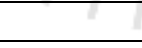 & + & (313) & $(1,377)$ & $(5,832)$ & $(8,791)$ \\
\hline Escudo fiscal por Depreciación & & 360 & 360 & 360 & 360 & 55 \\
\hline FLUJO DE CAJA ECONÓMICO & $-66,740$ & 2,601 & 5,836 & 19,621 & 25,030 & 121,470 \\
\hline
\end{tabular}




\section{COK ANUAL (\%) \\ VANE \\ TIRE \\ $9.21 \%$ \\ 51,403 \\ $24.64 \%$}

Para determinar el costo de oportunidad del capital o tasa de descuento del proyecto, se utilizó la fórmula de CAPM el cual tiene como componentes rf: Tasa libre de riesgo o bonos de tesoro de los Estados Unidos; rm: la rentabilidad del mercado de invertir en el proyecto; b: beta apalancado del sector; y rp: riesgo país, es el riesgo que pueden incurrir los inversionistas a la hora de invertir en un proyecto. Véase el siguiente cuadro.

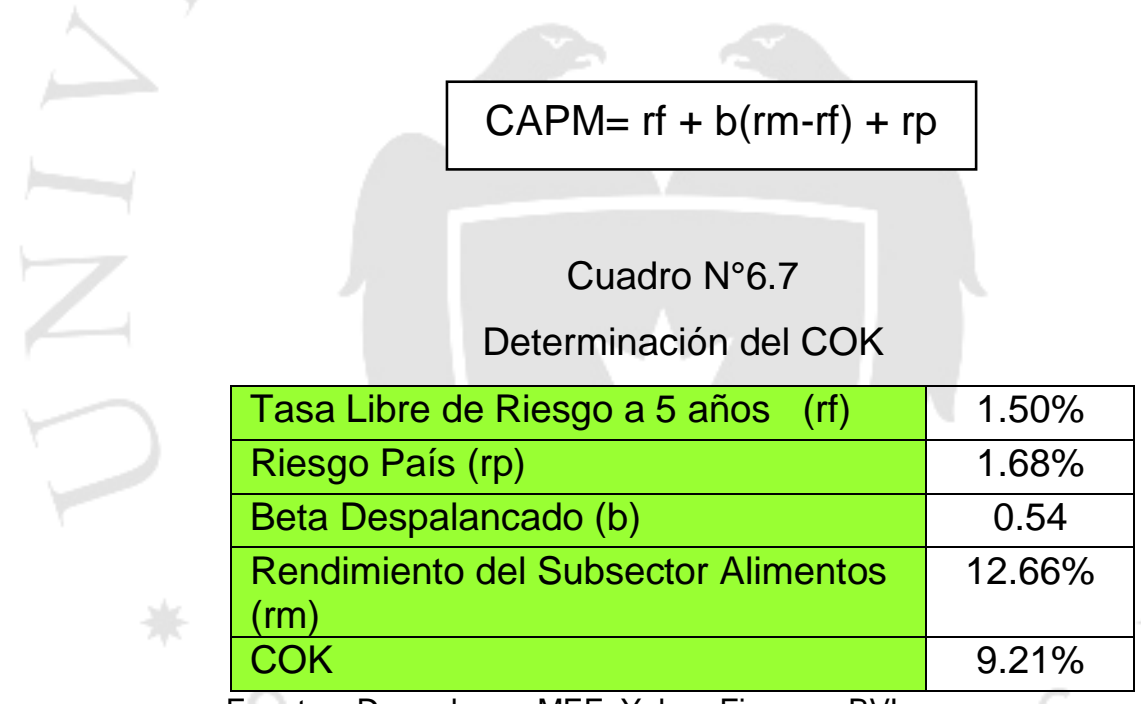

Fuentes: Damodaran, MEF, Yahoo Finance, BVL

Se observa un saldo positivo de efectivo desde el segundo año en el que se inicia la venta de banano orgánico.

El Valor Actual Neto es mayor a cero, por lo que el proyecto debe aceptarse, ya que indica que la inversión se recuperará y generará una rentabilidad adicional, resultado de un proyecto rentable y viable. 
En cuanto a la Tasa Interna de Retorno (TIR), se observa que se obtiene un 24.64\%. Al ser mayor al costo de oportunidad de los accionistas (COK), se determina que el proyecto es rentable, además, el hecho de que sea menor a $50 \%$ muestra la factibilidad del mismo y la certidumbre de la generación de fondos. 


\subsection{Estado de Situación Financiera}

Como se puede apreciar en el Cuadro N6.8 el Balance General de Golden Banana S.A.C. es bastante simple, dado que en el pasivo, debido a su política de financiamiento, no tendrá préstamos, ni otros instrumentos adicionales al efectivo necesario para cubrir sus operaciones. Con respecto al capital social, se puede mencionar que este se mantiene en los cinco años.

Los resultados acumulados son determinados por concepto de las utilidades retenidas el periodo interior, las cuales son reinvertidas en la empresa desde su inicio, constituyendo así, una forma de financiamiento interno.

Cuadro $\mathrm{N}^{\circ} 6.8$

Estado de Situación Financiera (en Nuevos Soles)

\begin{tabular}{|c|c|c|c|c|c|}
\hline \multicolumn{6}{|c|}{ Estado de Situación Financiera } \\
\hline Años & 1 & 2 & 3 & 4 & 5 \\
\hline \multicolumn{6}{|c|}{ Activo } \\
\hline \multicolumn{6}{|c|}{ Activo Corriente } \\
\hline Caja y Bancos & $57,895.24$ & $63,683.94$ & $84,008.77$ & $108,678.32$ & $230,092.97$ \\
\hline Saldo a favor IGV & $1,063.59$ & & & & 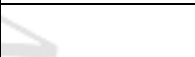 \\
\hline Cuenta por cobrar & $2,224.00$ & $2,224.00$ & $2,224.00$ & $2,224.00$ & $2,224.00$ \\
\hline Total Activo Corriente & $61,182.83$ & $65,907.94$ & $86,232.77$ & $110,902.32$ & $232,316.97$ \\
\hline \multicolumn{6}{|c|}{ Activo No Corriente } \\
\hline $\begin{array}{c}\text { Inmueble, Maquinaria y } \\
\text { Equipo }\end{array}$ & $4,708.27$ & $3,507.73$ & $2,307.19$ & $1,106.64$ & 922.20 \\
\hline Activos Intangibles & & & & & \\
\hline Total Activo No Corriente & $4,708.27$ & $3,507.73$ & $2,307.19$ & $1,106.64$ & 922.20 \\
\hline Total Activos & $65,891.10$ & $69,415.67$ & $88,539.96$ & $112,008.96$ & $233,239.17$ \\
\hline \multicolumn{6}{|c|}{ Pasivo y Patrimonio } \\
\hline \multicolumn{6}{|c|}{ Pasivo corriente } \\
\hline Impuestos por pagar & & 312.86 & $5,831.15$ & $8,790.05$ & $39,006.08$ \\
\hline Total Pasivo Corriente & & 312.86 & $5,831.15$ & $8,790.05$ & $39,006.08$ \\
\hline Total Pasivos & & 312.86 & $5,831.15$ & $8,790.05$ & $39,006.08$ \\
\hline Capital Social & $66,739.95$ & $66,739.95$ & $66,739.95$ & $66,739.95$ & $66,739.95$ \\
\hline Utilidades del Periodo & $(848.85)$ & $3,211.71$ & $13,606.01$ & $20,510.11$ & $91,014.18$ \\
\hline Resultados Acumulados & & $(848.85)$ & $2,362.86$ & $15,968.86$ & $36,478.97$ \\
\hline Total Patriminio & $65,891.10$ & $69,102.81$ & $82,708.81$ & $103,218.92$ & $194,233.10$ \\
\hline $\begin{array}{c}\text { Total Pasivos y } \\
\text { Patrimonio } \\
\end{array}$ & $65,891.10$ & $69,415.67$ & $88,539.96$ & $112,008.96$ & $233,239.17$ \\
\hline
\end{tabular}




\subsection{Estado de Resultados}

Este estado de partidas refleja la situación económica de la empresa y muestra tanto los ingresos como los egresos en los que se incurrió para finalmente obtener una utilidad.

\section{Cuadro $\mathrm{N}^{\circ} 6.9$}

\section{Estado de Resultados (en Nuevos Soles)}

\begin{tabular}{|l|c|c|c|c|c|}
\hline \multicolumn{7}{|c|}{ Estado de Ganancias y Pérdidas } \\
\hline Concepto / Años & 1 & 2 & 3 & 4 & 5 \\
\hline Ventas & 340,200 & 437,400 & 534,600 & 680,400 & 826,200 \\
\hline Costo de Ventas & $(204,120)$ & $(297,432)$ & $(363,528)$ & $(495,720)$ & $(561,816)$ \\
\hline Utilidad Bruta & 136,080 & 139,968 & 171,072 & 184,680 & 264,384 \\
\hline Gastos de Venta y de Administración & $(135,728)$ & $(134,179)$ & $(150,434)$ & $(154,179)$ & $(134,179)$ \\
\hline EBITDA & 352 & 5,789 & 20,638 & 30,501 & 130,205 \\
\hline Depreciación & $(1,201)$ & $(1,201)$ & $(1,201)$ & $(1,201)$ & $(184)$ \\
\hline UAll & $(849)$ & 4,588 & 19,437 & 29,300 & 130,020 \\
\hline Intereses & 0 & 0 & 0 & 0 & 0 \\
\hline UAI & $(849)$ & 4,588 & 19,437 & 29,300 & 130,020 \\
\hline Impuesto a la Renta (30\%) & & $(1,376)$ & $(5,831)$ & $(8,790)$ & $(39,006)$ \\
\hline U.Neta & $(849)$ & 3,212 & 13,606 & 20,510 & 91,014 \\
\hline
\end{tabular}




\subsection{Análisis de Riesgos}

En el comercio internacional existe una diversidad de riesgos provenientes tanto del ámbito nacional como del internacional. Éstos deben ser tomados en cuenta para plantear estrategias de gestión de riesgos, con el fin de reducir la vulnerabilidad y aumentar la capacidad de respuesta. A continuación se explicarán los riesgos que se consideran de mayor impacto en la comercialización de banano orgánico a Canadá.

\subsubsection{Fraude y Estafa}

La mejor manera de protegerse contra el fraude y estafa es informándose sobre la solidez financiera de los clientes a través de instituciones financieras y seleccionando el medio de pago adecuado para las ventas internacionales que ofrezca la mejor relación entre seguridad de cobro, agilidad y costo.

\subsubsection{Riesgo País}

Puede significar un mayor costo para las empresas interesadas en comercializar, lo cual genera que más intermediarios participen pero a costos de más comisiones y sobre costos, pudiendo incluso no suceder la compra venta internacional. En el caso de Canadá, éste ha recibido la calificación máxima según la agencia calificadora Standar \& Poor's. Esta calificación (AAA) simboliza la alta capacidad de pago de capital e intereses y la inexistencia de factores de riesgo. 


\subsubsection{Fenómenos Naturales}

Dentro de los fenómenos naturales más relevantes están los terremotos y el fenómeno del niño. Debido a que el Perú se encuentra en el denominado cinturón de fuego, donde ocurren el $80 \%$ de las actividades sísmicas mundiales 71 . Esto puede generar daños a la infraestructura de carreteras, caminos y puentes, interrupción del fluido eléctrico.

El fenómeno del niño trae consigo manifestaciones en la costa, siendo el norte del país la zona más afectada debido a las lluvias extremas, que causan inundaciones y desbordes de ríos. Esta zona coincide con el área de mayor producción de banano, que tiene lugar en la costa norte de nuestro país. Este fenómeno ocasiona un incremento en los costos de producción y cambios en las condiciones organolépticas del producto, ya que aumenta la humedad de las plantas, contribuyendo a la incidencia de plagas y enfermedades en cultivos como el del banano. En resumen, este fenómeno tiene consecuencias devastadoras, ya que, en líneas generales, interrumpe la producción y afecta la infraestructura (transporte, comunicaciones, etc.) $)^{7273}$

Ambos fenómenos tienen implicancias perjudiciales no solo en el aspecto económico, sino también social, ya que muchas viviendas se ven afectadas por estos. No es tarea fácil predecir estos hechos, debido al ambiente de incertidumbre e inseguridad, generado por la inestabilidad climatológica que se presenta en la actualidad. Por eso, se recomienda incluir dentro del planeamiento estratégico, una estrategia de gestión del riesgo. A pesar de que, debido a la ubicación geográfica del Perú, la producción no se ve afectada por actividad volcánica ni huracanes, la frecuencia con la que se dan los sismos y el efecto del fenómeno del niño representan un riesgo considerable a tener presente.

\footnotetext{
${ }^{71}$ Radio Programas del Perú. "El Perú reside en zona donde ocurren el 80\% de las actividades sísmicas"

72 Ministerio de Agricultura. "Problemática del Fenómeno del Niño"

${ }^{73}$ Asociación de Productores de Banano Orgánico El Monte y Anexos Mallaritos (APBOSMAM). "Pautas para la gestión del Riesgo y Seguro frente al Fenómeno del Niño"
} 


\subsubsection{Riegos de Operación}

Este riesgo se presenta por las malas decisiones de gestión, control de calidad deficiente y la falta de preparación para adecuar el producto al mercado de destino.

\subsection{Análisis de Sensibilidad}

A través del análisis de sensibilidad se busca medir cómo una variación en el precio puede afectar la rentabilidad del proyecto, a partir de una serie de suposiciones.

Debido a que solo se toma como referencia el cambio en el precio, nos encontramos frente a un análisis unidimensional. Además, es importante mencionar que la cantidad exportada se asume como una cuota constante.

En el peor panorama de inversión, el resultado es el fracaso del proyecto, mientras que el escenario optimista muestra una motivación para invertir en el proyecto a pesar del riesgo.

El escenario normal es al que apunta el proyecto debido a que representa el resultado más probable

Cuadro $\mathrm{N}^{\circ} 6.10$

Análisis de Sensibilidad

\begin{tabular}{|c|c|c|c|c|}
\hline \multicolumn{2}{|c|}{ ESCENARIO } & PRECIO & VAN & TIR \\
\hline \multirow{3}{*}{ Optimista } & $+15 \%$ & S/.2.88 & 155,086 & $61.02 \%$ \\
\cline { 2 - 5 } & $+10 \%$ & S/.2.75 & 120,208 & $47.94 \%$ \\
\cline { 2 - 5 } Normal & $+5 \%$ & S/.2.63 & 86,282 & $36.11 \%$ \\
\hline \multirow{3}{*}{ Pesimista } & $0 \%$ & S/. 2.50 & 51,403 & $24.64 \%$ \\
\cline { 2 - 5 } & $-5 \%$ & S/.2.38 & 17,477 & $14.29 \%$ \\
\cline { 2 - 5 } & $-10 \%$ & S/.2.25 & 17,401 & $4.32 \%$ \\
\hline
\end{tabular}




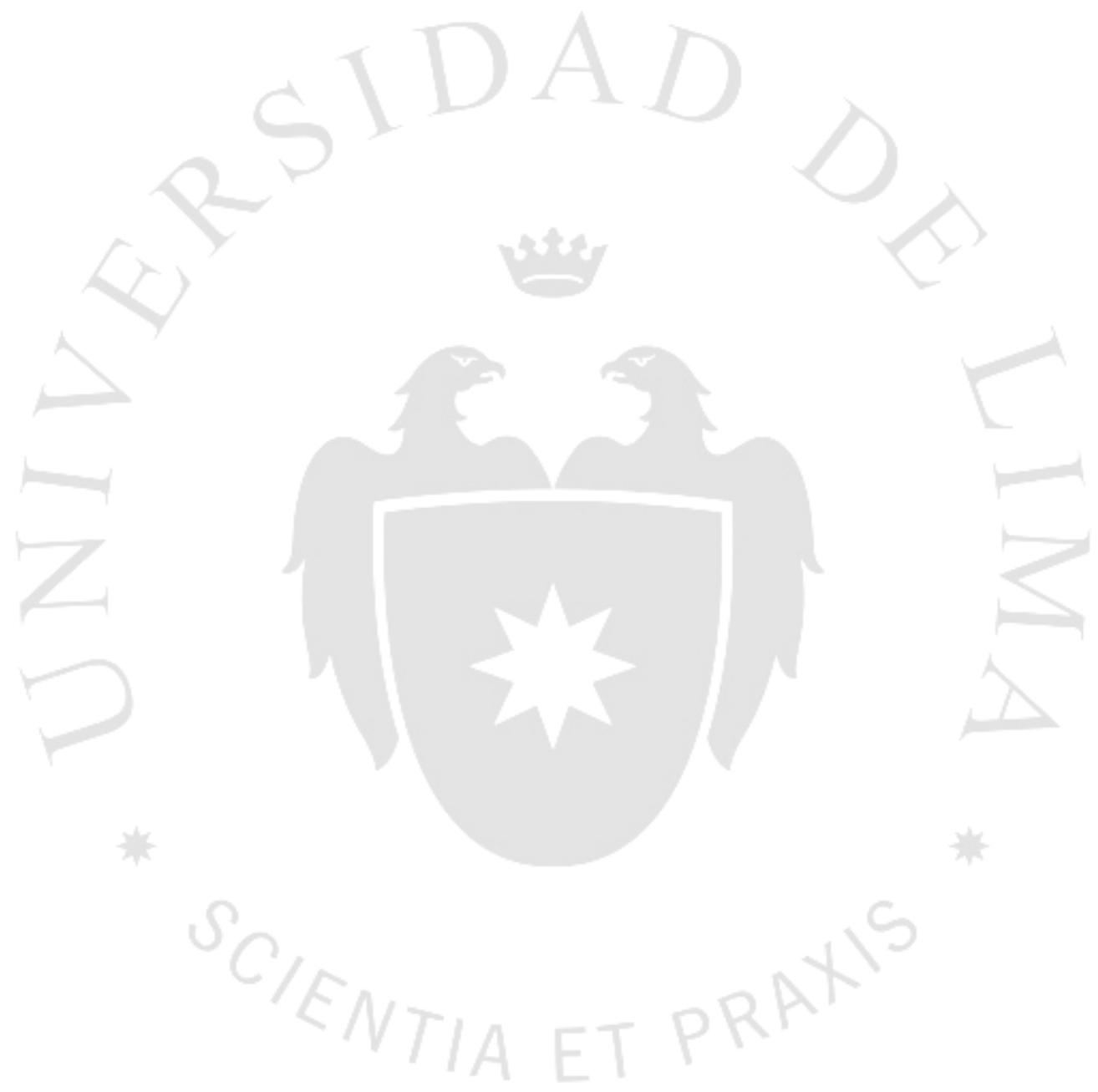




\section{CONCLUSIONES}

1. La calidad del banano que sale de parcela y el control logístico durante su empaque, transporte y distribución son aspectos claves que determinan el estado, en el que el banano llega al consumidor.

2. Canadá es un mercado potencial y el más idóneo para direccionar las exportaciones peruanas de banano orgánico. Sus ciudades ubicadas en el sureste que poseen mayor desarrollo económico, entre estas Toronto, presentan una buena posibilidad acceso para el banano orgánico peruano, no solo por el crecimiento importador de este producto en los últimos años, sino también por factores como las regulaciones, características y tendencias del mercado.

3. Las cooperativas productoras de banano orgánico no cuentan con la capacidad suficiente para exportar por si solos, problema que para nosotros representa una oportunidad como empresa acopiadora que cuenta con los estándares suficientes para exportar.

4. El nivel de producción nacional no es restrictivo, ya que la oferta solicitada representa solo un $0.07 \%$ de la oferta total peruana. Además, al realizarse una proyección de la demanda, se concluye que ésta muestra una tendencia al alza, lo que asegura las ventas, junto con la existencia de un nicho de mercado dispuesto a para un precio superior.

5. La empresa proveedora de banano orgánico es CEPIBO, debido a su experiencia, reputación, nivel de producción y ubicación geográfica, que facilita el flujo del producto al puerto de Paita debido a su cercanía con este. 
6. La evaluación financiera del proyecto muestra dos hechos, que concuerdan en que se trata de un proyecto rentable y factible. Primero, se calculó una TIR de $24.64 \% \%$, siendo ésta mayor al costo de oportunidad del capital (COK), es decir, el rendimiento sobre el capital que el proyecto genera, es superior al mínimo aceptable para la realización del proyecto, lo que coincide con el criterio de decisión de aceptar un proyecto en dicha situación. Segundo, se calculó un VAN mayor a cero, que refleja que la suma actualizada de todos los beneficios provenientes del proyecto es superior a la suma de los costos actualizados y de la inversión. Este último resultado asevera la viabilidad del proyecto.

7. Hemos encontrado que el mercado de Canadá tiene un potencial crecimiento en la importación de frutas orgánicas, debido a que el consumo per cápita de este tipo de productos tiende al alza y, en la actualidad, sólo el $1.3 \%$ del total de granjas de Canadá son dedicadas a la producción de orgánicos. 


\section{RECOMENDACIONES}

1. Promover el desarrollo el cultivo de banano orgánico entre los pequeños productores de banano del norte del Perú, reducir su vulnerabilidad agroecológica y mejorar su posicionamiento comercial en mercados de exportación de productos orgánicos, todo ellos para incrementar los ingresos de familias campesinas y a la vez reducir la pobreza.

2. En relación a otras formas de consumo de banano, una oportunidad importante de exportación son las mezclas de puré de banano con varios productos entre los que se destacan los alimentos infantiles como papillas y compotas, además de la harina de banano, ambos productos relacionados de los cuales se derivan rentabilidad atractivas.

3. Organizar seminarios de capacitación que permitan a los empresarios beneficiarse de un fortalecimiento de las capacidades productivas, organizativas y empresariales, para que así puedan hacer frente a la gestión débil con la que operan, logren una mayor autonomía y se conecten con los mercados internacional.

4. Debido a que a las cooperativas se les presenta como reto principal integrarse a cadena dominadas por actores que demandan altos volúmenes, estandarización e inocuidad, se debe ofrecer programas de formación con el fin de aumentar los rendimientos de los cultivos y puedan articularse adecuadamente a las dinámicas del comercio internacional del banano orgánico. 
5. Atraer IED interesada en incursionar en este rubro de negocios, surtiendo de infraestructura y tecnología de punta a las cooperativas, contribuyendo a que éstas cuenten con las capacidades necesarias para reducir sus costos. Esto, en conjunto con una mayor asistencia técnica y capacitación, repercutiría una mejor participación de mercado y desarrollo institucional.

6. Promover las exportaciones con valor agregado, con énfasis en las pequeñas y medianas empresas de manera descentralizada, a través de un incremento del apoyo financiero por parte de instituciones bancarias para poder invertir en un proyecto de exportación en el sector agrícola.

7. Los Gobiernos Regionales deberían en sus Planes estratégicos de Exportación (PERX) promover los cultivos que poseen ventaja comparativa regional para la exportación en los pequeños agricultores dentro de los productos del Boom exportador agroindustrial actual.

8. Promover a los pequeños productores a través de programas que les faciliten el acceso a financiamiento. Las empresas peruanas en su mayoría son pequeñas o medianas, pero debido al gran número de estas, podrían representar importantes cifras dentro de las exportaciones peruanas. 


\section{BIBLIOGRAFÍA}

1. Alimentación Sana. Propiedades y Usos de la Banana o Plátano. www.alimentacionsana.com.ar/Portal\%20nuevo/actualizaciones/propiedadesbanana.htm

2. Andina: Agencia Peruana de Noticias. Expertos israelíes mostrarán innovaciones para impulsar desarrollo agrícola en Perú.

3. Andino Investment Holding. Puerto de Paita comienza a atender con grúas móviles. www.andino.com.pe/noticia/puerto-de-paita-comienza-a-atender-con-gruas-moviles

4. Asesoría Financiera por el Profesor Carlos Azabache - Proyectos de Emprendimiento de la Universidad de Lima

5. Asociación de Bananeros de Colombia. www.augura.com.co

6. Asociación de Bananeros de Magdalena y Guajira (ASBAMA). www.asbama.com

7. Asociación Macroregional de Productores (AMPEX). www.ampex.com.pe

8. Best Health Magazine. Are Canadians too fat?

9. CBC News. $31 \%$ of Canadian kids are overweight or obese.

10. Central Intelligence Agency. World Factbook.

11. Comisión de Promoción del Perú para la Exportación y el Turismo (PROMPERU). Guía Exportadora 2012. http://issuu.com/promperu/docs/guiaexportadora2012

12. Congreso de la República del Perú. Ley de Promoción del Sector Agrario №27360. 
13. CÓRDOBA, Marcial. Formulación y evaluación de proyectos. Colombia, Ecoe Ediciones, 2006.

14. Corporación Bananera Nacional. www.corbana.co.cr

15. Departamento de Agro y Agroindustria de la Sub Dirección de Promoción Comercial (PROMPERÚ). Desenvolvimiento del Comercio Exterior Agroexportador. 2015.

16. Departamento de Salud y Servicios Comunitarios de Canadá. School Food Guidelines. Canadá. Segunda Edición.

17. Diario el Universo. Exportaciones de banano piden revisión de precio.

18. Entrevista al Ing. Wiliam Arteaga Donayre - Coordinador de Proyectos Agrícolas en Promperú.

19. Entrevista a Juan Luis Kuyeng Ruiz - Gerente de Programas y Proyectos Multisectoriales en Promperú.

20. Entrevista al Profesor Miguel Arroyo - Docente de la Universidad de Lima.

21. Food and Agriculture Organization of the United Nations. www.fao.org

22. Foro Económico Mundial. Reporte Global de Competitividad 2015.

23. GALLO, Maricarmen; OFT, Philine y TORRES, Swing. Pautas para la Gestión del Riesgo y Seguro frente al Fenómeno del Niño. Piura, 2011.

24. Gobierno Regional de Piura. www.regionpiura.gob.pe

25. Índice de Libertad Económica 2015. www.heritage.org/index/country/canada

26. Informe Mensual de Exportaciones: Sector Agro Perú 2015. www.siicex.gob.pe/siicex/resources/exportaciones/438888563rad7E9FF.pdf

27. Iniciativa para la Integración de la Infraestructura Regional Suramericana (IIRSA). www.iirsa.org/proyectos/detalle_proyecto.aspx $\mathrm{h}=25 \& \mathrm{x}=9$ \&idioma $=\mathrm{ES}$ 
28. Instituto de Promoción de Exportaciones e Inversiones (ProEcuador). www.proecuador.gob.ec

29. Instituto Nacional de Estadística e Informática (INEI). Estadísticas de las Tecnologías de Información y Comunicación en los Hogares.

30. LICATA, Marcela. "El plátano, excelente combinación de vitaminas, minerales y energía". www.zonadiet.com/comida/platano.htm

31. Ministerio de Comercio Exterior y Turismo. "Plan Operativo de Mercado de Canadá". Perú. Primera edición, 2010.

32. Oficina Económica y Comercial de la Embajada de España en Toronto. El mercado de Alimentación en Canadá. 2012

33. Oficina Económica y Comercial de la Embajada de España en Toronto. El mercado de productos orgánicos en Canadá. 2007.

34. Sub Dirección de Inteligencia de Mercados y Prospectiva Comercial (PROMPERÚ). Guía de Mercado Canadá. Perú.

35. TANAKA, Gustavo. Análisis de Estados Financieros Para la Toma de Decisiones. Pontificia Universidad Católica del Perú. Perú, 2005.

36. Ministerio de Agricultura. Boletín Banano. http://www.minag.gob.pe/portal/download/pdf/herramientas/cendoc/manualesboletines/banano/banano_feb11.pdf

37. Ministerio de Agricultura. Ministerio de Agricultura mejora la oferta tecnológica del banano orgánico.

38. Ministerio de Agricultura. Herramienta de información: SISAGRI. http://sisagri.minag.gob.pe:8080/sisagri/portal/index.jsf

39. Ministerio de Agricultura, Ganadería, Acuacultura y Pesca. Reglamento a la ley para estimular y comercializar el banano. http://www.agricultura.gob.ec/wp- 
content/uploads/downloads/2012/09/reglamento-a-la-ley-para-estimular-ycomercializar-el-banano.pdf

40. Ministerio de Producción. Guía de Constitución y Formalización de Empresas

41. Organic Agriculture 2012: Key Indicators and Leading Countries. www.organicworld.net

42. Sistema Integrado de Información de Comercio Exterior (SIICEX). www.siicex.gob.pe

43. The Star. Obesity Rates in Canada: Adult obesity rates in Canada reaching historic highs, UBC study warns. http://www.thestar.com/news/canada/2013/02/28/adult_obesity_rates_in_canada_reac hing_historic_highs_ubc_study_warns.html

44. TAPIA, Evelyn. La producción de banano creció en tres trimestres. EI Comercio. Perú, Octubre 2014. www.elcomercio.com/actualidad/produccion-bananocrecio-ecuador-cifras.html

45. TOKESHI, Alberto. Planifique, desarrolle y apruebe su tesis: Guía para mejores resultados. Lima: Universidad de Lima, Fondo Editorial, 2012. 


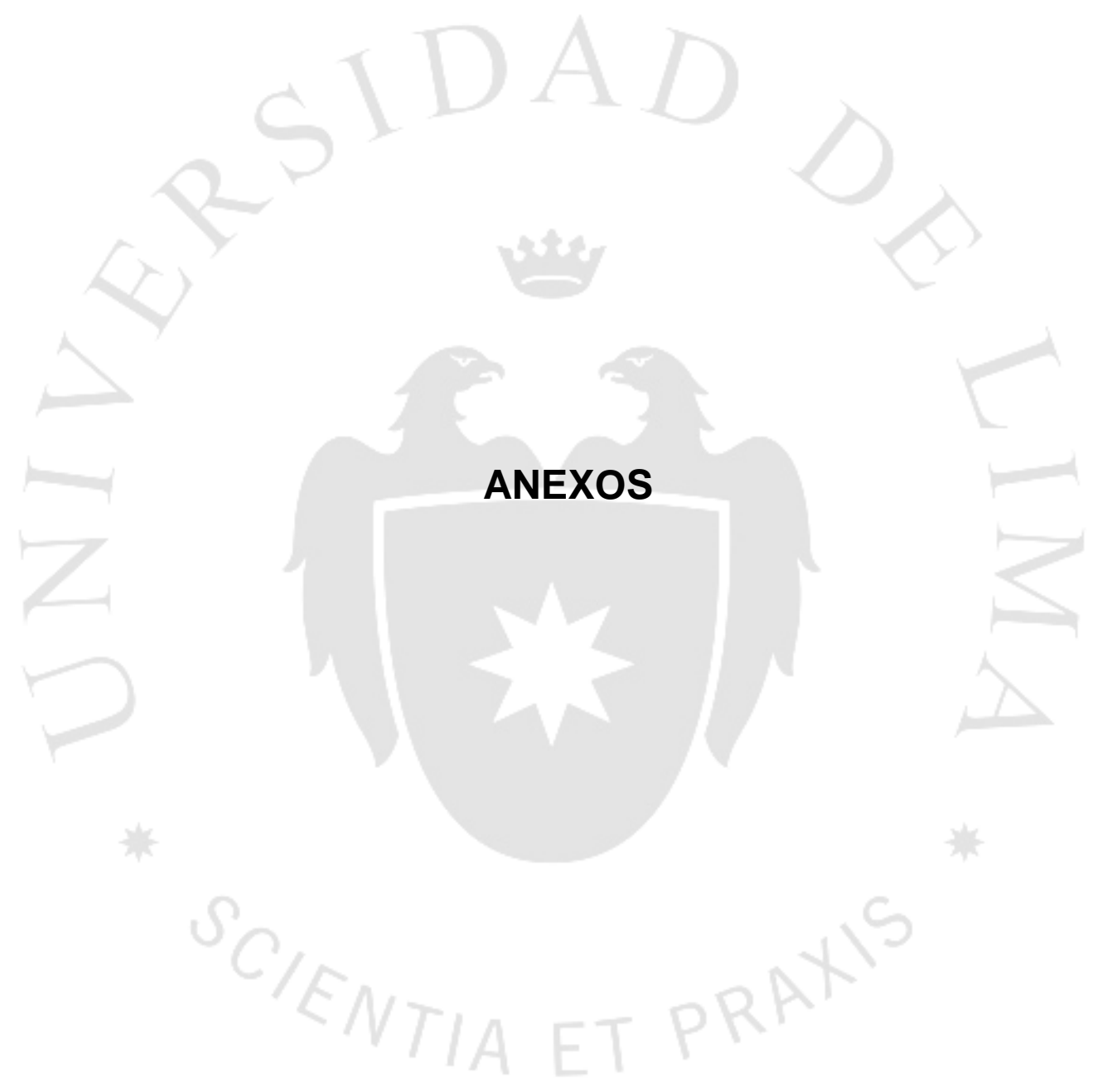




\section{Anexo $\mathrm{N}^{\circ} 1$}

\section{Agricultura impulsa productividad de banano orgánico en Piura}

Dicho proyecto se dará en el valle del Chira, San Lorenzo, Morropón, Medio y Bajo Piura.

12 de octubre del $2015-11: 51$ AM

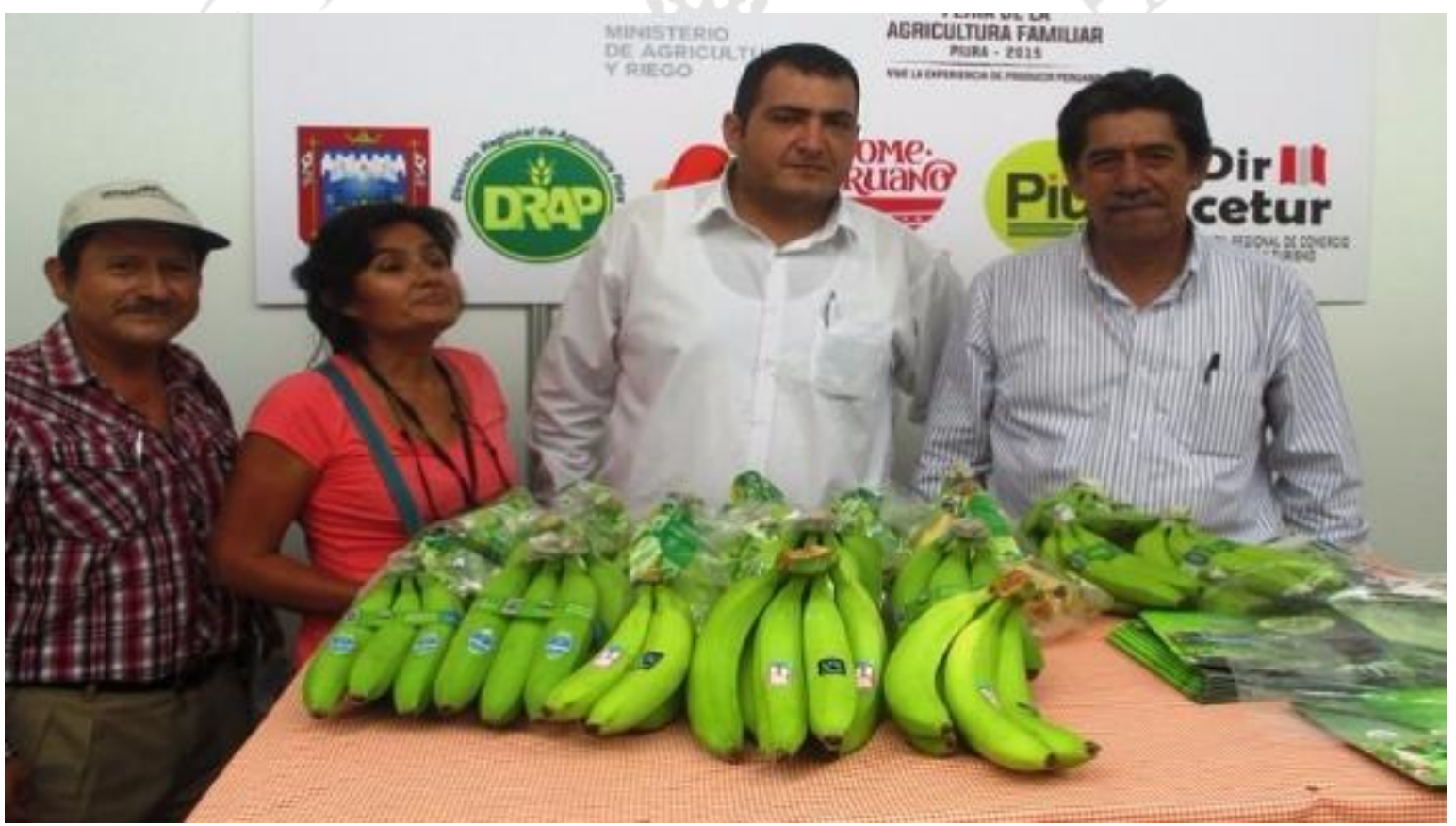

El proyecto cuenta con un presupuesto de 9 millones de soles | Fuente: Cortesía (Dirección de Agricultura)

La Dirección Regional de Agricultura de Piura, con financiamiento del gobierno regional por un costo superior a los 9 millones de soles, ejecuta el Proyecto de Inversión Pública (PIP) denominada "Mejoramiento de la competitividad de la cadena productiva del banano orgánico para mejorar la oferta exportable en la región Piura". 
Dicho proyecto se elabora ya, con un primer desembolso monetario del gobierno regional, de más de 3 millones en el valle del Chira, San Lorenzo, Morropón, Medio Piura y en el Bajo Piura, donde se incentivará la siembra en zonas aptas para el cultivo; refirió el director regional de Agricultura, Mario Laberry.

EI PIP regional se ejecuta con la finalidad de poder incrementar el volumen de producción de 1200 caja por hectárea año, promedio actual de rendimiento del banano orgánico regional, hacia 3000 cajas por hectárea año, promedio de otros países competidores líderes, como Costa Rica; así lo manifestó Laberry. 


\section{Anexo $\mathrm{N}^{\circ} 2$}

\section{Productos orgánicos: El banano es el de mayor exportación en Perú}

21 de octubre de 2014

COMPARTE

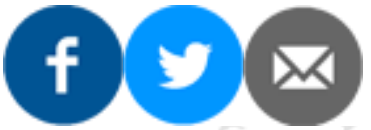

- Los bananos frescos son la principal presentación de exportación.

- Holanda es el principal mercado de destino del banano orgánico peruano.

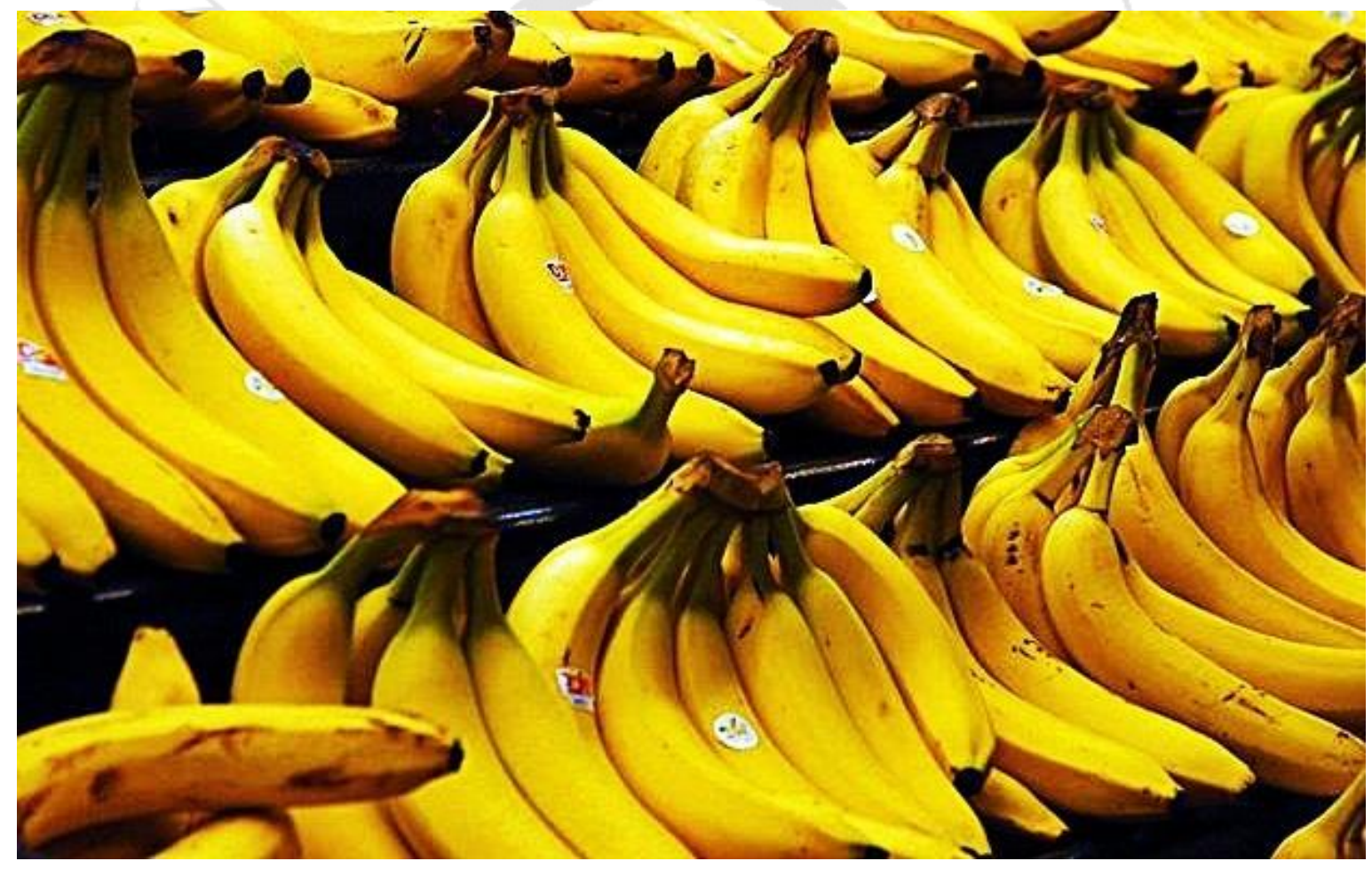

Casi la mitad de todos los productos orgánicos que se exportan corresponden a bananos convirtiéndolo en el principal producto orgánico de exportación de Perú. Para el 2013, el valor de las exportaciones de dicho producto ascendió a 88,1 millones de dólares. 


\section{PRODUCTOS ORGANICOS: EL BANANO}

Valor de las exportaciones en millones de US\$

2012

83,6

2013

88,1

\section{$5 \%$ más 2012}

Fuente: SUNAT.

proexpansion*

Nuestros bananos van principalmente a Holanda, principal mercado de destino, seguido de Estados Unidos y Alemania, países conocidos por tener una gran cantidad de consumidores de orgánicos en crecimiento. Sin embargo, casi todos los bananos que se envían al exterior son frescos con una muy pequeña participación de bananos secos.

Gladys Triveño:"Perú tiene grandes posibilidades de convertirse una potencia mundial en productos orgánicos"

Aunque las cifras anuales registran un crecimiento constante de las exportaciones de este producto desde el 2001, hay que tener en cuenta que ha habido un pequeño retroceso en la exportación de bananos secos. Hace falta, en ese sentido, que más empresas se entreguen a la tarea de desarrollar productos elaborados en base a banano orgánico, el cual goza de gran predilección en mercados como Canadá o Estados Unidos, donde lossnacks en base a bananos son los favoritos por sus consumidores. 


\section{ANEXO N³}

\section{Perú exportó banano orgánico por US\$ 145 millones en el 2015 Por Norma Rojas -}

\section{Febrero 26, 2016}

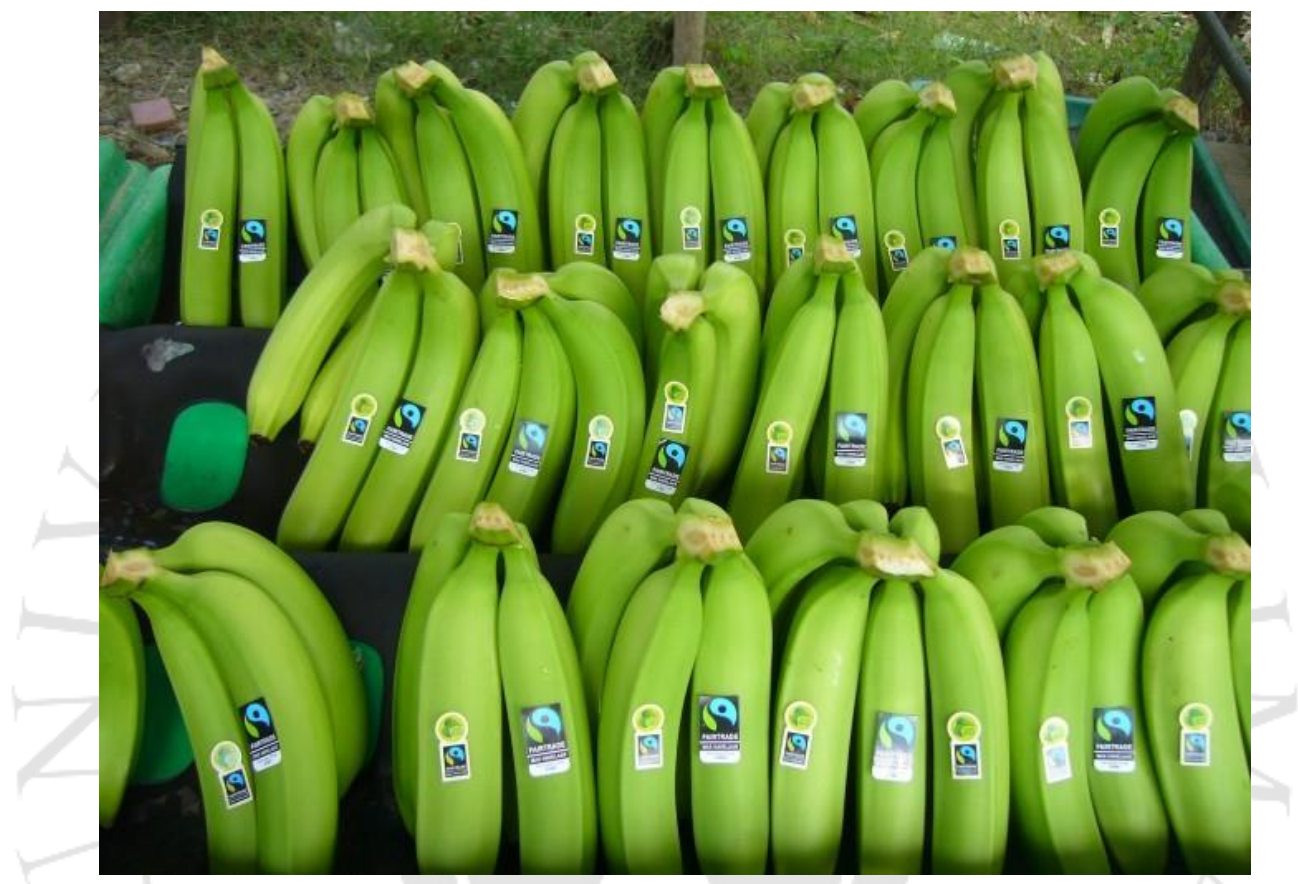

El cultivo del banano y plátano en el Perú, tienen una gran importancia económica y social, por ser uno de los productos fundamentales en la dieta alimentaria del poblador de la Amazonía peruana e incluso en la zonas tropicales del norte peruano en donde se cultiva intensivamente con fines de exportación. Estas zonas tienen diferentes sistemas de producción debido al clima y altura tan variada que presenta, algunos asociados a cultivos como es el café y cacao y otros como un monocultivo.

Cuando hablamos del plátano y banano, nos estamos refiriendo a una de las frutas más ricas en vitaminas, hidratos de carbono y minerales. Tiene muchas propiedades medicinales, así como cosméticas, además de ser una fruta de buen sabor y muy versátil. 
A lo largo del Perú la producción de banano y plátano se da en diferentes regiones como la selva norte (Loreto, Amazonas, San Martin), la selva central (Junin y Ucayali) y la costa norte (Tumbes, Piura y Lambayeque).

Es en la costa norte del Perú una zona de clima subtropical desértico y escasas lluvias donde se está desarrollando la producción de banano orgánico para la exportación. Zona que ha sufrido desde el año 2000 la conversión del banano convencional para el mercado local a la producción de banano orgánico para la exportación.

En el año 2000 se exportaron las primeras cajas de banano que sumaron 856 TM hacia EEUU, Holanda y Bélgica. A lo largo de estos años las exportaciones de este producto han ido en aumento cada año y diversificándose a otros mercados como Japón y Alemania. Esto gracias al aumento del consumo de productos orgánicos en los mercados externos.

Desde la primera exportación de banano orgánico peruano de la zona norte del Perú han pasado 16 años con exportaciones exponenciales a los largo de estos años. Actualmente Perú ocupa el tercer puesto de las exportaciones de banano orgánico mundiales, liderados por República Dominicana y seguido por Ecuador.

En el año 2015 se exportó un total de 190000 TM y representó un valor de US\$ FOB 145 millones, siendo el primer destino de exportación fue EE.UU., seguidos de Holanda, Alemania, Bélgica Corea, Finlandia y Japón. Esto indica que existe una creciente demanda del banano orgánico peruano en los mercados externos.

Se puede decir que ha transcurrido la primera etapa del banano orgánico peruano, encontrando nichos de mercado, diversificando la exportación a varios continentes y exportando bajo estándares de calidad adecuados. Ahora se ha entrado a la segunda fase que es de consolidar más a esta cadena productiva para mejorar la competitividad, ya que el mercado internacional al que se dirigen se rige por 
estándares de calidad cada vez mayores y más altos, son las afirmaciones de la consultara MCY Cursos y Banano Express.

E muy importante recalcar que parte del éxito del banano orgánico en la zona norte es debido al pequeño agricultor que ha dado el salto de productor convencional para el mercado local para algo más complejo que es exportar de forma orgánica.

La III Conferencia del Banano Orgánico a realizarse los días 7 y 8 de marzo de 9 am a $5 \mathrm{pm}$ en la ciudad de Lima y analizar con expertos internacionales los últimos acontecimientos con respecto a este cultivo. Lugar: Hotel Sol de Oro , Miraflores. Lima, Perú.

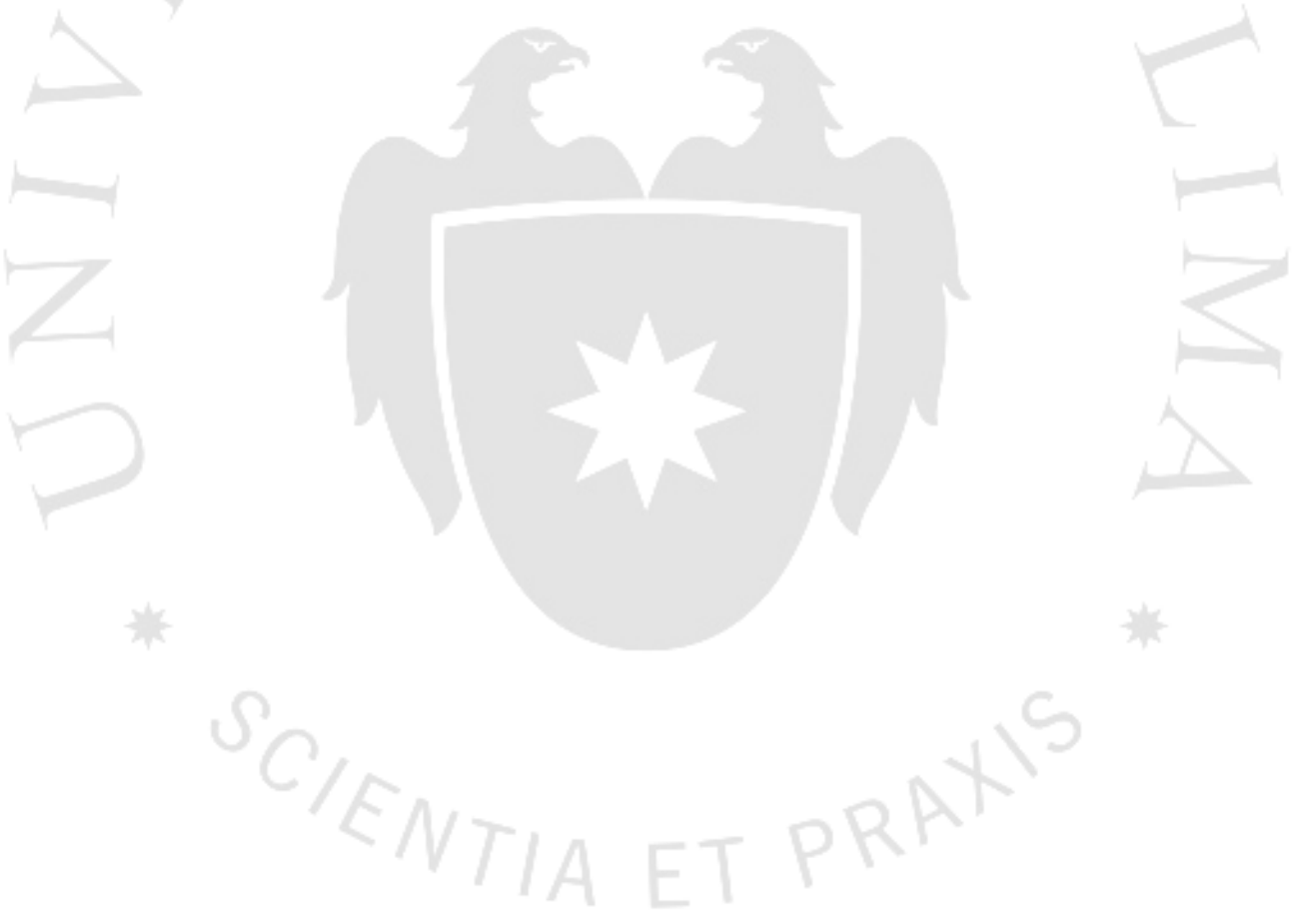




\section{ANEXO N4}

\section{Canada's organic market now fourth largest in the world}

November 21, 2013 at 12:36 pm by Food in Canada staff

(COTA) reveals that Canada's organic industry is growing dramatically.

The market for organics reached $\$ 3.5$ billion in 2012 , with sales of certified organic food and non-alcoholic beverages of $\$ 3$ billion, and is now triple the value of the market in 2006. This makes it the fastest-growing agri-food sector in Canada.

The report, Canada's Organic Market: Growth, Trends and Opportunities, is the most comprehensive study to date of the country's organic marketplace. And according to COTA, it contains the first data on the Canadian organic market since the federal government regulated the sector in 2009.

The estimated value of total organic food and beverage sales in 2012 were $\$ 2.9$ billion, or 1.7 per cent of the market share, while organic alcohol sales reached $\$ 135$ million, or 0.67 per cent of the market. Sales of organic pet food were $\$ 4.1$ million in 2012, with a 0.25 -per-cent market share. Fruits and vegetables made up 40 per cent of total organic food and beverage sales, followed by beverages at 16 per cent (coffee, shelf-stable juices and milk had the highest rates of growth in this category), and dairy and eggs at 15 per cent.

The study also found that there is a diverse consumer base for organics in Canada. More than half of Canadians buy organic products each week, while in British Columbia 66 per cent of consumers buy organics on a weekly basis.

The study was funded by Loblaw Companies, Taste of Nature, UNFI Canada, Whole Foods Market and the Organic Sector Development Program (OSDP). Funding for the OSDP comes from Agriculture and Agri-Food Canada's Canadian 
Agricultural Adaptation Program, which is delivered by the Investment Agriculture Foundation in B.C.

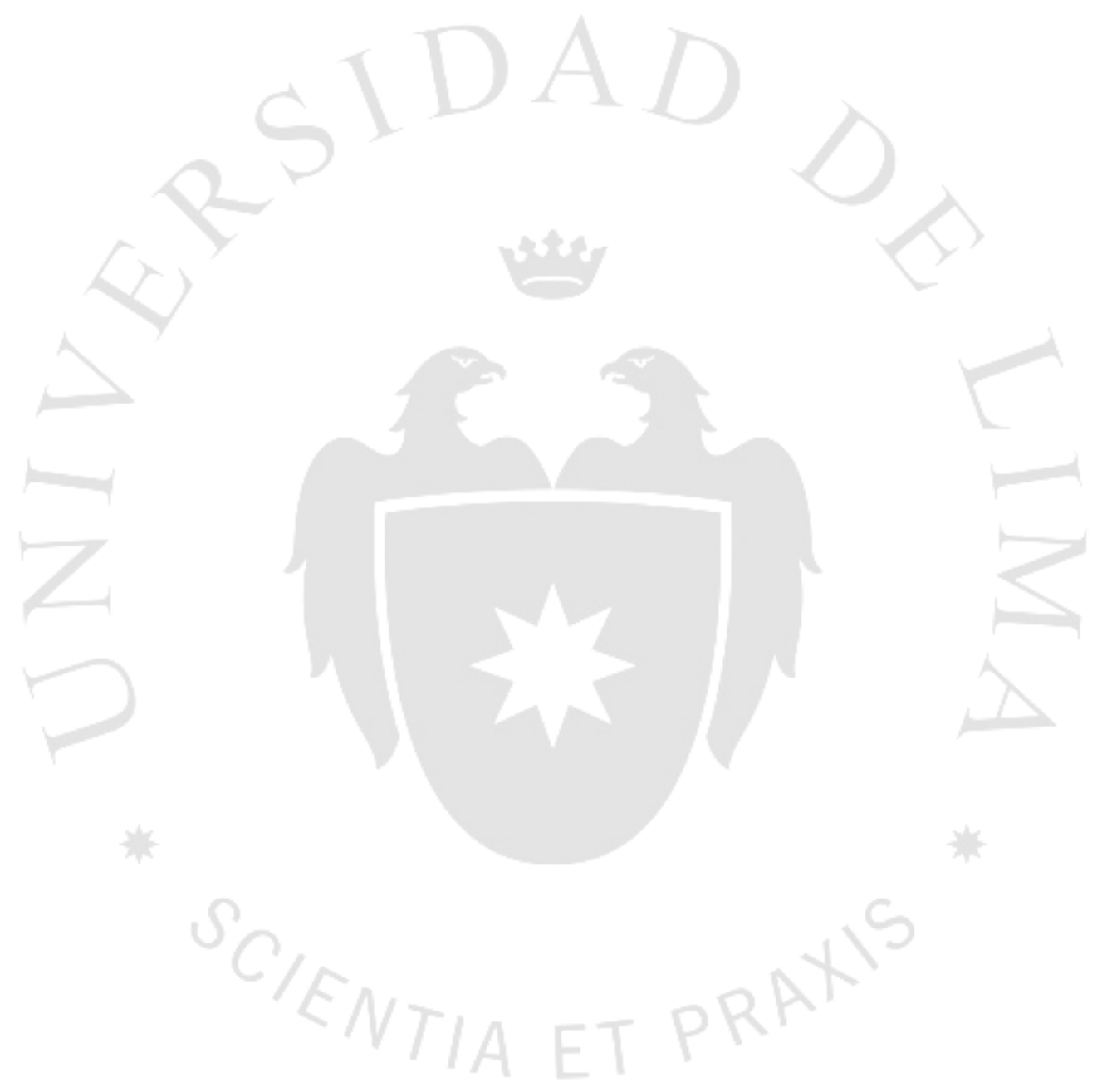




\section{ANEXO N5 $5^{74}$}

Perspectivas para un aumento del mercado para un producto importado por Canadá en 2011 Producto : 080300 bananas o platanos, frescos o secos.

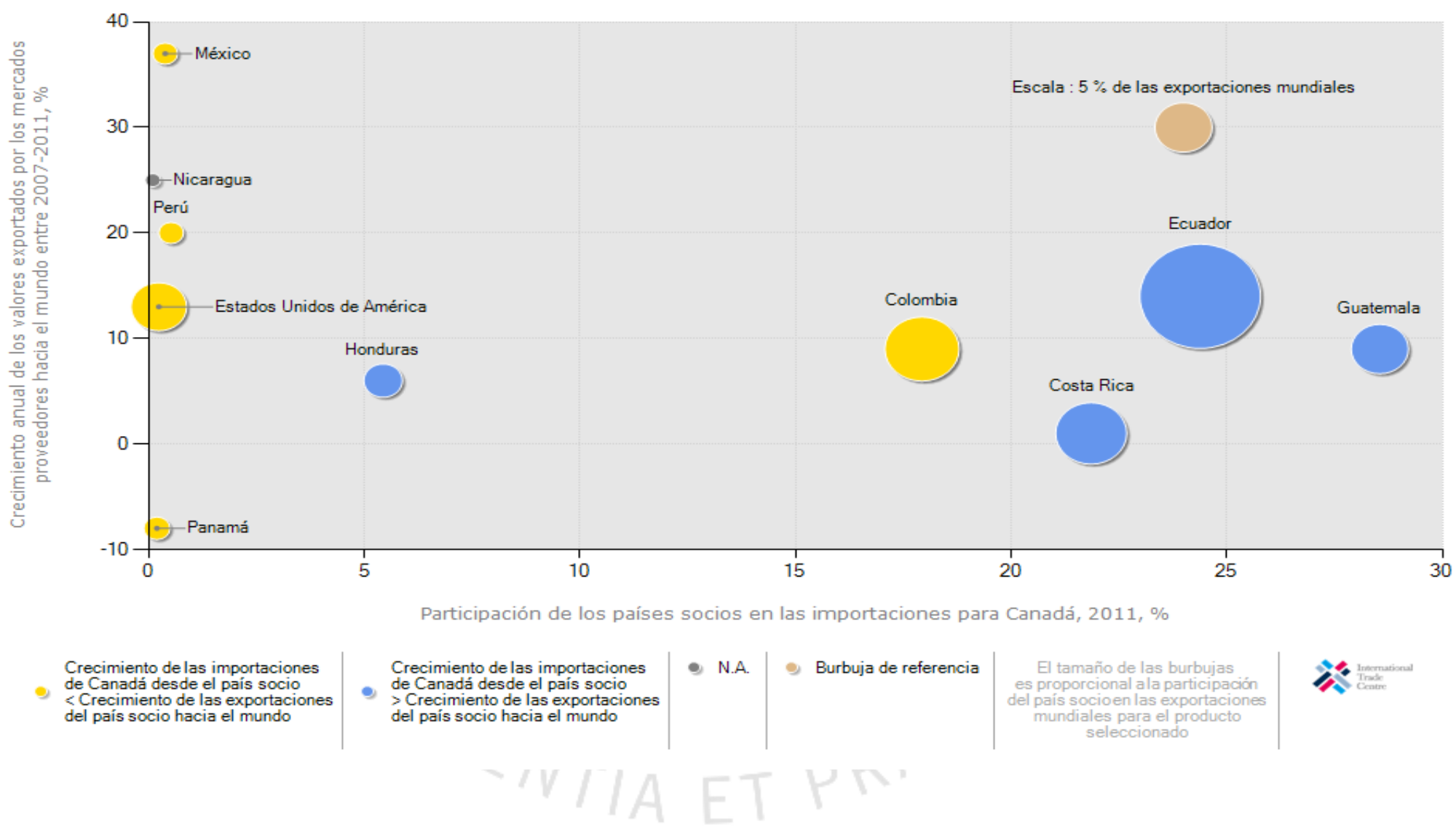

${ }^{74}$ Trade Map 


\title{
ANEXO N6
}

\author{
Minuta de Constitución
}

\section{ACTO CONSTITUTIVO DE SOCIEDAD ANONIMA CERRADA CON DIRECTORIO - CON APORTE DINERARIO}

\section{SEÑOR NOTARIO}

SÍRVASE EXTENDER EN SU REGISTRO DE ESCRITURAS PÚBLICAS UNA CONSTITUCIÓN SIMULTÁNEA DE SOCIEDAD ANONIMA CERRADA, QUE OTORGAN: CYNTHIA PILAR LA ROSA DUARTE DE NACIONALIDAD PERUANA, PROFESION NEGOCIOS INTERNACIONALES CON D.N.I. 46641613, ESTADO CIVIL SOLTERA; JAVIER ADOLFO LA ROSA DUARTE, DE NACIONALIDAD PERUANA, PROFESION INGENIERÍA INDUSTRIAL CON D.N.I. 41068015, ESTADO CIVIL CASADO, GIANFRANCO CAMAIORA, DE NACIONALIDAD, PROFESIÓN NEGOCIOS INTERNACIONALES CON D.N.I. 71258922, ESTADO CIVIL SOLTERO. SEÑALANDO DOMICILIO COMUN PARA EFECTOS DE ESTE INSTRUMENTO EN: PASAJE ANTONIO MORO NRO.150 OF. 511, URB. JACARANDA, DISTRITO DE SAN BORJA, PROVINCIA DE LIMA Y DEPARTAMENTO DE LIMA.

EN LOS TERMINOS SIGUIENTES:

PRIMERO.- POR EL PRESENTE PACTO SOCIAL, LOS OTORGANTES MANIFIESTAN SU LIBRE VOLUNTAD DE CONSTITUIR UNA SOCIEDAD ANONIMA CERRADA, BAJO LA DENOMINACION DE "GOLDEN BANANA SOCIEDAD ANONIMA CERRADA", PUDIENDO UTILIZAR LA DENOMINACIÓN ABREVIADA DE "GOLDEN BANANA S.A.C."; SE OBLIGAN A EFECTUAR LOS APORTES PARA LA FORMACION DEL CAPITAL SOCIAL Y A FORMULAR EL CORRESPONDIENTE ESTATUTO.

SEGUNDO.- EL MONTO DEL CAPITAL DE LA SOCIEDAD ES DE \$20,225.00 (VEINTE MIL DOSCIENTOS VEINTICINCO DÓLARES AMERICANOS) DIVIDIDO EN 3,236 ACCIONES NOMINATIVAS DE UN VALOR NOMINAL DE \$ 6.25 CADA UNA SUSCRITAS Y PAGADAS DE LA SIGUIENTE MANERA:

1. CYNTHIA PILAR LA ROSA DUARTE, SUSCRIBE 1,295 ACCIONES NOMINATIVAS Y PAGA \$ 9,093.75 MEDIANTE APORTES EN BIENES DINERARIOS.

2. JAVIER ADOLFO LA ROSA DUARTE, SUSCRIBE 970 ACCIONES NOMINATIVAS Y PAGA \$ 6,062.50 MEDIANTE APORTES EN BIENES DINERARIOS.

3. RAFAEL GALDOS HERRERA, SUSCRIBE 971 ACCIONES NOMINATIVAS Y PAGA $\$ 6,068.75$ MEDIANTE APORTES EN BIENES DINERARIOS.

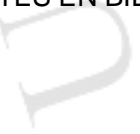

EL CAPITAL SOCIAL SE ENCUENTRA TOTALMENTE SUSCRITO Y PAGADO

TERCERO.- LA SOCIEDAD SE REGIRÁ POR EL ESTATUTO SIGUIENTE Y EN TODO LO NO PREVISTO POR ESTE, SE ESTARÁ A LO DISPUESTO POR LA LEY GENERAL DE SOCIEDADES - LEY 26887 - QUE EN ADELANTE SE LE DENOMINARA LA "LEY".

\section{ESTATUTO}

ARTICULO 1.- DENOMINACION-DURACION-DOMICILIO: LA SOCIEDAD SE DENOMINA: "GOLDEN BANANA SOCIEDAD ANONIMA CERRADA" PUDIENDO USAR LA DENOMINACIÓN ABREVIADA "GOLDEN BANANA S.A.C.".

TIENE UNA DURACION INDETERMINADA, INICIA SUS OPERACIONES EN LA FECHA DE ESTE PACTO Y ADQUIERE PERSONALIDAD JURIDICA DESDE SU INSCRIPCION EN EL REGISTRO DE PERSONAS JURIDICAS DE LIMA.

SU DOMICILIO ES LA PROVINCIA DE LIMA, DEPARTAMENTO DE LIMA PUDIENDO ESTABLECER SUCURSALES U OFICINAS EN CUALQUIER LUGAR DEL PAIS O EN EL EXTRANJERO. 
ARTICULO 2.- OBJETO SOCIAL: LA SOCIEDAD TIENE POR OBJETO DEDICARSE A: EL ACOPIO, EXPORTACION Y COMERCIALIZACION DE FRUTAS,

SE ENTIENDEN INCLUIDOS EN EL OBJETO SOCIAL LOS ACTOS RELACIONADOS CON EL MISMO QUE COADYUVEN A LA REALIZACION DE SUS FINES. PARA CUMPLIR DICHO OBJETO, PODRA REALIZAR TODOS AQUELLOS ACTOS Y CONTRATOS QUE SEAN LICITOS, SIN RESTRICCION ALGUNA.

ARTículo 3.- CAPITAL SOCIAL: EL MONTO DEL CAPITAL DE LA SOCIEDAD ES DE $\$ 20,225.00$ (VENTE MIL DOSCIENTOS VEINTICINCO DÓLARES AMERICANOS) REPRESENTADO POR 3,236 ACCIONES NOMINATIVAS DE UN VALOR NOMINAL DE \$ 6.25 CADA UNA.

EL CAPITAL SOCIAL SE ENCUENTRA TOTALMENTE SUSCRITO Y PAGADO.

ARTICULO 4.- TRANSFERENCIA Y ADQUISICION DE ACCIONES: LOS OTORGANTES ACUERDAN SUPRIMIR EL DERECHO DE PREFERENCIA PARA LA ADQUISICION DE ACCIONES, CONFORME A LO PREVISTO EN EL ULTIMO PARRAFO DEL ARTICULO 237을 LA "LEY".

ARTICULO 5.- ORGANOS DE LA SOCIEDAD: LA SOCIEDAD QUE SE CONSTITUYE TIENE LOS SIGUIENTES ORGANOS:

A) LA JUNTA GENERAL DE ACCIONISTAS;

B) EL DIRECTORIO Y

C) LA GERENCIA.

ARTICULO 6.- JUNTA GENERAL DE ACCIONISTAS: LA JUNTA GENERAL DE ACCIONISTAS ES EL ORGANO SUPREMO DE LA SOCIEDAD. LOS ACCIONISTAS CONSTITUIDOS EN JUNTA GENERAL DEBIDAMENTE CONVOCADA, Y CON EL QUORUM CORRESPONDIENTE, DECIDEN POR LA MAYORIA QUE ESTABLECE LA "LEY" LOS ASUNTOS PROPIOS DE SU COMPETENCIA. TODOS LOS ACCIONISTAS INCLUSO LOS DISIDENTES Y LOS QUE NO HUBIERAN PARTICIPADO EN LA REUNION, ESTAN SOMETIDOS A LOS ACUERDOS ADOPTADOS POR LA JUNTA GENERAL.

LA CONVOCATORIA A JUNTA DE ACCIONISTAS SE SUJETA A LO DISPUESTO EN EL ART. 245 DE LA "LEY". EL ACCIONISTA PODRA HACERSE REPRESENTAR EN LAS REUNIONES DE JUNTA GENERAL POR MEDIO DE OTRO ACCIONISTA, SU CONYUGE, O ASCENDIENTE O DESCENDIENTE EN PRIMER GRADO, PUDIENDO EXTENDERSE LA REPRESENTACION A OTRAS PERSONAS.

ARTICUL07.- JUNTAS NO PRESENCIALES: LA CELEBRACION DE JUNTAS NO PRESENCIALES SE SUJETA A LO DISPUESTO POR EL ARTICULO 246 DE LA "LEY".

ARTÍ́CULO 8.- EL DIRECTORIO: LA SOCIEDAD TENDRÁ UN DIRECTORIO INTEGRADO POR TRES (3) MIEMBROS QUE PUEDEN O NO, SER ACCIONISTAS, CUYO PERÍODO DE DURACIÓN SERÁ DE TRES (3) AÑOS, PUDIENDO SUS MIEMBROS SER REELEGIDOS.

EL CARGO DE DIRECTOR SÓLO RECAE EN PERSONAS NATURALES. LOS DIRECTORES PUEDEN SER REMOVIDOS EN CUALQUIER MOMENTO POR LA JUNTA GENERAL. EL CARGO DE DIRECTOR ES RETRIBUIDO. LOS DIRECTORES SERÁN ELEGIDOS CON REPRESENTACIÓN DE LA MINORÍA, DE ACUERDO A LA LEY GENERAL DE SOCIEDADES. 
ARTíCULO 9.- VACANCIA: VACA EL CARGO DE DIRECTOR POR FALLECIMIENTO, RENUNCIA, REMOCIÓN O POR INCURRIR EL DIRECTOR EN ALGUNA DE LAS CAUSALES DE IMPEDIMENTO SEÑALADAS POR LA LEY. EN CASO DE VACANCIA, EL MISMO DIRECTORIO PODRÁ ELEGIR A LOS REEMPLAZANTES PARA COMPLETAR SU NÚMERO POR EL PERÍODO QUE AÚN RESTA AL DIRECTORIO. EN CASO DE QUE SE PRODUZCA VACANCIA DE DIRECTORES EN NÚMERO TAL QUE NO PUEDA REUNIRSE VÁLIDAMENTE EL DIRECTORIO, LOS DIRECTORES HÁBILES ASUMIRÁN PROVISIONALMENTE LA ADMINISTRACIÓN Y CONVOCARÁN DE INMEDIATO A LA JUNTA DE ACCIONISTAS QUE CORRESPONDA PARA QUE ELIJAN NUEVO DIRECTORIO. DE NO HACERSE ESTA CONVOCATORIA O DE HABER VACADO EL CARGO DE TODOS LOS DIRECTORES, CORRESPONDERÁ AL GERENTE REALIZAR DE INMEDIATO DICHA CONVOCATORIA. SI LAS REFERIDAS CONVOCATORIAS NO SE PRODUJESEN DENTRO DE LOS DIEZ DIAS SIGUIENTES, CUALQUIER ACCIONISTA PUEDE SOLICITAR AL JUEZ QUE LA ORDENE, POR EL PROCESO SUMARISIMO.

ARTí́CULO 10.- CONVOCATORIA, QUÓRUM Y ACUERDOS: EL DIRECTORIO SERÁ CONVOCADO POR EL PRESIDENTE, O QUIEN HAGA SUS VECES, CONFORME A LO ESTABLECIDO EN EL ARTÍCULO 167을 LA LEY GENERAL DE SOCIEDADES. EL QUÓRUM PARA LA REUNIONES DEL DIRECTORIO SERÁ DE LA MITAD MÁS UNO DE SUS MIEMBROS. SI EL NÚMERO DE DIRECTORES ES IMPAR, EL QUÓRUM ES EL NÚMERO ENTERO INMEDIATO SUPERIOR AL DE LA MITAD DE AQUÉL. CADA DIRECTOR TIENE DERECHO A UN VOTO. LOS ACUERDOS DE DIRECTORIO SE ADOPTAN POR MAYORÍA ABSOLUTA DE VOTOS DE LOS DIRECTORES PARTICIPANTES; EN CASO DE EMPATE, DECIDE QUIEN PRESIDE LA SESIÓN.

ARTíCULO 11.- GESTIÓN Y REPRESENTACIÓN: EL DIRECTORIO TIENE LAS FACULTADES DE GESTIÓN Y DE REPRESENTACIÓN LEGAL NECESARIAS PARA LA ADMINISTRACIÓN DE LA SOCIEDAD, DENTRO DE SU OBJETO, CON EXCEPCIÓN DE LOS ASUNTOS QUE LA LEY O EL ESTATUTO ATRIBUYAN A LA JUNTA GENERAL.

ARTíCULO 12.- DELEGACIÓN: EL DIRECTORIO PUEDE DELEGAR SUS FACULTADES CONFORME A LO ESTABLECIDO EN EL ARTÍCULO 174ํㅡㄹ LA LEY GENERAL SOCIEDADES.

ARTíCULO 13.- RESPONSABILIDAD: LA RESPONSABILIDAD DE LOS DIRECTORES SE RIGE POR LO ESTABLECIDO EN LOS ARTÍCULO 177ํY SIGUIENTES DE LA LEY GENERAL SOCIEDADES.

ARTíCULO 14.- GERENTE GENERAL: LA SOCIEDAD TENDRÁ UN GERENTE GENERAL. LA DURACIÓN DEL CARGO ES POR TIEMPO INDEFINIDO. EL GERENTE PUEDE SER REMOVIDO EN CUALQUIER MOMENTO POR EL DIRECTORIO O POR LA JUNTA GENERAL, CUALQUIERA QUE SEA EL ÓRGANO DEL QUE HAYA EMANADO SU NOMBRAMIENTO.

ARTíCULO 15.- ATRIBUCIONES: EL GERENTE GENERAL ESTA FACULTADO PARA LA EJECUCION DE TODO ACTO Y/O CONTRATO CORRESPONDIENTES AL OBJETO DE LA SOCIEDAD, PUDIENDO ASIMISMO REALIZAR LOS SIGUIENTES ACTOS:

A. DIRIGIR LAS OPERACIONES COMERCIALES Y ADMINISTRATIVAS.

B. ASISTIR CON VOZ PERO SIN VOTO A LAS SESIONES DEL DIRECTORIO, SALVO QUE ESTE ACUERDE SESIONAR DE MANERA RESERVADA.

C. ASISTIR CON VOZ PERO SIN VOTO A LAS SESIONES DE JUNTA GENERAL, SALVO QUE ESTA DECIDA LO CONTRARIO.

D. REPRESENTAR A LA SOCIEDAD ANTE TODA CLASE DE AUTORIDADES. EN LO JUDICIAL GOZARA DE LAS FACULTADES SENALADAS EN LOS ARTICULOS 74, 75, 77 Y 436 DEL CODIGO PROCESAL CIVIL, ASI COMO LA FACULTAD DE REPRESENTACION PREVISTA EN EL ARTICULO 10 DE LA LEY 26636 Y DEMAS NORMAS CONEXAS Y COMPLEMENTARIAS; TENIENDO EN TODOS LOS CASOS FACULTAD DE DELEGACION O SUSTITUCION. ADEMAS, PODRA CELEBRAR CONCILIACION EXTRAJUDICIAL, PUDIENDO SUSCRIBIR EL ACTA CONCILIATORIA, GOZANDO DE LAS FACULTADES SENALADAS EN LAS DISPOSICIONES LEGALES QUE LO REGULAN. ADEMAS PODRA CONSTITUIR Y REPRESENTAR A LAS ASOCIACIONES QUE CREA CONVENIENTE Y DEMAS NORMAS CONEXAS Y COMPLEMENTARIAS. 
E. ABRIR, TRANSFERIR, CERRAR Y ENCARGARSE DEL MOVIMIENTO DE TODO TIPO DE CUENTA BANCARIA; GIRAR, COBRAR, RENOVAR, ENDOSAR, DESCONTAR Y PROTESTAR, ACEPTAR Y REACEPTAR CHEQUES, LETRAS DE CAMBIO, PAGARES, CONOCIMIENTO DE EMBARQUE, CARTA DE PORTE, POLIZAS, CARTAS FIANZAS Y CUALQUIER CLASE DE TITULOS VALORES, DOCUMENTOS MERCANTILES Y CIVILES; OTORGAR RECIBOS CANCELACIONES, SOBREGIRARSE EN CUENTA CORRIENTE CON GARANTIA O SIN ELLA, SOLICITAR TODA CLASE DE PRESTAMOS CON GARANTIA HIPOTECARIA.

F. ADQUIRIR Y TRANSFERIR BAJO CUALQUIER TITULO; COMPRAR, VENDER, ARRENDAR, DONAR, DAR EN COMODATO, ADJUDICAR Y GRAVAR LOS BIENES DE LA SOCIEDAD SEAN MUEBLES O INMUEBLES, SUSCRIBIENDO LOS RESPECTIVOS DOCUMENTOS YA SEAN PRIVADOS O PUBLICOS. EN GENERAL PODRA CONSTITUIR GARANTIA HIPOTECARIA, MOBILIARIA Y DE CUALQUIER FORMA. PODRA CELEBRAR TODA CLASE DE CONTRATOS NOMINADOS E INNOMINADOS, INCLUSIVE LOS DE LEASING O ARRENDAMIENTO FINANCIERO, LEASE BACK, FACTORY Y/O UNDERWRITING, CONSORCIO, ASOCIACION EN PARTICIPACION Y CUALQUIER OTRO CONTRATO DE COLABORACION EMPRESARIAL, VINCULADOS CON EL OBJETO SOCIAL. ADEMAS PODRA SOMETER LAS CONTROVERSIAS A ARBITRAJE Y SUSCRIBIR LOS RESPECTIVOS CONVENIOS ARBITRALES.

G. SOLICITAR, ADQUIRIR, TRANSFERIR REGISTROS DE PATENTE, MARCAS, NOMBRES COMERCIALES CONFORME A LEY, SUSCRIBIENDO CUALQUIER CLASE DE DOCUMENTOS VINCULADOS A LA PROPIEDAD INDUSTRIAL O INTELECTUAL.

H. PARTICIPAR EN LICITACIONES, CONCURSOS PUBLICOS Y/O ADJUDICACIONES, SUSCRIBIENDO LOS RESPECTIVOS DOCUMENTOS, QUE CONLLEVE A LA REALIZACION DEL OBJETO SOCIAL.

EL GERENTE GENERAL PODRA REALIZAR TODOS LOS ACTOS NECESARIOS PARA LA ADMINISTRACION DE LA SOCIEDAD, SALVO LAS FACULTADES RESERVADAS A LA JUNTA GENERAL DE ACCIONISTAS.

ARTÍCULO 16.- RESPONSABILIDAD: EL GERENTE RESPONDE ANTE LA SOCIEDAD, LOS ACCIONISTAS Y TERCEROS, CONFORME A LO QUE SE ESTABLECE EN EL ARTíCULO 190" DE LA LEY GENERAL DE SOCIEDADES.

EL GERENTE ES RESPONSABLE, SOLIDARIAMENTE CON LOS MIEMBROS DEL DIRECTORIO CUANDO PARTICIPE EN ACTOS QUE DEN LUGAR A RESPONSABILIDAD DE ÉSTOS O CUANDO, CONOCIENDO LA EXISTENCIA DE ESOS ACTOS, NO INFORME SOBRE ELLOS AL DIRECTORIO O A LA JUNTA GENERAL.

ARTICULO 17.- MODIFICACION DEL ESTATUTO, AUMENTO Y REDUCCION DEL CAPITAL: LA MODIFICACION DEL PACTO SOCIAL, SE RIGE POR LOS ARTICULOS 198 Y 199 DE LA "LEY", ASI COMO EL AUMENTO Y REDUCCION DEL CAPITAL SOCIAL, SE SUJETA A LO DISPUESTO POR LOS ARTICULOS 201 AL 206 Y 215 AL 220, RESPECTIVAMENTE, DE LA "LEY".

ARTICULO 18.- ESTADOS FINANCIEROS Y APLICACION DE UTILIDADES: SE RIGE POR LO DISPUESTO EN LOS ARTICULOS 40, 221 AL 233 DE LA "LEY".

ARTICULO 19 - DISOLUCION, LIQUIDACION Y EXTINCION: EN CUANTO A LA DISOLUCION, LIQUIDACION Y EXTINCION DE LA SOCIEDAD, SE SUJETA A LO DISPUESTO POR LOS ARTICULOS 407, 409, 410, 412, 413 A 422 DE LA "LEY".

CUARTO -- EL PRIMER DIRECTORIO DE LA SOCIEDAD ESTARÁ INTEGRADO POR:

PRESIDENTE DEL DIRECTORIO: CYNTHIA PILAR LA ROSA DUARTE, D.N.I. 46641613

DIRECTOR: JAVIER ADOLFO LA ROSA DUARTE, D.N.I. 41068015

DIRECTOR: GIANFRANCO CAMAIORA CASTAÑEDA, D.N.I. 71258922

QUINTO -- QUEDA DESIGNADO COMO GERENTE GENERAL : CYNTHIA PLAR LA ROSA DUARTE CON D.N.I. 46641613, CON DOMICILIO EN: PASAJE ANTONIO MORO NRO 150 OF. 511, URB. JACARANDA, DISTRITO DE SAN BORJA, PROVINCIA DE LIMA, DEPARTAMENTO DE LIMA. 
CLAUSULA ADICIONAL I.- SE DESIGNA COMO SUB-GERENTE DE LA SOCIEDAD A JAVIER ADOLFO LA ROSA DUARTE CON D.N.I. 41068015, CON DOMICILIO EN: AVENIDA REDUCTO 1091, DISTRITO DE MIRAFLORES, PROVINCIA DE LIMA, DEPARTAMENTO DE LIMA., QUIEN TENDRA LAS SIGUIENTES FACULTADES:

- REEMPLAZAR AL GERENTE EN CASO DE AUSENCIA.

- INTERVENIR EN FORMA INDIVIDUAL O CONJUNTA CON EL GERENTE GENERAL, EN LOS CASOS PREVISTOS EN LOS INCISOS E, F, G Y H DEL ARTÍCULO 15 DEL ESTATUTO.

AGUREGUE USTED, SEÑOR NOTARIO, LO QUE FUERE DE LEY Y SÍRVASE CURSAR PARTES CORRESPONDIENTES AL REGISTRO DE PERSONAS JURÍDICAS DE LIMA PARA SU RESPECTIVA INSCRIPCIÓN.

LIMA, 24 DE ABRIL DEL 2015 


\section{ANEXO N7 \\ Precio en el consumidor final}

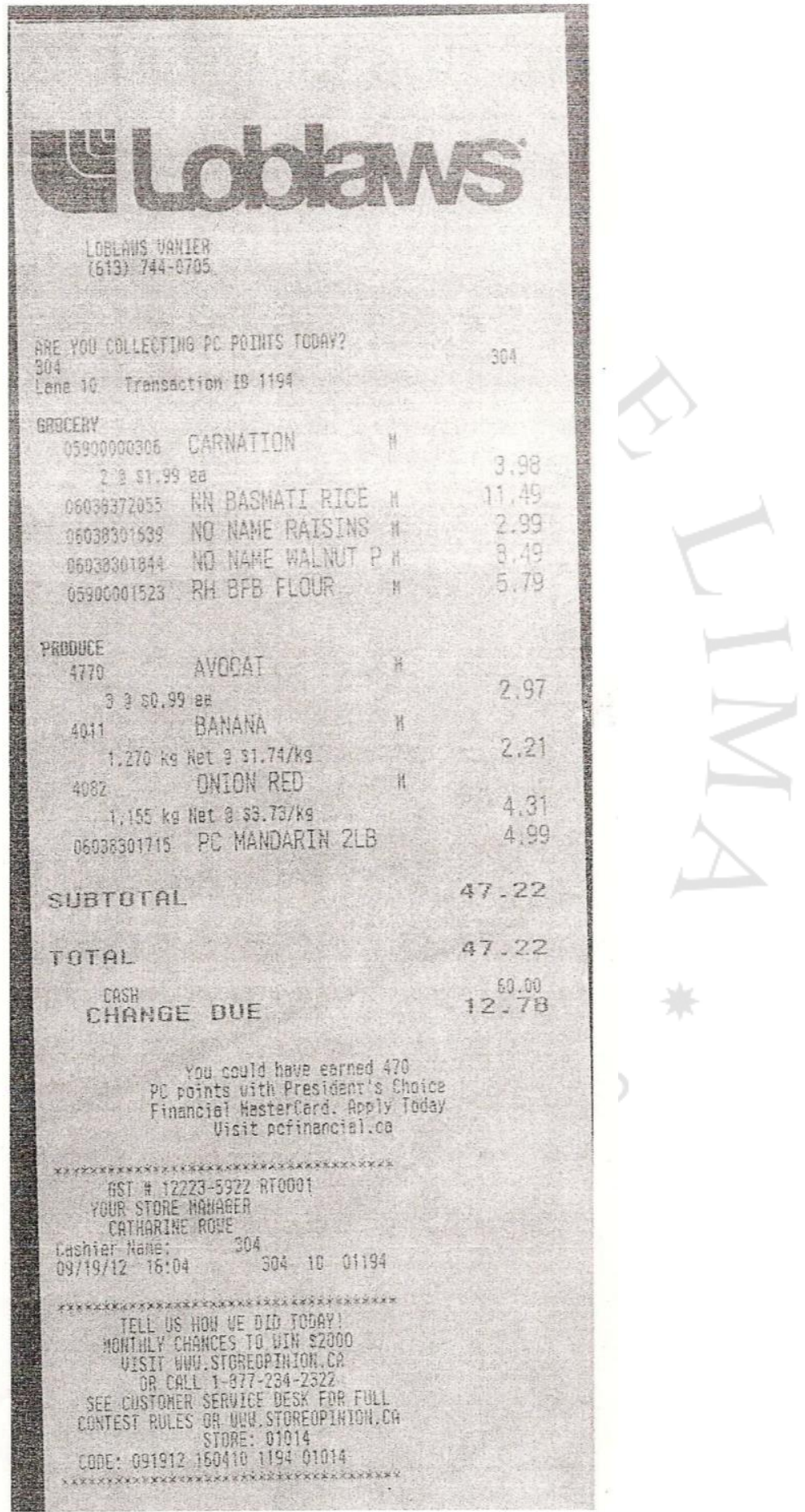

